\title{
Mercury Remediation Technology Development for Lower East Fork Poplar Creek-FY 2016 Progress Report
}

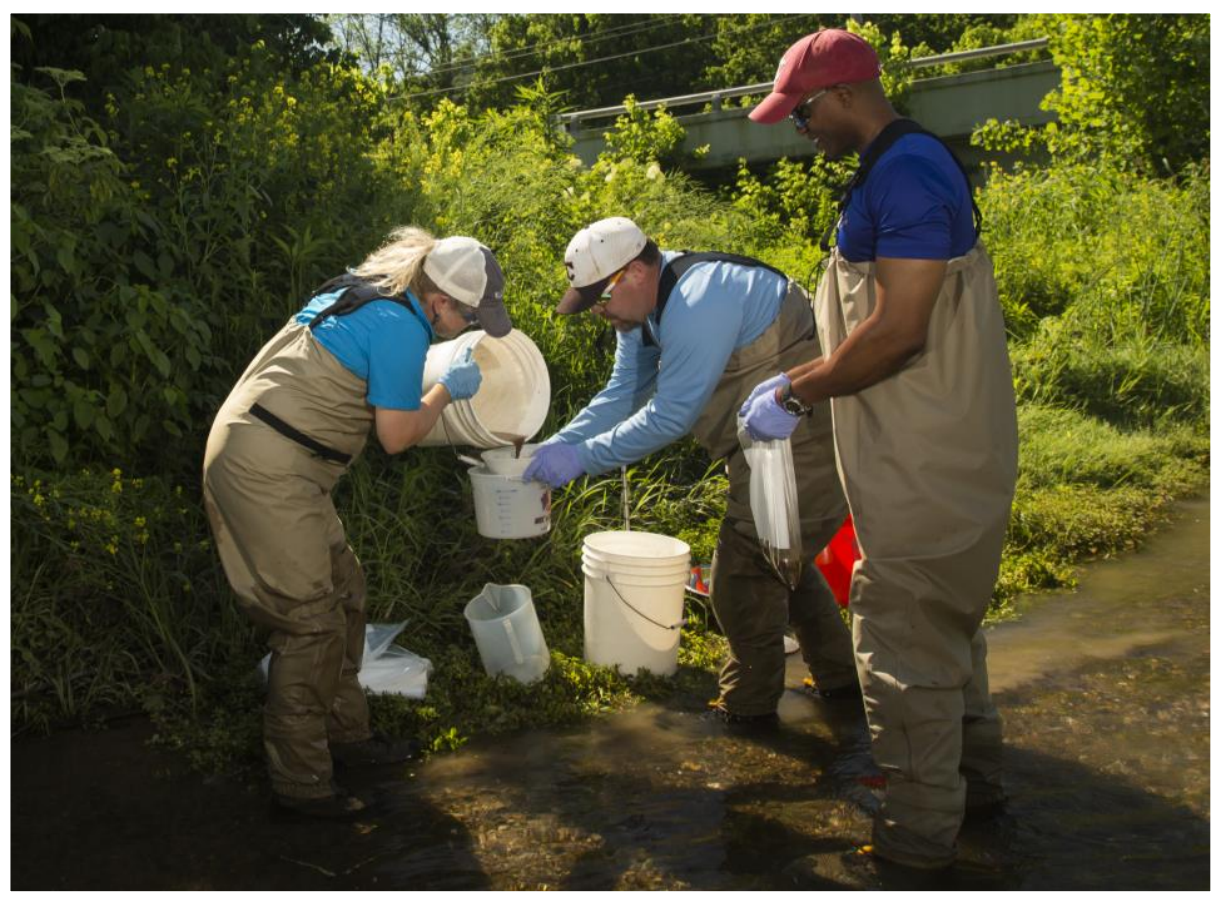

Approved for public release. Distribution is unlimited. 


\section{DOCUMENT AVAILABILITY}

Reports produced after January 1, 1996, are generally available free via US Department of Energy (DOE) SciTech Connect.

Website http://www.osti.gov/scitech/

Reports produced before January 1, 1996, may be purchased by members of the public from the following source:

National Technical Information Service

5285 Port Royal Road

Springfield, VA 22161

Telephone 703-605-6000 (1-800-553-6847)

TDD 703-487-4639

Fax 703-605-6900

E-mail info@ntis.gov

Website http://classic.ntis.gov/

Reports are available to DOE employees, DOE contractors, Energy Technology Data Exchange representatives, and International Nuclear Information System representatives from the following source:

Office of Scientific and Technical Information

PO Box 62

Oak Ridge, TN 37831

Telephone 865-576-8401

Fax 865-576-5728

E-mail reports@osti.gov

Website http://www.osti.gov/contact.html

This report was prepared as an account of work sponsored by an agency of the United States Government. Neither the United States Government nor any agency thereof, nor any of their employees, makes any warranty, express or implied, or assumes any legal liability or responsibility for the accuracy, completeness, or usefulness of any information, apparatus, product, or process disclosed, or represents that its use would not infringe privately owned rights. Reference herein to any specific commercial product, process, or service by trade name, trademark, manufacturer, or otherwise, does not necessarily constitute or imply its endorsement, recommendation, or favoring by the United States Government or any agency thereof. The views and opinions of authors expressed herein do not necessarily state or reflect those of the United States Government or any agency thereof.

Cover image: Carlos Jones, ORNL 
Environmental Sciences Division

\title{
MERCURY REMEDIATION TECHNOLOGY DEVELOPMENT FOR LOWER EAST FORK POPLAR CREEK-FY 2016 PROGRESS REPORT
}
Task 1-Soil and Groundwater Source Control
Melanie Mayes (Task Lead)
Alex Johs
Johnbull Dickson
Tonia Mehlhorn
Leroy Gonez Rodriguez
Christopher DeRolph

Project Lead

Mark J. Peterson

\author{
Task 2-Surface Water and \\ Sediment Manipulation \\ Scott Brooks (Task Lead) \\ David Watson \\ Virginia Eller \\ Todd Olsen \\ Kenneth Lowe
}

\author{
Task 3-Ecological \\ Manipulation \\ Teresa Mathews (Task Lead) \\ Ryan McManamay \\ John Smith \\ Jesse Morris \\ Monica Poteat
}

Date Published: July 2017

Prepared for

Janice Hensley, UCOR/RSI

Oak Ridge, TN 37831

Prepared by

OAK RIDGE NATIONAL LABORATORY

Oak Ridge, TN 37831-6283

managed by

UT-BATTELLE, LLC

for the

US DEPARTMENT OF ENERGY

under contract DE-AC05-00OR22725 



\section{CONTENTS}

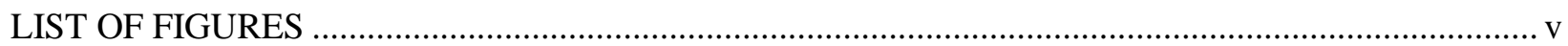

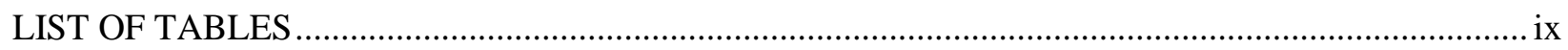

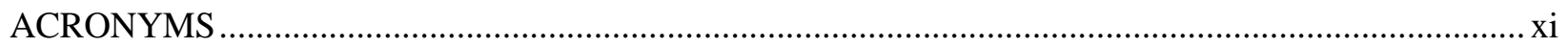

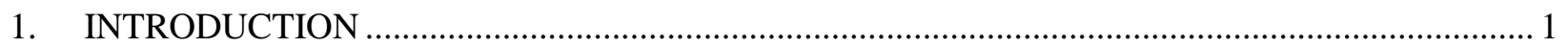

2. TASK 1, SOIL AND GROUNDWATER SOURCE CONTROL ............................................. 3

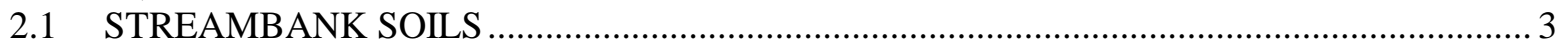

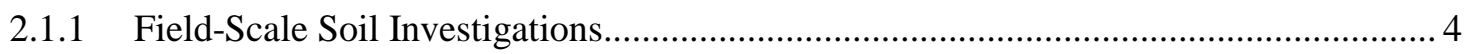

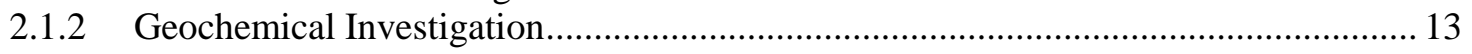

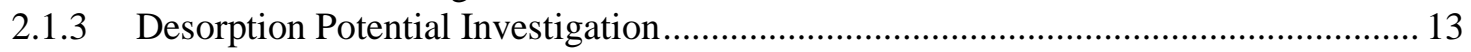

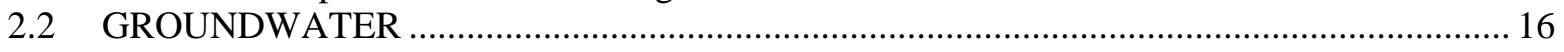

2.2.1 Groundwater Well Installation and Sensor Instrumentation ....................................... 16

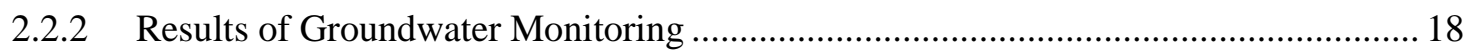

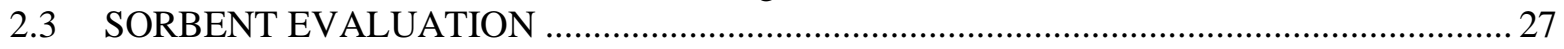

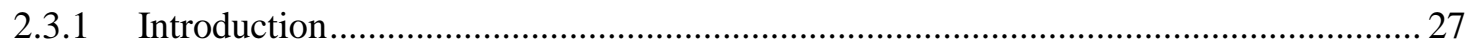

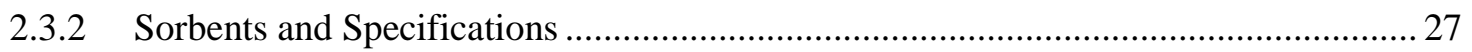

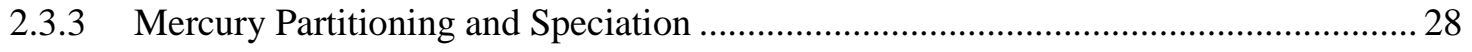

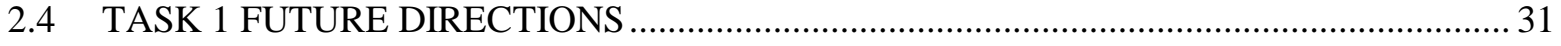

3. TASK 2, SURFACE WATER AND SEDIMENT MANIPULATION …....................................... 34

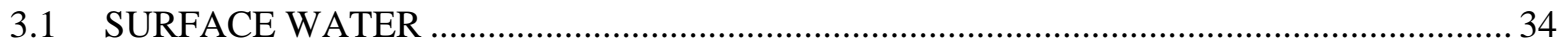

3.1.1 Approach to Water Chemistry Investigations ......................................................... 34

3.1.2 Role of UEFPC Y-12 Water Chemistry and Flux on LEFPC ..................................... 35

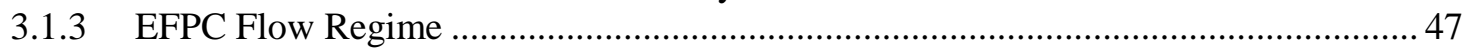

3.1.4 Estimates of Mercury and Monomethylmercury Flux along EFPC........................... 48

3.1.5 Effect of Flow Management Cessation in LEFPC ................................................. 50

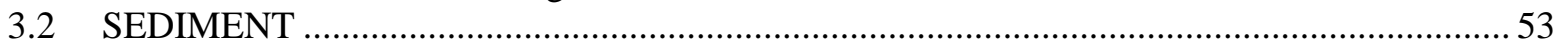

3.3 SHORT-TERM PATTERNS IN MERCURY AND MONOMETHYLMERCURY

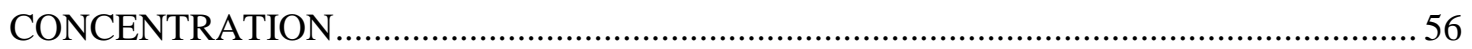

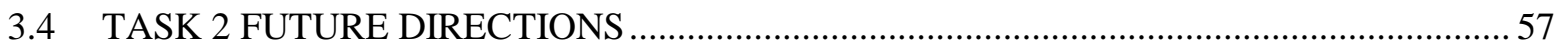

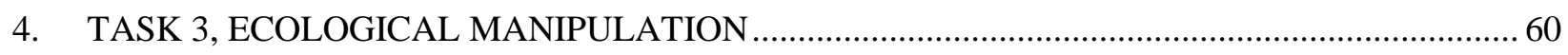

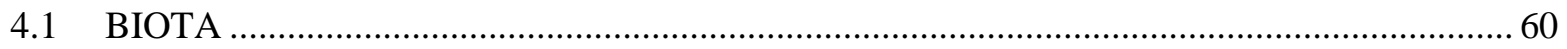

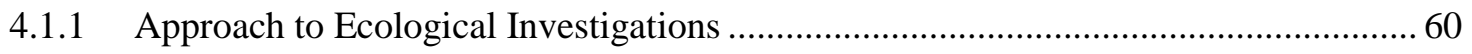

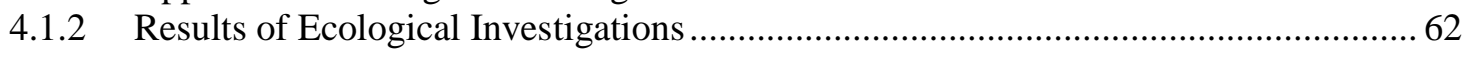

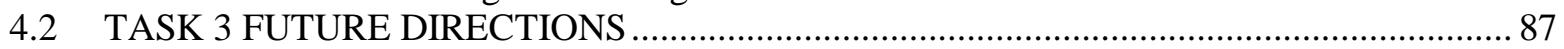

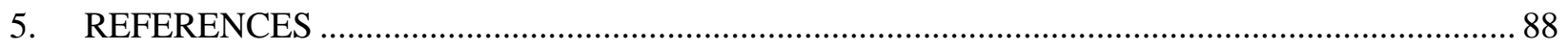





\section{LIST OF FIGURES}

Fig. 2-1. Sediment sampling in Lower East Fork Poplar Creek. ......................................................... 5

Fig. 2-2. Average concentrations of total mercury from the 2014 and 2015 longitudinal surveys............... 6

Fig. 2-3. Total Hg concentrations from targeted sampling of the historical release deposit (HRD). ........... 7

Fig. 2-4. Detailed profiles of total Hg concentrations near the outcrop of the historical release

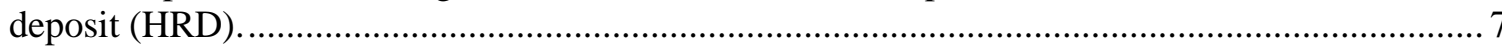

Fig. 2-5. The log of $\mathrm{Hg}$ concentrations in creek bank and stream sediments (top), with the dotted

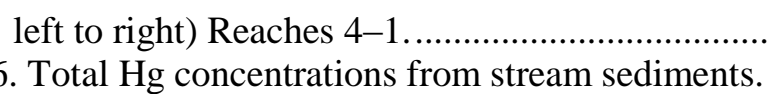
lines denoting (from left to right) Reaches $4-1$, and (bottom) the log of $\mathrm{MeHg}$
concentrations in creek bank and stream sediments, with the dotted lines denoting (from
lines denoting (from left to right) Reaches $4-1$, and (bottom) the log of $\mathrm{MeHg}$
concentrations in creek bank and stream sediments, with the dotted lines denoting (from

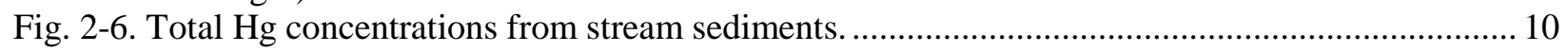

Fig. 2-7. Average concentrations of $\mathrm{MeHg}$ from the 2014 and 2015 longitudinal surveys....................... 10

Fig. 2-8. MeHg concentrations from targeted sampling of the historical release deposit (HRD).............. 11

Fig. 2-9. Summary of MeHg concentrations from stream sediments. .................................................. 11

Fig. 2-10. Enrichment factor (EF) of the $\mathrm{Hg}$ concentration of the bank soils relative to the $\mathrm{Hg}$ concentration of the stream sediments (all values in $\log _{10}$ ). .................................................. 13

Fig. 2-11. Desorption extents as a function of particle size in artificial creek water (ACW) solution (a, left) in typical creek bank soils, and (b, right) in HRD.

Fig. 2-12. Desorption extents from the 0.125 to $1.00 \mathrm{~mm}$ size fraction as a function of different extractant solutions, including Hinds Creek water (HCW), East Fork Poplar Creek water (EFPC), artificial creek water with $1 \mathrm{mg} \mathrm{kg}^{-1}$ natural organic matter (NOM), and artificial creek water (ACW) - (a, left) in typical creek bank soils represented by EFK 18.51, and (b, right) in HRD represented by EFK 19.02 .

Fig. 2-13. The Mercury Technology Development project's groundwater sampling locations at NOAA (EFK 22), Bruner (17.8), and Horizon (EFK 8.7), along East Fork Poplar Creek (EFPC).

Fig. 2-14. Groundwater and surface water wells, including (left) a surface water stilling well installed near the NOAA location at East Fork Poplar Creek kilometer 22. ....

Fig. 2-15. Example potentiometric surfaces (i.e., elevations of equal head) at (A) EFK 22, (B) EFK 17.8, and (C) EFK 8.7.

Fig. 2-16. Groundwater and stream water analyses at EFKs 22, 17.8, and 8.7, at upstream (U), downstream (D), and inland groundwater wells (I), and in stream water (S) ............................ 23

Fig. 2-17. Soil moisture sensors at Bruner location 17.8 EFK. ........................................................ 24

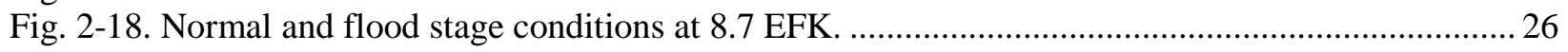

Fig. 2-19. Langmuir-Freundlich isotherms for the sorption of $\mathrm{Hg}-\mathrm{NOM}$ for A. biochar; B. SediMite ${ }^{\mathrm{TM}}$; C. lignin carbon fiber A; D. lignin carbon fiber B; E. lignin carbon foam A; F. lignin carbon foam B; G. Organoclay MRM; H. Organoclay PM-199; I. Thiol-

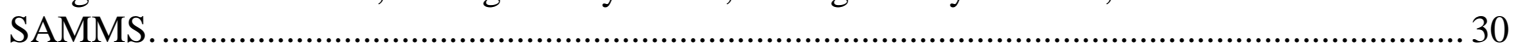

Fig. 2-20. Relationship between surface area and $\mathrm{Hg}$ sorption for carbon-based sorbents. ..................... 31

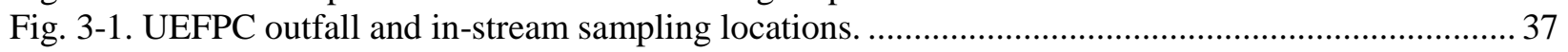

Fig. 3-2. UEFPC outfall and in-stream flow data in gallons per minute (gpm) ................................... 38

Fig. 3-3. UEFPC outfall and in-stream HgT (mercury unfiltered) fluxes in grams per day (g/day).......... 40

Fig. 3-4. OF034 $\mathrm{Hg}(0)_{1}$ bead testing showing current the practice of treating chlorine in OF034 with ammonium bisulfite may enhance the leaching and mobilization of $\mathrm{HgT}$ compared with switching to an ascorbic acid dechlorination treatment. ...

Fig. 3-5. OF109 $\mathrm{Hg}(0)_{1}$ bead testing showing OF109 water with trace chlorine results in more leaching and mobilization of $\mathrm{HgT}$ than OF109 water treated with ascorbic acid.

Fig. 3-6. Impact of residual chlorine in tap water on leaching of $\mathrm{HgT}$ from UEFPC sediments over time (sediment: $\mathrm{HgT}=64.4 \mathrm{mg} / \mathrm{kg}$; medium size fraction $=250 \mathrm{um}-1 \mathrm{~mm}$ ). .45 
Fig. 3-7. Impact of ammonium bisulfite on leaching of $\mathrm{HgT}$ from UEFPC sediments over time (sediment: $\mathrm{HgT}=64.4 \mathrm{mg} / \mathrm{kg}$; medium size fraction $=250 \mathrm{um}-1 \mathrm{~mm}$ ).

Fig. 3-8. Impact of ammonium bisulfite concentration on leaching of HgT from UEFPC sediments with DI water and artificial creek water (sediment: medium size fraction $=250$ um-1 mm; HgT = $64.4 \mathrm{mg} / \mathrm{kg}$; fine fraction = 125-250 um; HgT = $100.1 \mathrm{mg} / \mathrm{kg}$ ).

Fig. 3-9. Impact of ascorbic acid concentration on leaching of $\mathrm{HgT}$ from UEFPC sediments with DI water and artificial creek water (sediment: medium size fraction $=250 \mathrm{um}-1 \mathrm{~mm}$; $\mathrm{HgT}=64.4 \mathrm{mg} / \mathrm{kg}$; fine fraction $=125-250 \mathrm{um} ; \mathrm{HgT}=100.1 \mathrm{mg} / \mathrm{kg}$ ).

Fig. 3-10. Change in (a) dissolved and (b) total $\mathrm{Hg}$ flux between in the upper (black) and lower (red) reaches of LEFPC.

Fig. 3-11. Ratio of MMHg production rate in the lower reach of LEFPC versus the upper reach of LEFPC.

Fig. 3-12. Changes in (a) Hg solid-water partitioning coefficient and (b) dissolved $\mathrm{Hg}$ after flow

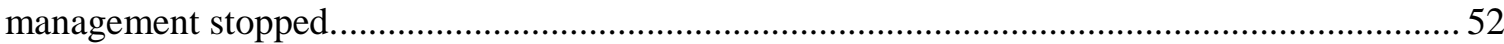

Fig. 3-13. Dissolved MMHg concentration after flow management stopped.......................................... 53

Fig. 3-14. Total Hg in bulk sediments along East Fork Poplar Creek. ................................................... 54

Fig. 3-15. Particulate $\mathrm{Hg}$ (a) and $\mathrm{MMHg}$ (b) over a 30-hour diel sampling campaign conducted September 17-18, 2015, at three locations in EFPC.

Fig. 4-1. Total mercury concentrations in unfiltered water (A) and periphyton (B) collected monthly from five sites in EFPC and the Hinds Creek reference site (March 2015-July 2016).

Fig. 4-2. Relative abundance of different algal groups collected monthly at five EFPC sampling sites, June 2015-May 2016.

Fig. 4-3. Mean (+/- 1 sd) total mercury concentrations in fish (bars) and water (circles) at two sites in East Fork Poplar Creek over time.

Fig. 4-4. (A). Total taxa richness (number of taxa/sample), (B) EPT taxa richness (number of taxa/sample), (C) density (number $\left./ \mathrm{m}^{2}\right)$, and (D) biomass $\left(\mathrm{grams} / \mathrm{m}^{2}\right)$ for benthic macroinvertebrate samples collected at EFKs 13.8 and 23.4 for three different periods considered.

Fig. 4-5. Density and biomass for benthic macroinvertebrate samples collected at EFKs 13.8 and 23.4 for three different periods considered in this study for different functional feeding groups: (A) scrapers, (B) collector-filterers, (C) collector-gatherers, and (D) predators.

Fig. 4-6. Total and methylmercury concentrations in invertebrates from the collector-filterer feeding group at five collection sites in EFPC.

Fig. 4-7. Total and methylmercury concentrations in invertebrates from the collector-gatherer feeding group at five collection sites in EFPC.

Fig. 4-8. Total and methylmercury concentrations in invertebrates from the shredder feeding group at five collection sites in EFPC.

Fig. 4-9. Total and methylmercury concentrations in invertebrates from the scraper feeding group at five collection sites in EFPC.

Fig. 4-10. Total and methylmercury concentrations in invertebrates from the predator feeding group at five collection sites in EFPC.

Fig. 4-11. The relationship between methylmercury concentrations ( $\mu \mathrm{g} / \mathrm{g}$ dry wt.) in crayfish muscle tissue and body size, as shown by the log of total body weight $(\mathrm{g})$

Fig. 4-12. Total and methylmercury concentrations in whole body fish at five collection sites in

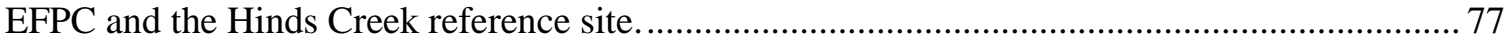

Fig. 4-13. Methylmercury concentrations in fish fillets collected throughout EFPC. .............................. 78

Fig. 4-14. The relationship between methylmercury concentrations and trophic level in the food webs of two selected sites in EFPC.

Fig. 4-15. Schematic representation of food webs at upstream (East Fork Poplar Creek [EFPC] kilometer [EFK] 24) and downstream (EFK 13) sites of EFPC. 
Fig. 4-16. Unfiltered grab samples of methylmercury (MeHg) in surface water collected in summer and winter at EFKs 23.4 and 13.8.

Fig. 4-17. Weighted methylmercury (MeHg) concentrations (left) and biomass of MeHg (right) in macroinvertebrate samples from EFKs 23.4 and 13.8.

Fig. 4-18. Age groupings for redbreast sunfish based on hierarchical Bayesian clustering of length information...

Fig. 4-19. Weight-at-age relationships developed from averages of age classes.................................. 84

Fig. 4-20. Stoneroller per capita growth at age versus population density at EFK 23.4 ….................... 85

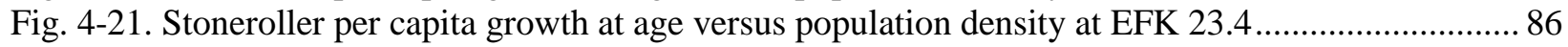

Fig. 4-22. Observed and estimated MeHg body concentrations for redbreast sunfish at EFK 23.4.......... 87 



\section{LIST OF TABLES}

Table 2-1. Mercury concentrations observed in a survey of soil cores from the floodplains near the former Bruner's Market (EFK 17.8, denoted by BR), NOAA (EFK 22, denoted by NO), and a tributary near NOAA (denoted by TR)

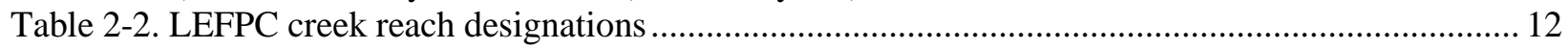

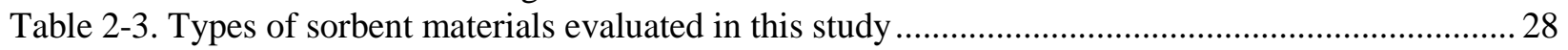

Table 3-1. Results of UEFPC June 6, 2016, outfall sampling and analysis............................................ 39

Table 4-1. Top four functional feeding groups represented at sites along East Fork Poplar Creek during three periods of 3 years each ....................................................................................... 68

Table 4-2. Breakdown of invertebrate and fish samples collected during FY 2016 sampling efforts on East Fork Poplar Creek 



\section{ACRONYMS}

\begin{tabular}{ll} 
ACW & artificial creek water \\
AFRI & Applied Field Research Initiative \\
ANOVA & analysis of variance \\
ASTM & American Society of Testing Method \\
BCF & bioconcentration factor \\
BGS & below ground surface \\
BMAP & Biological Monitoring and Abatement Program \\
DI & deionized \\
DOC & dissolved organic carbon \\
DOE & Department of Energy \\
DOM & dissolved organic matter \\
dw & dry weight \\
EF & enrichment factor \\
EFK & East Fork Poplar Creek kilometer \\
EFPC & East Fork Poplar Creek \\
EM & Environmental Management \\
EPT & Ephemeroptera, Plecoptera, and Trichoptera \\
FRS & Field Research Station \\
FY & fiscal year \\
GPS & Global Positioning System \\
HCW & Hinds Creek water \\
Hg & mercury \\
Hg(II) & mercury cation \\
HgD & dissolved mercury \\
Hg & particulate Hg \\
HgS & mercuric sulfide \\
HgT & total mercury \\
HRD & historical release deposit \\
IQR & interquartile range \\
$K_{d}$ & sorbent:water partition coefficient \\
LEFPC & lower East Fork Poplar Creek \\
MeHg & methylmercury \\
MMHg & monomethylmercury \\
MMHg & particulate MMHg \\
NOAA & National Oceanic and Atmospheric Administration \\
NOM & natural organic matter \\
OC & organic carbon \\
OF & outfall \\
OREM & Oak Ridge Office of Environmental Management \\
ORNL & Oak Ridge National Laboratory \\
ORWTF & Oak Ridge Wastewater Treatment Facility \\
ppb & parts per billion \\
ppm & parts per million \\
RSI & Restoration Services Inc. \\
sd & standard deviation \\
SEM & scanning electron microscopy \\
& specific ultraviolet-absorbance \\
\hline technology development
\end{tabular}


TRL Technology Readiness Level

TSS total suspended solids

TVA Tennessee Valley Authority

UCOR URS |CHM2 Oak Ridge LLC

UEFPC upper East Fork Poplar Creek

UV ultraviolet

WEMA West End Mercury Area

XRF $\quad \mathrm{X}$-ray fluorescence

Y-12 Y-12 National Security Complex 


\section{INTRODUCTION}

Mercury remediation is a high priority for the US Department of Energy (DOE) Oak Ridge Office of Environmental Management (OREM), especially at and near the Y-12 National Security Complex (Y-12) where historical mercury use has resulted in contaminated buildings, soils, and downstream surface waters. To address mercury contamination of East Fork Poplar Creek (EFPC), the DOE has adopted a phased, adaptive management approach to remediation, which includes mercury treatment actions at Y-12 in the short-term and research and technology development (TD) to evaluate longer-term solutions in the downstream environment (US Department of Energy 2014).

Mercury research and TD in Oak Ridge is a direct consequence of significant strategic planning efforts in the 2014-2016 time period. The strategic planning efforts involved multiple meetings and workshops engaging DOE management, site contractors, scientists and engineers, and local stakeholders such as EPA, TDEC, and the SSAB. Five important planning reports have been issued over this period documenting the long-term strategy for mercury remediation and technology development in Oak Ridge:

1. Strategic Plan for Mercury Remediation at the Y-12 National Security Complex, Oak Ridge, Tennessee (2014; DOE/OR/01-2605\&D2), providing the overall remediation roadmap for mercury remediation at $\mathrm{Y}-12$

2. Mercury Technology Development Plan for Remediation of the Y-12 Plant and East Fork Poplar Creek (2014; DOE/ORO-2489), which highlights the priorities for mercury technology development in Oak Ridge

3. Mercury Remediation Technology Development for Lower East Fork Poplar Creek (2015; ORNL/SPR-2014/645), providing the overall strategy for mercury technology development activities in lower EFPC (LEFPC)

4. Technology Plan to Address the EM Mercury Challenge, a DOE Headquarters 2016 report summarizing the overall approach to the DOE Environmental Management (EM) mercury challenge in Oak Ridge and at Savannah River

5. Mercury Remediation Technology Development for Lower East Fork Poplar Creek-FY 2015 Progress Report (ORNL/TM-2016/48), providing mercury TD 2015 progress and 2016 plans for LEFPC

An outcome of strategic planning efforts was the start of the LEFPC Mercury Remediation Technology Development Program in August 2014. The program's goal is to develop strategies and technologies that may lead to new options for mercury remediation in LEFPC. The broad goal of this document is to present results from the second year of investigations (covering FY2016).

The adopted TD strategy, which to date has emphasized understanding mercury transport and fate processes in the EFPC system as an important precursor to the development of targeted remedial technologies, is consistent with the adaptive management paradigm and DOE's Technology Readiness Level (TRL) guidelines. A major emphasis of TD studies in 2016 has been on field characterization and obtaining a watershed-scale understanding. Task 1, Soil and Groundwater Source Control, focuses on addressing downstream mercury sources to the creek (especially floodplain and bank soils) and groundwater. Task 2, Surface Water and Sediment Manipulation, centers on potential manipulation of instream processes, including the many water and sediment chemistry factors that affect mercury methylation. Task 3, Ecological Manipulation, investigates methods to manipulate the food chain at both lower and higher levels of organization to decrease mercury concentrations in fish. Together, the three 
study tasks focus on manipulating the key factors that affect mercury concentrations in fish: the amount of inorganic mercury available to an ecosystem, the conversion of inorganic mercury to methylmercury, and the bioaccumulation of methylmercury through the food web. 


\section{TASK 1, SOIL AND GROUNDWATER SOURCE CONTROL}

\subsection{STREAMBANK SOILS}

Legacy mercury contamination in creek banks, floodplain soils, and stream sediments accounts for the majority of the annual export of mercury to the EFPC watershed. As legacy mercury is eroded from bank and floodplain soils, it contributes to concentrations in the water column and sediments and provides a source for in-stream production of methylmercury. In fact, past studies suggest that approximately $85 \%$ of the mercury inventory is associated with floodplain soils on the $18 \mathrm{~km}$ reach of LEFPC immediately downstream of Y-12 (Southworth et al. 2013).

The LEFPC bank soils, however, have never been systematically characterized to determine their spatial variability. Considerable progress was made in FY 2014-15, with four major field campaigns beginning with two longitudinal surveys involving mercury and methylmercury concentrations as a function of bank height at 143 locations. Basic soil characteristics such as total carbon, organic carbon, nitrogen, sulfur, and $\mathrm{pH}$ were also determined. In the second longitudinal campaign, researchers identified frequent but spatially variable outcroppings of a historical release deposit (HRD) in the $6 \mathrm{~km}$ immediately downstream of Y-12. Observations indicated the HRD was much more widespread than previously believed. Identification is facilitated by the dark color of the HRD. Subsequently, the third sampling activity involved a detailed survey of the HRD distribution and characteristics at approximately 60 locations, with analyses focusing on mercury, methylmercury, and soil characteristics. Finally, the soil-forming properties of the creek bank soils were characterized and mapped at high resolution. A technical manuscript has been prepared and after review will be published separately (Dickson et al. In review.).

In FY 2016, researchers completed a variety of analyses associated with these previous activities and worked with the Sediment Task 2 on an additional field campaign to determine mercury and methylmercury concentrations of bulk stream sediment. The team also determined vertical profile concentrations of mercury in the HRD outcrop area and conducted a limited campaign to determine if the HRD was present in the floodplains at two other locations in Oak Ridge: National Oceanic and Atmospheric Administration (NOAA) facility and the former Bruner's Market.

In general, researchers found that the $6 \mathrm{~km}$ of EFPC immediately downstream of Y-12 is more enriched in mercury than the lower $13 \mathrm{~km}$. In this reach, the creek bank soils are also enriched with respect to the stream sediments. The HRD outcrops are important locations of concentrated mercury and methylmercury. For example, the 25th to 75th interquartile range (IQR) of the typical creek bank soils from the longitudinal surveys ranges from 7.67 to $24.9 \mathrm{mg} \mathrm{kg}^{-1}$, whereas that of the HRD ranged from 185 to $1,040 \mathrm{mg} \mathrm{kg}^{-1} \mathrm{IQR}$. Researchers also found that the HRD might extend into the floodplain near EFK 17.8 and EFK 22. The mercury concentration of the bulk stream sediments averaged $16.1 \pm 4.90 \mathrm{mg}$ $\mathrm{kg}^{-1}$ with a minimum and maximum of 9.10 and $27.3 \mathrm{mg} \mathrm{kg}^{-1}$.

Methylmercury concentrations also tend to track total mercury concentrations, so the same patterns are observed for methylmercury as a function of distance downstream, and when comparing creek bank soils, HRD, and stream sediments. For example, the concentration of methylmercury in the typical creek bank soils from the longitudinal surveys varied from 1.24 to $4.64 \mu \mathrm{g} \mathrm{kg}^{-1} \mathrm{IQR}$, the HRD had methylmercury concentrations of $11.3-30.1 \mu \mathrm{g} \mathrm{kg}{ }^{-1} \mathrm{IQR}$, and the bulk stream sediments ranged from 0.76 to $1.66 \mu \mathrm{g} \mathrm{kg}^{-1}$ IQR.

It is essential to determine the chemistry of the mercury and other minerals in the soils to understand conditions contributing to mercury stabilization and to predict the overall potential for release of mercury from the soils. Detailed geochemical analyses, however, are beyond the scope of the OREM TD project. Researchers therefore worked with the Applied Field Research Initiative Program (AFRI) to begin 
detailed geochemical characterization of the soils, particularly focusing on differences between the "typical" bank soils and the HRD. The team completed a series of chemical digests of the soils to quantitatively determine the total elemental composition. Scanning electron microscopy (SEM) with energy dispersive $\mathrm{x}$-ray was also used to identify collated sulfur and mercury in the soils. In collaboration with the Sediment Task 2, x-ray fluorescence (XRF) was used to compare elemental composition of the HRD, creek bank soils, and stream sediments. Additional analyses are planned for FY 2017.

There was limited understanding of the potential for desorption of mercury from the soils, so a series of investigations began in FY 2015 to determine the extent of release of mercury from the soils, again in collaboration with the AFRI project. The FY 2015 results demonstrated a high degree of unexplained variability of desorption extent, so in FY 2016, soils were partitioned according to particle size distribution, and the previous set of experiments was repeated. It is believed that large variations in soil particle size, geochemical properties, and in mercury concentrations were the reason for the high variability in the results. In FY 2016, researchers also expanded the soils under investigation to include HRD soils. Consistent results were indeed obtained by performing the experiments using specific particle size ranges. As a percentage with respect to the original concentration of $\mathrm{Hg}$ in the soils, the bank soils released $0.001 \%$ to $0.02 \%$, whereas the HRD soils released $0.003 \%$ to $0.05 \%$. The observed concentrations from the HRD were up to $12 \mu \mathrm{g} \mathrm{L}^{-1}$, which is several times higher than the concentration of $\mathrm{Hg}$ in EFPC stream water. EFPC water was added as a desorbant solution, in addition to water from a local background creek, a synthetic creek water, and a synthetic creek water with added natural organic matter. Some solutions were more effective at releasing mercury, and notably, different solutions were most effective for the HRD versus the creek bank soils. The results at this time are qualitative and lack a mechanistic interpretation. Now that the variability issue is resolved and the observations are consistent with respect to different soil samples and desorbant solutions, investigations to understand the mechanisms will begin.

The information regarding soil characteristics, as well as the mercury and methylmercury distribution, desorption potential, and chemistry will be used to develop credible and science-based remedial strategies for bank and floodplain soils in EFPC in the coming years. The initial focus of Oak Ridge National Laboratory's (ORNL's) efforts is to characterize the system to allow the formation of conceptual models describing the pools, stocks, exchanges, and transfers within the system. The formulation and continual updating of conceptual models is essential to planning remedial activities and in understanding their potential impacts.

\subsubsection{Field-Scale Soil Investigations}

Mercury export from the point source at Y-12 has significantly declined, but it is suspected that eroding bank soils sustain mercury contamination in LEFPC. The spatial variability of $\mathrm{Hg}$ and $\mathrm{MeHg}$ in EFPC, however, remains poorly understood because data density remains sparse and few studies systematically examine the relationship of $\mathrm{Hg}$ and $\mathrm{MeHg}$ between bank soils and streambed sediments; e.g., Southworth et al. (2010) and Southworth et al. (2013). A better understanding of the distribution and relation of contaminated bank soils and sediments will aid in understanding and ultimately abating contamination in the aquatic system. The goal of these efforts is therefore to gain better insight into the sources of $\mathrm{Hg}$ and $\mathrm{MeHg}$ to LEFPC and, in concert with the Sediment Task 2, to identify enrichment locations along the stream reaches. This work will ultimately aid in evaluation of contamination levels and in prioritizing locations for potential remedial activities. The overarching objectives of the FY 2016 work are to: (1) determine the spatial trends between $\mathrm{Hg}$ and $\mathrm{MeHg}$ in bank soils and streambed sediments, and (2) develop enrichment factors that help identify relationships between $\mathrm{Hg}$ and $\mathrm{MeHg}$ in banks soils and streambed sediments. 
To accomplish these goals, researchers analyzed $\mathrm{Hg}$ and $\mathrm{MeHg}$ in creek bank soils at 143 locations in the "longitudinal surveys" of FY 2014 and FY 2015 (Peterson et al. 2015a; Peterson et al. 2016). In both surveys, core samples measuring 1 inch in diameter and of variable lengths were collected at $15 \%, 50 \%$, and $85 \%$ of the creek bank height. In FY 2015, targeted 1-inch diameter core $(n=70)$ samples were collected within the HRD in the upper $5 \mathrm{~km}$ reach of the stream (Peterson et al. 2016), with analyses continuing into FY 2016. Additional soil core samples were collected in FY 2016 at $\sim 10 \mathrm{~cm}$ intervals from the ground surface to top of stream water level to elucidate the vertical distribution of mercury with depth at additional locations in the upper $5 \mathrm{~km}$ reach. Vertical cores were also collected from within floodplains near East Fork Poplar Creek kilometers (EFKs) 22 and 17.8 to determine inland mercury concentrations. Vertical soil samplers with core liners of up to $3 \mathrm{ft}$ in length were pushed into the soil at these locations and then removed. The soil cores were visually examined for the features consistent with the HRD — one or more dark-colored layers of total thickness less than 18 in. If the cores were visually suggestive of the HRD, then the thickness and depth of the potential HRD layers were recorded and the samples were collected and analyzed for total Hg. Global Positioning System (GPS) locations were recorded for every borehole regardless of whether the HRD was suspected to exist. All soils were analyzed using standard methods as described in Peterson et al. (2016). The properties of the creek bank soils were characterized and mapped at high resolution in FY2015. A draft technical manuscript has been prepared (Dickson et al. In review.).

Streambed sediment samples were also collected to determine the particle size distribution at 19 locations in FY 2016 (Fig. 2-1). The team coupled those particle size distributions with $\mathrm{Hg}$ and $\mathrm{MeHg}$ analyses of streambed sediments performed in three different particle size fractions (see Section 3.2) to yield bulk stream sediment concentrations of $\mathrm{Hg}$ and $\mathrm{MeHg}$ for comparison with bulk creek bank soil concentrations.

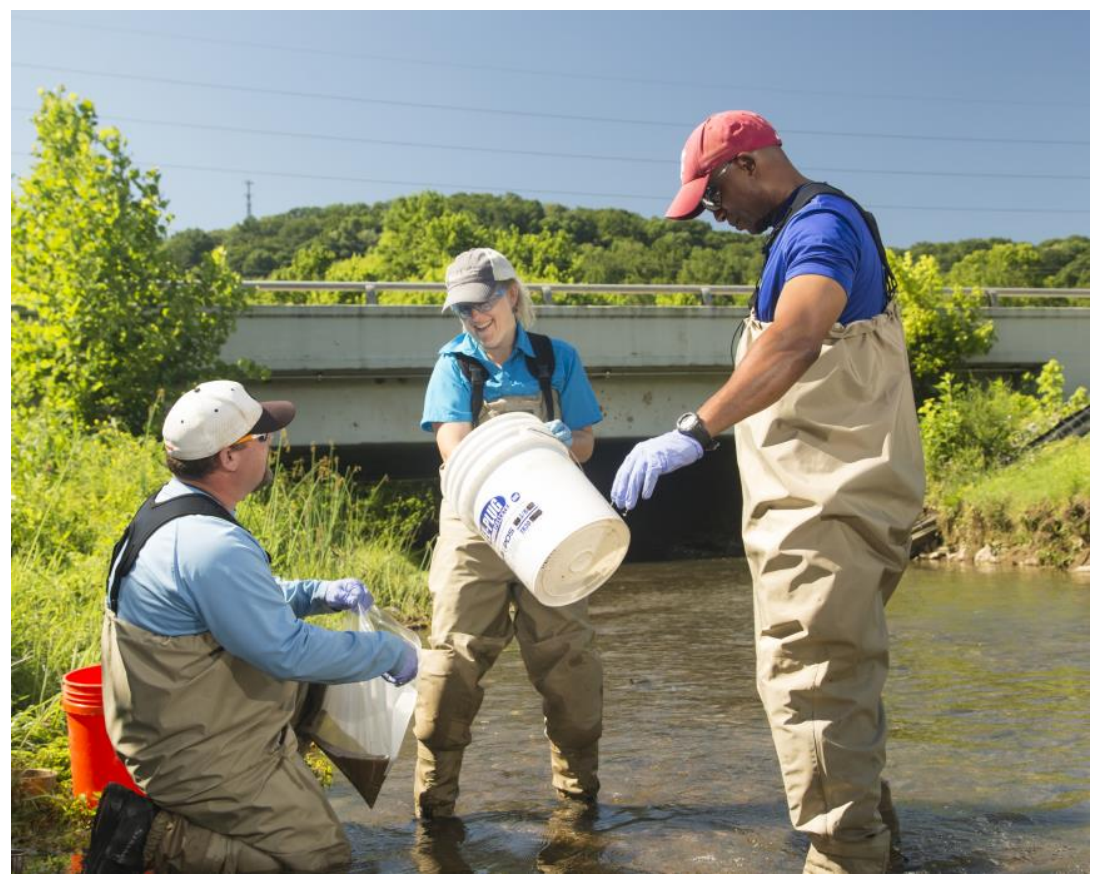

Fig. 2-1. Sediment sampling in Lower East Fork Poplar Creek. Photo credit Carlos Jones, ORNL.

\subsubsection{Mercury and methylmercury distribution}

The spatial distribution of $\mathrm{Hg}$ from the longitudinal soil surveys is depicted in Fig. 2-2. Total $\mathrm{Hg}$ concentrations of the longitudinal bank soil samples $(n=281)$ ranged from 7.67 to $24.9 \mathrm{mg} \mathrm{kg}^{-1}$, when 
represented as the 25th to 75th IQR, with a median and maximum of 15.5 and $941 \mathrm{mg} \mathrm{kg}^{-1}$, respectively. The distribution of $\mathrm{Hg}$ concentration in samples $(n=86)$ from the HRD (Fig. 2-3) ranged from 185 to 1,040 $\mathrm{mg} \mathrm{kg}^{-1} \mathrm{IQR}$, with a median and maximum of 429 and $4,600 \mathrm{mg} \mathrm{kg}^{-1}$, respectively.

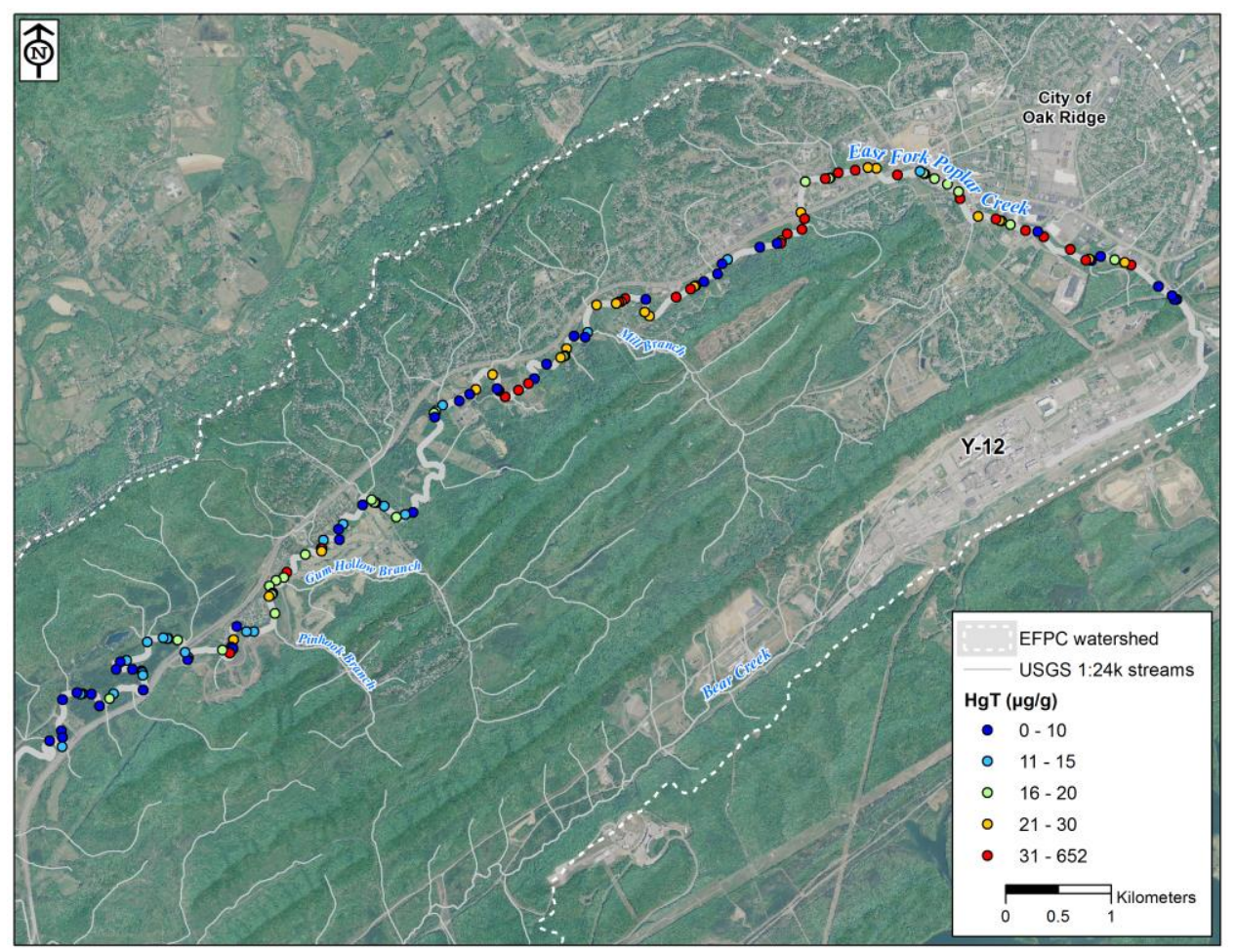

Fig. 2-2. Average concentrations of total mercury from the 2014 and 2015 longitudinal surveys.

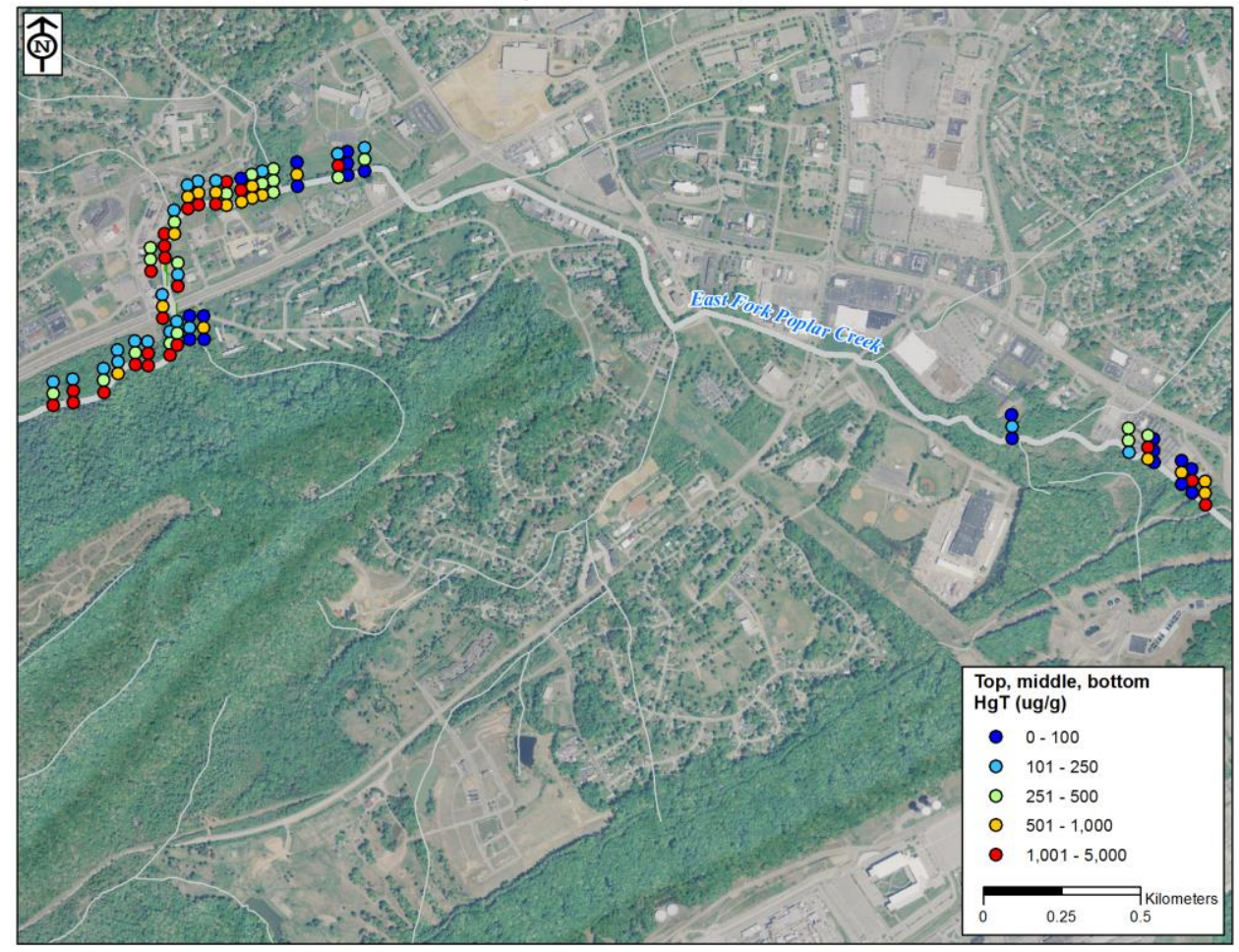


Fig. 2-3. Total Hg concentrations from targeted sampling of the historical release deposit (HRD).

The HRD appears to be a highly concentrated and localized source, with concentrations several orders of magnitude higher than the typical bank soils observed in the longitudinal surveys. The longitudinal surveys mostly missed the HRD layers, because at most locations the HRD occurs between 50\% and 85\% of the bank height. To aid in modeling (in the SourceID project), researchers also collected four detailed profiles of the soil banks near the HRD outcrop area (Fig. 2-4). These figures show that the high concentration zones are very localized, even within the HRD, although the visible signature of the HRD can be up to 18 inches thick.
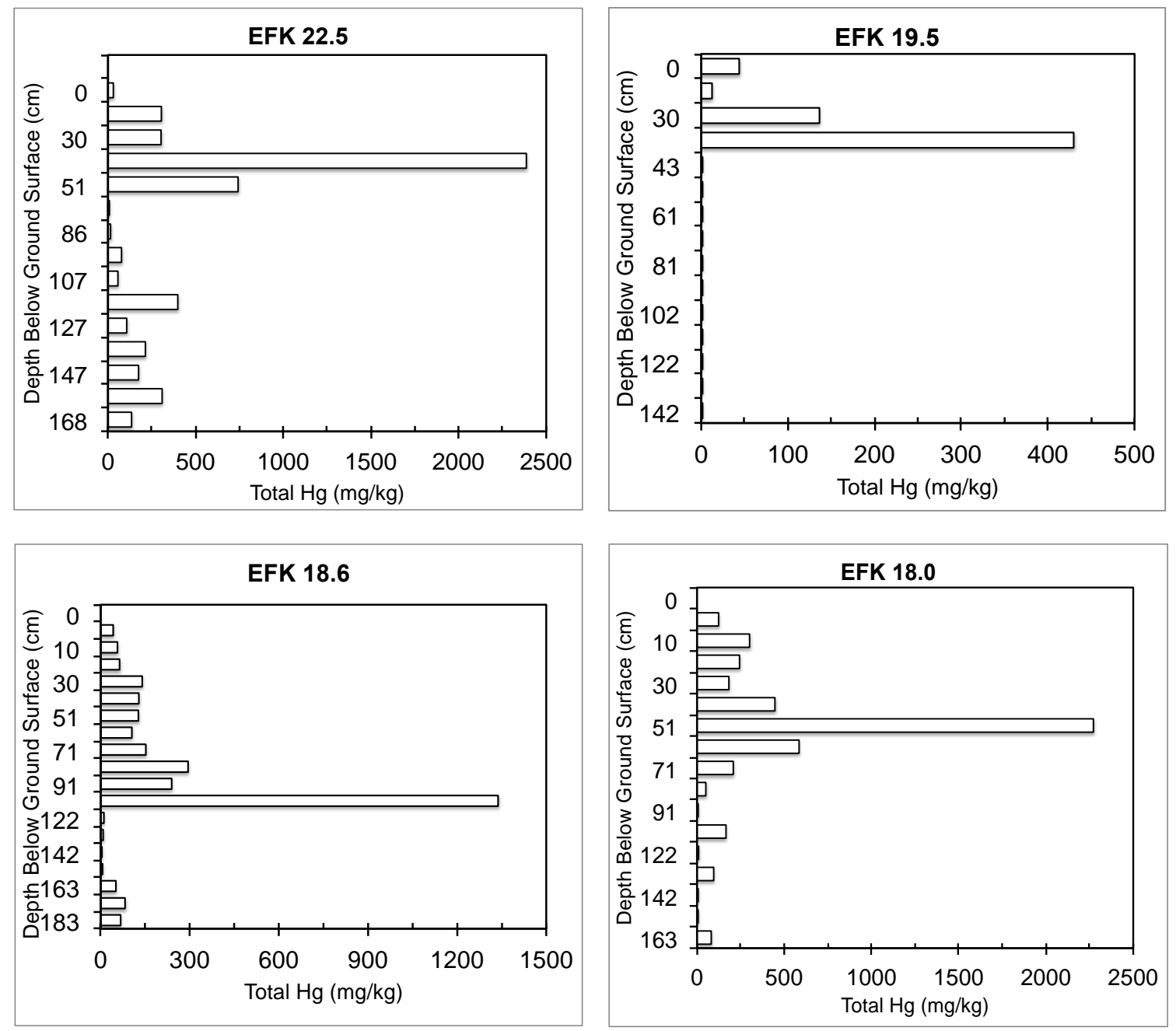

Fig. 2-4. Detailed profiles of total Hg concentrations near the outcrop of the historical release deposit (HRD).

Features consistent with the HRD (i.e., prominent dark layering) were identified by vertical coring in the floodplains near NOAA (EFK 22) and the former Bruner's Market (EKF 17.8). Of approximately 25 boreholes at Bruner, 14 cores had features consistent with the appearance of the HRD. Of approximately 10 boreholes at NOAA, four cores had features consistent with the appearance of the HRD. The analytical results show that mercury concentrations exceed the 75th IQR of the creek bank soils from the longitudinal survey $\left(24.9 \mathrm{mg} \mathrm{kg}^{-1}\right)$, and that most of the values lie within the 25 th and 75 th IQR of the HRD (185 to $1,040 \mathrm{mg} \mathrm{kg}^{-1}$ ). Of 18 total samples analyzed, two values exceed the 75th IQR of the HRD 
and three values are less than the 25th IQR of the HRD (Table 2-1). However, none of the values approach the highest observed mercury concentrations obtained in the HRD survey (Fig. 2-3). The fact that the $\mathrm{Hg}$ values in the floodplain samples are not as high as the creek bank HRD samples demonstrates that variability is high. The floodplain HRD appears not to be extensive or continuous, so a detailed mapping on a grid scale would be required to capture the extent of this deposit within the larger floodplain area. The IQR of the longitudinal survey integrates results from the length of EFPC beginning at EFK 23 and ending near EFK 4.7, and it is not clear if those results are representative of the concentrations of mercury in the soil overlying and underlying the HRD at either specific location. More analysis will be needed to determine whether the floodplain coring results actually represent the HRD layer. Additional sampling could also be warranted.

Table 2-1. Mercury concentrations observed in a survey of soil cores from the floodplains near the former Bruner's Market (EFK 17.8, denoted by BR), NOAA (EFK 22, denoted by NO), and a tributary near NOAA (denoted by TR)

\begin{tabular}{cc}
\hline Sample ID & HgT $(\mathbf{m g} / \mathbf{k g})$ \\
\hline BR 1 & 1461.28 \\
BR 2 & 268.00 \\
BR 3 & 282.39 \\
BR 4 & 280.28 \\
BR 5 & 331.60 \\
BR 6 & 497.08 \\
BR 7 & 101.66 \\
BR 8 & 306.79 \\
BR 9 & 217.96 \\
BR 10 & 296.42 \\
BR 11 & 305.14 \\
BR 12 & 159.12 \\
BR 13 & 87.23 \\
BR 14 & 490.67 \\
NO1-1 & 903.66 \\
NO1-2 & 580.35 \\
NO1-3 & 162.09 \\
TR-1 & 2172.24 \\
\hline
\end{tabular}

The distribution of $\mathrm{Hg}$ concentration in the bank soils is strongly correlated with stream distance $(\rho=$ $0.70, p=8.1 \mathrm{E}-4$ ), declining downstream along the 18-km stretch that is studied in this project (Fig. 2-5a). The total mercury concentration of the bulk stream sediments $(n=19)$ averaged $16.1 \pm 4.90 \mathrm{mg} \mathrm{kg}^{-1}$ with a minimum and maximum of 9.10 and $27.3 \mathrm{mg} \mathrm{kg}^{-1}$, respectively (Fig. 2-6). Stream sediment $\mathrm{Hg}$ concentrations also declined in the downstream direction $(\rho=0.65, p=2.7 \mathrm{E}-3)$.

The concentration of MeHg in the creek banks from the longitudinal surveys ( $n=163$ ) varied from 1.24 to $4.64 \mu \mathrm{g} \mathrm{kg}^{-1} \mathrm{IQR}$, with a median of $2.75 \mu \mathrm{g} \mathrm{kg}^{-1}$ and maximum of $43.0 \mu \mathrm{g} \mathrm{kg}{ }^{-1}$, respectively (Fig. 2-7). Bank samples from the HRD had MeHg concentrations of $11.3-30.1 \mu \mathrm{g} \mathrm{kg}{ }^{-1}$ IQR with a median of 17.8 and a maximum of $60.5 \mu \mathrm{g} \mathrm{kg}^{-1}$ (Fig. 2-8). As with the total mercury values, the higher concentrations of methylmercury in the HRD are apparent. Total $\mathrm{MeHg}$ content of the bulk stream sediments ranged from 0.76 to $1.66 \mu \mathrm{g} \mathrm{kg}^{-1} \mathrm{IQR}$ with a median of 1.11 and a maximum of $10.0 \mu \mathrm{g} \mathrm{kg}^{-1}$ (Fig. 2-9). Methylmercury in the creek bank soils was significantly $(\sim 5$ times $)$ higher $(p<<0.05)$ than the stream sediments. Bank 
MeHg concentrations declined with downstream distance $(\rho=0.72, p=5.0 \mathrm{E}-4)$. Typically the lognormalized total $\mathrm{Hg}$ concentrations were strongly correlated with $\mathrm{MeHg}$ concentration of streambank soil ( $\rho=0.74$, Pearson; $p<0.05)$, gradually declining downstream.

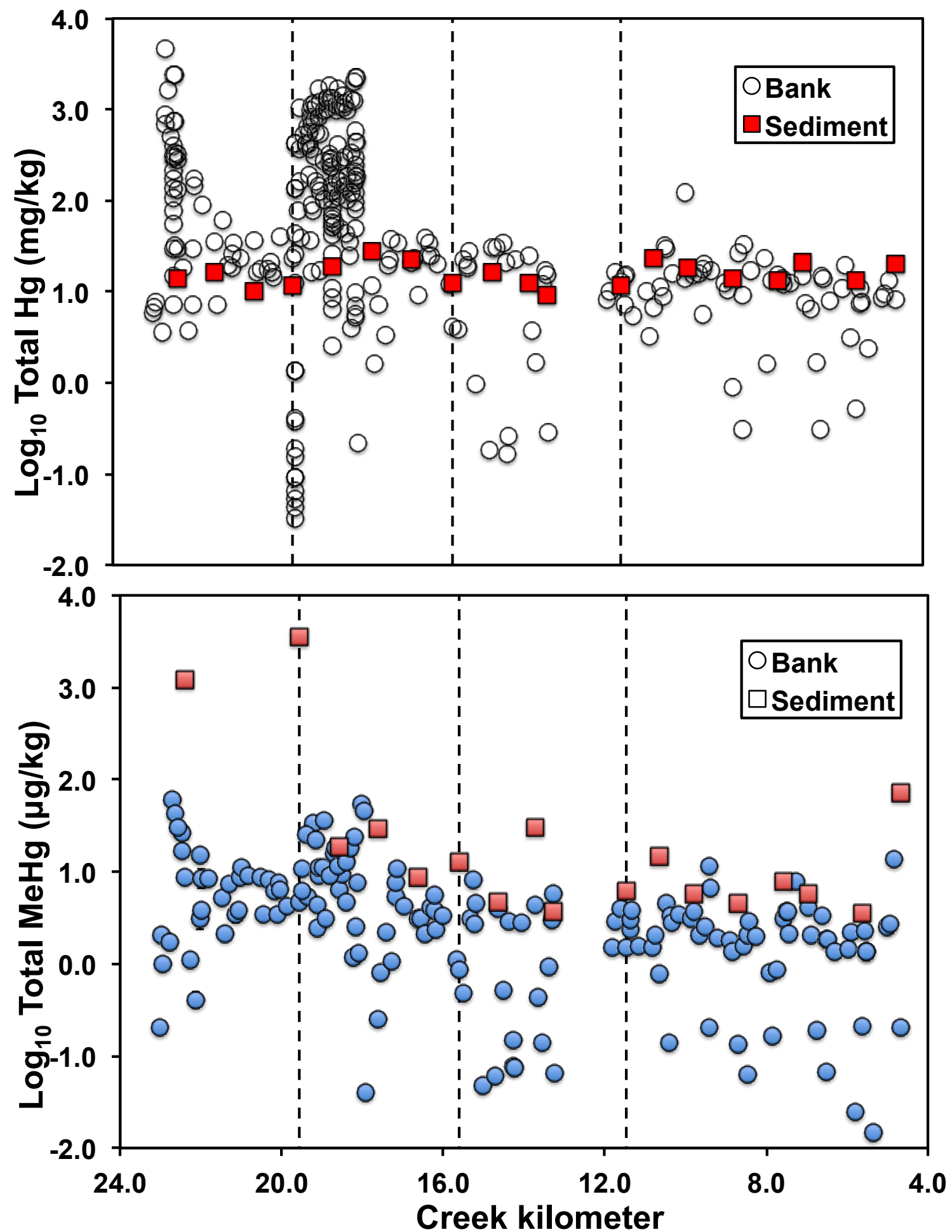

Fig. 2-5. The log of $\mathrm{Hg}$ concentrations in creek bank and stream sediments (top), with the dotted lines denoting (from left to right) Reaches 4-1, and (bottom) the log of MeHg concentrations in creek bank and stream sediments, with the dotted lines denoting (from left to right) Reaches 4-1. 


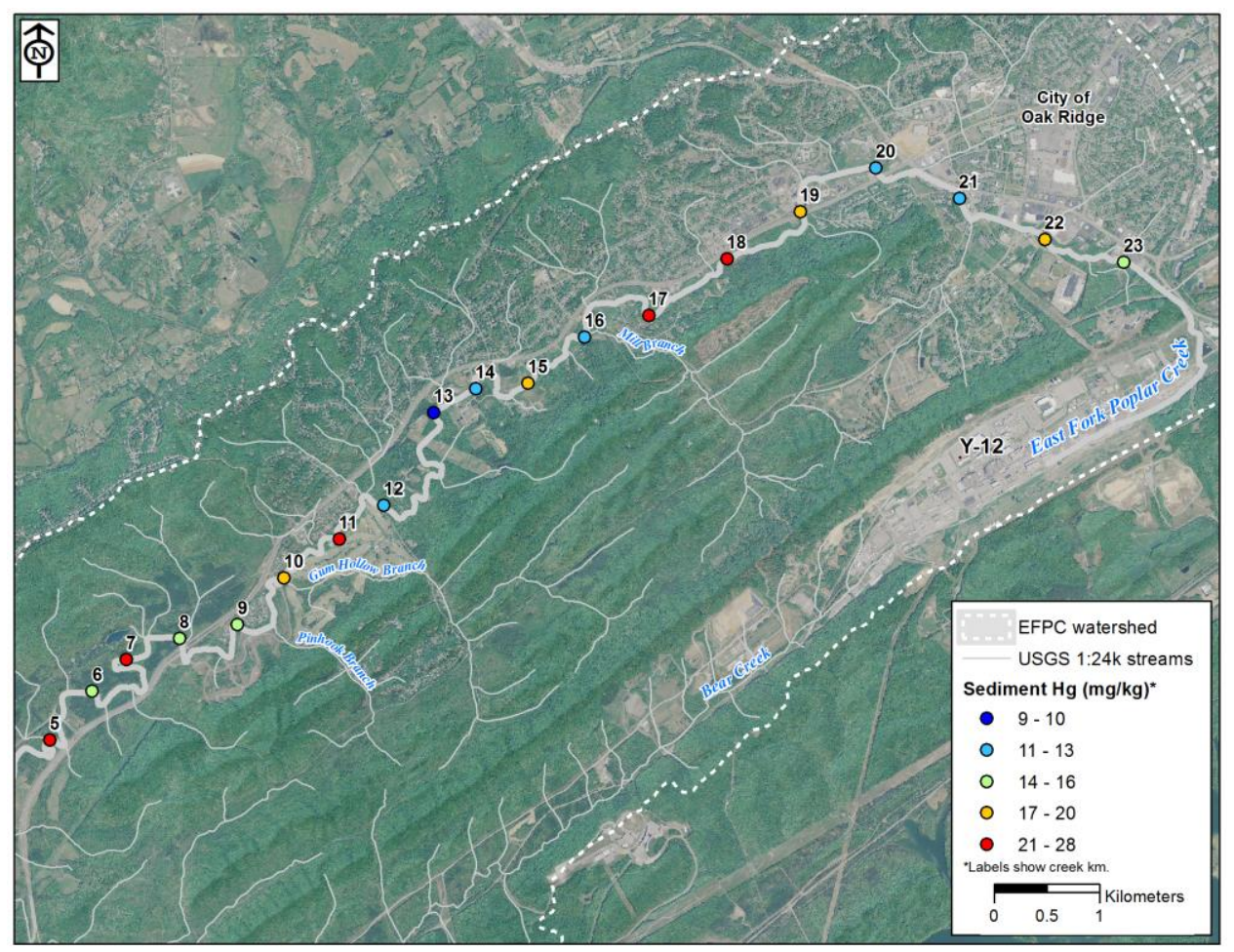

Fig. 2-6. Total Hg concentrations from stream sediments.

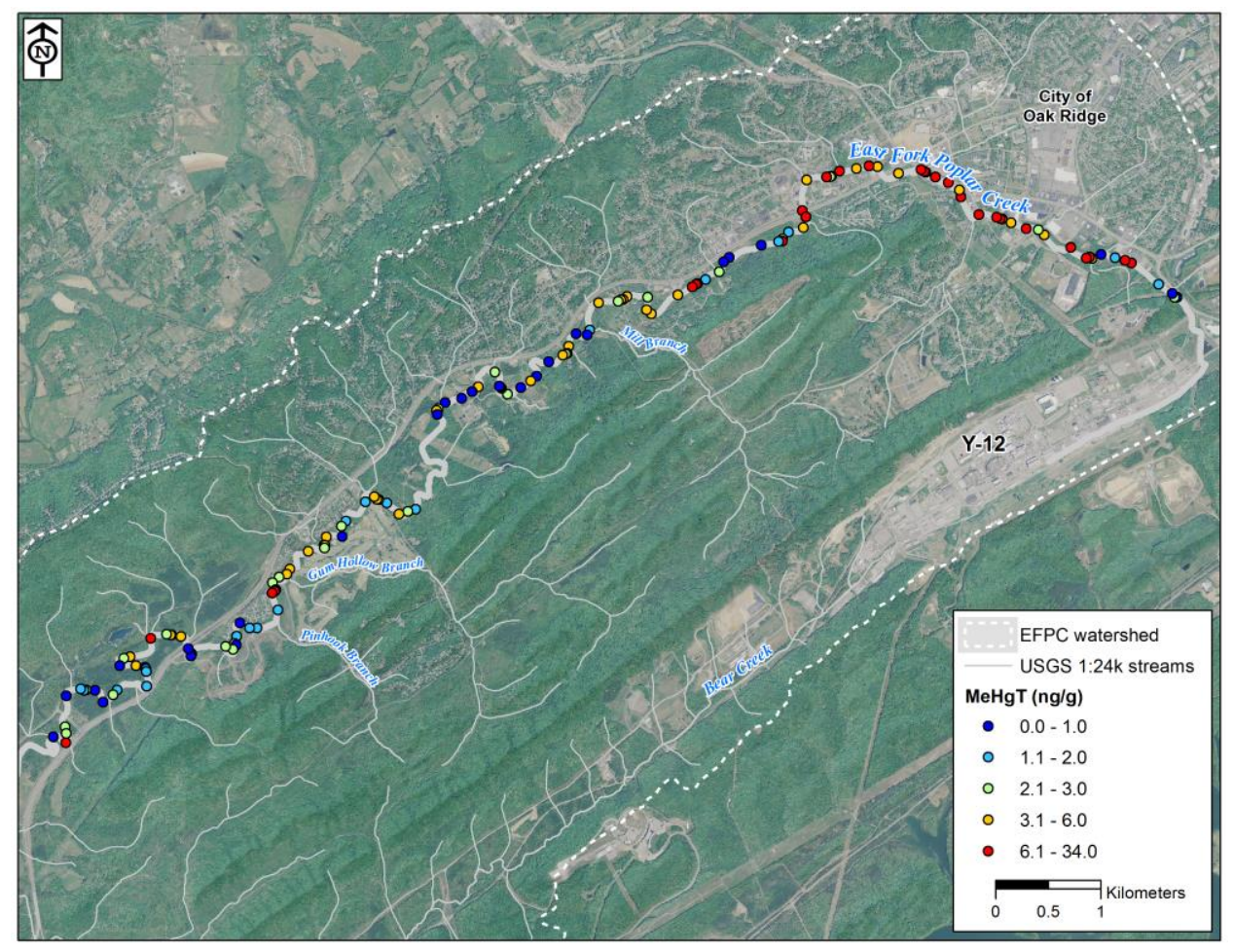

Fig. 2-7. Average concentrations of MeHg from the 2014 and 2015 longitudinal surveys. 


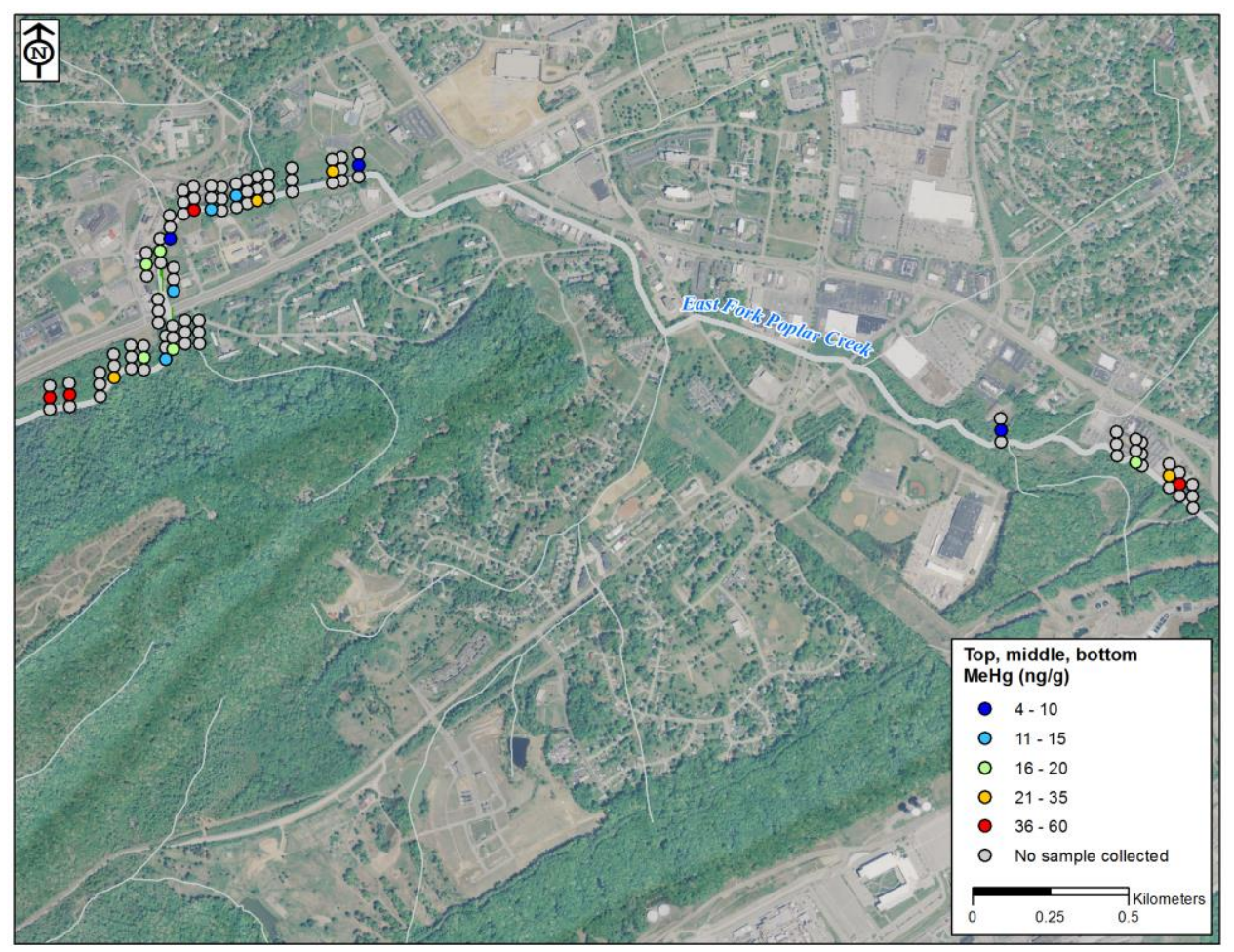

Fig. 2-8. MeHg concentrations from targeted sampling of the historical release deposit (HRD).

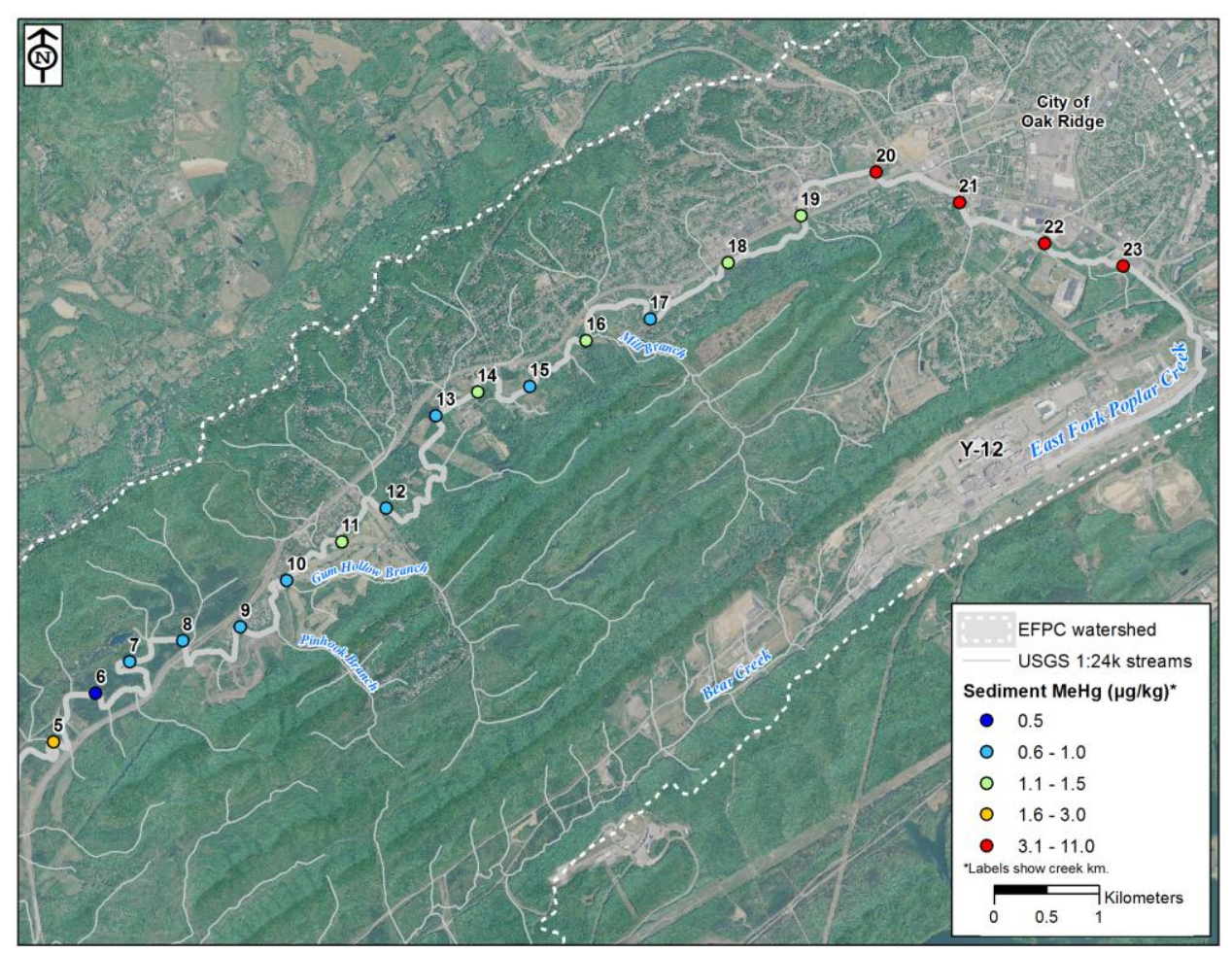

Fig. 2-9. Summary of MeHg concentrations from stream sediments. 


\subsubsection{Discussion and implications}

The bank soils are 200 times more contaminated than typical soils of the contiguous United States, which tend to range from 0.01 to $4.6 \mathrm{mg} \mathrm{kg}^{-1}$ (Shacklette and Boerngen 1984). Generally the highest bank soil $\mathrm{Hg}$ concentrations are immediately downstream of the Y-12 facility, and the high concentrations extend around $6 \mathrm{~km}$ downstream. Two major observable zones of the HRD in this area may be responsible for the observed higher contamination levels (Fig. 2-5a). In fact, Reaches 3 and 4 between EFK 23.4 and EFK 16.6 (Table 2-2) had significantly higher Hg concentrations $(n=240, p=2.5 \mathrm{E}-11)$ than the two remaining downstream Reaches 1 and 2 . The large peaks observed in the bank soils, particularly at EFK 18 (Fig. 2-5) are associated with an extensive outcropping of the HRD layer (Fig. 2-3). The HRD was dramatically observed in the March 2015 longitudinal sampling activity because of the lack of vegetative overgrowth. In fact, the extent of the HRD would not have been discovered were it not for its characteristic dark color, which is believed to be related to the presence of coal fines. In other words, it is a visible feature. However, creek bank slumping, bank soil reworking, and vegetative overgrowth can dramatically affect or completely hide its visibility. For example, the HRD was not observed to a great extent in the identical sampling event in September 2014, likely because of the intense vegetative cover. In addition, the significant lateral extent of the HRD was missed by all published studies of which the team is aware. In addition, both longitudinal samplings largely missed the HRD layer, because they sampled creek bank heights of 85\%, 50\%, and 15\%, and most of the HRD layer is between 50\% and 85\% bank height, which corresponds to 1-2 feet below the ground surface. Thus, there are large differences in Hg bank soil concentrations (Figs. 2-2 and 2-3), and in MeHg bank soil concentrations (Figs. 2-7 and 2-8). This also indicates the limited spatial extent of the HRD. Typically Reaches 1 and 2 do not differ from each other in $\mathrm{Hg}$ concentration $(p=0.958)$. However, an additional $\mathrm{Hg}$ peak was observed in the bank soils within Reach 1 ( EFK 10), coinciding with the possible occurrence of another legacy deposit along this stream reach identified by TVA (Tennessee Valley Authority 1985b, a). The investigations did not visually identify any HRD-like deposit in the bank soils at EFK 10.

Table 2-2. LEFPC creek reach designations

\begin{tabular}{ccc}
\hline Reach & Start (EFPC km) & End (EFPC km) \\
\hline 1 & 0.0 & 11.45 \\
2 & 11.46 & 15.60 \\
3 & 15.61 & 19.54 \\
4 & 19.55 & $23.40^{a}$ \\
\hline
\end{tabular}

${ }^{a}$ This is Station 17 - the point at which the creek exits the boundary of Y-12 and represents the farthest upstream point at which samples can be collected without additional access requirements. Station 17 also represents the boundary between Upper and Lower EFPC.

Over the entire LEFPC, creek bank Hg concentrations $(n=596)$ do not differ significantly from bulk stream sediments $(n=19, p=0.155)$. Creek bank soils do contain significantly higher $\mathrm{Hg}(p=4.0 \mathrm{E}-4)$ relative to the bulk stream sediment in Reaches 3 and 4. It is possible that the higher concentrations of $\mathrm{Hg}$ in the creek bank soils in the upper reaches of LEFPC drive Hg contamination in the stream sediments and water via erosion of the creek banks. To test this hypothesis, researchers used an enrichment factor (EF) calculation (Wallschlager et al. 1998) to compare Hg concentrations in the creek bank soils with respect to the stream sediments, as a function of distance (Fig. 2-10). The EF is a simple ratio of the $\mathrm{Hg}$ concentration of the bank soils to the stream sediments. Thus, when EF > 1 for logged $\mathrm{Hg}$ concentrations, this suggests that banks are acting as a source to the stream sediments. Figure 2-10 demonstrates that from approximately EFK 23 to EFK 15, the banks are enriched with respect to the stream sediments and could be serving as a source. 


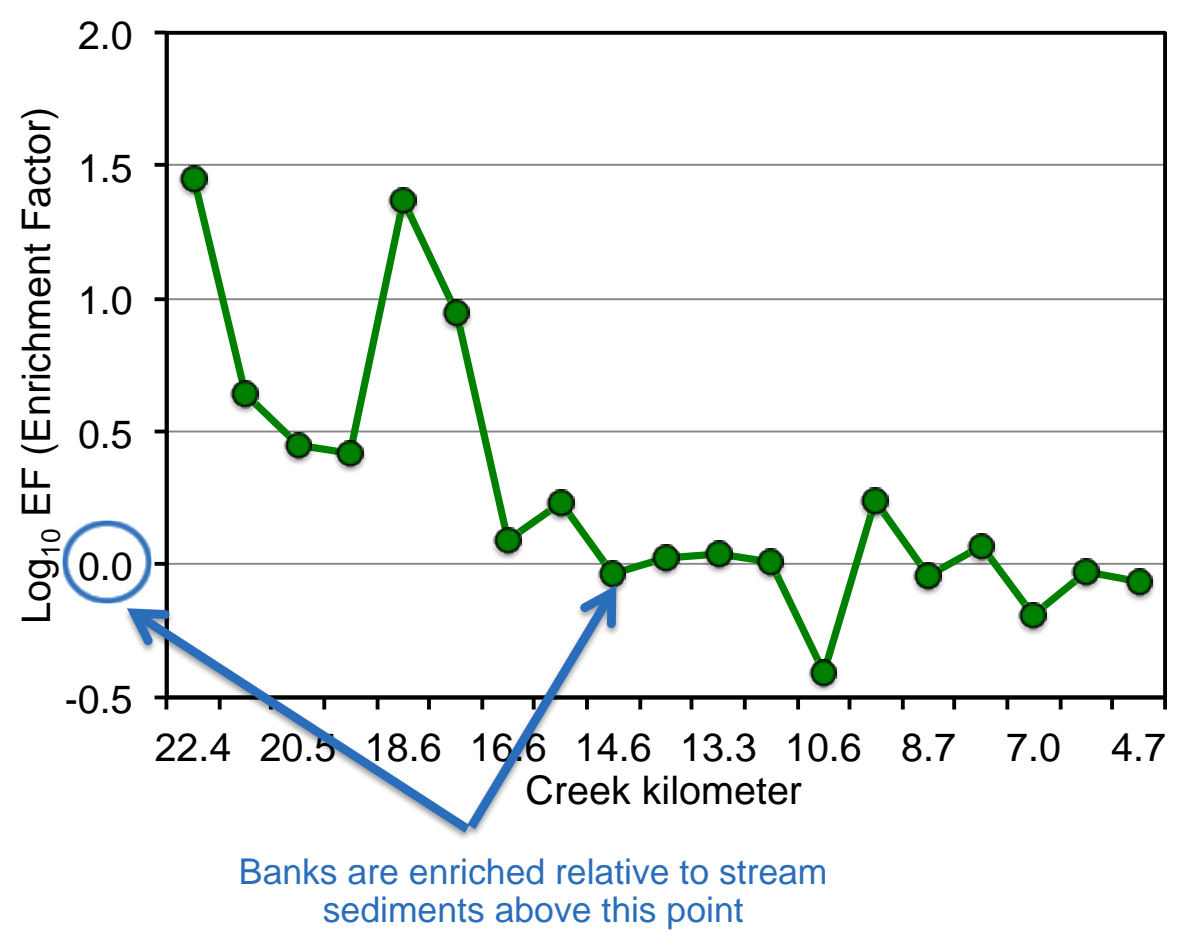

Fig. 2-10. Enrichment factor (EF) of the $\mathrm{Hg}$ concentration of the bank soils relative to the $\mathrm{Hg}$ concentration of the stream sediments (all values in $\log _{10}$ ).

\subsubsection{Geochemical Investigation}

In collaboration with the Mercury AFRI, the team initiated a more detailed geochemical characterization of the soils, particularly focusing on differences between the typical bank soils and the HRD. Although detailed geochemical characterization is beyond the scope of the OREM TD project, it is essential to determine the chemistry of the mercury and other minerals in the soils to understand conditions contributing to retention of the residual contamination and to predict the overall potential for release of mercury from the soils. The AFRI completed a series of total chemical digests on soil samples to quantitatively determine the total elemental composition. The chemical composition of the HRD is similar to that of fly ash, suggesting deposits transported downstream from anthropogenic sources within Y-12 during periods of active mercury use. HRD samples from bank soils have a different elemental content than the bank soils without HRD (non-HRD bank samples). HRD is enriched in $\mathrm{C}, \mathrm{S}, \mathrm{TOC}, \mathrm{Cu}, \mathrm{Ca}, \mathrm{N}$, $\mathrm{Fe}, \mathrm{Al}, \mathrm{Zn}$, and $\mathrm{P}$ but is poor in Si relative to non-HRD bank soils. This information along with elemental analysis of the sediment samples could help fingerprint sources of $\mathrm{Hg}$ in the sediment. Additionally, scanning electron images with energy dispersive spectroscopy measurements were conducted on bank soil and HRD. Results from the HRD samples suggest sulfur is collocated with mercury-enriched particles, confirming the collocation of mercury and sulfur in EFPC bank soils. Further, image analysis shows the size distribution of the $\mathrm{HgS}$ enriched particles ranged from 0.15 to $4.2 \mu \mathrm{m}$. Last, in collaboration with the Sediment Task 2, XRF was used to compare elemental composition of the HRD, creek bank soils, and stream sediments.

\subsubsection{Desorption Potential Investigation}

The extent of desorption of $\mathrm{Hg}$ from bank soils in lab scale experiments can serve as an indicator of the potential for mobility of $\mathrm{Hg}$ into LEFPC waters from eroding bank soils. In FY 2015, researchers began desorption experiments involving several typical creek bank soils, and three different solutions - an 
artificial creek water solution (ACW), water from nearby Hinds Creek (HCW), and artificial creek water with $1 \mathrm{mg} \mathrm{L}^{-1}$ Sewanee River natural organic matter (NOM). The Sewanee River NOM is used because most of the dissolved $\mathrm{Hg}$ in LEFPC stream water is strongly complexed with NOM, which can significantly alter the reactivity of $\mathrm{Hg}$. $\mathrm{HCW}$ typically contains about $1 \mathrm{mg} \mathrm{kg}^{-1} \mathrm{NOM}$, and is considered the uncontaminated background site for EFPC. Experiments were performed at an optimized ratio of $1 \mathrm{~g}$ soil to $30 \mathrm{~mL}$ solution and an optimized reaction time of $6 \mathrm{~h}$. As described in the FY 2015 report (Peterson et al. 2016), desorption extents ranged from $0.004 \%$ to $0.02 \%$ of the original $\mathrm{Hg}$ in the sample. The addition of NOM tended to increase desorption, but there was unexplained variability in the amount of desorption between the four soils, and in response to different background solutions - so much variability, in fact, that researchers were unable to draw any clear conclusions on controls over $\mathrm{Hg}$ desorption.

In FY 2016, the desorption work was expanded to also include seven HRD soils. Four different locations of typical creek bank soils were used, from EFKs 21.3, 18.51, 14.36, and 8.41; and seven locations of HRD soils from EFKs 22.46, 19.39, 19.02, 18.94, 18.49, 18.20, and 17.97. EFPC water was added as a desorption solution. The large variability in previous results was believed to be related to the wide particle size distribution of the soils and in the differential concentrations of $\mathrm{Hg}$ as a function of particle size. To reduce this variability, researchers used five different fractions of soil particle sizes, $<0.053,0.053-$ $0.125,0.125-1.00,1.00-2.36$, and $>2.36 \mathrm{~mm}$. In some cases, there were insufficient quantities of the clay-sized fraction, $<0.053 \mathrm{~mm}$. The $\mathrm{Hg}$ concentrations in each particle size fraction also were analyzed.

\subsubsection{Desorption Potential of Creek Bank Soils}

For both bank soils and HRD soils, the pattern of desorption is now much more discernable (Fig. 2-10). For example, among the bank soils (Fig. 2-11a), EFK 8.43 consistently shows greater desorption, and EFK 14.36 consistently shows lesser desorption. Among the HRD soils, EFK 19.39 consistently shows greater desorption, and EFK 18.20 consistently shows lesser desorption (Fig. 2-11b). Interestingly, desorption seems greater in the smaller particle sizes for many soils. This is a little surprising because last year's analysis comparing bank soil $\mathrm{Hg}$ concentrations and particle sizes observed greater concentrations of $\mathrm{Hg}$ associated with the sand fraction compared with the fine fractions (Peterson et al. 2016). Further, stronger chemical associations are usually observed in fine-grained materials for a wide range of contaminants. The HRD soils usually desorb much greater amounts of Hg compared with the typical bank soils, one to two orders of magnitude more (Fig. 2-11). As a percentage with respect to the original concentration of $\mathrm{Hg}$ in the soils, the bank soils release $0.001 \%$ to $0.02 \%$, whereas the HRD soils release $0.003 \%$ to $0.05 \%$. Although these percentages sound very small, the concentrations are two to three orders of magnitude greater than the typical aqueous concentrations of $\mathrm{Hg}$ in LEFPC stream water. 

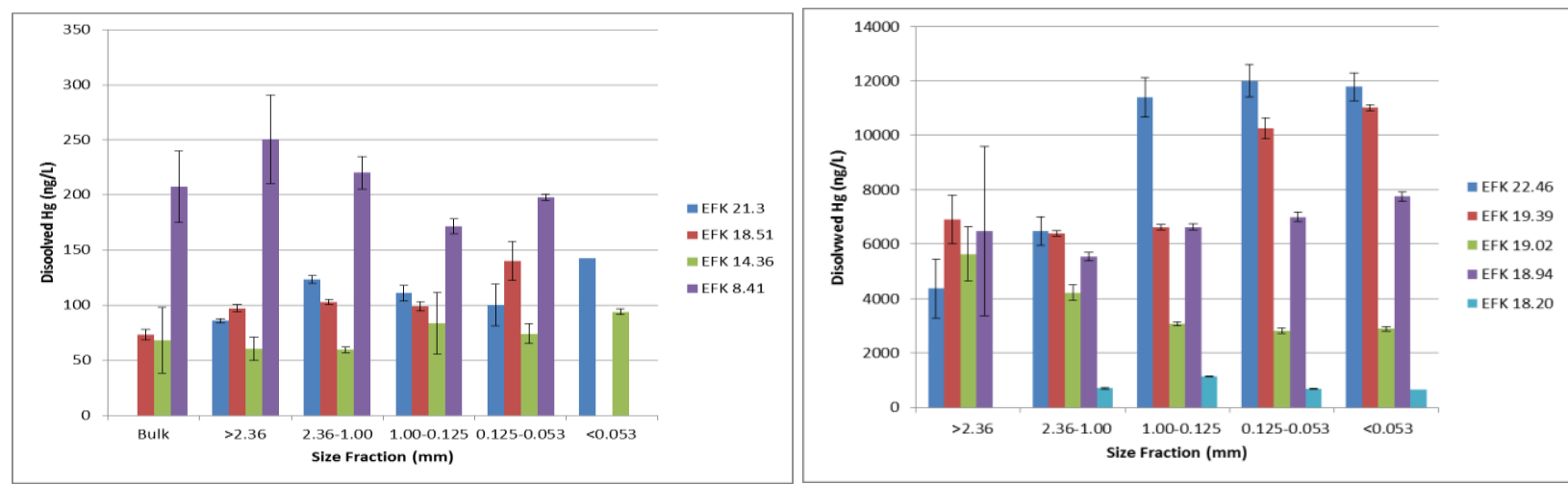

Fig. 2-11. Desorption extents as a function of particle size in artificial creek water (ACW) solution (a, left) in typical creek bank soils, and (b, right) in HRD. Note: in addition to contributions from the Mercury Technology

Development project, these experiments were also supported by the Applied Field Research Program and the Minority Serving Institutions Partnership Program.

The extent of desorption was also sensitive to the composition of the solution (Fig. 2-12). Desorption experiments were performed using the 0.125 to $1.00 \mathrm{~mm}$ size fraction and four different solutionsHCW, EFPC, NOM, and ACW. Results presented in Fig. 2-12 are representative of the results from the remaining three typical creek bank soils and the remaining six HRD soils. Desorption extent ranged from $0.003 \%$ to $0.018 \%$ in the creek bank soils and $0.004 \%$ to $0.041 \%$ in the HRD. For both soil types, the ACW desorbed the least $\mathrm{Hg}$. Interestingly, the HCW desorbed the most from the typical creek bank soils, and the EFPC desorbed the most from the HRD soils (Fig. 2-12).
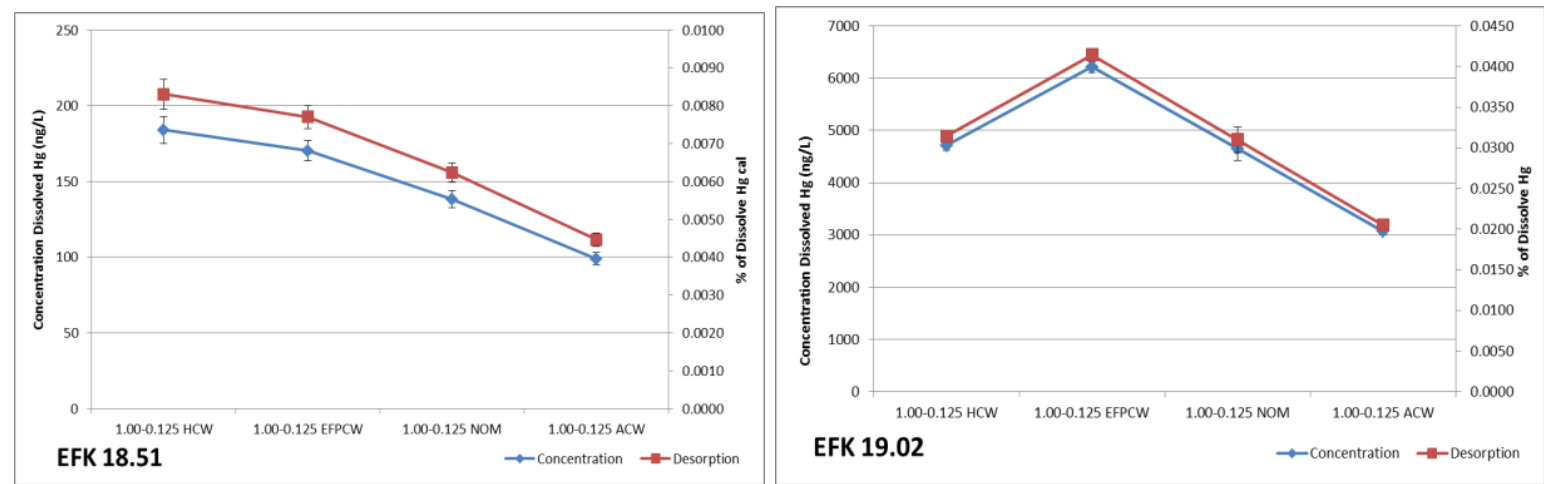

Fig. 2-12. Desorption extents from the 0.125 to $1.00 \mathrm{~mm}$ size fraction as a function of different extractant solutions, including Hinds Creek water (HCW), East Fork Poplar Creek water (EFPC), artificial creek water with $1 \mathrm{mg} \mathrm{kg}^{-1}$ natural organic matter (NOM), and artificial creek water $(\mathrm{ACW})$ - (a, left) in typical creek bank soils represented by EFK 18.51, and (b, right) in HRD represented by EFK 19.02. Note: in addition to contributions from the Mercury Technology Development project, these experiments were also supported by the Applied Field Research Program and the Minority Serving Institutions Partnership Program. 


\subsection{GROUNDWATER}

Groundwater can contribute to mercury leaching caused by infiltration through contaminated floodplain soils and subsequent discharge by groundwater into LEFPC, and recent recommendations for EFPC call for it to be studied (Looney et al. 2008; US Department of Energy 2014). Further, methylmercury production can be significant in the interface between groundwater and surface water, i.e., the hyporheic zone (Stoor et al. 2006; Kolka et al. 2011). The current SourceID model results suggest a very small potential of mercury or methylmercury groundwater contribution to EFPC, but additional on-site data would better support those findings. Because of the earlier recommendations for study (Looney et al. 2008; US Department of Energy 2014), and because of the potential importance of groundwater in generating methylmercury (Stoor et al. 2006; Kolka et al. 2011) a groundwater investigation was planned in FY 2015 and implemented in FY 2016. Possible mechanisms of interest for this investigation involved (1) the potential for mercury release due to desorption, and (2) the potential for methylmercury production in situ in groundwater. Researchers monitored the concentrations of $\mathrm{Hg}$ and $\mathrm{MeHg}$ in groundwater near LEFPC, seeking to understand the relation to surface water $\mathrm{Hg}$ and $\mathrm{MeHg}$ concentrations. Researchers also wanted to know how $\mathrm{Hg}$ and $\mathrm{MeHg}$ concentrations, as well as other indicators of groundwater chemistry, change over time and with seasonal variations in water table elevation.

Briefly, the FY 2016 investigations found that mercury concentrations in groundwater near EFPC are often significant, with total mercury concentrations ranging from 1 to $70 \mathrm{ng} \mathrm{L}^{-1}$ and variable over time and location. Concentrations of mercury may be higher or lower than stream water, depending on location and season. Of the three observation sites, the concentration of mercury was by far the highest in the vicinity of the HRD layer near EFK 17.8, where the groundwater wells directly penetrate the HRD. In this location in particular, groundwater mercury concentrations are usually greater than stream water concentrations. In addition, limited vadose zone observations at that site identified persistent high moisture contents within the HRD itself and lower moisture contents in the overlying and underlying soils. This suggests that the moisture within the HRD could promote leaching into underlying groundwater and/or the in situ production of methylmercury.

Methylmercury concentrations were observed ranging from 0.1 to $28 \mathrm{ng} \mathrm{L}^{-1}$. Most EFPC values are much higher than expected in uncontaminated sites, e.g., less than $0.6 \mathrm{ng} \mathrm{L}^{-1}$ near the Great Lakes (Stoor et al. 2006). Importantly, at the monitored groundwater wells, concentrations of methylmercury in groundwater samples were always greater than surface water, which could suggest production of methylmercury in groundwater. A predominance of reducing conditions in groundwater was identified, including significant concentrations of sulfide, dissolved iron, and reduced iron in many wells. Methylmercury production is associated with reducing conditions because the microbes responsible are typically sulfate reducers and methanogens, and these microbes are less active under oxic conditions. It is apparent that surface water and groundwater concentrations of all surveyed ions were quite different from each other, suggesting that conditions in groundwater differ from conditions in the stream. More monitoring will be needed to fully elucidate changes in observations with seasons and to understand the underlying mechanisms for the patterns. The FY 2016 conclusions suggest that groundwater monitoring is providing new and important insights into potential sources of mercury and methylmercury, and these activities should continue through FY 2017, at a minimum.

\subsubsection{Groundwater Well Installation and Sensor Instrumentation}

The installation of the groundwater wells was presented in the FY 2015 report (Peterson et al. 2016), even though it was technically an FY 2016 activity (October). Consequently, many details will not be repeated here. Briefly, there were three sites - the NOAA site at EFK 22, the former Bruner's Market site at EFK 17.8, and the Horizon site at EFK 8.7. Three groundwater wells were installed at each site. Two wells were installed in relatively upstream (U) and downstream (D) positions near the creek bank, respectively, 
and one well was installed somewhat inland (I), to make a triangle shape in map view. Wells at EFK 22 ranged from $5 \mathrm{ft}, 5 \mathrm{in}$. to $7 \mathrm{ft}, 6$ in. below ground surface (BGS); wells at EFK 17.8 ranged from $10 \mathrm{ft}, 5$ in. to $10 \mathrm{ft}, 10 \mathrm{in.} \mathrm{BGS}$; and wells at EFK 8.7 ranged from $7 \mathrm{ft}, 2$ in. to $10 \mathrm{ft}, 4.5 \mathrm{in.}$ BGS. In FY 2016, all wells were developed and surveyed for elevation and location using GPS. In addition, one stilling well was installed at each site in the stream (S) and attached to the creek bank (Figs. 2-13 and 2-14). In Situ ${ }^{\circledR}$ Aqua Troll 200 sensors were installed to gather continuous data on pressure head (water table elevation), temperature, and conductivity, for all groundwater and stream water wells in FY 2016.

As mentioned in Peterson et al. (2016), continuous cores from each location were collected and are currently under storage at $-80^{\circ} \mathrm{C}$ at ORNL. A complete investigation of the cores is necessary but should include microbiological characterization. Because microbiology is out of scope for this project, other funding sources for this activity must be sought in FY 2017.

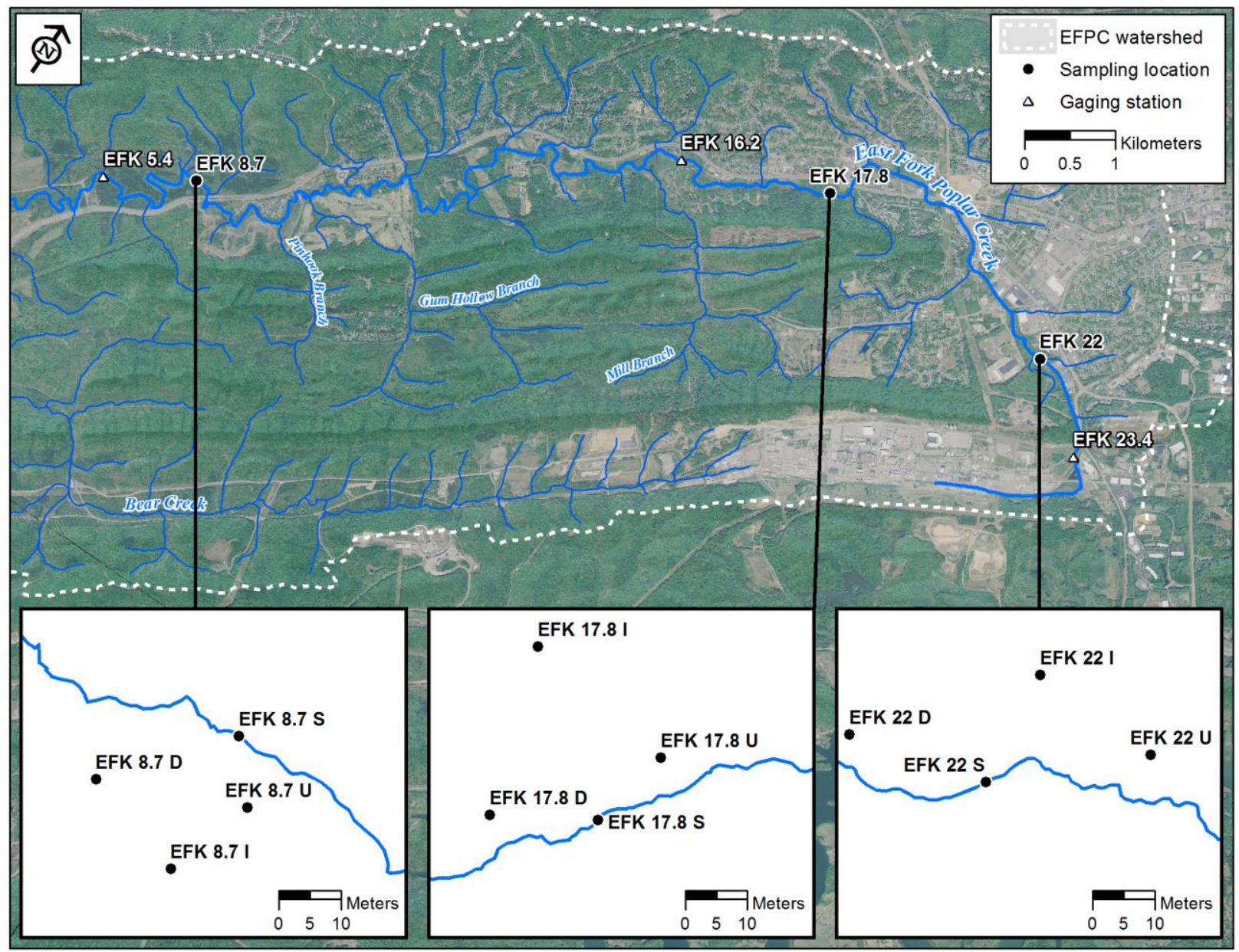

Fig. 2-13. The Mercury Technology Development project's groundwater sampling locations at NOAA (EFK 22), Bruner (17.8), and Horizon (EFK 8.7), along East Fork Poplar Creek (EFPC). (Notes: EFK = East Fork Poplar Creek kilometer; NOAA = National Oceanic and Atmospheric Administration). 

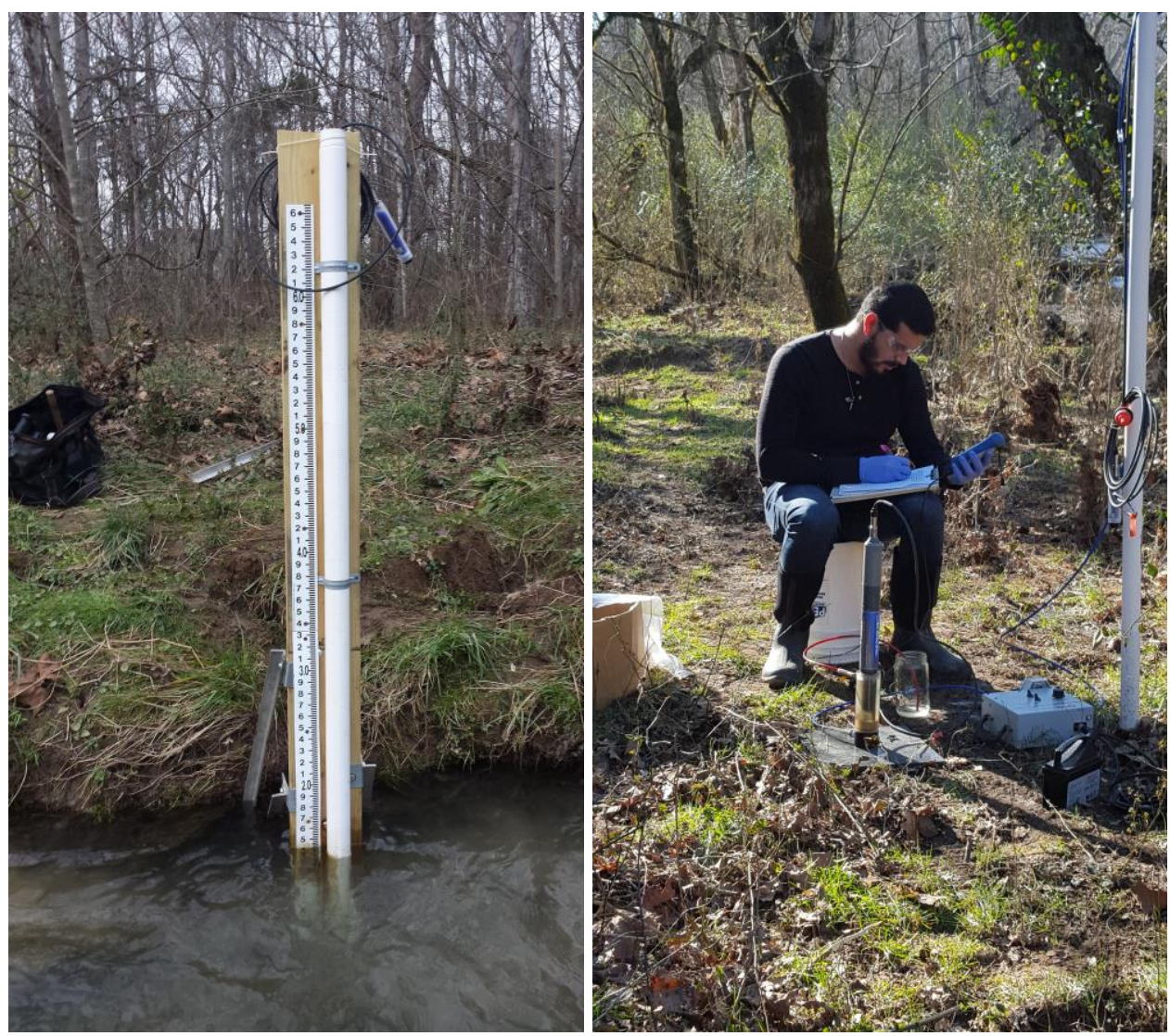

Fig. 2-14. Groundwater and surface water wells, including (left) a surface water stilling well installed near the NOAA location at East Fork Poplar Creek kilometer

22. Visible features include the staff gauge and metal supports in the creek bank. A sensor for automated and continuous monitoring of pressure head (water level), conductivity, and temperature is placed below the water level inside the PVC pipe. At right, ORNL staff shown sampling groundwater well at EFK 8.7.

\subsubsection{Results of Groundwater Monitoring}

Continuous automated monitoring of the pressure head levels (water table elevation) of the U, D, and I groundwater wells coupled with the in-stream $\mathrm{S}$ well will facilitate construction of the potentiometric surface of the water table in the vicinity of the creek (e.g., Fig. 2-15). Monthly average groundwater elevations for each monitoring location were calculated from data collected at 15 minute intervals by field data loggers. These average elevations were then interpolated into groundwater potentiometric surface maps using the Spline tool in ArcGIS. Finally, contours with a 0.1 foot interval were generated from the interpolated surfaces. This contour interval was selected because it seemed to capture a noticeable gradient for all sites and dates, and using the same interval for all maps allows for comparison across maps. The direction of stream flow is shown with the blue arrows. Flow can be inferred to be in the direction of decreasing groundwater elevations and perpendicular to the flowlines. In Fig. 2-15, groundwater elevations are averaged over every month, although some data is lacking (open circles) because funding was not available to purchase the full set of sensors for all four wells at each site until about mid-FY 2016. At EFK 22, groundwater flow in November is approximately parallel to the stream. Some changes are observed in December, with a water table depression in the area of EFK 22I. Through the winter and spring, groundwater flow is toward EFPC, although there is missing data in EFK 22U. In June, flow reverses direction and appears to source from the stream and enter the groundwater (Fig. 215a). This is exactly the kind of information that was expected - that interactions between groundwater 
and surface water will change as a function of season, and that at times, groundwater is a source to EFPC, and at times, EFPC is source to groundwater. At EFK 17.8, contours are a little tighter and flow is strongly toward the stream from November to June (Fig. 2-15b). In July, however, the trend reverses, and groundwater flow begins to source from EFPC and flow towards the inland wells. At EFK 8.7, the water table appears to be much more flat overall, and groundwater flow remains consistently toward the stream (Fig. 2-15c).

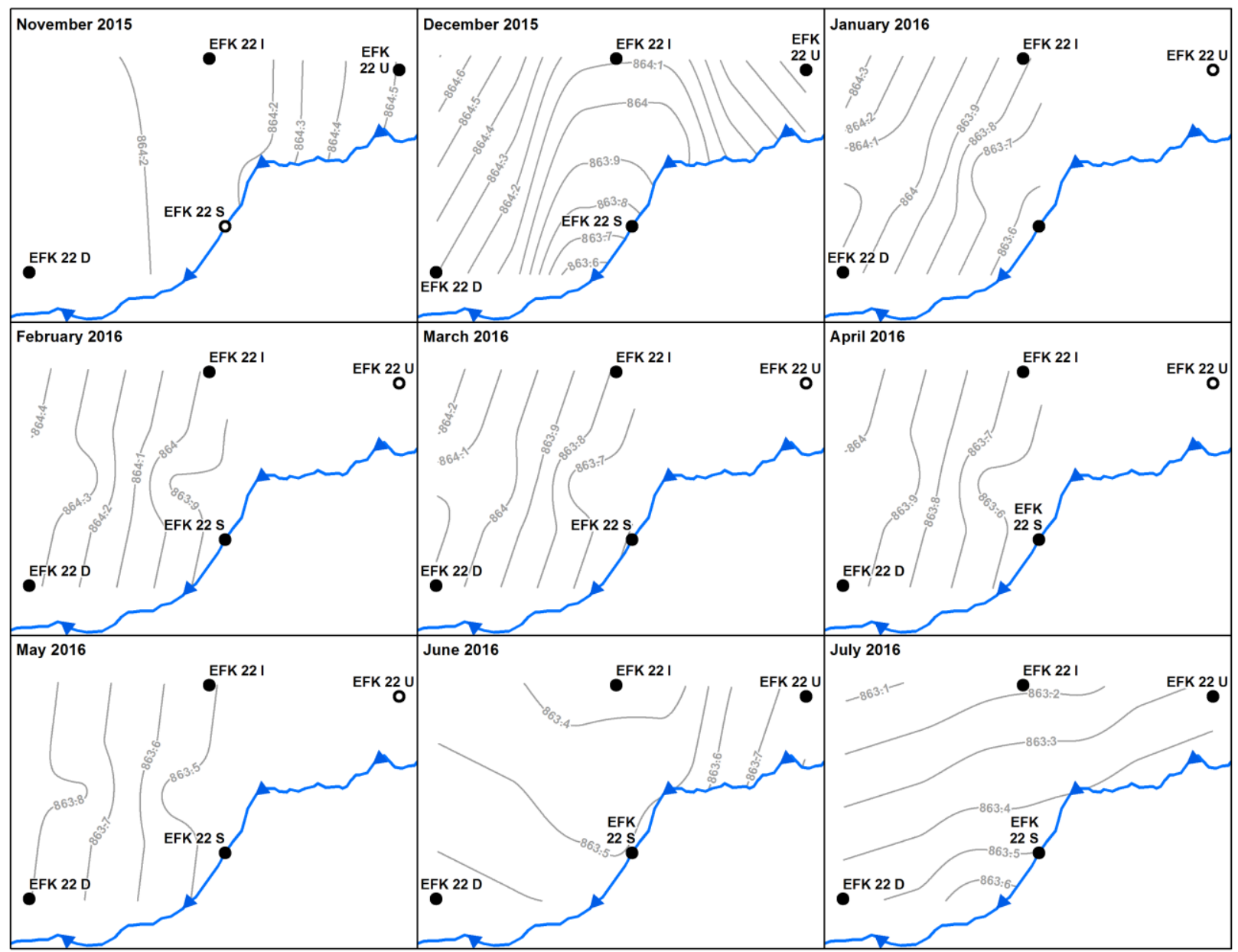

(A)

Fig. 2-15. Example potentiometric surfaces (i.e., elevations of equal head) at (A) EFK 22, (B) EFK 17.8, and (C) EFK 8.7. The inland (I), upstream (U), and downstream (D) wells, as well as the in-stream (S) stilling well, are depicted in real space on the inset figures. The stream is noted by the blue line and flow direction by the arrows. The potentiometric surface (water table elevation) is depicted with sub-parallel gray "flow lines" with groundwater elevations noted in feet. Flow direction may be inferred to be perpendicular to the flowlines. 


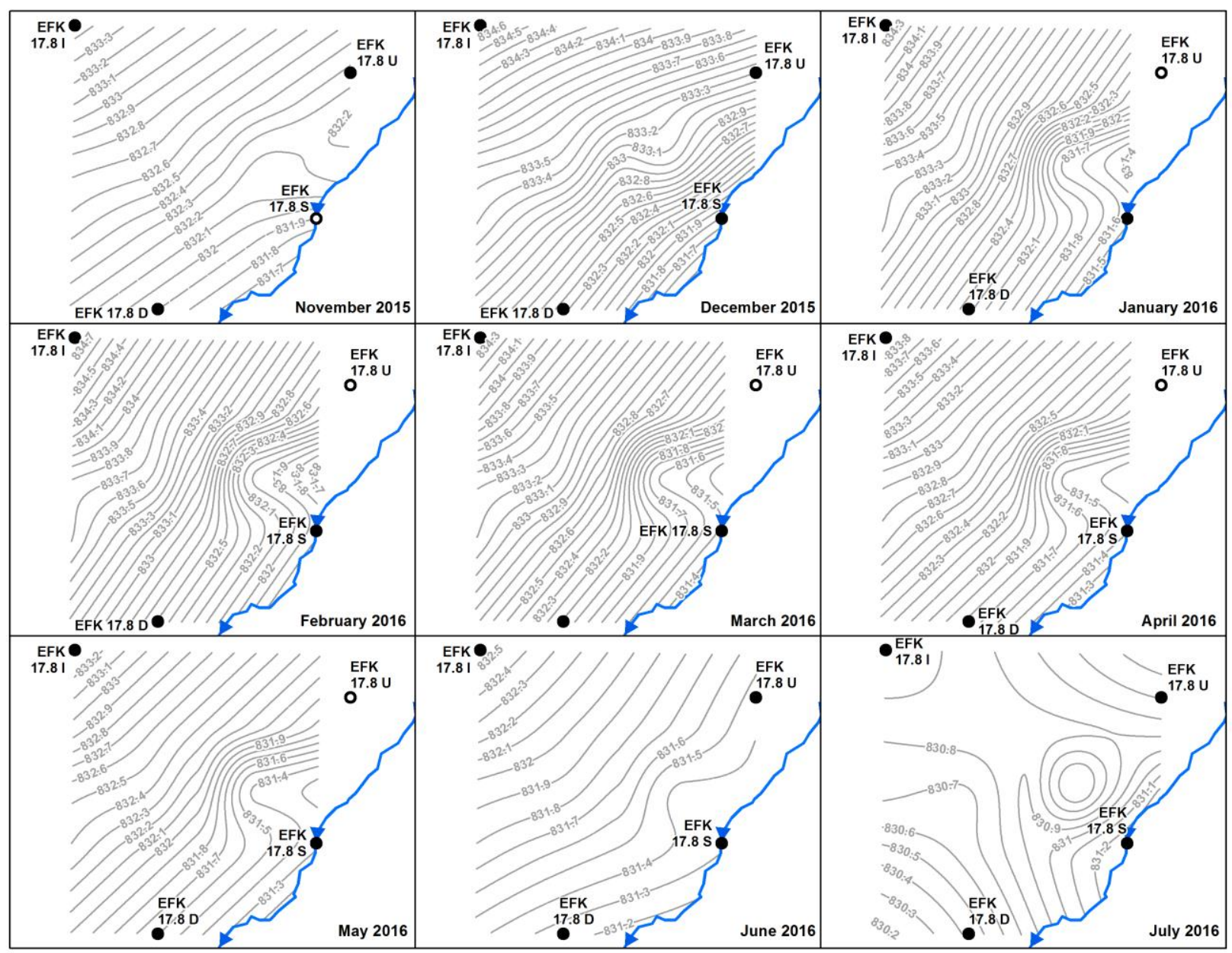

(B)

Fig. 2-15. (continued) 


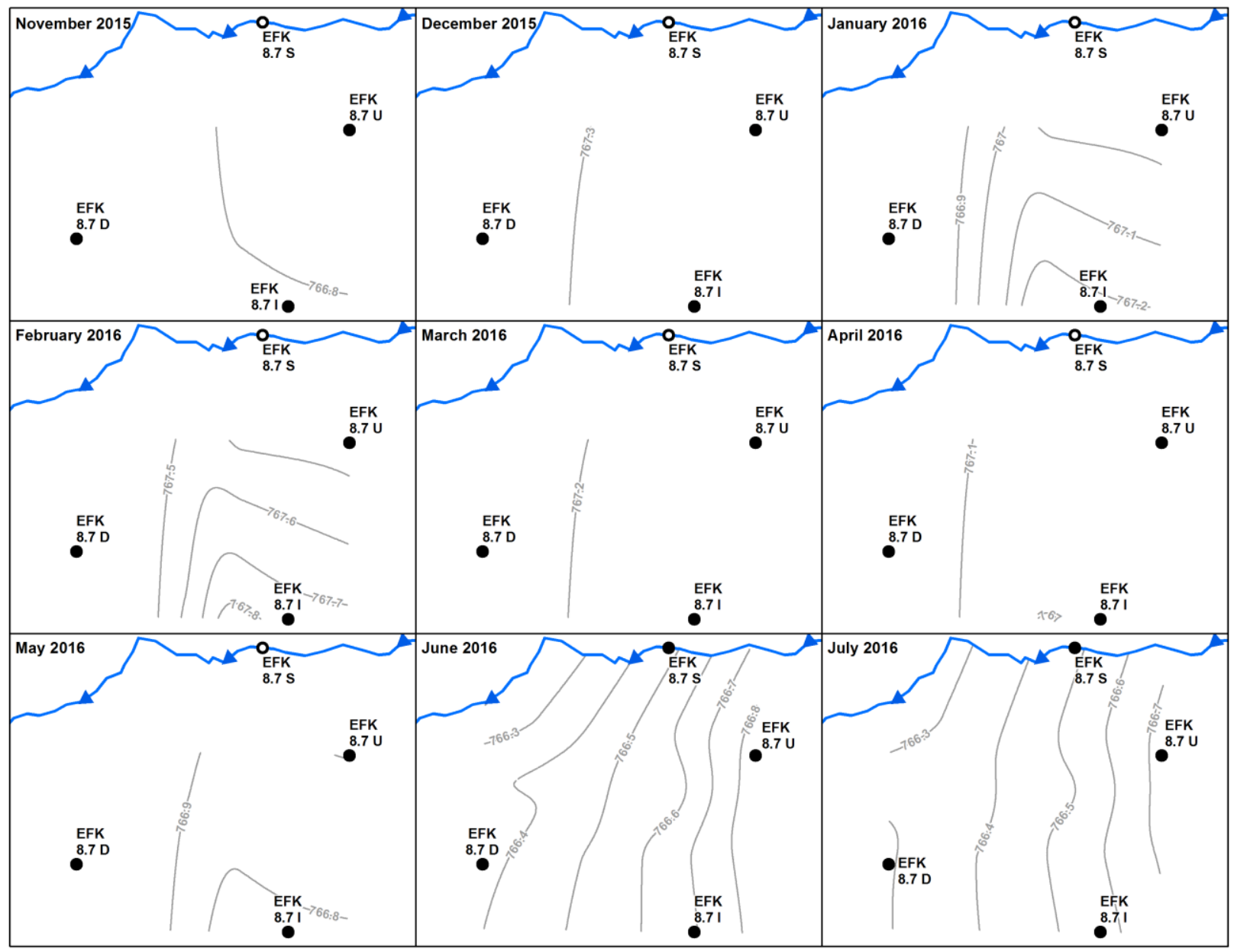

(C)

Fig. 2-15. (continued)

An understanding of how water table elevation changes as a function of time, e.g., during seasonal changes, storm events, drought events, etc., is possible because automated data is collected every 15 minutes. This is a very powerful way to understand relations between groundwater and surface water, and the extent to which groundwater contributes to the stream, and vice versa. In particular, examining the data as a function of time during different seasons, and during specific events, will also be interesting. Analysis of this information has just begun, and a deeper understanding might require 1-2 years of data. The temperature and conductivity readings (not shown) may also help elucidate the signature of the groundwater versus the surface water and connect to the potentiometric surface interpretations.

Manual sampling is performed to determine $\mathrm{Hg}$ and $\mathrm{MeHg}$ concentrations, dissolved organic carbon (DOC), dissolved oxygen, $\mathrm{pH}$, ferrous $\left(\mathrm{Fe}^{2+}\right)$ and total iron $(\mathrm{FeT})$, sulfate $\left(\mathrm{SO}_{4}{ }^{2-}\right)$ and sulfide $\left(\mathrm{S}^{2-}\right)$, anions and cations. Five groundwater samplings have occurred since December 2015. Results are still quite preliminary because multiple samplings are required to build a comprehensive understanding of groundwater-surface water interactions. In-stream $\mathrm{Hg}$ concentrations decrease with downstream distance, and $\mathrm{MeHg}$ concentrations increase downstream, which is consistent with findings from Task 2 in this project (Fig. 2-16). Figure 2-16a shows average $\mathrm{Hg}$ and $\mathrm{MeHg}$ concentrations over all five sampling events, with the color scheme representing DOC concentrations, where yellow concentrations are low and green concentrations are high. Qualitatively, high $\mathrm{Hg}$ seems associated with high DOC, which is 
consistent with numerous previous studies demonstrating that $\mathrm{Hg}$ in stream waters in LEFPC is associated with DOC. Figure 2-16b shows average MeHg concentrations over all five sampling events, with the color scheme representing dissolved sulfide concentrations, where yellow concentrations are low and green concentrations are high. Qualitatively, high sulfide concentrations appear to be associated with high $\mathrm{MeHg}$ concentrations, which could be related to the fact that methylation and sulfate reduction occur under similar geochemical conditions, i.e., reducing conditions, and involve a similar suite of the microbial community. More detailed analysis of the results will occur in FY 2017 and will be aided by additional sampling activities to enhance the groundwater geochemical database.

The 22U well shows both high $\mathrm{Hg}$ and high $\mathrm{MeHg}$, while 22D and 22I show lower concentrations, particularly of $\mathrm{MeHg}$. The temperature and conductivity readings of the $\mathrm{U}$ well are also different from the $\mathrm{D}$ and I wells. Even though the $\mathrm{Hg}$ concentrations in $22 \mathrm{U}$ are higher than those the other two wells, $\mathrm{Hg}$ in $22 \mathrm{U}$ is still about 5 times lower than the stream water (S) Hg concentrations. In contrast, DOC and sulfide concentrations are much higher than those in the stream. Therefore, the reasons for the different concentrations between the wells are not clear, nor are the differences between the stream and the groundwater. It is not, however, surprising that simple answers are not readily forthcoming after only a few months of monitoring. Understanding groundwater-surface water interactions will simply take more time, 1-2 years. Chloride can be a clear indicator of stream water-groundwater connections because it is mostly supplied by runoff from road deicing in the winter. Those results are available but have not yet been analyzed in detail.

Understanding might also be aided by analysis of the core samples collected during groundwater well installation. Higher ferrous and total iron, in addition to sulfate, are also observed in 22.2U (not shown). The ferrous and sulfide concentrations most likely indicate reducing conditions, which are necessary for the production of $\mathrm{MeHg}$. In contrast, sulfate is observed in much higher concentrations in 22.2D and 22.2I, suggesting more oxidized conditions in those wells, which may inhibit production of $\mathrm{MeHg}$.

At Bruner 17.8, the wells 17.8D and 17.8I both have very high concentrations of $\mathrm{Hg}$ and $\mathrm{MeHg}$, considerably higher than those in any other groundwater wells in the suite. All concentrations in the groundwater wells are considerably higher than literature values from uncontaminated sites; e.g., Stoor et al. (2006), where $\mathrm{MeHg}$ concentrations of up to $0.6 \mathrm{ng} \mathrm{L}^{-1}$ were observed in the groundwater in the vicinity of the Tahquamenon River in the Lake Superior watershed. For comparison, these values are 220 times higher. In addition, concentrations of redox indicators such as DOC, sulfide, and ferrous and total iron are consistently high in both of these wells, suggesting that the conditions for methylation of $\mathrm{Hg}$ are present. It is important to realize that the Bruner area is in the downstream enriched zone of the HRD (Fig. 2-3), so findings of more reduced groundwater conditions, higher $\mathrm{MeHg}$, and higher $\mathrm{Hg}$ may indicate reactions with the $\mathrm{HRD}$ that release $\mathrm{Hg}$ and promote the production of $\mathrm{MeHg}$.

The upstream well (17.8U) tends to have lower concentrations of both $\mathrm{MeHg}$ and $\mathrm{Hg}$ and lower concentrations of redox indicators such as DOC, sulfide, and ferrous and total iron. Therefore, some differences apparently exist in the geochemistry of the three Bruner wells. Again, geochemical and microbiological analysis of the core samples could aid in understanding the reason for these differences. 


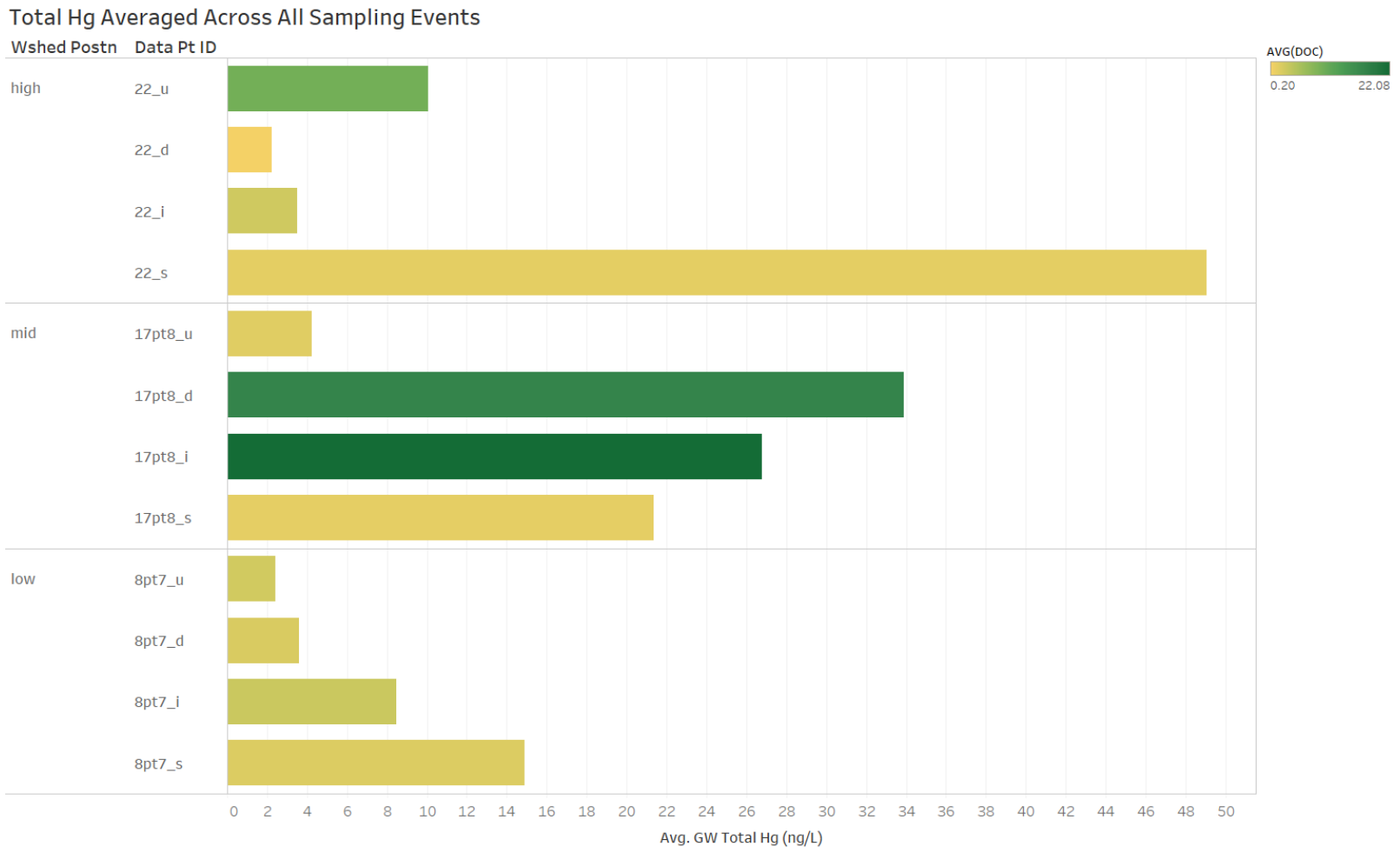

Average of gw thg for each Data Pt 10 broken down by Wshed Postn. Color shows average of DOC.

MeHg Averaged Across All Sampling Events

Wshed Postn Data Pt ID

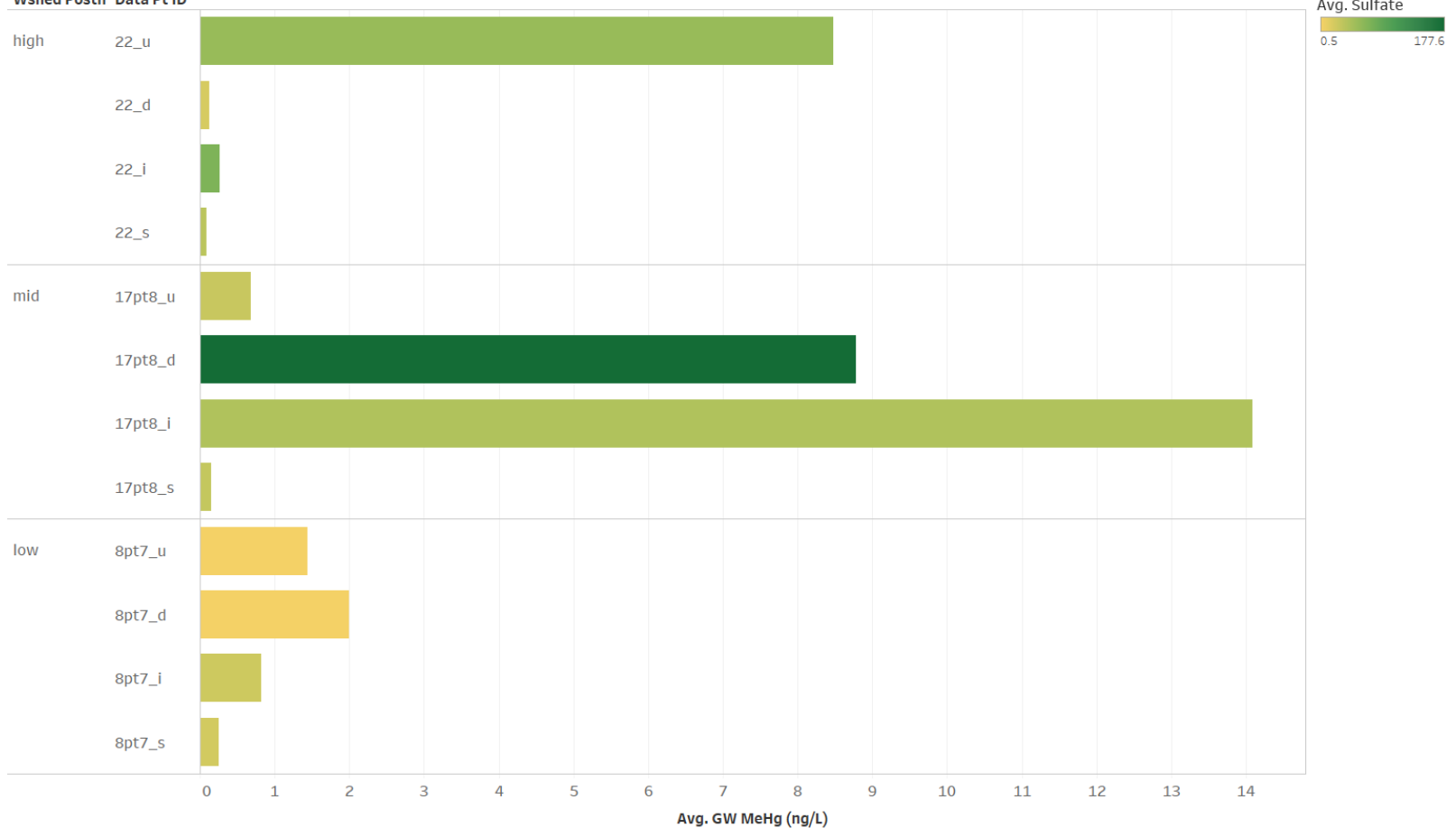

Fig. 2-16. Groundwater and stream water analyses at EFKs 22, 17.8, and 8.7, at upstream (U), downstream (D), and inland groundwater wells (I), and in stream water (S). (Top) total $\mathrm{Hg}\left(\mathrm{ng} \mathrm{L}^{-1}\right)$ as a function of dissolved organic carbon (DOC) concentrations, and (bottom) methylmercury $\left(\mathrm{ng} \mathrm{L}^{-1}\right)$ as a function of sulfide $\left(\mathrm{S}^{2-}\right)$ concentrations. 
Researchers were particularly interested to understand the moisture dynamics of the HRD layer, because if it remains wetter than the overlying and underlying soils, it could promote leaching of $\mathrm{Hg}$ or become a narrow zone for MeHg generation. The HRD is known to be texturally distinct, with lower bulk density, higher water content, and coarser particle sizes, in comparison to the overlying and underlying soils (Dickson et al. In review.). Normally, these properties would promote drainage. However, the overlying and underlying soils have high clay contents and are restrictive to infiltration (Dickson et al. In review.; Peterson et al. 2016). Therefore, researchers hypothesized the tighter surrounding bank soils could cause perching of moisture in the HRD layer. The creek bank was instrumented with four moisture and temperature sensors, with one overlying the HRD at $20 \mathrm{~cm} \mathrm{BGS,} \mathrm{two} \mathrm{sensors} \mathrm{inside} \mathrm{the} \mathrm{HRD} \mathrm{at} 50$ and $70 \mathrm{~cm}$ BGS, and one sensor below the HRD at $115 \mathrm{~cm}$ (Fig. 2-17a). Researchers identified clear and persistent high moisture contents in the HRD, especially at $70 \mathrm{~cm}$ but also at $50 \mathrm{~cm}$ (Fig. $2-17 \mathrm{~b}$ ), where the scale on the y-axis refers to relative moisture content (i.e., 1.0 means the layer in the vicinity of the sensor is saturated). These conditions persisted from the beginning of measurements in mid-April until mid-June.
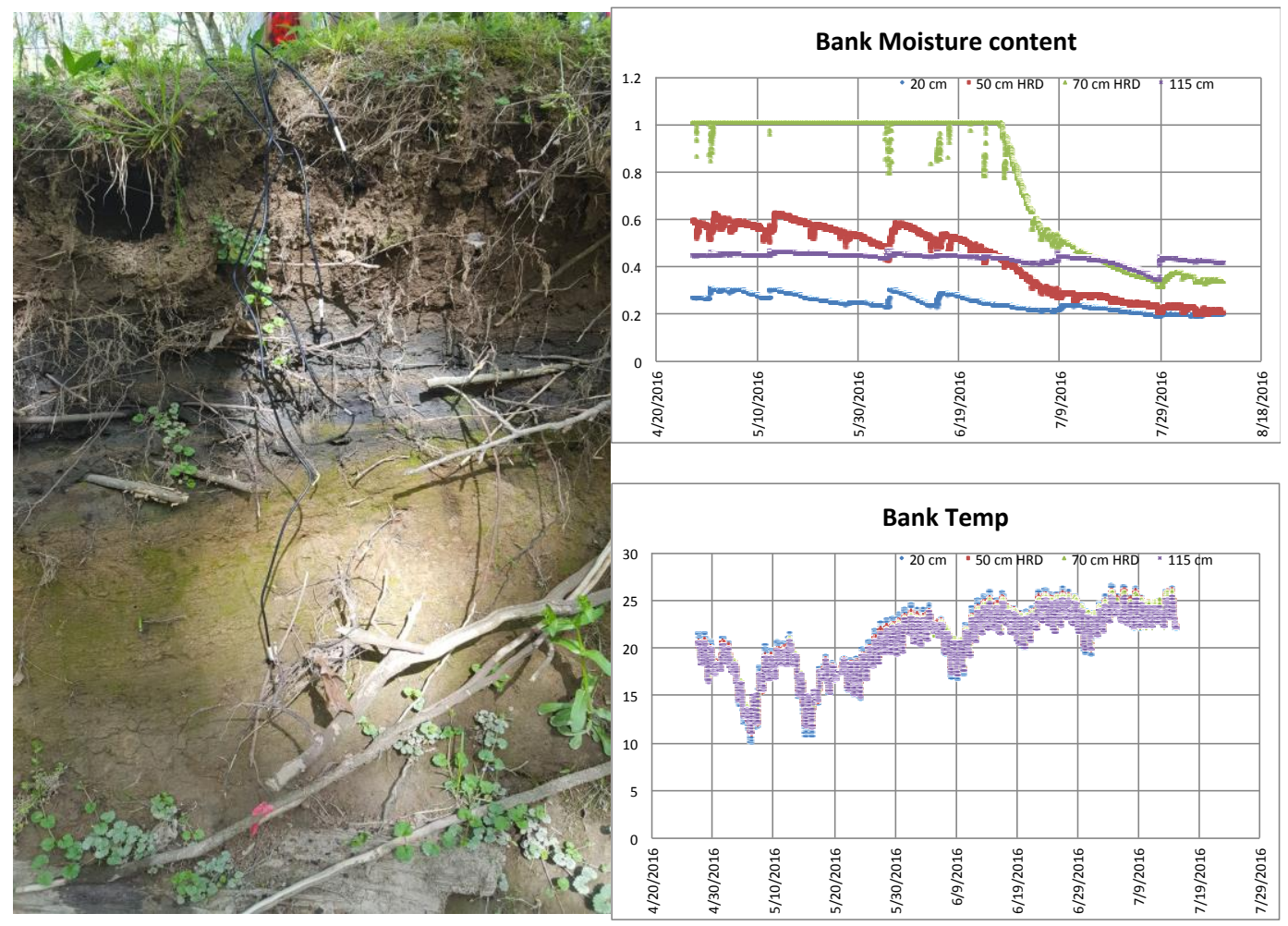

Fig. 2-17. Soil moisture sensors at Bruner location 17.8 EFK. (left) One sensor is emplaced overlying the historical release deposit (HRD) at $20 \mathrm{~cm}$ below ground surface (BGS), two inside the HRD at 50 and $70 \mathrm{~cm} \mathrm{BGS}$, and one below the HRD at $115 \mathrm{~cm} \mathrm{BGS}$; (top right) relative soil moisture as a function of time; and (bottom right) soil temperature as a function of time (in ${ }^{\circ} \mathrm{C}$ ).

The results suggest there may be persistent high moisture in the HRD, which could contribute to observed groundwater concentrations of $\mathrm{Hg}$ through leaching, although the mechanisms and understanding of potential transport to the creek is unknown. Researchers also don't yet have any analyses of porewater in the HRD layer to know for certain that reducing conditions are present, but the geochemical analyses of the groundwater at EFK 17.8 definitively shows high concentrations of reduced species (data not shown). Further, Stoor et al. (2006) observed only $0.6 \mathrm{ng} \mathrm{L}^{-1} \mathrm{MeHg}$ in groundwater wells, but they observed concentrations as high as $12 \mathrm{ng} \mathrm{L}^{-1}$ at the hyporheic zone at the interface of surface water and 
groundwater. Hyporheic zones and other water interfaces tend to be locations for redox-sensitive microbiological reactions, e.g., Hg methylation (Kolka et al. 2011).

Again, groundwater concentrations of $\mathrm{MeHg}$ and $\mathrm{Hg}$ are much higher at Bruner than at the other two locations. The findings at Bruner support continuing the groundwater investigation through FY 2017. Even though recent modeling results suggest that groundwater contributions could be small, these results show that important dynamics in the near-stream environment may be elucidated by continuing the investigation.

The three groundwater wells at the Horizon site, EFK 8.7, are very consistent with each other. They tend to show low but persistent concentrations of $\mathrm{MeHg}$ and $\mathrm{Hg}$, and both seem to be increasing with time from December to July. Although the values of $\mathrm{Hg}$ and $\mathrm{MeHg}$ appear to be low in comparison to those at EFK 22 and EFK 17.8, the values are still very high in comparison to published studies (Stoor et al. 2006) and to observed groundwater concentrations from the Mercury Science Focus Area at Horizon Center and at Mill Branch. The wells also show significant nitrate, sulfide, DOC, and ferrous and total iron, and only the inland well shows significant sulfate. The results suggest that reductive conditions are predominant in all wells at the site.

Finally, researchers have also had the opportunity to observe very large flooding events at all locations in FY 2016. Figure 2-18 shows two photos taken at approximately the same location at EFK 8.7 in April 2016, looking toward EFPC. The inland groundwater well is visible in the foreground, where the top of the PVC casing is at the elevation of the 100-year floodplain. EFPC is entirely out of its banks, likely resulting in an important saturation event in the soil. These occasional saturation events could fuel leaching of $\mathrm{Hg}$ and low redox conditions, thereby contributing to methylation in the soil and groundwater profiles. 

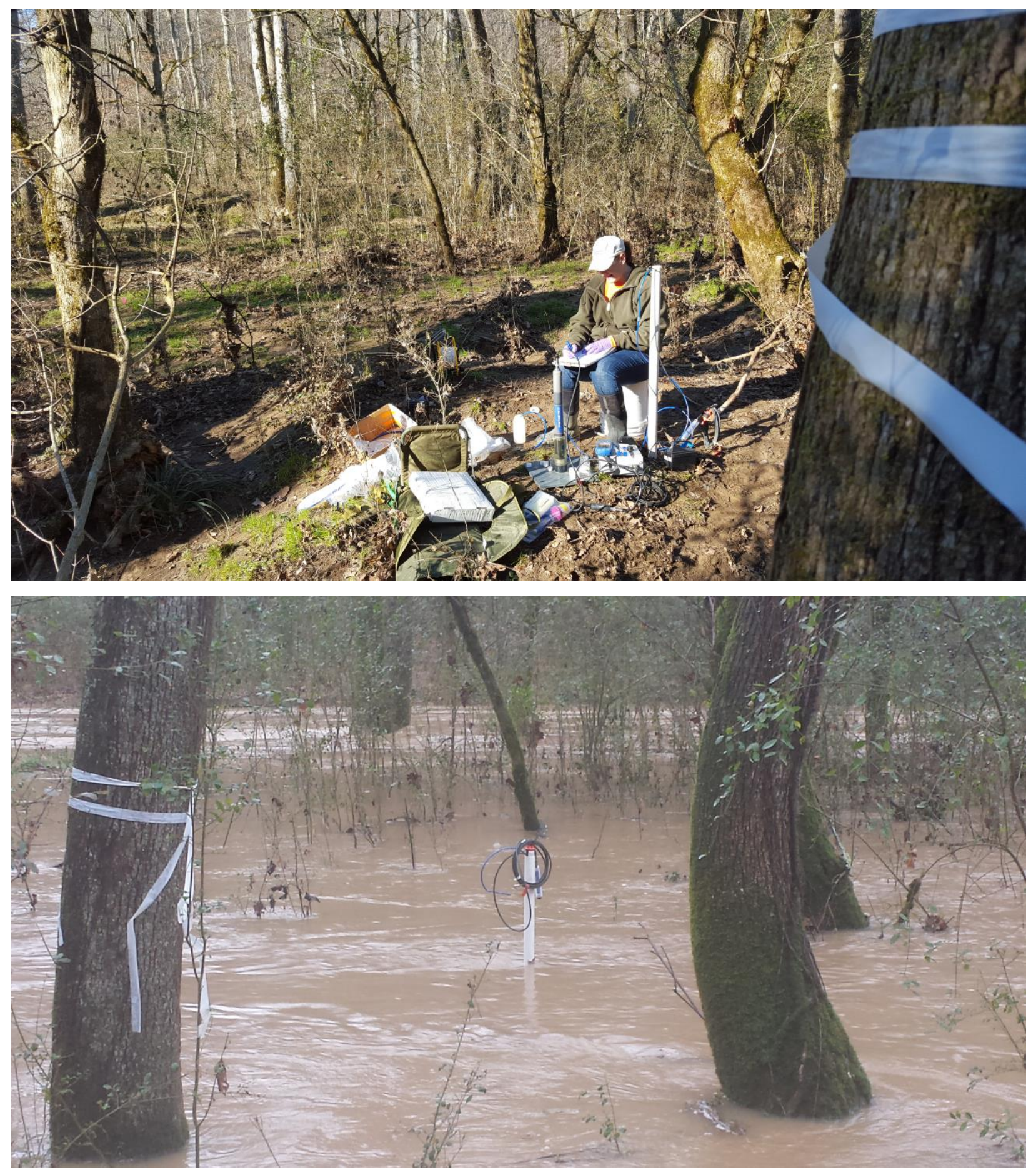

Fig. 2-18. Normal and flood stage conditions at 8.7 EFK. (top) ORNL staff sampling groundwater well, and (bottom) area in vicinity of groundwater well is submerged. The top of the PVC casing is at the elevation of a 100-year flood. 


\subsection{SORBENT EVALUATION}

\subsubsection{Introduction}

A large pool of residual mercury contamination present in EFPC bank soils and creek sediments presents a significant remediation challenge as mercury may be released gradually over long periods. Microbial activity can lead to the formation of highly toxic methylmercury, which bioaccumulates up trophic levels. Methylation sites in fresh water ecosystems are known to be associated with redox transition zones, where aerobic (oxygen-rich) conditions grade into anaerobic (oxygen-poor) zones that contain specific anaerobic microbes (e.g., sulfur- and iron-reducing microorganisms, methanogens, and syntrophic, acetogenic, and fermentative Firmicutes) that convert inorganic Hg to MeHg (Gilmour et al. 2013a; Hu et al. 2013; Parks et al. 2013). Furthermore, DOM and suspended solids exert significant influence on the speciation, distribution, transport, and bioavailability of mercury in freshwater ecosystems (Miller et al. 2009). For example, erosion events and periodic flooding can mobilize inorganic mercury $(\mathrm{Hg}[\mathrm{II}])$ and $\mathrm{MeHg}$ associated with DOM or particulates from sediments, bank soils, and floodplains contributing to elevated concentrations in downstream environments. The primary goal of mercury remediation efforts is to limit $\mathrm{MeHg}$ production and transfer into food webs.

Sorbent amendments are evaluated as a potential low-impact, low-cost approach for stabilization of contaminated soils and sediments in EFPC. The application of sorbents aims to capture bioavailable or reactive $\mathrm{Hg}$ species within a high affinity sorbent matrix with the intention to limit migration, mercury methylation, and bioaccumulation. The primary mode of action is strong binding of a contaminant species to the sorbent material, resulting in a reduction in the pore water concentration. Therefore, the effectiveness of sorbent treatments is determined by the partitioning of $\mathrm{Hg}$ species between sediments and solution phase (Gomez-Eyles et al. 2013). The lower the native sediment:water partition coefficients for mercury and methylmercury of the system, the more effective a potential sorbent treatment is (Gilmour et al. 2013b). In addition, NOM, suspended particles, and sulfidic species may compete with sorbents with respect to binding of mercury and methylmercury, which can have a significant impact on the effectiveness of a sorbent treatment. The primary aim is to evaluate sorbents amenable for incorporation into sediments or physical barriers such as bank stabilization structures with minimal impact on the ecosystem. Sorbent technologies that can effectively reduce the flux of $\mathrm{Hg}$ into EFPC are expected to contribute to a sustained reduction of $\mathrm{Hg}$ and $\mathrm{MeHg}$ concentrations to proposed regulatory limits.

\subsubsection{Sorbents and Specifications}

The team has evaluated a series of sorbents for the adsorption of mercury species, which can be grouped into four major classes (Table 2-3).

Thiol-SAMMS is an engineered material based on a high-surface-area mesoporous silica support functionalized with a self-assembled monolayer of thiol groups designed to achieve high sorption capacities and selectivity for mercury and other transition metals. Thiol-SAMMS was developed at Pacific Northwest National Laboratory (Carter and et al. 2008; Lexa and et al. 1990) and is manufactured by Steward Environmental Solutions. Organoclays are phyllosilicate clays modified with organophilic compounds. Functionalized clays find frequent application for the remediation of hydrophobic contaminants, such as oil products and other non-aqueous phase liquids. Some types of these materials were found to promote mercury methylation by sulfate-reducing bacteria under certain conditions (Gilmour et al. 2013b). Carbon-based sorbents in these experiments include SediMite ${ }^{\mathrm{TM}}$, a pelletized activated carbon blended with bentonite and quartz sand as a weighing agent. SediMite ${ }^{\mathrm{TM}}$ was developed by the University of Maryland for use as a sediment amendment and is manufactured by Exponent Inc. Biochar is from a pine wood feedstock and is manufactured by Biochar Now, LLC (Loveland, Colorado) using a slow pyrolysis process. Lignin-based carbon materials are obtained by carbonization of lignin 
feedstocks under various processing conditions and were obtained through a collaboration with ORNL's Materials Science and Technology Division and the University of Tennessee, Knoxville. Commercialgrade granular activated carbon is frequently used for water filtration purposes because of its broad selectivity for many types of contaminants (Calgon Carbon). Canola oil or limonene polysulfide has been developed at Flinders University and has shown potential for the sorption of mercury and other heavy metals (Crockett et al. 2016). Brass granules (Alfa Aesar) were previously shown to sequester mercury from industrial waste streams by reduction of $\mathrm{Hg}(\mathrm{II})$ to $\mathrm{Hg}^{0}$ followed by amalgamation.

Table 2-3. Types of sorbent materials evaluated in this study

\begin{tabular}{|c|c|c|c|}
\hline $\begin{array}{c}\text { Class of } \\
\text { Materials }\end{array}$ & Sorbent & Type & Manufacturer \\
\hline $\begin{array}{l}\text { Functionalized } \\
\text { mesoporous } \\
\text { silica }\end{array}$ & Thiol-SAMMS ${ }^{\circledR}$ & $\begin{array}{l}\text { Thiol-functionalized self-assembled monolayer on } \\
\text { mesoporous silica support }\end{array}$ & $\begin{array}{l}\text { Steward } \\
\text { Environmental } \\
\text { Solutions, LLC }\end{array}$ \\
\hline \multirow[t]{2}{*}{$\begin{array}{l}\text { Functionalized } \\
\text { clays }\end{array}$} & $\begin{array}{l}\text { Organoclay } \\
\text { MRM }\end{array}$ & $\begin{array}{l}\text { Functionalized bentonite-based clay } \\
\text { (sulfur impregnated) }\end{array}$ & CETCO \\
\hline & $\begin{array}{l}\text { Organoclay } \\
\text { PM199 }\end{array}$ & Functionalized bentonite-based clay & CETCO \\
\hline \multirow{5}{*}{$\begin{array}{l}\text { Carbon-based } \\
\text { materials }\end{array}$} & SediMite ${ }^{\mathrm{TM}}$ & Activated charcoal, bentonite, and sand as a weighing agent & Exponent \\
\hline & Biochar & $\begin{array}{l}\text { Natural charcoal from Colorado pine converted by slow } \\
\text { pyrolysis }\end{array}$ & Biochar Now \\
\hline & $\begin{array}{l}\text { Lignin-based } \\
\text { carbon }\end{array}$ & $\begin{array}{l}\text { Carbon materials with tunable properties prepared from } \\
\text { lignin precursors and processed into carbon fiber mats or } \\
\text { foams }\end{array}$ & ORNL/UTK \\
\hline & $\begin{array}{l}\text { Granular } \\
\text { activated carbon }\end{array}$ & Activated carbon & Calgon Carbon \\
\hline & $\begin{array}{l}\text { Canola oil } \\
\text { polysulfide }\end{array}$ & Canola oil or limonene vulcanized with elemental sulfur & $\begin{array}{l}\text { Flinders } \\
\text { University }\end{array}$ \\
\hline Metal alloy & Brass wire gauze & $\begin{array}{l}\mathrm{Cu} / \mathrm{Zn} \text { alloy, immobilizes } \mathrm{Hg}(\mathrm{II}) \text { by reductive } \\
\text { amalgamation }\end{array}$ & Alfa Aesar \\
\hline
\end{tabular}

\subsubsection{Mercury Partitioning and Speciation}

Partitioning of mercury and methylmercury species between soil or sediment particles and water is a measure for the degree of contaminant mobility in the environment and may affect bioavailability for methylation and bioaccumulation. In general, the partitioning for any mercury species can be described by the equilibrium partition or distribution coefficient $K_{d, H g}$. The distribution coefficient of $\mathrm{Hg}$ between a solid and an aqueous phase is defined in Equation (2.1).

$$
K_{d, H g}=\frac{\left[g_{\text {solid }}\right]}{[\text { Hgaqueous }]}
$$

Thus, the $K_{d, H g}$ can also be used as a measure for the effectiveness of a sorbent to bind $\mathrm{Hg}$ species in the system. Therefore, the sorbent $K_{d, H g}$ sorbent and mass fraction of sorbent $f_{\text {sorbent }}$, relative to the sediment $K_{d, H g}$ sediment and mass fraction of the sediment $f_{\text {sediment }}$ determine the effectiveness of the treatment.

$$
f_{\text {sorbent }} \cdot K_{d, H g \text { sorbent }} \gg f_{\text {sediment }} \cdot K_{d, H g \text { sediment }}
$$

The $K_{d, H g}$ for a particular sorbent is influenced by competing ligands, such as natural organic matter. In freshwater systems, $\mathrm{Hg}-\mathrm{NOM}$ complexes are the predominant $\mathrm{Hg}$ species in pore and surface waters. 
Sorbent treatments for soils or sediments are most effective if they are able to outcompete NOM and soils or sediments for binding of $\mathrm{Hg}$.

A standardized $\mathrm{Hg}-\mathrm{NOM}$ complex at a molar $\mathrm{Hg}: \mathrm{C}_{\mathrm{NOM}}$ ratio of $2 \cdot 10^{-6}$ and at a fixed mercury concentration of $2 \mathrm{ppb}$ was used to evaluate the sorbent materials in a series of batch experiments. Researchers adapted ASTM D 4646-03, "Standard Test Method for 24-h Batch-Type Measurement of Contaminant Sorption by Soils and Sediments" to determine sorbent:water partition coefficients $\left(K_{d}\right)$ and sorption isotherms experimentally. To evaluate the impact of NOM complexation on the sorption of mercury, experiments have been conducted to determine sorption isotherms for an uncomplexed $\mathrm{Hg}$ (II) provided as $\mathrm{Hg}\left(\mathrm{NO}_{3}\right)_{2}$ in solution.

The sorption of $\mathrm{Hg}$ by sorbent materials can be described by Langmuir and Freundlich isotherms, which correlate solution concentration of a solute to the concentration sorbed to a solid phase. The Langmuir adsorption isotherm assumes monolayer adsorption onto a surface containing a finite number of uniform adsorption sites. The surface reaches a saturation point, where maximum sorption of adsorbate on a monolayer is reached. The Freundlich isotherm is an empirical model that better represents sorption processes with variable adsorption sites. The relationships between adsorbed and solution concentrations for the Langmuir (2.3) and Freundlich (2.4) isotherms are as follows:

$$
\begin{gathered}
Y=\frac{Y_{\max } \cdot K_{L} \cdot C}{1+K_{L} \cdot C} \\
Y=K_{F} \cdot C^{\frac{1}{n}}
\end{gathered}
$$

where $Y$ is the mass or mol fraction of the adsorbate on the sorbent; $Y_{\max }$ is the sorption capacity; $C$ is the equilibrium concentration of sorbate in solution; and $K_{L}, K_{F}$, and $n$ are sorption parameters for Langmuir and Freundlich isotherms, respectively. The Langmuir-Freundlich isotherm derived by Sposito (1980) offers a way to better account for variable sorption affinities described by a unimodal continuous distribution of sorption sites.

$$
Y=\frac{Y_{\max } \cdot K_{S} \cdot C^{n}}{1+K_{S} \cdot C^{n}}
$$

where $K_{S}$ is the modal value of the binding affinity distribution and $n$ is a measure for the heterogeneity in the distribution of sorption sites. Thus as $n$ approaches 1, the equation reduces to the Langmuir isotherm; conversely, at very low $C$, the term in the denominator approaches 1 and the equation reduces to the Freundlich equation. Eq. (2.5) was used to fit sorption data for all tested sorbents and compared sorption characteristics of mercury (Fig. 2-19). 

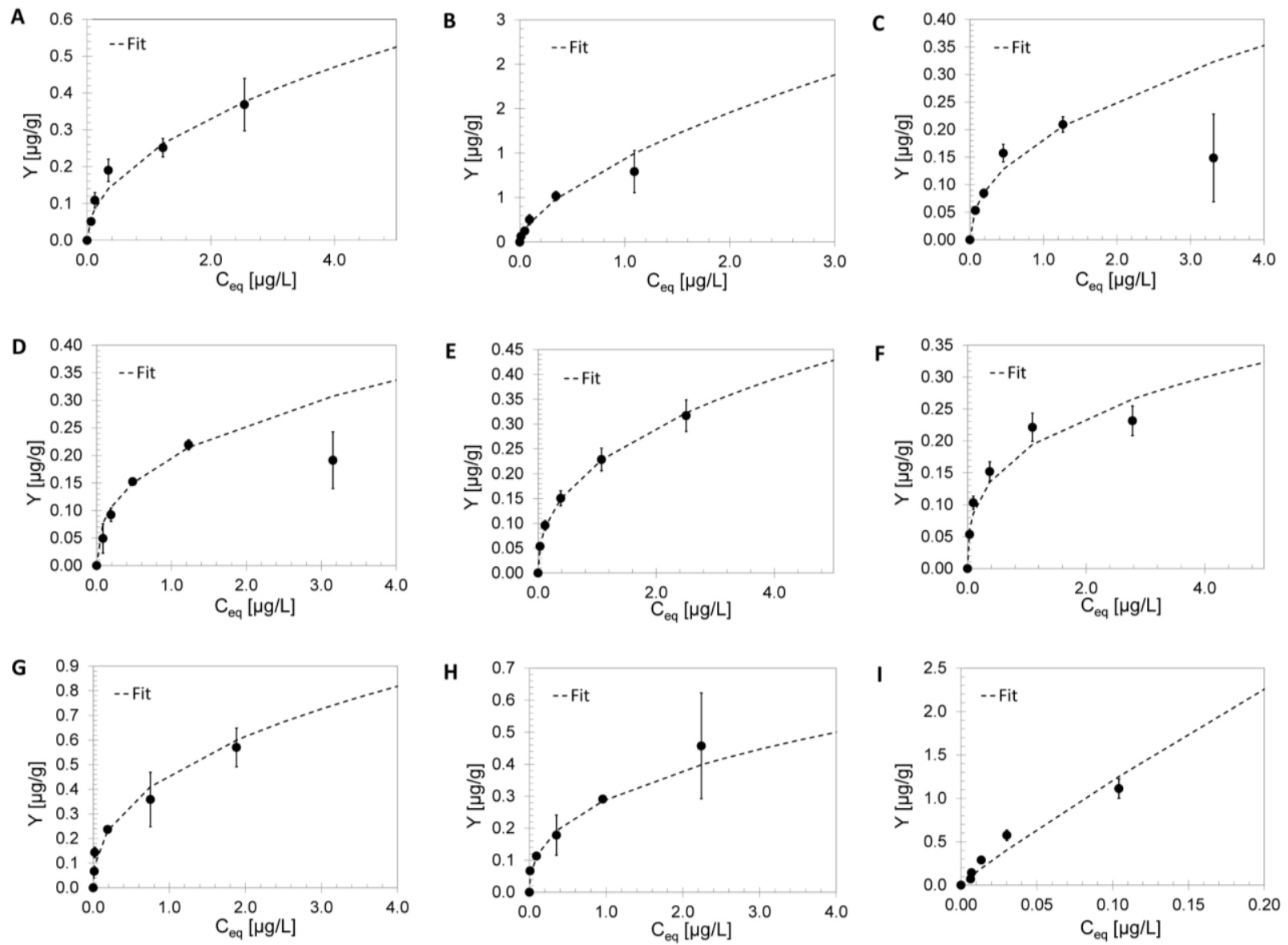

Fig. 2-19. Langmuir-Freundlich isotherms for the sorption of Hg-NOM for A. biochar; B. SediMite ${ }^{\mathrm{TM}}$; C. lignin carbon fiber A; D. lignin carbon fiber B; E. lignin carbon foam A; F. lignin carbon foam B; G. Organoclay MRM; H. Organoclay PM-199; I. Thiol-SAMMS.

A detailed comparison was also performed of various carbon-based sorbents to gain insights into the role of surface area for the sorption of $\mathrm{Hg}$ from $\mathrm{Hg}-\mathrm{NOM}$ in solution. If the BET surface area of a material is known, the theoretical surface density of sorbed $\mathrm{Hg}$ can be calculated. The results allow a direct comparison of $\mathrm{Hg}$ surface densities between materials (Fig. 2-20). The results show that carbon materials can achieve Hg sorption densities comparable to engineered sorbents such as Thiol-SAMMS. These results indicate that carbon-based materials with relatively low surface areas can perform very well at low Hg concentrations. 

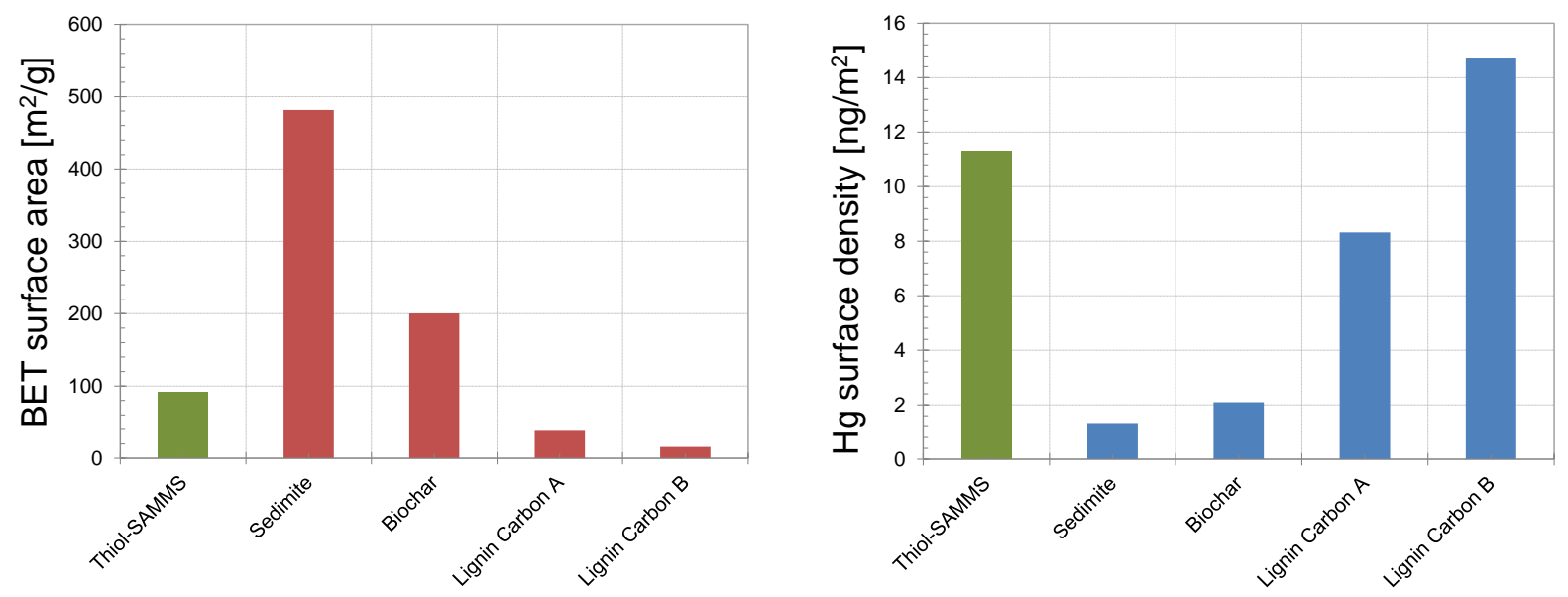

Fig. 2-20. Relationship between surface area and Hg sorption for carbon-based sorbents.

\subsection{TASK 1 FUTURE DIRECTIONS}

There are five major directions proposed for FY 2017. First, analysis of the field-scale bank soil investigation is ongoing. As described in Section 2.1.1.2, a draft manuscript incorporating all of the fieldscale soil investigation has been prepared. The manuscript will be completed and submitted for publication early in FY 2017. In addition, a draft technical manuscript summarizing the streambank soil characterization effort is near completion. A second manuscript describing the detailed geochemistry of the bank soils and the HRD materials, in collaboration with the AFRI project, will also be completed and submitted. At this point, it is believed these two publications will sufficiently describe the distribution, concentration, and variability of mercury and methylmercury in the creek bank soils to inform the investigations in the immediate future. Thus, a key metric for bank soils characterization will be met in FY 2017. Subsequently, the project will begin to consider potential technology development activities to inhibit the release of mercury and methylmercury from bank soils. Therefore, the progression of Task 1 activities is toward higher TRLs over time, which is consistent with scope and needs of this project.

A second major direction for FY 2017 involves continued efforts regarding the desorption potential of the creek bank soils including the HRD materials. At this point, researchers have a good qualitative understanding of mercury releases but still lack an understanding of the underlying controls. Therefore, researchers are now beginning to use the geochemical analyses of the soils described in Section 2.1.1.2 to understand the characteristics of the soils used in these experiments. Analysis of the reacted solution chemistry will begin to help understand the chemical composition of mercury in the solutions. These efforts should yield significant predictability for the controls over mercury desorption in the creek bank soils and in the HRD layer. Drafting a publication resulting from this work is likely to take place later in FY 2017. This kind of information is key to determining the efficacy of any bank stabilization efforts that may be developed in this project. This effort can still be considered basic science that is necessary to inform higher TRL activities.

The third major direction involves continued effort on the groundwater task (Section 2.2). The initial results suggest that mercury and methylmercury contamination in groundwater near EFPC is significant and much higher than would be observed in uncontaminated environments. Researchers will continue the automated, continuous monitoring of the water table elevation, temperature, and conductivity of the stream and groundwater at the three monitoring locations (EFKs 22, 17.8, 8.7). This data will enable construction of the potentiometric surface (water table elevation) and how it changes in response to seasonal and event-based fluctuations, and ultimately to determine how groundwater and surface water 
interact. Bimonthly manual sampling for mercury, methylmercury, anions, cations, $\mathrm{pH}$, DOC, and redox indicators (ferrous iron, total iron, dissolved oxygen, and sulfide) will continue throughout FY 2017. Researchers will look specifically for correlations between methylmercury concentrations and redox indicators to determine if conditions in groundwater are contributing to methylmercury production. Coupled with the potentiometric surface data, the team should be able to determine if groundwater is acting as a source of methylmercury to EFPC.

Monitoring of the vadose zone at EFK 17.8 will continue. At this location, the groundwater wells are installed below a prominent outcrop of the HRD. Vadose zone monitoring identified persistent saturated conditions within the HRD well into the summer of FY 2016, so monitoring moisture content at this location will continue. Researchers will also install solution samplers at this location to directly sample the porewater of the HRD and overlying and underlying soil horizons. Further, the literature on methylmercury production in groundwater points to the hyporheic zone as being a particularly productive area of methylation activity because of frequent redox fluctuations, the availability of nutrients, and an active microbiological community (Stoor et al. 2006). Therefore, additional (but as yet undetermined) sampling strategies will be considered to investigate the surface water-groundwater interface. The groundwater work is definitely still in the realm of basic science (TRLs 1-2). More information is needed to determine the trajectory of the groundwater task beyond FY 2017 and the applicability of the findings to potential remedial technologies.

The preliminary findings of the groundwater investigation presented in this report appear to confirm its significance. Therefore, analysis of the continuous intact cores collected from each well location could provide key insights into the characteristics of the media being sampled. Basic soil characterization and mercury and methylmercury concentrations should be determined. A complete investigation should also involve microbiological characterization to identify the presence of genes capable of mercury methylation. This activity can be quite costly and is beyond the scope of the current project; further, the TD project does not involve qualified microbiological staff. Other funding sources for experienced microbiologist collaborators will be sought in FY 2017.

The fourth major direction involves a continued effort to evaluate sorbent materials under field-relevant conditions. The present results from batch sorption experiments with engineered sorbents highlight that the significance of biogeochemistry and speciation in EFPC on mercury partitioning between the solution phase and sorbent. Inorganic $\mathrm{Hg}$ and methylmercury form strong complexes with natural organic matter (NOM). Sorbent materials designed to control mercury flux and net methylmercury production need to be able to compete with organic matter, soil particles and other constituents present in soils or sediments for binding of mercury species. Researchers conducted a comprehensive characterization of sorbents (Table 2-3) under controlled conditions and determined partition coefficients and sorption isotherms for mercury in the presence and absence of a standardized NOM reference material. A manuscript describing the results of these experiments will be completed in early in FY 2017. In addition, evaluation is planned of bone apatite, which is a low-cost material that has been successfully used in the remediation of other metal contaminants. Batch experiments on a subset of sorbents will be conducted to determine $\mathrm{MeHg}$ partition coefficients using samples from EFPC. These studies will transition into batch and column studies with sorbents and soils as described below.

The fifth major direction will seek to validate the efficacy of engineered sorbents in the presence of bank soils, using a combination of batch and column experiments. Later in FY 2017, the desorption and engineered sorbent subtasks will transition to coupled experiments involving both sorbents and soils. Different creek bank soils including the HRD will be packed into cylindrical soil columns. Contaminated water will be introduced into the columns, and effluent volumes, mercury, methylmercury, and other geochemical indicators will be monitored over time to provide an estimate of the mobility of mercury from the soils. In addition, the most effective engineered sorbents from Section 2.3 will be mixed with the 
contaminated soils/sediments to provide an estimate of the mobility of mercury in the presence of engineered sorbents. Batch-type experiments may be performed as preliminary work to the columns in FY 2017.

Studies using contaminated soil columns with incorporated engineered sorbents will provide key information to validate the efficacy of engineered sorbents, and further, to define key details such as the ratio of sorbent to contaminated sediments, the characteristics of the sorbents such as particle size and chemistry, the importance of environmental controls such as oxygen and geochemistry, and the variety of responses possible in floodplain, creek bank, and HRD soils. Eventually, this work will transition to the Field Research Station (FRS). The FRS will enable measurements of true, long-term continuous reactions with EFPC water rather than relying on artificial solutions or transferring EFPC water to the lab, both of which can introduce considerable artifacts and increase the workload. In addition, the FRS will enable many more experiments at larger and more field-relevant scales and will minimize the production of wastes in the laboratory environment. A solid set of validation experiments is truly essential before pilotscale testing in the field can commence.

The coupled soil column and sorbent work may be placed within TRLs 2-3, where technological solutions are beginning to be applied to problems having sufficient scientific underpinning. Sorbent technologies are expected to limit mobilization of mercury species from contaminated soils and thereby effectively reduce bioaccumulation of methylmercury in LEFPC. Bank stabilization may be combined with in situ amendments informed by the studies in Section 2.3, allowing deployment of sorbents in key locations identified in Section 2.1, with minimum perturbation to the existing environment and the ecosystem. Ideally, bank stabilization approaches designed to avoid large-scale, expensive, and destructive soil removal will be identified. It is likely that sorbents will need to be applied in concert with other bank rehabilitation methods such as vegetation removal, bank angle reductions, bank stabilization through physical armoring, and vegetative replantings to stabilize creek banks. Monitoring baseline conditions and manipulation responses is essential to determining the outcomes of pilot-scale tests and identifying the most promising technologies for full-scale implementation. In combination with comprehensive field characterization efforts, these studies will establish a solid scientific basis for testing and future implementation of remediation activities to reduce mercury fluxes and mercury concentrations in fish. 


\section{TASK 2, SURFACE WATER AND SEDIMENT MANIPULATION}

\subsection{SURFACE WATER}

\subsubsection{Approach to Water Chemistry Investigations}

Water chemistry can affect the speciation, transformation, and transport of mercury and methylmercury, but there remain significant knowledge gaps, particularly in freshwater stream systems. These knowledge gaps limit the ability to make informed remediation decisions for EFPC. In FY 2016, as part of earlier TD project efforts, the current understanding of factors and variables controlling mercury transformations and potential remediation alternatives was summarized (Peterson et al. 2015a), and several key questions were developed to guide research efforts, including the following:

- What changes in mercury and methylmercury flux occur along the length of EFPC? Can these changes help to prioritize shorter reaches of the creek for targeted action(s) addressing specific issues?

- Are mercury and methylmercury dynamics during high flow events indicative of any significant out-of-stream sources of these constituents to EFPC?

Fieldwork in FY 2016 has been designed largely to address the first of these two questions. The efforts in FY 2016 will provide a foundation for future work that includes addressing the second question.

East Fork Poplar Creek is operationally divided into two sections: upper EFPC (UEFPC; the $\sim 2 \mathrm{~km}$ portion of the creek within the Y-12 facility boundaries) and LEFPC (the $\sim 23 \mathrm{~km}$ of the creek downstream of the Y-12 facility). The water chemistry between these two portions of the stream is very different, and mercury and methylmercury behavior is thus very different. Control and mitigation strategies need to account for these differences in mercury behavior and speciation as the water chemistry changes throughout the creek. Whereas the bulk of this project deals with technology development to develop strategies to mitigate mercury contamination in LEFPC, there are reasons to consider treating UEFPC within the broader strategy. Mercury in surface water in UEFPC is accessible, is under DOE control, and is primarily dissolved $\mathrm{Hg}(\mathrm{II})$, a highly mobile, reactive, and bioavailable form of mercury. This combination of access and chemistry provides an opportunity to manipulate the water chemistry to reduce the flux of mercury and the accumulation of methylmercury in fish throughout the entire LEFPC stream system.

In FY 2016, through a combination of laboratory and field studies, the research team (1) examined the role of chemicals present in UEFPC water due to ongoing plant operations on the flux and forms of mercury present and mercury methylation processes, (2) estimated mercury flux at several locations along EFPC, and (3) characterized streambed sediments along the length of EFPC. These efforts are ongoing and will provide a solid knowledge base upon which the effects of in-stream manipulations can be evaluated. Results presented in this section are given in terms of both concentration and flux or loading. Whereas biological receptors are likely responsive to concentration, flux is more important from a site management perspective. Flux estimates (1) help support site characterization and conceptual model development; (2) help prioritize locations within a site for remedial action; (3) are used in exposure and risk assessment; (4) inform remediation selection and design; and (5) are used in performance, compliance, and long-term monitoring. 


\subsubsection{Role of UEFPC Y-12 Water Chemistry and Flux on LEFPC}

The overall goal in these investigations is to assess whether there are viable alternatives to current chemical treatment and discharge practices and/or implement chemical manipulations in surface water that would reduce mercury migration to LEFPC and mercury bioavailability. The DOE Office of Environmental Management plans to construct a water treatment facility at Outfall 200 (OF200) to remove mercury and, therefore, chemical manipulation alternatives would need to be compatible and complementary to those plans. The role of chemicals present in the EFPC water due to ongoing plant operations on the flux and forms of mercury present and mercury methylation processes is being evaluated in a phased approach using a combination of laboratory- and field-scale experiments. The results of these experiments will be used to help develop water chemistry approaches or technologies that might be used to further reduce mercury flux to LEFPC. Technologies developed, including the use of alternative treatment chemicals, could be considered in the LEFPC alternatives evaluation in the early to mid-2020s.

There have been numerous investigations evaluating the influence of Y-12 at EFPC's headwaters on downstream water chemistry and mercury fluxes and concentrations. OF200 discharges from the West End Mercury Area (WEMA) portion of Y-12 are a major source of base flow mercury loading to LEFPC (Peterson et al. 2011). Multiple individual outfalls downstream of OF200 within the east plant area of Y12 and the UEFPC stream channel itself also contribute important but poorly understood/quantified fluxes of mercury to LEFPC. Extensive historical spills of liquid mercury beads $\left(\mathrm{Hg}[0]_{1}\right)$ in buildings, soils, and storm drains in the WEMA and east plant area are the sources of dissolved mercury in UEFPC surface water and the mercury that is attached to creek sediment. Mercury contaminated sediments and $\operatorname{Hg}(0)_{1}$ found in the Y-12 storm drains and UEFPC are exposed to some anthropogenic chemicals on a continuous basis, whereas other chemicals are discharged only episodically (Peterson et al. 2015a). Chlorine (in potable water), dechlorination chemicals (ammonium bisulfite), and steam plant corrosion inhibitors (primarily amines) are released on a continuous basis via permitted discharges at Y-12. Treatment chemicals from cooling tower blowdown water are used and discharged only on an intermittent basis, primarily in hotter weather. Many of these low-level continuous- and intermittent-use chemical discharges are known to or have the potential to affect the form and flux of mercury to LEFPC.

With a relatively low solubility, $\mathrm{Hg}(0)$ can be oxidized to the more soluble and mobile $\mathrm{Hg}(\mathrm{II})$ form by chemical oxidants. Y-12 uses City of Oak Ridge tap water in its industrial processes; this water contains residual chlorine that, when discharged to the storm drain system, can react and oxidize the dissolved $\left(\mathrm{Hg}[0]_{\mathrm{d}}\right)$ and liquid $\mathrm{Hg}(0)_{1}$ beads present and transform them into the more soluble and mobile $\mathrm{Hg}(\mathrm{II})$ form. Researchers have measured free chlorine concentrations as high as $3.4 \mathrm{ppm}$ in the $\mathrm{Y}-12$ storm drain system. This suggests that exposure of $\mathrm{Hg}(0)_{\mathrm{d}}$ and $\mathrm{Hg}(0)_{1}$ in the storm drain system to residual chlorine could result in the formation of soluble $\mathrm{Hg}$ (II) species and increased mercury fluxes to LEFPC.

Laboratory testing in FY 2015 confirmed that beads of $\mathrm{Hg}(0)_{1}$ exposed to the chlorine in tap water and water samples from the Y-12 WEMA outfalls result in much higher levels of dissolved $\mathrm{Hg}$ (II) in solution (up to 85 times higher) than water samples without chlorine.

Chlorination byproducts like trihalomethanes and haloacetic acids form through the reaction of chlorine with other chemicals or trace amounts of organic carbon. Historical sampling data from the Oak Ridge Environmental Information System and ORNL sampling conducted in FY 2015 show that low levels of chlorination byproducts are detected frequently in the WEMA storm drain system (e.g., Outfall 150) and at OF200. The chlorination byproducts have the potential to form complexes with $\mathrm{Hg}$ (II) (Mousavi 2011) which could enhance the mercury solubility. Binding of $\mathrm{Hg}$ (II) to organics can also affect bioavailability of $\mathrm{Hg}$ (II) in aquatic ecosystems (Haitzer, Aiken, and Ryan 2002) and limit $\mathrm{Hg}$ (II) availability to methylating bacteria (Ravichandran 2004). 
The operation of Y-12 cooling towers requires use of a variety of chemicals for corrosion control, acid cleaning, and microbiological control, as well as anti-foaming agents and surfactants (Peterson et al. 2015a). Blowdown cooling water is released to the storm drains episodically, especially during warm months. The released chemicals may have a variety of impacts on the mercury contacted within the storm drains depending on the specific chemicals released; however, the net impact could be an increase in the flux of mercury to LEFPC because of the temporary increase in flow and chemical interactions with mercury in the storm drains. Amines, used in the treatment of boiler system equipment, have the potential to form complexes with $\mathrm{Hg}$ (II) (Mousavi 2011). Amines can also react with chlorine to form chloramine, an oxidizing agent similar to chlorine that also can oxidize $\mathrm{Hg}(0)$ to $\mathrm{Hg}(\mathrm{II})$. Although chloramine is not as strong of an oxidizer as chlorine, it has a much longer half-life than other forms of chlorine and may release ammonia when degraded. ORNL sampling and laboratory experiments conducted in FY 2015 and early FY 2016 suggests that chloramine is forming in Outfall 150 (OF150). When exposed to beads of $\mathrm{Hg}(0)_{1}$, water samples from OF150 did not produce as much $\mathrm{Hg}(\mathrm{II})$ in solution as some other locations with higher free chlorine present (e.g., Outfall 169).

Ammonium bisulfite currently is used as the primary in situ dechlorinating agent. Based on ORNL testing conducted in FY 2015 (Peterson et al. 2016), exposing beads of $\mathrm{Hg}(0)_{1}$ to dechlorinated tap water results in a significant reduction in the production of $\mathrm{HgT}$ (i.e., $\mathrm{Hg}[\mathrm{II}]$ ) compared with tap water that has not been dechlorinated. Despite this, some dechlorination compounds (e.g., ammonium bisulfite, Na-bisulfite, and $\mathrm{Na}$ thiosulfate) result in significant amounts of $\mathrm{HgT}$ in solution compared with control samples. Dechlorination methods using ascorbic acid, Na-sulfite, and ultraviolet (UV) light followed by carbon filtration produced the least amount of $\mathrm{HgT}$ in solution when exposed to beads of $\mathrm{Hg}(0)_{1}$.

In FY 2015 the focus of ORNL studies was on conducting preliminary sampling and laboratory experiments to assess the potential impact of chlorination and dechlorination chemicals on the transformation of $\operatorname{Hg}(0)_{1}$ found in the WEMA storm drain system to a more soluble mobile $\mathrm{Hg}(\mathrm{II})$ form (Peterson et al. 2016). In early FY 2016, the focus switched to quantifying the flows and fluxes of $\mathrm{Hg}$ downstream of OF200 related to east end outfalls and UEFPC. Sampling and analysis and laboratory experiments were conducted in FY 2016 to determine the impacts of chlorine and dechlorination chemicals on the mobilization of mercury from contaminated sediments and $\mathrm{Hg}(0)_{1}$ found in the east end storm drains and UEFPC. Very little is currently known about the impact of chlorine and dechlorination compounds on UEFPC mercury contaminated sediments. Mercury contaminated sediments are widespread in UEFPC and the mercury is more likely to be in a $\mathrm{Hg}$ (II) form complexed to the sediments. Therefore, chlorination and dechlorination chemicals are likely to interact and react differently with the mercury contamination attached to sediment than what was previously observed in experiments using $\mathrm{Hg}(0)_{1}$ beads. The results of FY 2016 sampling activities and laboratory experiments are described in greater detail below.

\subsubsection{UEFPC outfall and creek sampling and analysis}

FY 2016 UEFPC outfall and creek sampling and analysis activities included the following:

1. Researchers conducted a preliminary inspection and sampling of select outfalls and UEFPC to help determine where and how dechlorination is taking place and the approximate magnitude of chlorine and sulfite levels.

2. ORNL coordinated with URS |CHM2 Oak Ridge LLC and Restoration Services Inc. (UCOR/RSI) samplers to conduct a comprehensive base flow sampling event of UEFPC outfalls and several instream locations on June 7, 2016, to help quantify influxes of flow and $\mathrm{Hg}$ downstream of OF200 and to help determine impacts of chlorine and dechlorination chemicals on mercury fluxes. The outfall investigation was a result of upper EFPC Integrated Project Team (IPT) discussions. The planned 
field surveys provided an opportunity for obtaining additional water chemistry information helpful to the TD project.

All the outfalls discharging from the west end of Y-12 (including the WEMA) are dechlorinated with ammonium bisulfite in the short distance between Outfall 200A6 (OF200A6) and OF200 before discharging to UEFPC at OF200 (see Figs. 3-1 and 3-2). Outfalls 135 (OF135), 034 (OF034) and 021 located in the east plant area (see Figs. 3-1 and 3-2) are treated individually for chlorine before discharging to UEFPC using ammonium bisulfite drip systems and small equilibration basins for each outfall. The water discharging from Outfall 109 (OF109) (see Fig. 3-1), which was found to contain trace amounts of chlorine, appears to have been intermittently treated in the past with Na sulfite tablets. Chlorine concentrations detected at the other outfalls using a Hach chlorine test kit also tend to be low and variable. Measurements of chlorine concentrations in OF034 before treatment with ammonium bisulfite were typically in the range of $1.0 \mathrm{mg} / \mathrm{l}$. Concentrations of chlorine in the other outfalls were lower than $1.0 \mathrm{mg} / \mathrm{l}$ and many times not detectable even though there may be a chemical odor present (e.g., OF135), suggesting the presence of cooling tower water or steam condensate.

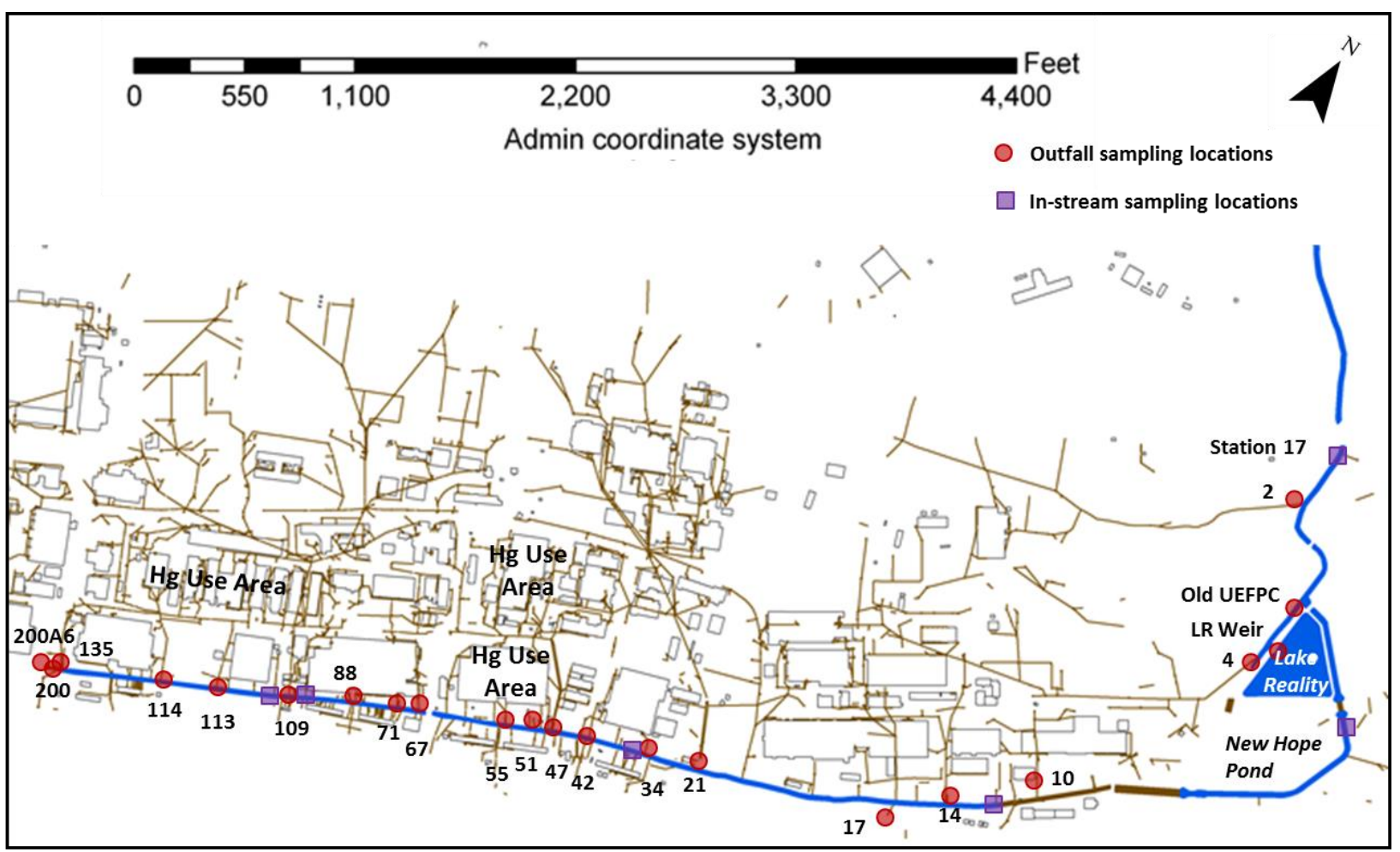

Fig. 3-1. UEFPC outfall and in-stream sampling locations. (Note: all outfalls that were flowing on June 7, 2016, the day of sampling, were sampled.) 


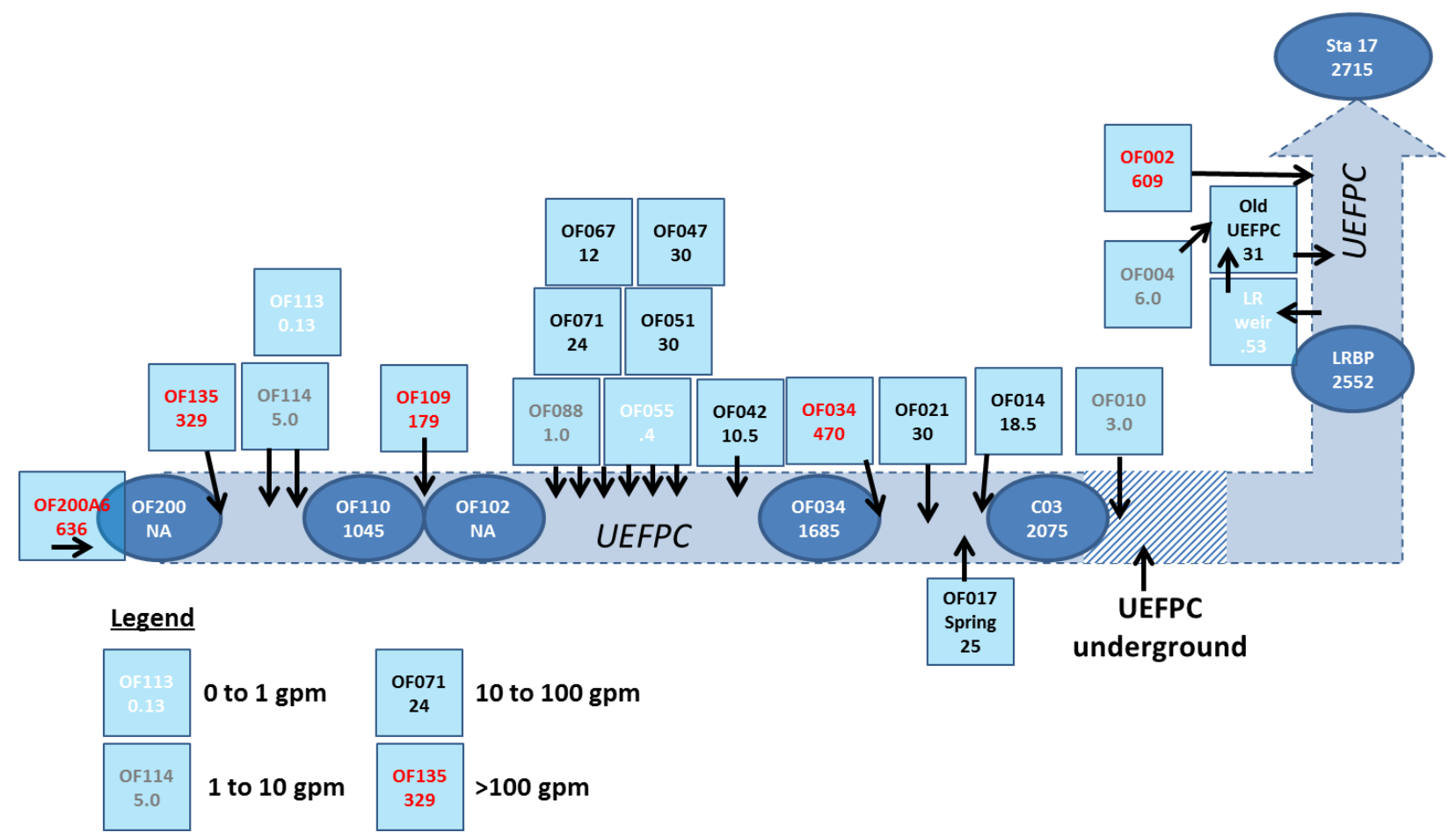

Fig. 3-2. UEFPC outfall and in-stream flow data in gallons per minute (gpm).

Sulfite measurements were made using a Hach sulfite test kit to provide an indication of the quantity of residual unconsumed dechlorination chemical (i.e., ammonium bisulfite) in the outfalls and UEFPC. Sulfite was detected in OF135 discharging at concentrations as high as $\sim 7.0 \mathrm{mg} / \mathrm{l}$ on May 20, 2016, and found to be as high as $\sim 5.1 \mathrm{mg} / \mathrm{l}$ in UEFPC downstream of OF200 and OF135. At about $100 \mathrm{~m}$ downstream of OF200, the sulfite was still detected at $\sim 1.6 \mathrm{mg} / \mathrm{l}$ but was not detectable $\sim 350$ meters downstream of OF200. On the same day, the concentration of sulfite discharging from OF034 was $\sim 2.3$ $\mathrm{mg} / \mathrm{l}$. These measurements suggest that there is a potential for excess ammonium bisulfite to be present in UEFPC and available to interact with the mercury that is present.

ORNL coordinated with UCOR/RSI samplers to conduct a base flow sampling event of UEFPC outfalls and several in-stream locations on June 7, 2016, to help quantify influxes of flow and mercury between OF200 and Station 17. Another objective of the sampling was to evaluate if any mercury fluxes are at least partially related to the use of chlorination and dechlorination chemicals.

Approximately 22 outfalls (pre- and post-dechlorination for several outfalls) and 6 in-stream locations were sampled (see Fig. 3-1) and analyzed for the following:

- Mercury-unfiltered

- Mercury-filtered (0.45 micron)

- Chlorine (total and free)

- Turbidity

- Flow

ORNL also conducted a few sulfite field analyses on the same day. Flow was measured by a variety of methods including bucket gauging, instantaneous flow meter and depth measurements, dedicated gauging stations (e.g., Station 17, OF135, and OF200A6), and visual methods, depending on the location. The coarse methods available for storm drain flow testing are an additional area of uncertainty in calculating 
mercury flux. Flow conditions were representative of high base flow conditions with the last rainfall that took place on June 4-5, 2016, being fairly significant in magnitude ( 2.6-2.9 in.). The stream conditions were not storm flow (flushing flows from storm drains had receded previously and the water was clear), but lower base flows conditions may yield very different results. For grab sample synoptic surveys of this type, ideally multiple surveys would be conducted over a variety of flow and seasonal conditions. The June 7, 2016 sampling provides insight into spatial trends but should be repeated under a variety of field conditions before making any definitive conclusions on the relative mercury flux.

After transfer of the UEFPC samples to ORNL, ORNL researchers conducted preliminary screening of the mercury levels in the samples using the Lumex analyzer to determine the amount of dilution that would be required for final higher quality analysis that was conducted with the MERX analyzer. The sampling data and quality assurance/quality control results were put into a Project Environmental Measurements System upload compatible format and provided to UCOR for entry into the Oak Ridge Environmental Information System database. Results of the sampling are summarized in Table 3-1.

Table 3-1. Results of UEFPC June 6, 2016, outfall sampling and analysis

ORNL conducted mercury analysis, and UCOR/RSI conducted sampling and field measurements

\begin{tabular}{|c|c|c|c|c|c|c|c|c|c|}
\hline SITE ID (SAMPLED 6/7/16) & TIME & $\begin{array}{l}\text { TURBIDITY } \\
\text { (NTU) }\end{array}$ & $\begin{array}{c}\text { TOTAL } \\
\text { CHLORINE } \\
(\mathrm{mg} / \mathrm{L}) \\
\end{array}$ & $\begin{array}{c}\text { FREE } \\
\text { CHLORINE } \\
(\mathrm{mg} / \mathrm{L}) \\
\end{array}$ & $\begin{array}{c}\text { HG } \\
\text { UNFILTERED } \\
\text { (ng/l) }\end{array}$ & $\begin{array}{c}\text { HG } \\
\text { FILTERED } \\
(\mathrm{ng} / \mathrm{l})\end{array}$ & $\begin{array}{c}\text { \% HG } \\
\text { DISSOLVED }\end{array}$ & $\begin{array}{l}\text { FLOW } \\
\text { (GPM) }\end{array}$ & $\begin{array}{c}\text { FLUX } \\
\text { (g/day) }\end{array}$ \\
\hline STATION 17 (INSTREAM) & 710 & 3.4 & 0.02 & 0 & 114.72 & 38.05 & 33.2 & 2715 & 1.70 \\
\hline OF002 & 730 & 6.3 & 0.03 & 0.06 & 1.83 & 0.57 & 30.9 & 609 & 0.0061 \\
\hline OLD UEFPC (BEFORE BYPASS) & 750 & 8.4 & 0.01 & 0.01 & 175.36 & 11.55 & 6.6 & 31 & 0.0296 \\
\hline OF004 & 857 & 2.3 & 0.02 & 0.04 & 46.49 & 30.55 & 65.7 & 6 & 0.0015 \\
\hline LAKE REALITY WEIR & 810 & 28 & 0.06 & 0.1 & 77.22 & 11.68 & 15.1 & 0.53 & 0.0002 \\
\hline LAKE REALITY BYPASS (INSTREAM) & 822 & 2.3 & 0.02 & 0.02 & 210.57 & 65.27 & 31.0 & 2552 & 2.9292 \\
\hline OF010 BASIN EAST OF 9725 & 912 & 2.3 & 0.03 & 0.05 & 7.19 & 3.71 & 51.6 & 3 & 0.0001 \\
\hline C03 (INSTREAM) & 927 & 2.5 & 0.04 & 0.04 & 219.98 & 84.23 & 38.3 & 2075 & 2.4881 \\
\hline OF014 & 948 & 2.5 & 0.05 & 0.11 & 426.32 & 67.72 & 15.9 & 18.5 & 0.0430 \\
\hline OF 017 SPRING SOUTH OF CREEK & 959 & 1.7 & 0.03 & 0.05 & 2.66 & 0.71 & 26.7 & 25 & 0.0004 \\
\hline OF 021 AT FLUME & 1011 & 3.6 & 0.03 & 0.07 & 10.99 & 3.21 & 29.2 & 30 & 0.0018 \\
\hline 021 (PRE DECHLOR IN HEADWALL) & 1019 & 2.6 & 0.04 & 0.05 & 9.33 & 3.28 & 35.2 & 30 & 0.0015 \\
\hline OF034 OUTFALL & 1033 & 1.7 & 0.04 & 0.03 & 63.67 & 25.44 & 40.0 & 470 & 0.1631 \\
\hline OF034 (PRE DECHLOR) & 1042 & 2.7 & 0.09 & 0.05 & 80.23 & 13.26 & 16.5 & 470 & 0.2055 \\
\hline UEFPC UP FROM OF034 (INSTREAM) & 1052 & 2.2 & 0.06 & 0.04 & 323.17 & 105.33 & 32.6 & 1685 & 2.9683 \\
\hline OF042 & 1252 & 2 & 0.02 & 0.03 & 1.41 & 0.53 & 37.6 & 10.5 & 0.0001 \\
\hline OF047 (BASIN B4101 AT STOP SIGN) & 1303 & 1 & 0.06 & 0.11 & 63.22 & 34.16 & 54.0 & 30 & 0.0103 \\
\hline OF051 & 1314 & 2.3 & 0.03 & 0.04 & 1097.00 & 679.80 & 62.0 & 30 & 0.1794 \\
\hline OF055 & 1325 & 0.09 & 0.04 & 0.02 & 154.49 & 119.89 & 77.6 & 0.4 & 0.0003 \\
\hline OF067 & 1340 & 1.2 & 0.05 & 0.08 & 1.20 & 0.78 & 65.0 & 12 & 0.0001 \\
\hline OF071 & 1350 & 1.1 & 0.05 & 0.08 & 2.23 & 1.29 & 57.8 & 24 & 0.0003 \\
\hline OF088 & 1402 & 1.9 & 0.02 & 0.03 & 9.34 & 2.49 & 26.7 & 1 & 0.0001 \\
\hline UEFPC @ OF102 (INSTREAM) & 1413 & 2.2 & 0.08 & 0.1 & 381.77 & 173.03 & 45.3 & 1045 & 2.1747 \\
\hline OF109 & 1423 & 2.5 & 0.11 & 0.1 & 20.97 & 13.92 & 66.4 & 179 & 0.0205 \\
\hline UEFPC @ OF 110 (INSTREAM) & 1437 & 2 & 0.05 & 0.09 & 453.44 & 235.42 & 51.9 & 976 & 2.4124 \\
\hline OF113 & 1452 & 1.3 & 0.09 & 0.06 & 33.18 & 26.38 & 79.5 & 0.13 & 0.0000 \\
\hline OF114 & 1505 & 0.5 & 0.03 & 0.02 & 9.02 & 4.26 & 47.2 & 5 & 0.0002 \\
\hline OF135 (WEIR) & 1525 & 1.4 & 0.01 & 0.03 & 442.41 & 343.03 & 77.5 & 329 & 0.7934 \\
\hline OF135 (PRE DECHLOR) & 1538 & 0.08 & 1.15 & 2.5 & 438.69 & 392.07 & 89.4 & 329 & 0.7867 \\
\hline OF200 HEADWALL (INSTREAM) & 1550 & 0.8 & 0 & 0.1 & 604.64 & 537.92 & 89.0 & 636 & 2.0962 \\
\hline OF200A6 (PRE DECHLOR) & 1600 & 5.7 & 0.47 & 0.34 & 500.72 & 422.17 & 84.3 & 636 & 1.7359 \\
\hline
\end{tabular}

Figure 3-2 shows a depiction of the magnitudes of outfall and UEFPC flow measurements. Based on in situ dedicated gauging station data, it was estimated that flows entering UEFPC at OF200A6 were $636 \mathrm{gpm}$, and flows leaving UEFPC and entering LEFPC at Station 17 were 2,715 gpm; this was a difference of 2,079 gpm. By totaling individual outfall discharge measurements, the flow contribution from the outfalls was estimated to be 1,814 gpm. Flow between OF200 and Station 17 increased by over four times, primarily because of discharges from the outfalls. The extra $265 \mathrm{gpm}$ could be the result of 
groundwater and other ungauged discharges, although it could also just be that the measurements are within the limits of quantification and measurement error.

Figure 3-3 shows the magnitude of outfall and UEFPC HgT (mercury unfiltered) flux estimates. The percent dissolved (filtered) mercury in UEFPC dropped from $\sim 89 \%$ at OF200 to $33 \%$ at Station 17. The percent dissolved $\mathrm{Hg}$ in outfalls varied between $7 \%$ and $89 \%$. The $\mathrm{HgT}$ flux entering UEFPC at OF200A6 was estimated to be $1.74 \mathrm{~g} /$ day. However, significant HgT fluxes (1.23 g/day) were estimated to be entering UEFPC during the high base flow sampling episode from outfalls downstream of OF200A6. The majority of the HgT outfall flux based on this survey was coming from OF135 (0.79 g/day), OF034 (0.21 g/day) and OF051 (0.18 g/day), with OF051 (1,097 ng/l) having the highest HgT concentration detected. Elevated concentrations of mercury were also detected in OF014 (426 ng/l), OF055 (154 ng/l), and old UEFPC before reentering UEFPC (175 ng/l), but fluxes of mercury were relatively low because the quantity of water discharging from these outfalls is relatively low.

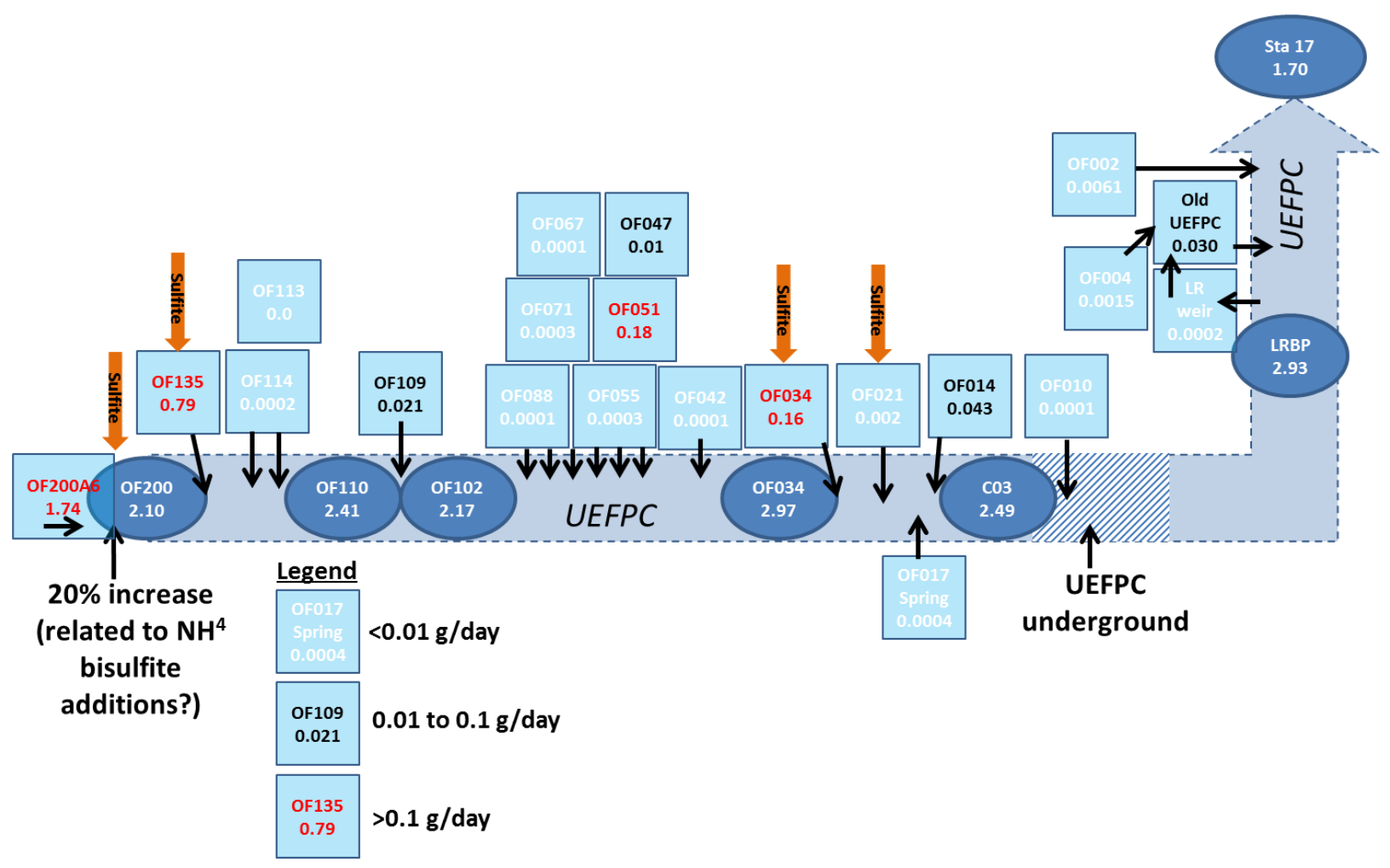

Fig. 3-3. UEFPC outfall and in-stream HgT (mercury unfiltered) fluxes in grams per day (g/day).

The HgT flux increased in the short distance between OF200A6 and the OF200 headwall by $0.36 \mathrm{~g} / \mathrm{day}$, for a total measured influx of $\mathrm{HgT}$ from outfalls of $1.59 \mathrm{~g} /$ day. A hypothesis is that the increase in $\mathrm{HgT}$ flux between OF200A6 and OF 200 could be related partially to the introduction of a dechlorination chemical, ammonium bisulfite, between the two locations because there are no other known influxes of mercury in this area. During the sampling event, sulfite was detected in OF135 (3.8 ppm), OF034 (1.3 $\mathrm{ppm})$ and in-stream at OF200 (1.5 ppm) to $100 \mathrm{~m}$ downstream of OF200 (1 ppm). It is not clear why there is such a large drop in HgT concentration and flux between the Lake Reality Bypass in-stream measurement location and Station 17. If related to partitioning of the mercury to EFPC sediment and bank materials, this mercury would be available for future mobilization during storms. It is also possible that there is some measurement or analytical issue because the upstream Lake Reality Bypass flow (2,552 gpm) plus the significant flow (609 gpm) entering from Outfall 002 (OF002) is greater (i.e., 3,161 gpm) 
than the estimated flow for Station 17 (2,712 gpm). Again, this is a one-point-in time survey that provides important insights regarding the UEFPC system, but needs to be repeated under varying flow and seasonal conditions before making any definitive conclusions about relative flux.

Analysis of the June 7, 2016 analytical and flow data substantiates conclusions from the Y-12 Conceptual Model Report (Peterson et al 2011) that there are significant contributions to the EFPC HgT flux downstream of OF200. The survey provides intriguing information that suggests chlorination and dechlorination processes could be a factor influencing mercury mobilization and flux. Additional studies are needed under varying flow and discharge/operational conditions to better understand and quantify the UEFPC mercury fluxes that are affecting LEFPC.

\subsubsection{Assessment of chlorine and dechlorination chemical impacts on $\mathrm{Hg}(0)_{1}$ transformations and mobilization from UEFPC}

Chemical additions in the Y-12 east plant area (e.g., chlorine, ammonium bisulfite, and cooling tower water) are being investigated because they are thought to have an impact on the mercury dynamics and flux to LEFPC and are not going to be captured by the water treatment facility being constructed at OF200. Testing of the impact of chlorine and dechlorination chemicals on $\mathrm{Hg}(0)_{1}$ beads conducted in FY 2015 (Peterson et al. 2016) showed that chlorine and certain dechlorination chemicals enhance the transformation of $\mathrm{Hg}(0)_{1}$ to the more soluble and mobile $\mathrm{Hg}(\mathrm{II})$ form, but this testing focused on conditions found in the WEMA. In FY 2016, ORNL conducted additional $\mathrm{Hg}(0)_{1}$ bead tests on water samples collected from east plant area outfalls. Results of $\mathrm{Hg}(0)_{1}$ bead tests conducted on OF034 and OF109 (see Fig. 3-1 for locations) are shown in Figs. 3-4 and 3-5.

The methodology used to conduct the $\mathrm{Hg}(0)_{1}$ experiments on OF034 and OF109 water was similar to experiments conducted in FY 2015 (Peterson et al. 2016). Small beads of acid washed $\operatorname{Hg}(0)_{1}(50 \mu l)$ were removed from a stock container using a gastight syringe and placed in a $40 \mathrm{ml}$ glass vial. All tests were conducted in duplicate. The vial cap was fitted with an outlet port consisting of a Teflon tube $(1.6 \mathrm{~mm}$ internal diameter) secured approximately $10 \mathrm{~mm}$ from the base of the vial. Aqueous samples $(1 \mathrm{ml})$ were withdrawn from the vial with a plastic syringe following a $0.5 \mathrm{~mL}$ flush of the sample line. A subsample was analyzed immediately for dissolved $\mathrm{Hg}(0)_{\mathrm{d}}$, and the remaining aliquot was preserved with bromine monochloride for total mercury analysis. The concentrations of dissolved $\operatorname{Hg}(0)_{\mathrm{d}}$ and total mercury were measured multiple times between 10 and 300 minutes using a modification of US Environmental Protection Agency (EPA) method 1631E (Miller et al. 2013). Oxidized mercury, the combination of $\mathrm{Hg}(\mathrm{I})$ and $\mathrm{Hg}(\mathrm{II})$, was determined by the difference between the $\mathrm{HgT}$ and $\mathrm{Hg}(0)_{\mathrm{d}}$. However, $\mathrm{Hg}$ (II) is used to denote all oxidized species of mercury because $\mathrm{Hg}(\mathrm{II})$ is the most likely species present.

For the OF034 testing, samples were collected at the OF034 discharge point before treatment (i.e., with residual chlorine) and after treatment with the ammonium bisulfite drip system to remove the residual chlorine. The $\mathrm{Hg}(0)_{1}$ experiments were conducted on (1) the OF034 water sample containing residual chlorine, (2) the OF034 sample treated at the point of discharge with ammonium bisulfite, and (3) the OF034 water sample with residual chlorine treated with ascorbic acid to remove the chlorine instead of ammonium bisulfite. The OF034 tests show that there is about 2.5 times less HgT generated if the sample is dechlorinated with ascorbic acid instead of ammonium bisulfite (see Fig. 3-4). As might be expected, the chlorinated sample from OF034 produces the most HgT in solution, $~ 10$ times more than the sample dechlorinated with ascorbic acid (see Fig. 3-4).

For the OF109 testing, samples of OF109 water from the point of discharge were collected and tested before and after treatment with ascorbic acid in the laboratory to remove any trace amounts of chlorine. This testing was conducted to determine if even these trace amounts of chlorine detected in OF109 could affect the $\mathrm{Hg}(0)_{1}$ transformation to $\mathrm{Hg}(\mathrm{II})$. The results shown in Fig. 3-5 indicate that for OF109, there is 
about 3 times less $\mathrm{HgT}$ generated if the sample is dechlorinated using ascorbic acid compared with the total $\mathrm{HgT}$ that is generated if the water currently discharging directly to UEFPC at OF109 containing trace chlorine is exposed to the beads of $\mathrm{Hg}(0)_{1}$.

These results suggest that the presence of chlorine and bisulfite compounds in UEFPC could increase the concentration and flux of $\mathrm{HgT}$ in the creek if $\mathrm{Hg}(0)_{1}$ is present. The use of an alternative dechlorination chemical such as ascorbic acid might reduce the mercury concentration and flux downstream. However, these are preliminary grab sample tests and application of alternative chemicals with in-pipe testing is needed to evaluate the efficacy of this approach.

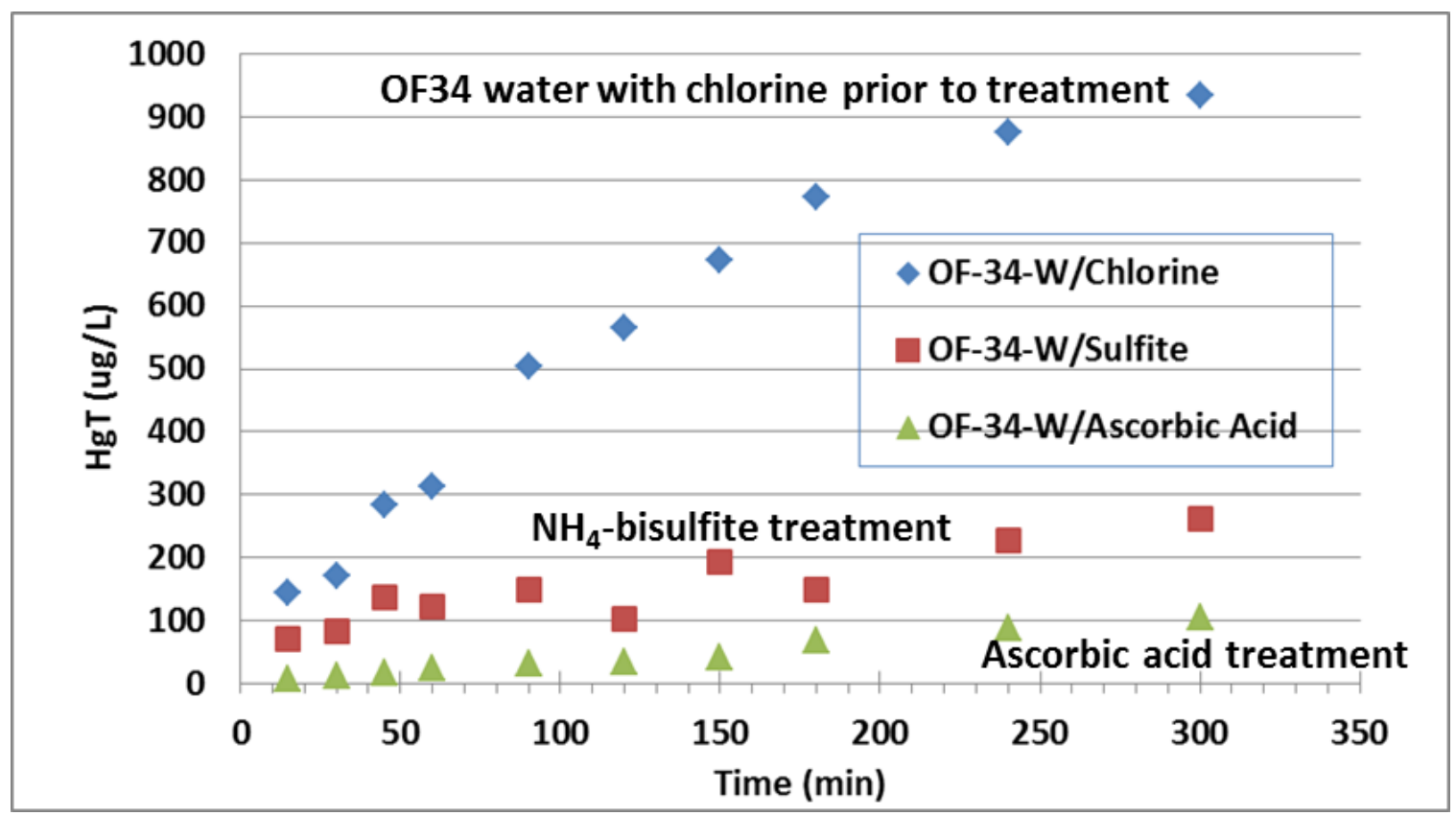

Fig. 3-4. OF034 $\mathrm{Hg}(0)_{1}$ bead testing showing current the practice of treating chlorine in OF034 with ammonium bisulfite may enhance the leaching and mobilization of $\mathrm{HgT}$ compared with switching to an ascorbic acid dechlorination treatment. 


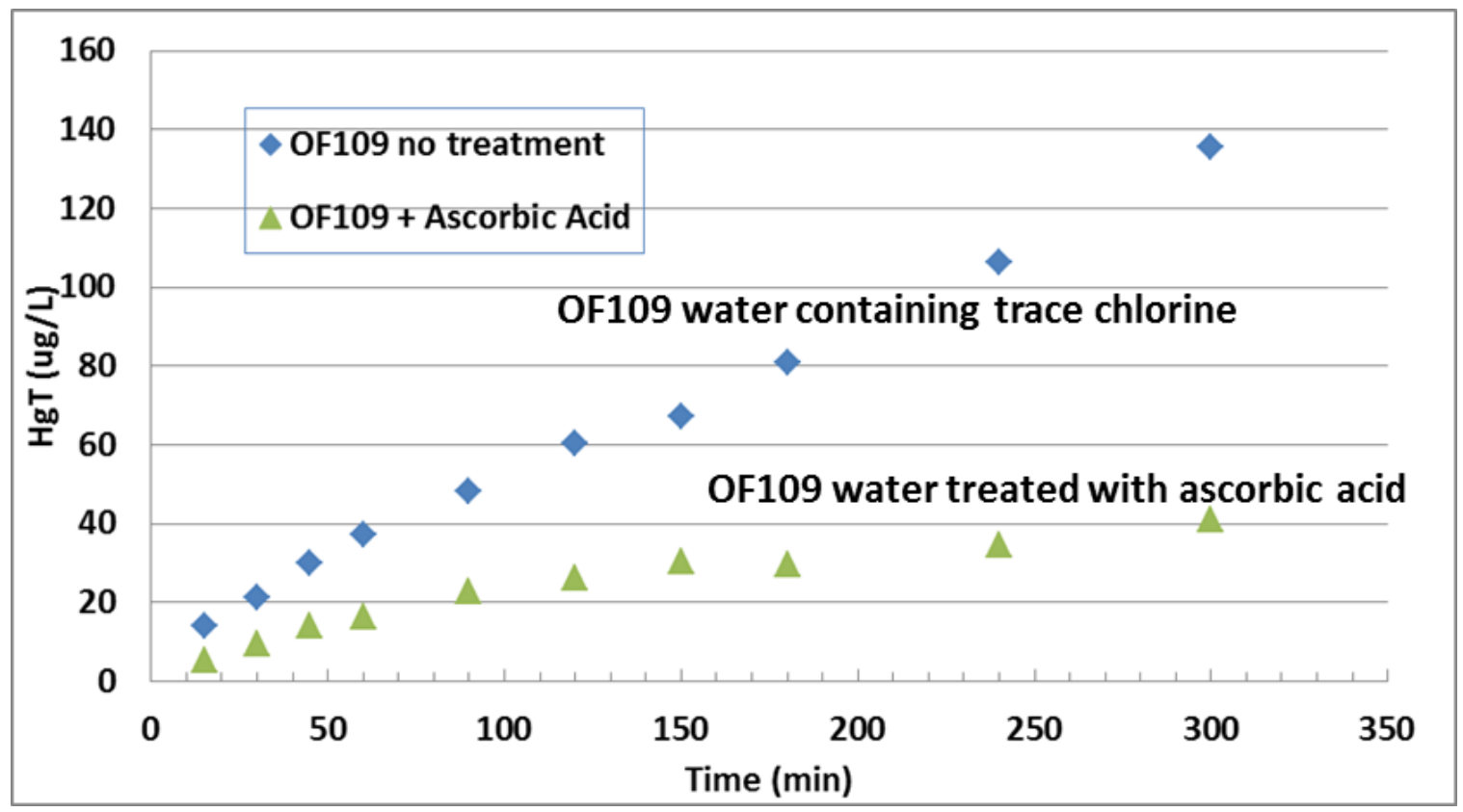

Fig. 3-5. OF109 $\mathrm{Hg}(0)_{1}$ bead testing showing OF109 water with trace chlorine results in more leaching and mobilization of $\mathrm{HgT}$ than $\mathrm{OF} 109$ water treated with ascorbic acid. 


\subsubsection{Assessment of chlorine and dechlorination chemical impacts on mercury transformations and mobilization of UEFPC contaminated sediment}

The mercury found on contaminated sediments in UEFPC is likely to be in a $\mathrm{Hg}$ (II) form complexed to the sediments. Therefore chlorination (oxidizing) and dechlorination (reducing) chemicals will interact and react differently with the mercury on the sediment than previously observed in experiments using $\mathrm{Hg}(0)_{1}$ beads. The general experimental design for the sediment testing was similar to the methods described above for the $\mathrm{Hg}(0)_{1}$ bead tests with the primary difference being that 0.5 or 1 gram of sediment collected from near OF109 was placed in the test container instead of a $\mathrm{Hg}(0)_{1}$ bead. Two different sediment size fractions tested include (1) a fine sediment fraction having a 125-250 micron particle size and (2) a medium fraction having a 250 micron to $1 \mathrm{~mm}$ particle size. The concentration of mercury on the fine fraction was $100.1 \mathrm{mg} / \mathrm{kg}$, and the concentration on the medium fraction was $64.4 \mathrm{mg} / \mathrm{kg}$. The tests assessing dechlorination compounds were initially conducted using tap water, but the chlorine in the water was causing quantification and data interpretation problems, so chlorine free deionized (DI) water and/or an artificial (synthetic) creek water that has similar $\mathrm{pH}(\sim 8.0)$ and major ion composition to LEFPC was used instead. To reduce the number of analyses required, time series testing was initially conducted to determine how much the concentrations changed over time and to determine if a single 6 hour incubation and sampling time would be representative of equilibrium concentrations (see Figs. 3-6 and 3-7).

Figure 3-6 shows that the concentration of mercury in solution per gram of sediment does not change very much over a 24 hour incubation period when the medium fraction sediment is exposed to tap water containing $\sim 2.6 \mathrm{mg} / \mathrm{l}$ chlorine. This experiment (and other tests not presented) resulted in a concentration of approximately $1.0 \mathrm{ug}$ of $\mathrm{Hg}$ in solution/g of sediment that remained fairly steady throughout the 24 hour incubation period. Figure 3-7 shows the concentration of mercury $(\sim 0.045 \mathrm{ug} \mathrm{Hg}$ in solution/g of sediment) does not change very much from 3 hours to 24 hours when the medium fraction sediment is exposed to tap water $(\sim 2.6 \mathrm{mg} / \mathrm{l}$ chlorine) that has been dechlorinated with ammonium bisulfite. The resulting sulfite concentration in solution was $\sim 1.9 \mathrm{mg} / \mathrm{l}$ for this test. At the concentrations tested, exposure of the medium fraction sediment to ammonium bisulfite did result in an increase in the mercury in solution; however, it was much less than what resulted from exposure of the sediment to residual chlorine. From these initial tests, it was determined that for comparison purposes between experiments, a 6 hour incubation period is adequate and representative of equilibrium conditions.

Because some relatively high concentrations of sulfite were measured near OF200 ( 7.0 mg/l in OF135 and $~ 5.1$ in the creek), testing was conducted with DI water and ACW to assess the impact of ammonium bisulfite concentration on the leaching of mercury from UEFPC sediments. Figure 3-8 shows that, for both types of water and for both the fine and coarse sediment fractions, the $\mathrm{HgT}$ in solution increases in a fairly linear fashion as the sulfite concentration (i.e., ammonium bisulfite) increases. The exception is the batch test, where fine (125-250 micron) sediment that was incubated in ACW resulted in unexplained higher $\mathrm{HgT}$ in solution and greater scatter in the concentration detected relative to the other test scenarios. It was not conclusive what combination of sediment type (fine versus medium) and water solutions (DI versus ACW) resulted in more mercury being leached. However, it is clear that the addition of ammonium bisulfite to the solutions (sulfite up to $10 \mathrm{mg} / \mathrm{L}$ ) could increase the $\mathrm{HgT}$ in solution from $<0.01 \mathrm{ug} \mathrm{Hg}$ in solution/g of sediment to as much as $0.14 \mathrm{ug} \mathrm{Hg}$ in solution/g of sediment.

Figure 3-9 shows that, for a similar set of sediment incubation experiments conducted using ascorbic acid, the amount of $\mathrm{HgT}$ in solution was generally less than what resulted from the ammonium bisulfite incubations and was not sensitive to the concentration of ascorbic acid in solution. For the ascorbic acid experiments, the $\mathrm{HgT}$ concentration in solution per gram of sediment was actually greater for the medium sediment fraction than for the fine fraction, even though the fine fraction had a higher concentration of mercury. This suggests that the mercury is probably bound to the fine fraction differently and more tightly 
than it is bound to the medium fraction. Sequential extractions conducted on these two sediment samples also showed that more mercury was extracted using the F1, F2, and F3 extraction solutions for the medium fraction $(3.8 \mathrm{mg} / \mathrm{kg})$ than for the fine fraction $(\sim 0.5 \mathrm{mg} / \mathrm{kg})$. This could be because the organic carbon that the mercury might be bound to was higher in the fine fraction $(5.2 \mathrm{mg} / \mathrm{kg})$ than in the medium fraction $(3.1 \mathrm{mg} / \mathrm{kg})$. The DI water resulted in greater $\mathrm{HgT}$ in solution than the ACW, probably because the $\mathrm{pH}$ of the DI water is lower compared with the ACW water.

These sediment testing results are noteworthy because they suggest that the presence of chlorine and bisulfite compounds in UEFPC could increase the concentration and flux of $\mathrm{HgT}$ in the creek due to mobilization of mercury from the mercury-contaminated sediments and bank material. The testing also shows that the use of an alternative dechlorination chemical such as ascorbic acid might reduce the mercury concentration and flux in UEFPC.

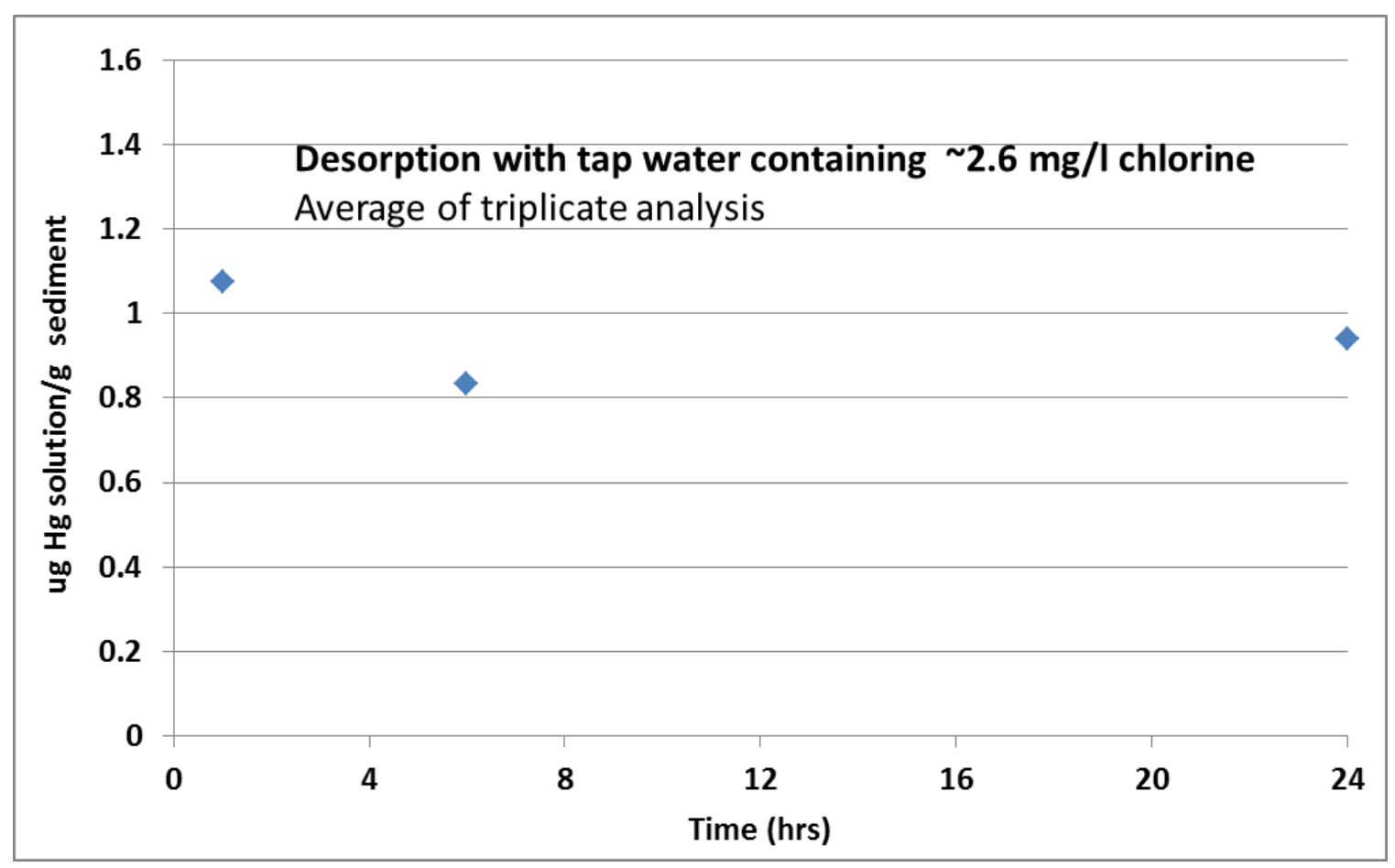

Fig. 3-6. Impact of residual chlorine in tap water on leaching of HgT from UEFPC sediments over time (sediment: $\mathrm{HgT}=64.4 \mathrm{mg} / \mathrm{kg}$; medium size fraction $=250 \mathrm{um}-1 \mathrm{~mm}$ ). 


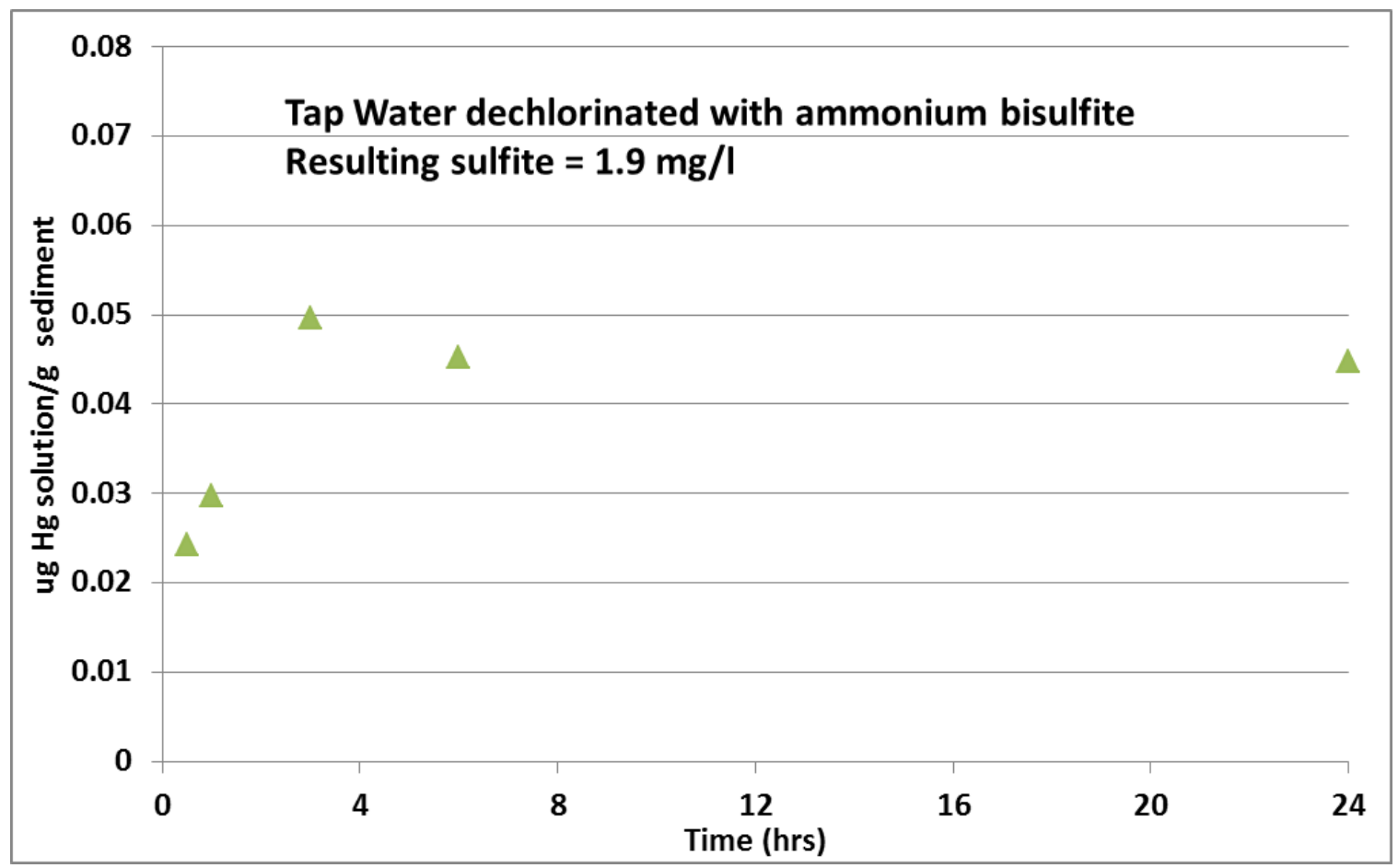

Fig. 3-7. Impact of ammonium bisulfite on leaching of $\mathrm{HgT}$ from UEFPC sediments over time (sediment: $\mathrm{HgT}=64.4 \mathrm{mg} / \mathrm{kg}$; medium size fraction $=250 \mathrm{um}-1 \mathrm{~mm}$ ).

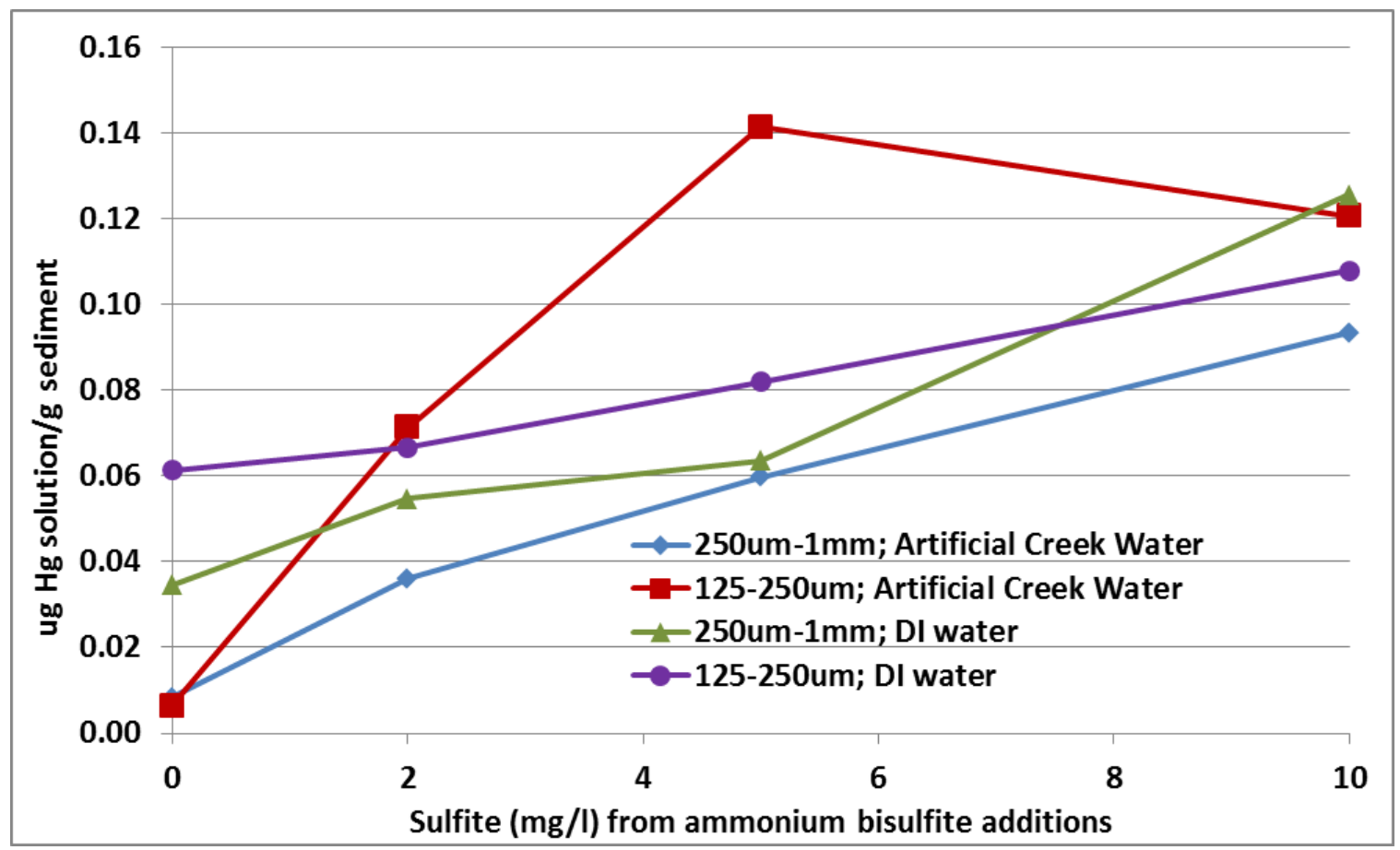

Fig. 3-8. Impact of ammonium bisulfite concentration on leaching of HgT from UEFPC sediments with DI water and artificial creek water (sediment: medium size fraction $=250 \mathrm{um}-1 \mathrm{~mm}$; 


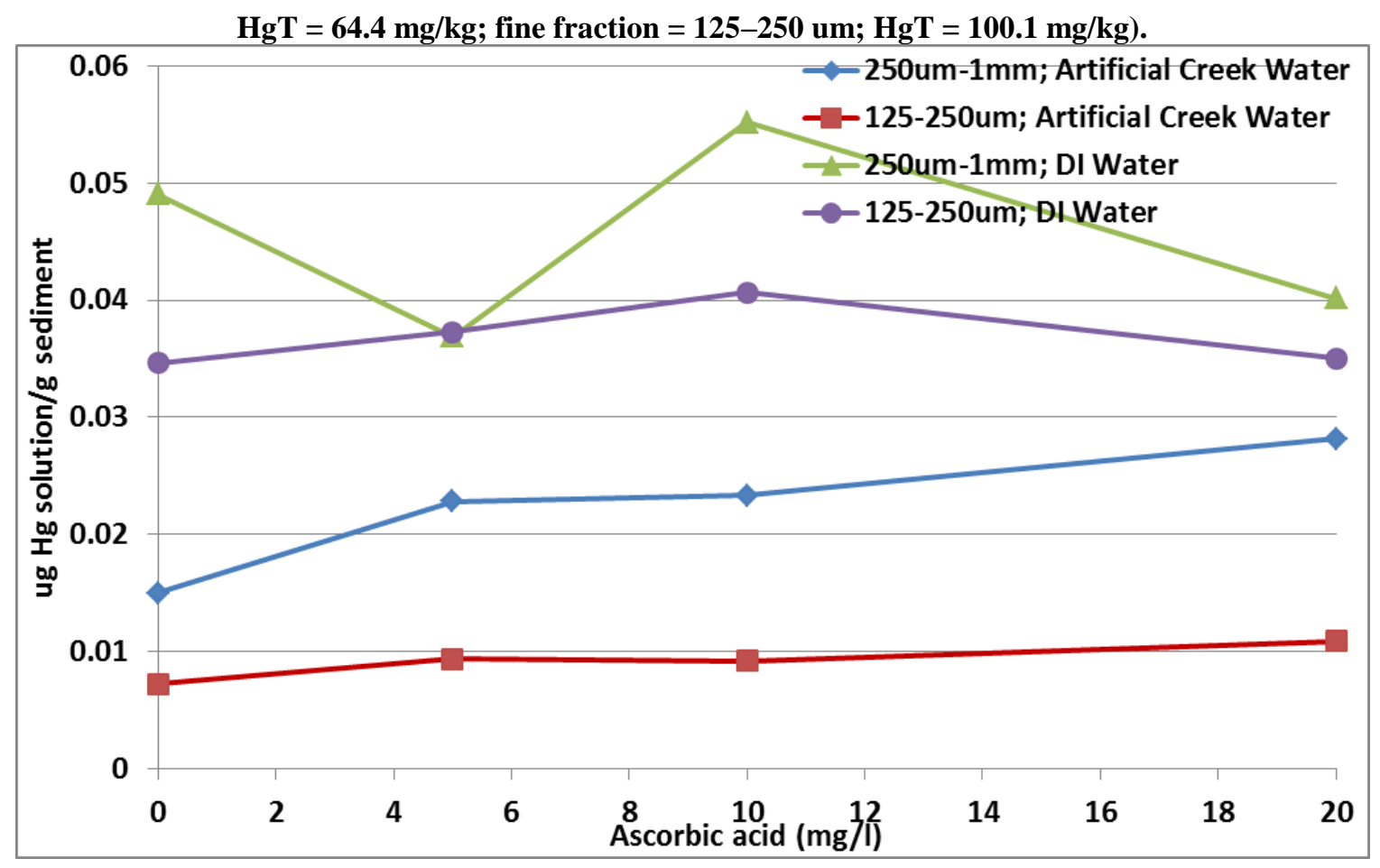

Fig. 3-9. Impact of ascorbic acid concentration on leaching of HgT from UEFPC sediments with DI water and artificial creek water (sediment: medium size fraction $=250 \mathrm{um}-1 \mathrm{~mm} ; \mathrm{HgT}=64.4$ $\mathrm{mg} / \mathrm{kg}$; fine fraction $=125-250 \mathrm{um} ; \mathrm{HgT}=100.1 \mathrm{mg} / \mathrm{kg}$ ).

\subsubsection{EFPC Flow Regime}

EFPC is a mixed-use watershed that is highly developed upstream with a large percentage of impervious surface area. Watershed land cover characteristics gradually change downstream, transitioning to more forested and some open field areas. The surrounding land cover has direct implications for the flow regime in EFPC and possible consequences for creek bank stability and habitat suitability.

A high percentage of impervious surface area results in high runoff ratios - the runoff from a 1 acre parking lot is 16 times greater than the runoff for undeveloped land. During stormflow events, water levels rise and fall faster and reach higher peak flows than would be the case without impervious surfaces. These changes lead to channel instability and increased bank erosion. To the extent creek banks hold a significant inventory of $\mathrm{Hg}$ (see Task 1), alterations to stream flow resulting from land cover changes can accelerate the delivery of bank-soil derived $\mathrm{Hg}$ loads to EFPC.

The installation of equalization tanks in the city of Oak Ridge and future installation of similar tanks inside Y-12 associated with the Mercury Treatment Facility likely will alter flow regime characteristics of lower EFPC. In turn, bank erosion and sediment transport rates and processes may be altered. Decreased bank erosion associated with lower peak flows would be viewed as a positive change. Conversely, lower peak flows will decrease sediment transport characteristics and could lengthen or diminish the effectiveness of natural contaminated sediment-removal processes. The net effect of these competing processes remains to be determined. 


\subsubsection{Estimates of Mercury and Monomethylmercury Flux along EFPC}

Both particulate and dissolved $\mathrm{Hg}$ concentrations in water decrease with distance downstream, whereas creek discharge increases downstream. One question to ask of this pattern is whether the decrease in concentration is due to actual removal of $\mathrm{Hg}$ from the water or, alternatively, whether it is due to dilution by cleaner water entering the creek. One approach to resolving this question is to make measurements of concentration and stream discharge to calculate mass flux:

$$
J=C Q
$$

where $J=$ mass flux (mass per time), $C=$ concentration (mass per volume), and $Q=$ discharge (volume per time)

Regular measurements of stream discharge and water composition are being made under base flow conditions at three locations along EFPC to support flux calculations. These measurements are made at EFKs 23.4, 16.2, and 5.4; by comparing the flux between consecutive stations, one can estimate whether that reach of the creek is a net source or sink of the measured constituent. All three sampling locations are in the LEFPC administrative section of the creek. For purposes of the discussion that follows, the reach from EFK 23.4 to EFK 16.2 is referred to as the upper reach of LEFPC, and the reach from EFK 16.2 to EFK 5.4 is referred to as the lower reach of LEFPC. Findings to date are summarized below.

Diffuse legacy sources of $\mathrm{Hg}$ in both the upper and lower reaches of EFPC contribute up to $80 \%$ of the dissolved $\mathrm{Hg}$ flux and up to $90 \%$ of the total $\mathrm{Hg}$ flux as measured at EFK 5.4. The lower reach of LEFPC makes contributions that are equal to or greater than the upper reach of LEFPC (Fig. 3-10). The Oak Ridge Wastewater Treatment Facility (ORWTF) is not a source of Hg.

Mercury stable isotope studies, conducted under the $\mathrm{Hg}$ Science Focus Area project, suggest that hyporheic water may be a likely source of the added $\mathrm{Hg}$. This finding supports investigations that target creek sediments to control $\mathrm{Hg}$ flux in EFPC. 
(a)

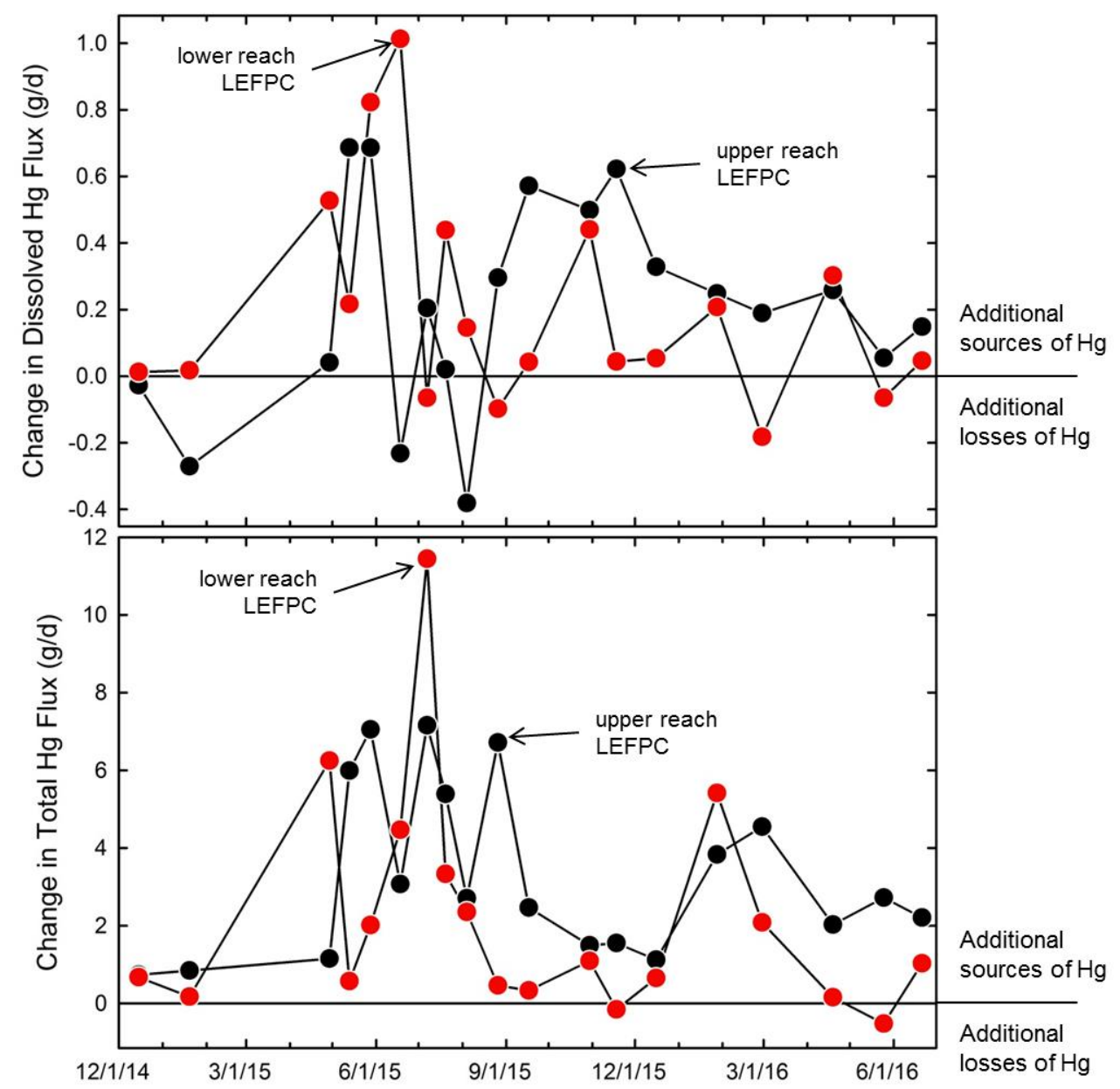

Fig. 3-10. Change in (a) dissolved and (b) total Hg flux between in the upper (black) and lower (red) reaches of LEFPC.A value of zero indicates no change in flux-concentration decreases can be accounted for by dilution alone. Negative values indicate losses of $\mathrm{Hg}$ from the system, whereas positive values indicate other sources that add $\mathrm{Hg}$ to the water. All but a few samples indicate there are additional sources of $\mathrm{Hg}$ to the creek outside of $\mathrm{Y}-12$.

Monomethylmercury (MMHg) is produced from inorganic $\mathrm{Hg}$ by anaerobic microorganisms in the environment. In contrast to patterns in $\mathrm{Hg}$ concentration downstream, dissolved and particulate $\mathrm{MMHg}$ increase with downstream distance in EFPC. There is also a strong seasonal component to the concentration increase where the downstream concentration increase is steeper in warmer months and flatter in cooler months. One question to ask is whether this pattern is due to a constant rate of production and subsequent accumulation downstream or if the rate of production varies along the creek. One method to address this question is to make similar flux calculations for MMHg from which an effective net rate of MMHg change can be derived. Note that this is a net rate because, after it is formed, MMHg can also be demethylated back into inorganic $\mathrm{Hg}$ by biotic and abiotic processes.

Both the upper and lower reaches are net sources of MMHg. Additionally, the results show that MMHg production rates for the two reaches are similar during the cooler months. A similar production rate for the upper and lower reaches of LEFPC is consistent with the flatter concentration gradient in cooler 
months. During the warmer months, the rate of MMHg production increases more in the lower reach than in the upper reach (Fig. 3-11). Greater increases in the lower reach during warmer months would result in a steeper concentration gradient, as observed.

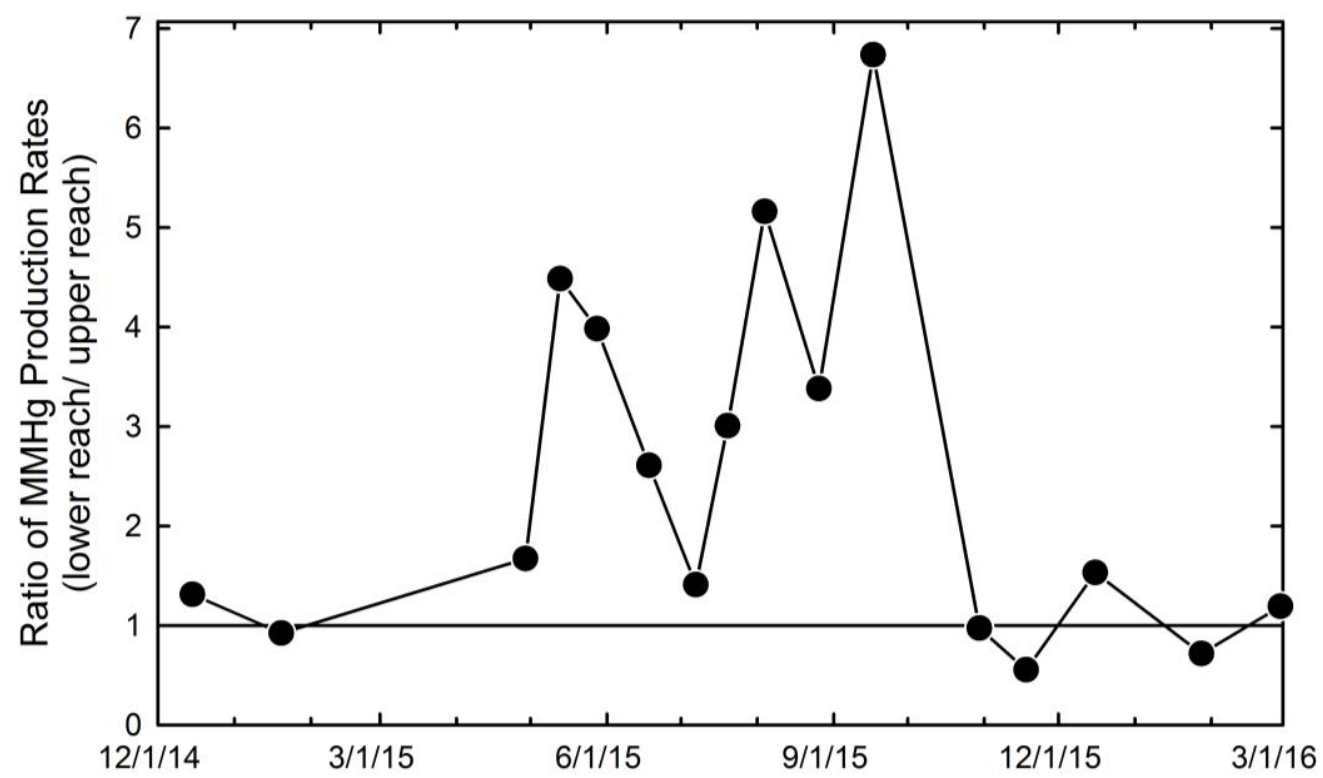

Fig. 3-11. Ratio of MMHg production rate in the lower reach of LEFPC versus the upper reach of LEFPC. A value of 1 indicates the same production rate in both reaches, a value less than one indicates the rate in the upper reach is larger than the rate in the lower reach, and a value greater than 1 indicates the rate in the lower reach is greater than the rate in the upper reach. In the cooler months, the MMHg production rate was comparable between the two reaches. In warmer months, the MMHg production rate in the lower reach was up to $\sim 7 \times$ higher than the rate in the upper reach.

\subsubsection{Effect of Flow Management Cessation in LEFPC}

Beginning in late 1996, a flow management project was initiated in which $\sim 4.5$ million gallons of water per day from Melton Hill Lake were added to upper EFPC just a few meters downstream from OF200. The flow management project ceased on April 30, 2014, with the intent of decreasing Hg flux exiting Y12 at EFK 23.4 (Station 17). Since that time, water quality along the length of EFPC has been monitored to assess what, if any, ancillary effects there may be throughout the creek corridor. A summary of current results is provided below with an emphasis on $\mathrm{Hg}$ and $\mathrm{MMHg}$ behavior.

Early in this project, the value of monitoring and understanding $\mathrm{Hg}$ partitioning between the solid and dissolved phases was highlighted, as discussed in Peterson et al. (2015a), p. 35. This behavior can be quantified via the distribution coefficient, or $K_{d}$

$$
K_{d}\left(\frac{V}{M}\right)=\frac{H g_{\text {solid }}\left(\frac{\text { Mass } H g}{\text { Mass solid }}\right)}{H g_{\text {dissolved }}\left(\frac{\text { Mass } H g}{\text { Volume solution }}\right)}
$$


where $K_{d}=$ distribution coefficient (units of volume per mass); $H g_{\text {solid }}=\mathrm{Hg}$ concentration on solid phase (mass per mass); and $H g_{\text {dissolved }}=$ dissolved concentration of $\mathrm{Hg}$ (mass per volume). A higher $K_{d}$ value corresponds to a higher affinity of $\mathrm{Hg}$ for the solid phase. In this work, dissolved $\mathrm{Hg}$ is operationally defined as that which passes through a $0.2 \mu \mathrm{m}$ pore size filter. Other workers, and much of the historical data for EFPC, have used a $0.45 \mu \mathrm{m}$ pore size filter to operationally define dissolved $\mathrm{Hg}$. Use of a larger pore size may lead to higher estimates of dissolved $\mathrm{Hg}$ concentration and consequently a lower, or underestimated, $K_{d}$ value.

The $K_{d}$ values presented here were derived by measuring the total and dissolved $\mathrm{Hg}$ concentration in water and the concentration of total suspended solids (TSS; mass per volume). Concentration on the solid phase was derived as the difference between the total and dissolved concentration divided by the TSS value. The resulting $K_{d}$ is an apparent value because these do not strictly conform to assumptions of a true $K_{d}$ value. For example, samples were collected throughout the year, so temperature varied among samples and the underlying equilibrium assumption is uncertain.

Throughout LEFPC, the $K_{d}$ value for Hg has decreased substantially since cessation of the flow management program (Fig. 3-12). Current $K_{d}$ estimates are up to 10 times smaller than estimates based on historical data. The decline in $K_{d}$ could be even greater-as mentioned previously the use of larger pore size filters in previous studies may have resulted in underestimates of $K_{d}$. With respect to Eq. 3.2, the decline in $K_{d}$ has been driven by a combination of both lower $\mathrm{Hg}$ concentration on the solid phase and increased dissolved $\mathrm{Hg}$ concentration.

In a more mechanistic sense, $\mathrm{pH}$ and DOC concentration have a large influence on metal solid:liquid partitioning in general and for $\mathrm{Hg}$ in particular. Neither the $\mathrm{pH}$ of the creek nor the DOC concentration has shown directional changes that would be consistent with the observed changes in $\mathrm{Hg} K_{d}$. In addition to measuring DOC concentration, the UV light-absorbance of water samples has been measured. This measurement, referred to as the specific ultraviolet absorbance at $245 \mathrm{~nm}$ (SUVA-254), is a proxy measure of organic matter composition in the water sample. This characteristic has been shown to be positively correlated with organic matter molecular weight, percent aromaticity, and hydrophobicity. More importantly in this case, the SUVA-254 value has been positively correlated with dissolved Hg and, dissolution of $\mathrm{HgS}$ minerals and strongly correlated with $\mathrm{Hg}$ methylation rate constants. Since flow management was turned off, the SUVA-254 of water has increased throughout much of LEFPC. Thus, changes in $\mathrm{Hg} K_{d}$ may be due, in part, to changes in the composition, rather than the concentration, of organic matter in EFPC. 
(a)

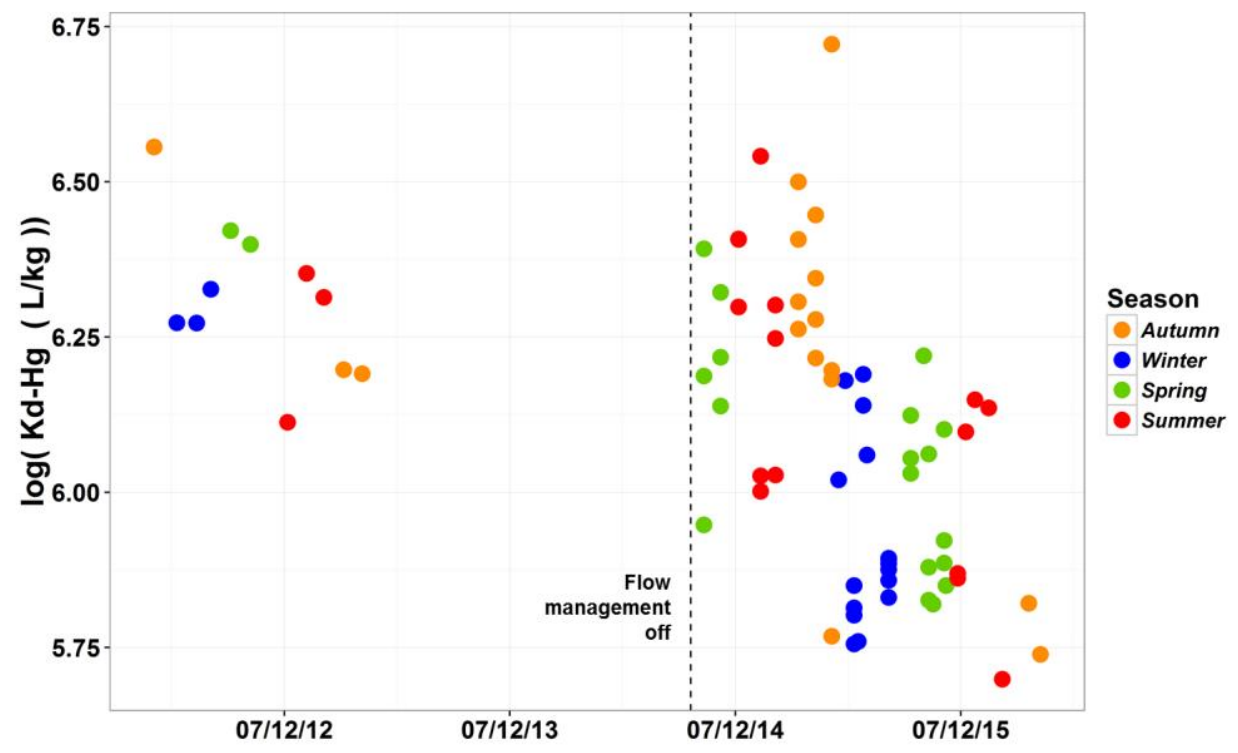

(b)

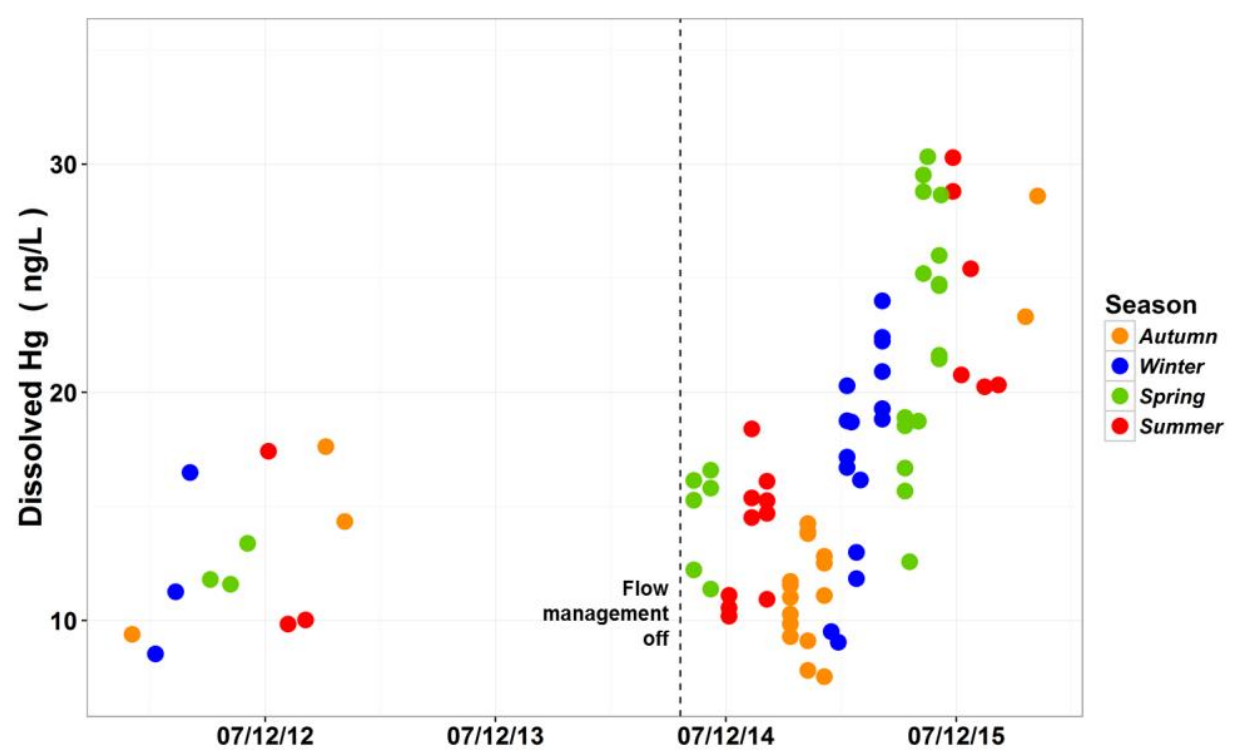

Fig. 3-12. Changes in (a) Hg solid-water partitioning coefficient and (b) dissolved $\mathrm{Hg}$ after flow management stopped. Data shown are for the section of EFPC between EFK 16.2 and EFK 13.8, which is upstream of the ORWTF. In this section, the decreasing $K_{d}$ is driven by increases in dissolved $\mathrm{Hg}$ concentration.

In addition to monitoring $\mathrm{Hg}$ concentration and partitioning behavior, water sample analyses included total and dissolved MMHg. Throughout LEFPC, dissolved MMHg concentrations have increased during mid- to late spring and early summer. In some cases, measured MMHg concentrations are the highest on record. A recent analysis of predictors of $\mathrm{Hg}$ concentration in fish concluded that high $\mathrm{MMHg}$ water concentrations in the preceding year, particularly if they occur during months of the growing season, were most strongly related to $\mathrm{Hg}$ concentration in fish. If this general conclusion holds in EFPC, it may signal possible future increases in $\mathrm{Hg}$ concentration in fish. 


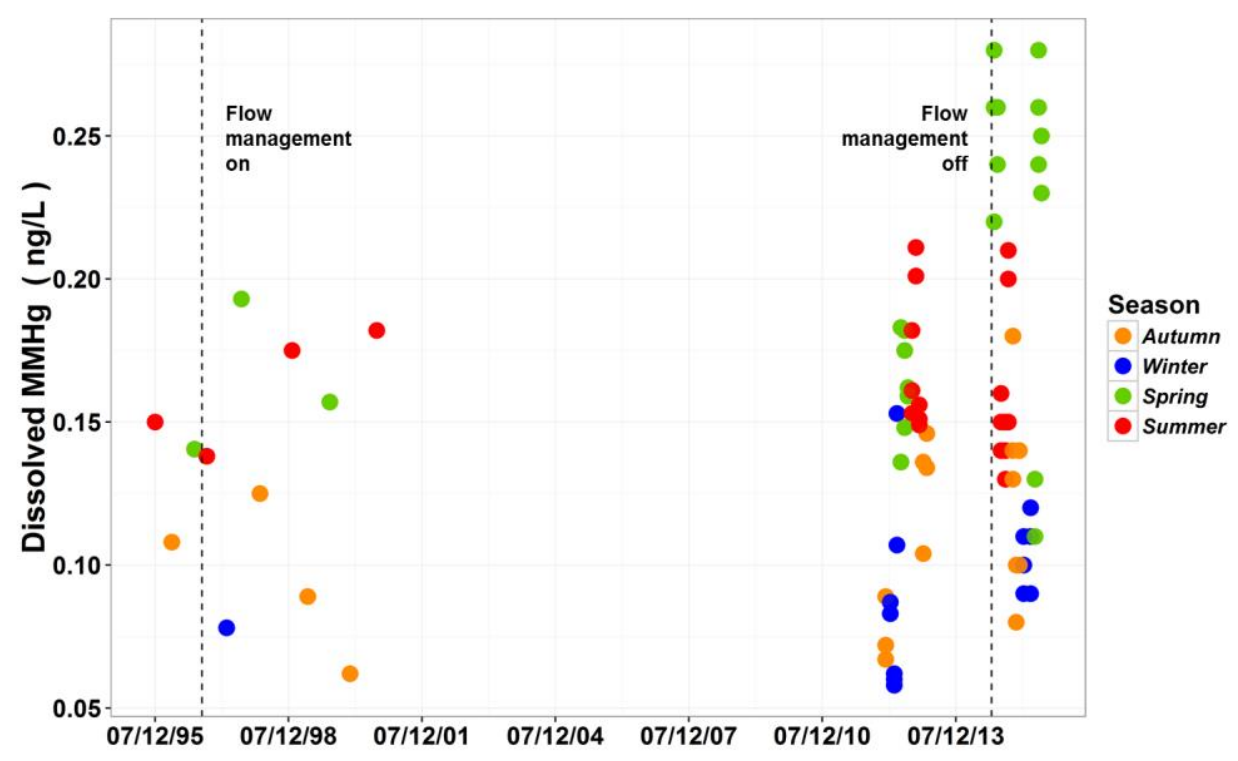

Fig. 3-13. Dissolved MMHg concentration after flow management stopped. Data shown are for the section of EFPC between EFK 18.2 and EFK 17.8, which is upstream of the ORWTF.

The solid:water partitioning coefficient for $\mathrm{MMHg}$ has remained unchanged. Referring to Eq. 3.2, given that dissolved MMHg values have increased, for $K_{d}$ to remain unchanged, the solid phase concentration must show a proportional increase. Therefore, increasing dissolved MMHg coupled with a constant $K_{d}$ implies there is more total MMHg in the system.

\subsection{SEDIMENT}

The last comprehensive assessment of $\mathrm{Hg}$ concentration in creek sediments of EFPC was in 1984. Because of the potentially important role bed sediments can play in overall ecosystem health, $\mathrm{Hg}$ inventory, and its source for the more toxic and (MMHg coupled with the 30-year elapsed time, an updated assessment of EFPC creek sediments was warranted. Objectives of this study included the following:

- To provide a current assessment of total $\mathrm{Hg}$ and MMHg concentration in EFPC bed sediment at approximately $1 \mathrm{~km}$ spatial resolution and to compare these values to previous data sets

- To relate EFPC sediment $\mathrm{Hg}$ concentrations to published sediment quality guidelines

- To quantify $\mathrm{Hg}$ and $\mathrm{MMHg}$ concentrations in bed sediments as a function of grain size

- To assess the strength of $\mathrm{Hg}$ sediment association through the use of a sequential extraction procedure

- To examine the relationship among $\mathrm{Hg}$ and other sediment chemical and physical characteristics (e.g., carbon content, specific surface area)

- To provide a contemporary baseline against which system response to future remedial actions can be compared 
- To determine if some segments of the creek are more highly contaminated than others as a means to guide targeted actions addressing creek bed sediment

A comprehensive report on the results of this investigation has been prepared and is being reviewed internally by co-authors. The key points from that report are summarized below:

Medium grain sized sediment $(1 \mathrm{~mm}>x>250 \mu \mathrm{m})$ dominated the collected materials by mass. Sediments were angular to subrounded with intermediate to high sphericity. Sediments became lighter in appearance with decreasing grain size and with increasing distance downstream.

Total Hg in bulk sediments is relatively constant downstream of Y-12. A localized reach of higher concentration coincides with the HRD. A similar but less prominent feature farther downstream is suggestive of another localized area of creek bank or floodplain with elevated $\mathrm{Hg}$ levels. Overall, sediment $\mathrm{Hg}$ concentration has decreased substantially over the last 30 years but still remains far above consensus-based sediment quality guidelines.

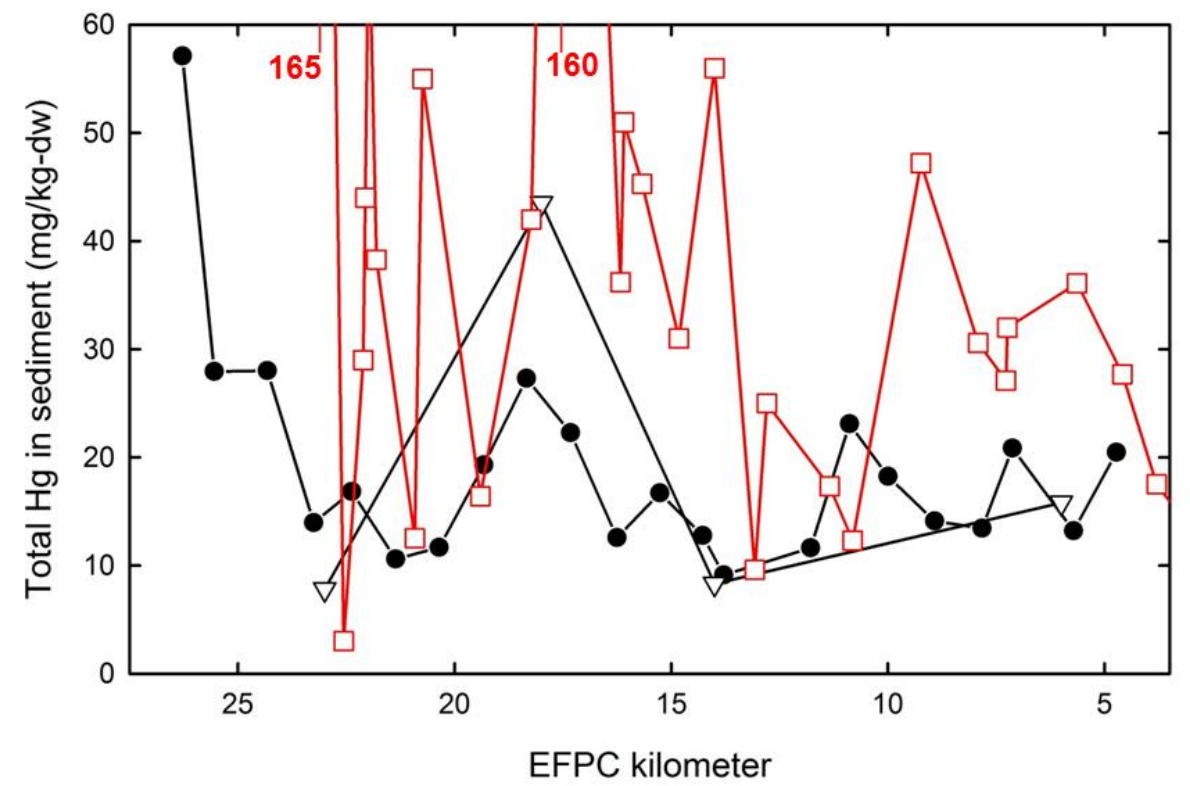

Fig. 3-14. Total Hg in bulk sediments along East Fork Poplar Creek. Circles represent the same data collected in this study. Red squares represent the data from the Tennessee Valley Authority report (1985a); the red numbers indicate $\mathrm{Hg}$ concentrations for two samples from the TVA report that are off-scale. Open inverted triangles represent the data from Southworth et al. (2010).

Sediment $\mathrm{Hg}$ concentration varied with particle size. In the upper reaches of the creek concentration as a function of grain size followed the expected pattern fine $(250 \mu \mathrm{m}>x>125 \mu \mathrm{m})>$ medium $>$ coarse $(2 \mathrm{~mm}>x>1 \mathrm{~mm})$. In the lower reaches of the creek, this pattern unexpectedly reversed (coarse $=$ medium $>$ fine) because of unknown causes.

More than $85 \%$ of sediment $\mathrm{Hg}$ was strongly bound regardless of grain size or location along the creek, being removed only with concentrated acid or a mixture of concentrated acids. In the fine sediments, the amount of $\mathrm{Hg}$ held less strongly and increased steadily downstream. The fraction of $\mathrm{Hg}$ removed by this reagent has been positively correlated with $\mathrm{Hg}$ methylation potential in aquatic sediments. This may 
indicate an increasing propensity for sediment-associated $\mathrm{Hg}$ to be methylated with increasing distance downstream from Y-12.

MMHg in bulk sediment generally decreased monotonically with distance downstream. A 3 kilometer reach from EFK 23 to EFK 20 had significantly higher MMHg concentrations reaching $10.4 \mu \mathrm{g} / \mathrm{kg}$. The region with elevated $\mathrm{MMHg}$ concentration occurred upstream of the region with elevated total $\mathrm{Hg}$ in sediments. The reasons for this localized enrichment are not understood. The trend of decreasing sediment $\mathrm{MMHg}$ concentration with downstream distance opposes the increase in water column dissolved $\mathrm{MMHg}$ over the same length of creek.

In general, MMHg concentration decreased monotonically downstream for all grain sizes similar to the bulk sediment. However, the localized enrichment in MMHg from EFK 23 to EFK 20 was due solely to higher concentration in the coarse-grained sediments in this reach. MMHg concentration in the mediumand fine-grained sediments did not change or decreased over the same reach. $\mathrm{MMHg}$ concentration in medium and fine sediments was significantly correlated with $\mathrm{Hg}$. The percent $\mathrm{MMHg}$ with distance varied by grain size: percent $\mathrm{MMHg}$ decreased downstream for the coarse sediments, did not change in the medium sediments, and increased in the fine sediments. The percent MMHg in fine sediments was significantly correlated with the fraction of $\mathrm{Hg}$ extracted by the $\mathrm{F} 3$ reagent.

The current inventory of $\mathrm{Hg}$ in EFPC bed sediments was estimated to be $334 \mathrm{~kg}$, which represents a $\sim 67 \%$ decrease relative to the initial investigations in 1984. Improved sediment quality likely resulted from improvements in quality of water being released from Y-12, transport of contaminated sediment out of EFPC, and inputs of cleaner sediment to the creek. Elevated Hg flux from Y-12 associated with storm drain cleanout actions in 2011-2012 was too small to detect reliably in EFPC sediments using the current methods. Monomethylmercury sediment inventory was estimated to be $44.1 \mathrm{~g}$, lower but roughly similar to past estimates. Comparing $\mathrm{MMHg}$ concentrations or inventories among different data sets is more challenging than doing so for total $\mathrm{Hg}$ because of a dependence on sampling data, among other factors.

Mercury and MMHg are correlated with sediment OC and nitrogen (N). The $\mathrm{Hg}$ to OC ratio increased downstream for coarse and medium sediments but decreased for fine sediments. The divergent patterns in $\mathrm{Hg}$ :OC by grain size coupled with similarity of $\mathrm{Hg}$ :OC between bank soils and fine sediments suggests contribution of fine particles from creek bank soils to the bed sediments. Organic carbon to nitrogen ratio suggests out-of-stream sources are the dominant source of organic carbon to the creek. The narrow range of sediment OC:N values throughout EFPC coupled with their similarity to bank soils suggest bank soil erosion and entrainment into the creek sediments.

This study provided new information on sediment $\mathrm{Hg}$ and $\mathrm{MeHg}$ content and chemistry. The results support the relevance and potential impacts of other active and planned investigations within the TD project (e.g., assessment and control of bank soil inputs, sorbents for MMHg removal, re-introduction of freshwater clams to EFPC) and identify gaps in current understanding that represent opportunities to understand controlling variables that may inform future technology development studies. 


\subsection{SHORT-TERM PATTERNS IN MERCURY AND MONOMETHYLMERCURY CONCENTRATION}

Intraday concentration patterns of filtered and particulate $\mathrm{Hg}$ and $\mathrm{MMHg}$ were assessed by sampling bihourly for a 30-hour period at three locations (EFKs 23.4, 16.2, and 5.4) on September 17-18, 2015. Objectives of the study were the following:

1. Determine if $\mathrm{Hg}$ and $\mathrm{MMHg}$ concentrations in EFPC respond rapidly within a diel cycle.

2. Quantify diel patterns in particulate and dissolved $\mathrm{Hg}$ or $\mathrm{MMHg}$ and associated water quality parameters.

3. Determine if diel patterns in $\mathrm{Hg}$ or $\mathrm{MMHg}$ are related to the daily photocycle or other short-term cycles.

4. Determine if diel variability in turbidity corresponds to particulate $\mathrm{Hg}$ or $\mathrm{MMHg}$ and if diel variability in DOM composition corresponds to DOC or dissolved $\mathrm{Hg}$ or $\mathrm{MMHg}$.

Results of this sampling campaign showed that particulate $\mathrm{Hg}$ and $\mathrm{MMHg}\left(\mathrm{Hg}_{\mathrm{P}}\right.$ and $\mathrm{MMHg}_{\mathrm{P}}$, respectively) increased substantially at night concurrent with increases in total suspended solids (Fig. 3-15). Ancillary short-term and long-term data indicate the activity of macrobiota (e.g., fish feeding behavior) is responsible for (re)suspending streambed particulates causing the overnight increase in $\mathrm{Hg}_{\mathrm{P}}$ and $\mathrm{MMHg}_{\mathrm{P}}$.

Dissolved MMHg (MMHg $\left.\mathrm{D}_{\mathrm{D}}\right)$ increased during the day at EFKs 16.2 and 5.4, reaching a mid- to lateafternoon maximum then declining overnight. At EFK 23.4, daytime $\mathrm{MMHg}_{\mathrm{D}}$ concentration was significantly greater than at nighttime concentration, but there was no similar diel pattern as seen at the two downstream sampling locations. The variability in $\mathrm{MMHg}_{\mathrm{D}}$ appears to be correlated with the daily photocycle and implies key controls on net methylation occur within the stream or on the streambed and include such factors as small scale temperature changes in the water column and photosynthetic activity of stream biofilms. Both of these factors are under active investigation in the Hg SFA project. Additionally, the diel variability in $\mathrm{MMHg}_{\mathrm{D}}$ demonstrates that the amount of this solute can respond rapidly to changing conditions, which is positive news with regard to projected time scales of water concentration response to targeted remedial actions.

Dissolved $\mathrm{Hg}\left(\mathrm{Hg}_{\mathrm{D}}\right)$ showed no diel pattern at EFKs 16.2 or 5.4. In contrast, at EFK $23.4, \mathrm{Hg}_{\mathrm{D}}$ varied by $96 \%$ over the 30 -hour sampling cycle with a clear pattern of increasing concentration during the day, peaking in mid-afternoon and decreasing overnight. The $\mathrm{Hg}_{\mathrm{D}}$ pattern at EFK 23.4 may have been because of scheduled operations within Y-12. Creek discharge at EFK 23.4 followed a pattern roughly similar to $\mathrm{Hg}_{\mathrm{D}}$ but varied by $11 \%$ over the period.

Finally, flux estimates from the diel sampling were compared to flux estimates made from point sampling described earlier. For $\mathrm{Hg}_{\mathrm{D}}$ and $\mathrm{MMHg}_{\mathrm{D}}$, the two flux estimates produced comparable results. There were larger differences between the two estimates for $\mathrm{Hg}_{\mathrm{P}}$ and $\mathrm{MMHg}_{\mathrm{P}}$ because of the strong diel patterns in the concentration of these two constituents. The greatest disagreement was for $\mathrm{MMHg}_{\mathrm{P}}$ at EFK 23.4 due, in part, to the generally very low concentration measured at that location. Because of the low diel variability in flow at all three stations, flow-proportional sampling would not change the flux estimates appreciably but likely would miss the diel patterns seen in this investigation and would introduce the potential for severe sampling artifacts (Riscassi, Brooks, and Miller 2014). 
(a)

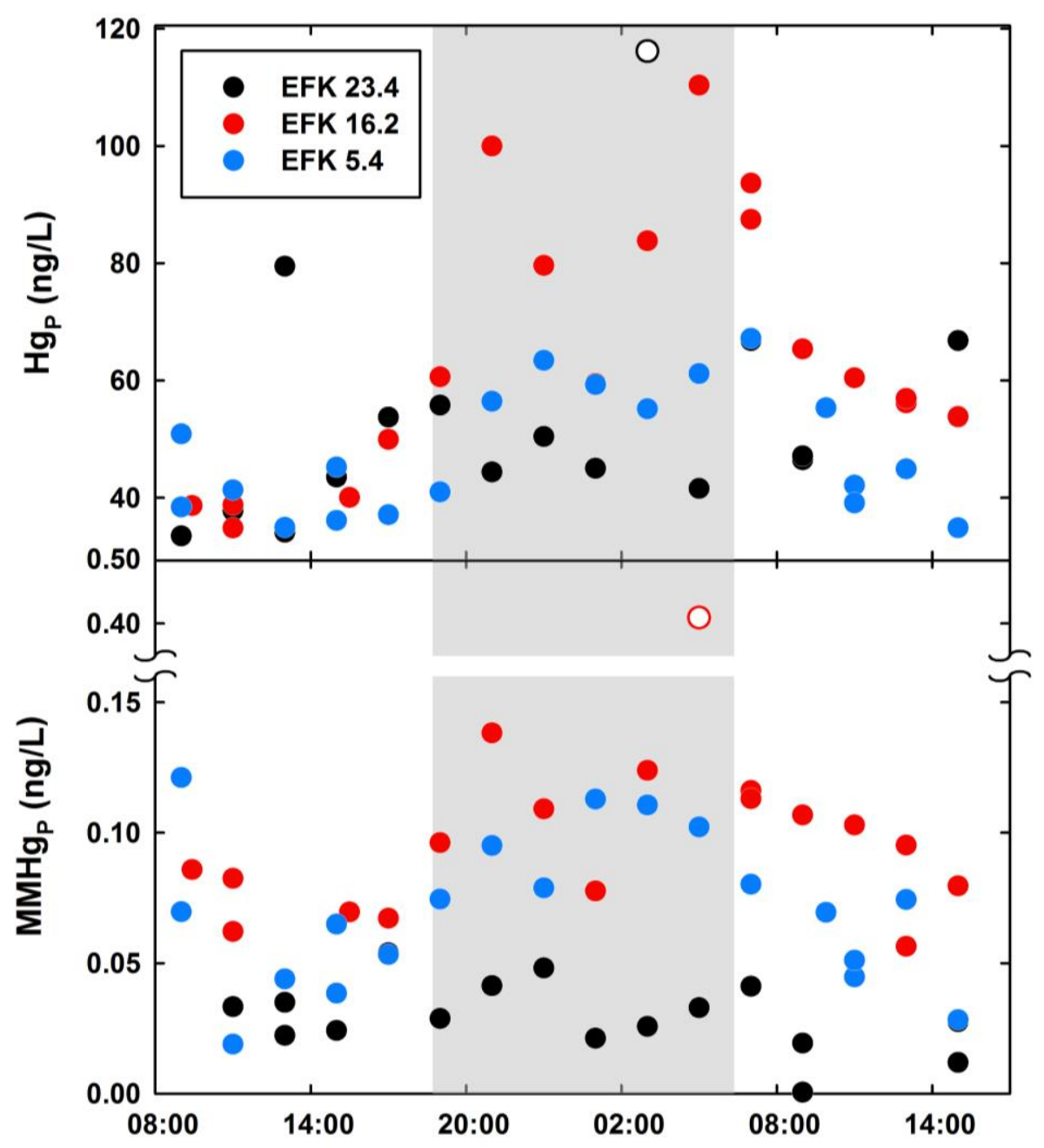

Fig. 3-15. Particulate Hg (a) and MMHg (b) over a 30-hour diel sampling campaign conducted September 17-18, 2015, at three locations in EFPC. Potential outliers are indicated by open symbols.

\subsection{TASK 2 FUTURE DIRECTIONS}

Within UEFPC, various alternatives (Peterson et al. 2015a) to current chemical treatment and discharge methods used in Y-12 industrial processes, in addition to controlled chemical additions and manipulations, are being considered to reduce mercury fluxes and forms that enhance migration of mercury to LEFPC. Because the impacts of some of the numerous chemicals present in UEFPC water on mercury forms and transport are still not that well understood, a systematic phased approach of alternatives identification and evaluation, combined with laboratory- and field-scale experiments, is needed to test and select viable alternatives for implementation. This is particularly true for the large assortment of chemicals currently used for the treatment of cooling tower blowdown water and other intermittent industrial discharges to the storm drains.

Most of the flow in the storm drain system contains residual chlorine because of the discharge of chlorinated process water (drinking water from the City of Oak Ridge water supply system) from various 
uses (primarily cooling water). Residual chlorine is aggressive in its oxidation and solubilization of mercury, and therefore, the mercury in water exiting Outfall 200 and other outfalls contains reactive dissolved $\mathrm{Hg}(\mathrm{II})$. Results show that eliminating or reducing chlorine concentrations in the storm drain system could significantly reduce the amount of soluble $\mathrm{Hg}$ (II) produced as chlorinated water comes in contact with liquid $\mathrm{Hg}(0)_{1}$ and dissolved $\mathrm{Hg}(0)_{\mathrm{d}}$ and also could reduce the total mercury discharged to LEFPC. Reduction of chlorine concentrations in the storm drain system could be accomplished by conducting dechlorination of the process water before or just downstream of discharge points to the storm drain, especially in areas with $\mathrm{Hg}(0)_{1}$ and dissolved $\mathrm{Hg}(0)_{\mathrm{d}}$, and also could reduce the total mercury discharged to LEFPC.

Future investigations or activities that may be conducted in FY2017 related to the chlorination/dechlorination studies including the following:

1. Complete preliminary laboratory and field testing, including chlorine- $\mathrm{Hg}(0)$ oxidation experiments.

2. Continue discussions with Y-12 Compliance staff to better understand the potential for mercury and chlorine interactions, and likely locations for within-storm drain tests.

3. Based on 1 and 2, conduct preliminary field tests in one of the $\mathrm{Y}-12$ storm drains to assess the effect of dechlorinating at the point of process water release to the storm drain, and the effect of using ascorbic acid as the dechlorinating agent.

Within LEFPC, in the near term, samples will continue to be analyzed that have been collected. Additionally, ongoing efforts will continue to quantify water quality and creek discharge at existing locations. These results are critical to support the evaluation of source areas and fluxes and their considerable spatio-temporal variability. Therefore, it is highly advisable to capture as much of that variability as possible. It will be difficult at best to distinguish real system response to remedial actions from natural variability without a better idea of that variability.

Preliminary sampling conducted in March 2015 indicated intraday variability in the concentration of some constituents along EFPC. Dissolved $\mathrm{MeHg}$ concentration was $16 \%$ and $20 \%$ greater in the afternoon relative to the morning at EFK 23.4 and EFK 5.4, respectively. These samples were collected at a time of year when the system was in transition from winter minima to large springtime increases in concentration, so the samples likely represent conservative estimates of diel variability. A second sampling is planned later this year to quantify intraday variability during a time of year when $\mathrm{MeHg}$ concentrations are near their peak. Better understanding of this variability has important implications for source attribution.

There have been noticeable changes in the flow regime of LEFPC relative to historical data from 1960 to 1988. Average and peak flows are higher today and are likely to result in the undesirable decrease in bank stability/increased bank erosion. Ongoing and planned future actions along EFPC suggest more changes are forthcoming. To document and quantify these changes, continued flow monitoring along LEFPC is warranted. Additionally, these flow measurements are integral to the flux estimates. Therefore, a plan has been developed to maintain flow and water quality monitoring activities because these provide the basis against which system response to future actions will be compared.

Flux estimates, enabled by flow and water quality data, demonstrate that diffuse legacy sources of $\mathrm{Hg}$ outside of Y-12 contribute additional Hg to LEFPC. Additional data from other projects suggest that hyporheic water may be a source of the additional $\mathrm{Hg}$. Movement of hyporheic water from the sediments to surface water may also be a source of MMHg because the fine-grained sediment deposits can harbor zones of MMHg production. Accordingly, and by working cooperatively with other projects, researchers 
will leverage resources to install and monitor instream piezometers at several locations to measure water composition in the sediment interstitial pore water and vertical head gradients across the hyporheic interface. These measurements will indicate the propensity for water movement and solute transport between surface water and subsurface areas that may be sources of additional $\mathrm{Hg}$ and active zones of mercury methylation. Understanding the potential contributions of hyporheic/subsurface water to the surface water $\mathrm{Hg}$ and $\mathrm{MMHg}$ budgets is necessary for the evaluation and design of potential sedimentcapping remedial strategies.

An important finding to date is that the apparent MMHg production rate in the lower reaches of LEFPC is greater than that in the upper reaches of LEFPC. This finding provides direct feedback and guidance to targeted actions in LEFPC that would address MMHg concentrations-applying those remedial approaches to the lower reaches of the creek are indicated.

During the previous year, researchers worked cooperatively with Task 1 in the evaluation of sorbents for $\mathrm{Hg}$ removal from solution and the impact of organic matter on sorbent behavior. In the coming year this collaboration will continue and be strengthened. Details of these plans are provided in the Task 1 section. Briefly, they include evaluation of sorbent effectiveness in the three-phase system (water, sediments, sorbents) and sorbent evaluation for $\mathrm{MMHg}$ removal. The ability of sorbents to remove $\mathrm{Hg}$ from solution is one criterion by which they can be ranked and evaluated. However, equally or perhaps more importantly, the sorbed $\mathrm{Hg}$ should not be available to be converted into MMHg. Each sorbent may differ in its ability to render $\mathrm{Hg}$ unavailable for methylation. Researchers will explicitly test the sorbents with respect to their ability to prevent $\mathrm{Hg}$ methylation as an important and necessary property of sorbent to quantify before any field deployment.

Design of column flow-through experiments will begin to assess treatment effectiveness under dynamic flow conditions with the goal of beginning preliminary tests at the beginning of the fiscal year. These experiments could be transitioned to the FRS when that facility is completed. Finally, approaches and initial design considerations for amendment delivery alternatives to soils and sediments will be conducted. These can be tested in the flow-through experiments. 


\section{TASK 3, ECOLOGICAL MANIPULATION}

\subsection{BIOTA}

\subsubsection{Approach to Ecological Investigations}

In contrast to virtually all other metals, mercury (especially in its organic form, $\mathrm{MeHg}$ ) biomagnifies, or becomes increasingly concentrated as it is transferred through aquatic food chains, leading to elevated concentrations of this toxin in fish. Because the primary exposure route for mercury in humans and other wildlife is through the consumption of contaminated fish, national guidelines for the protection of human and ecological health include a fish tissue concentration $(0.3 \mathrm{ppm} \mathrm{MeHg}$ in fish fillet), which is considered to be a more consistent indicator of exposure and risk than aqueous guidelines. Because of this explicit regulatory guideline, remediation actions and research efforts have long focused on understanding and mitigating mercury bioaccumulation in EFPC fish.

The Biological Monitoring and Abatement Program (BMAP) at ORNL has tracked the progress of remediation efforts in EFPC since 1985. Over the past 30 years, bioaccumulation monitoring in EFPC has shown that remediation efforts have succeeded in significantly reducing aqueous $\mathrm{HgT}$ concentrations, but these reductions in water concentrations have not affected fish HgT concentrations (Mathews et al. 2013; Southworth et al. 2013). This disconnect is likely because: (1) mercury bioaccumulation is largely driven by $\mathrm{MeHg}$ (not $\mathrm{HgT}$ ) concentrations, and (2) bioaccumulation of mercury occurs predominantly through food chain (not aqueous) exposure.

Like many other bioaccumulation monitoring programs at mercury-contaminated sites, BMAP has focused on comparing $\mathrm{HgT}$ concentrations in fish to ambient water $\mathrm{HgT}$ concentrations collected at strategic locations throughout the creek. Although the fish tissue guideline is a MeHg (not $\mathrm{HgT}$ ) concentration, $\mathrm{MeHg}$ is not routinely measured in water or fish; $\mathrm{MeHg}$ analysis can be prohibitive in terms of cost and time and previous studies have shown that $>90 \%$ of the $\mathrm{HgT}$ in fish fillets is $\mathrm{MeHg}$. Total mercury concentrations are therefore assumed to be a reasonable proxy for $\mathrm{MeHg}$ concentrations in fish fillet in EFPC. Further, previous studies have shown that the length of the food chain leading to fish affects mercury bioaccumulation, where longer food chains offer more opportunities for mercury to biomagnify, leading to higher concentrations in fish (Cabana and Rasmussen 1994). To date, mercury transfer throughout the EFPC food chain has not been characterized, though food web dynamics are likely critical to understanding and explaining observed mercury bioaccumulation patterns in EFPC fish.

The objective of Task 3 is to mitigate mercury transfer to fish by manipulating the aquatic food web in EFPC. This could be achieved, for example, through the addition or removal of key species that can significantly disrupt mercury transfer, or through the manipulation of physical factors (e.g., nutrients, light) that may favor mercury transformation. There is precedent on the Oak Ridge Reservation for the proposed mitigation strategy; ecological manipulations have been implemented previously to mitigate contaminant bioaccumulation, obtaining positive results at a fraction of the cost of traditional remediation methods; e.g., Peterson et al. (2015b).

As with any other remediation technology, a thorough baseline characterization is needed before manipulation to discern the effectiveness of the action. The current understanding of mercury bioaccumulation in EFPC is limited to a few target fish species; however, the BMAP fish and macroinvertebrate community data sets provide valuable information on the food web structures and, therefore, on the potential opportunities for ecological manipulations. By quantifying the mercury transfer within EFPC food webs using historical data and field surveys, the key linkages for mercury transfer and manipulation strategies to decrease that transfer can be identified. 
Once field characterization is completed, a detailed food web complete with mercury transfer essentially can provide a road map outlining key focus areas of efficient mercury transfer, which may be amenable to manipulation. From this road map, detailed pilot studies at the mesoscale (e.g., in streamside tanks) are needed to assess the effects of manipulations in the laboratory before field implementation. By conducting studies using DOE's TRL approach, technologies and approaches that have the most merit can move beyond laboratory and field testing to larger-scale pilot testing.

Presented here are the results of the food web characterization studies conducted in FY 2016, obtained through both the analysis of historical BMAP community structure data and targeted field sampling.

\subsubsection{Site and community characterization}

Field surveys were conducted in the fall of 2015 and the spring of 2016 to characterize mercury/methylmercury bioaccumulation and trophic transfer throughout the food chain at sites along EFPC. Invertebrates and fish were targeted in separate sampling events. Periphyton, sediment, water, and TSS samples were taken monthly. Historical BMAP data were used to inform the selection of species from each site along EFPC.

Water, sediment, periphyton, and TSS were collected from five sites along EFPC-EFKs 24.5, 23.4, 18.2, 13.8, and 6.3. Sediment samples were collected in glass jars at each site and transported to ORNL on ice. Water grab samples were taken at each site in acid-washed, high-density polyethylene containers and transported on ice to ORNL. Filtered $(0.2 \mu \mathrm{m})$ and unfiltered water samples were frozen until further analysis. At each site, two to four rocks were collected in plastic containers with stream water and transported to ORNL on ice. In the laboratory, each rock was scrubbed with a small brush to remove periphyton, and samples were frozen until further analysis. Five milliliter aliquots of homogenized samples were then preserved with $2 \%$ formalin solution to estimate cell densities. Cell densities were obtained by counting preserved samples using a Benchtop FlowCAM (Fluid Imaging Technologies Inc., Yarmouth, ME, USA) after diluting with water. Samples were pumped at $0.2 \mathrm{ml} \mathrm{min}-1$ through a FC100 FlowCAM chamber, with observation/data acquisition using a $\times 10$ magnification lens. Images were captured in auto-trigger mode, which was pre-programmed with specific size criteria for the model strains employed at 20 frames s-1. Images were classified manually in different groups of algae. Estimates of the periphyton-covered surface area of each rock were calculated by wrapping the scrubbed portion of each rock in aluminum foil, tracing the outline of the scrubbed portion, and cutting out the shape. All water, periphyton, and sediment samples were processed and analyzed for mercury and methylmercury. Samples of periphyton, sediment, and TSS (collected from water samples) were analyzed by continuous flow isotope ratio mass spectrometer at the University of California, Davis, to determine the relative abundance of stable isotopes of carbon and nitrogen $\left(\delta^{13} \mathrm{C}\right.$ and $\left.\delta^{15} \mathrm{~N}\right)$.

The goal of invertebrate and fish field surveys was to collect species that represent the food chain leading to redbreast or rock bass (target fish species for mercury monitoring) at each of the five EFPC sampling sites. Invertebrates were collected qualitatively in fall 2015 and spring 2016 with kick nets, sweep nets, and removal from rocks with stainless steel forceps. Samples were brought back to the laboratory on ice, were rinsed and sorted into composite samples by the lowest distinguishable taxon (family or genus for most), and then were placed into new $50 \mathrm{ml}$ Falcon tubes until further processing could be completed. For taxa where there was enough biomass, samples were subdivided into replicate samples or samples of different size classes. Samples were dried to a constant weight in a freeze dryer and homogenized before analysis for total $\mathrm{Hg}$ by thermal decomposition and cold vapor atomic absorption using a Direct Mercury Analyzer (DMA-80, Milestone). Samples were analyzed for $\mathrm{MeHg}$ by distillation, aqueous ethylation, purge and trap, and cold vapor atomic fluorescence spectrometry (CEBAM, Bothell, WA). Stable isotope ratios $\left(\delta^{13} \mathrm{C}\right.$ and $\left.\delta^{15} \mathrm{~N}\right)$ in invertebrates and fish were measured at the University of California, Davis, by continuous flow isotope ratio mass spectrometer. 
Fish were collected in fall 2015 and spring 2016 at the five EFPC sampling sites in conjunction with BMAP fish community sampling. Sampling focused on collecting the most abundant/ecologically important species at each site. Fish were obtained by electroshocking and brought to the laboratory on ice. In the laboratory, efforts were made to obtain replicates of species groups with sufficient body mass as well as to split fish of the same species into different size/age classes. Lengths and weights of each individual fish were recorded. Fillets of larger fish (e.g., rock bass, redbreast) and whole bodies of smaller fish (e.g., shiners, stonerollers) were used for analysis. Tissue was freeze-dried and analyzed for mercury, methylmercury, and stable isotopes using methods described above.

\subsubsection{Results of Ecological Investigations}

\subsubsection{Periphyton surveys}

Consistent with previous studies, aqueous total mercury concentrations were found to be highest at EFK 24.5, and concentrations decreased with increasing distance downstream (Fig. 4-1A). There was a significant amount of temporal variability at all sites, with the highest concentrations seen in spring months. The mercury concentrations seen in periphyton collected concurrently were also variable and did not follow the same patterns as water samples (Fig. 4-1B). The highest concentrations in periphyton were seen at EFK 18.2 in the fall and winter of 2015. Concentrations in periphyton collected at EFK 24.5 were also elevated with respect to other sites and follow similar temporal patterns to water concentrations at this site. Because periphyton is a complex mix of different algal and bacterial cells, which are increasingly recognized to play an important role in mercury methylation, it is important to understand how the periphyton community changes over time and between the different sites. Figure 4-2 shows the relative abundance of different algal taxa at each of the five sampling sites in EFPC over time. The proportion of blue green algae is highest at the uppermost site (EFK 24.5) and decreases with increasing distance downstream. The proportion of green algae follows opposite patterns, being lowest in upper EFPC and increasing with increasing downstream distance. Further, there is no consistent seasonal pattern to the relative abundance of the different algal species at any of the sites.

Whereas these are relative measurements, researchers are working on quantitative measurements to determine how the biomass of the periphyton community changes over time. In addition, because it is virtually impossible to sample periphyton without sampling associated detrital and sediment particles, it is important to quantify the percent of the sample mass that is indeed algal material. Samples have been collected to determine the percent organic material (by loss on ignition). These samples are currently being processed for analysis, and results are pending. This information may help explain the temporal variation in mercury concentrations seen in periphyton (Fig. 4-1B). For example, storm events can deposit large quantities of inorganic sediment particles within the periphyton, which can affect mercury concentrations; mercury concentrations in periphyton will be related to percent organic matter in the sample once data are received. Methylmercury concentrations in periphyton are pending. 
A.

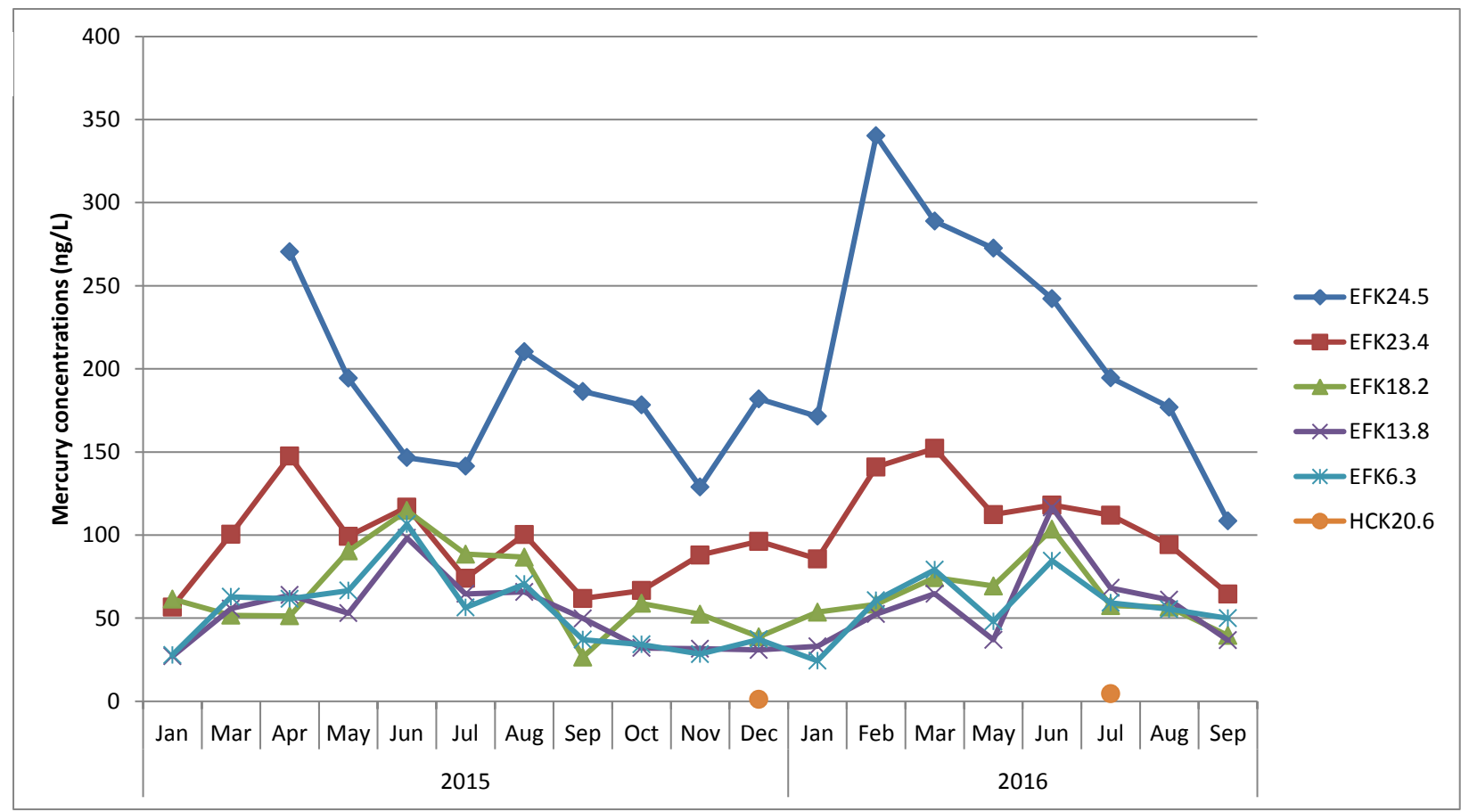

B.

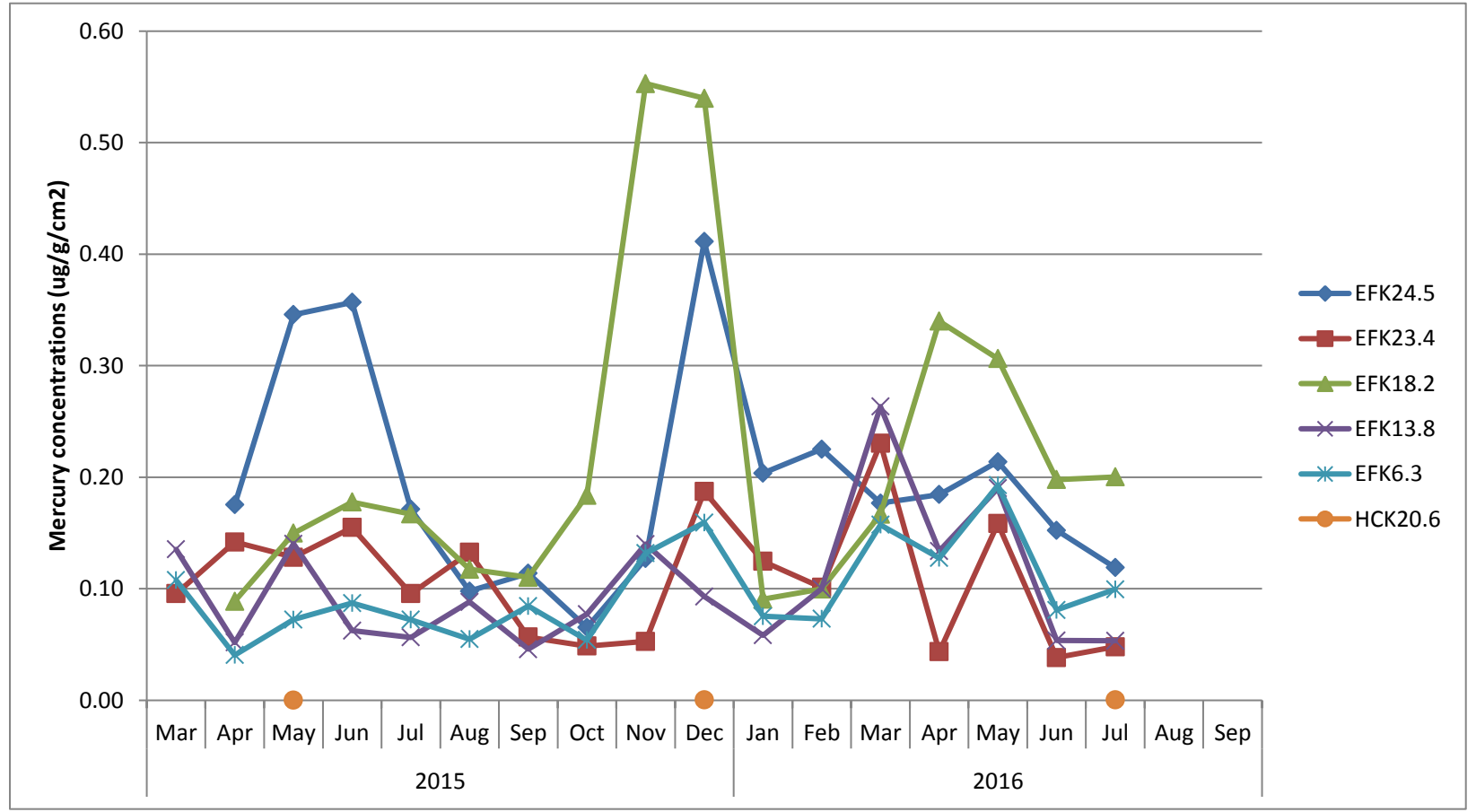

Fig. 4-1. Total mercury concentrations in unfiltered water (A) and periphyton (B) collected monthly from five sites in EFPC and the Hinds Creek reference site (March 2015-July 2016). Periphyton concentrations are reported per $\mathrm{cm}^{2}$ of rock scraped. 


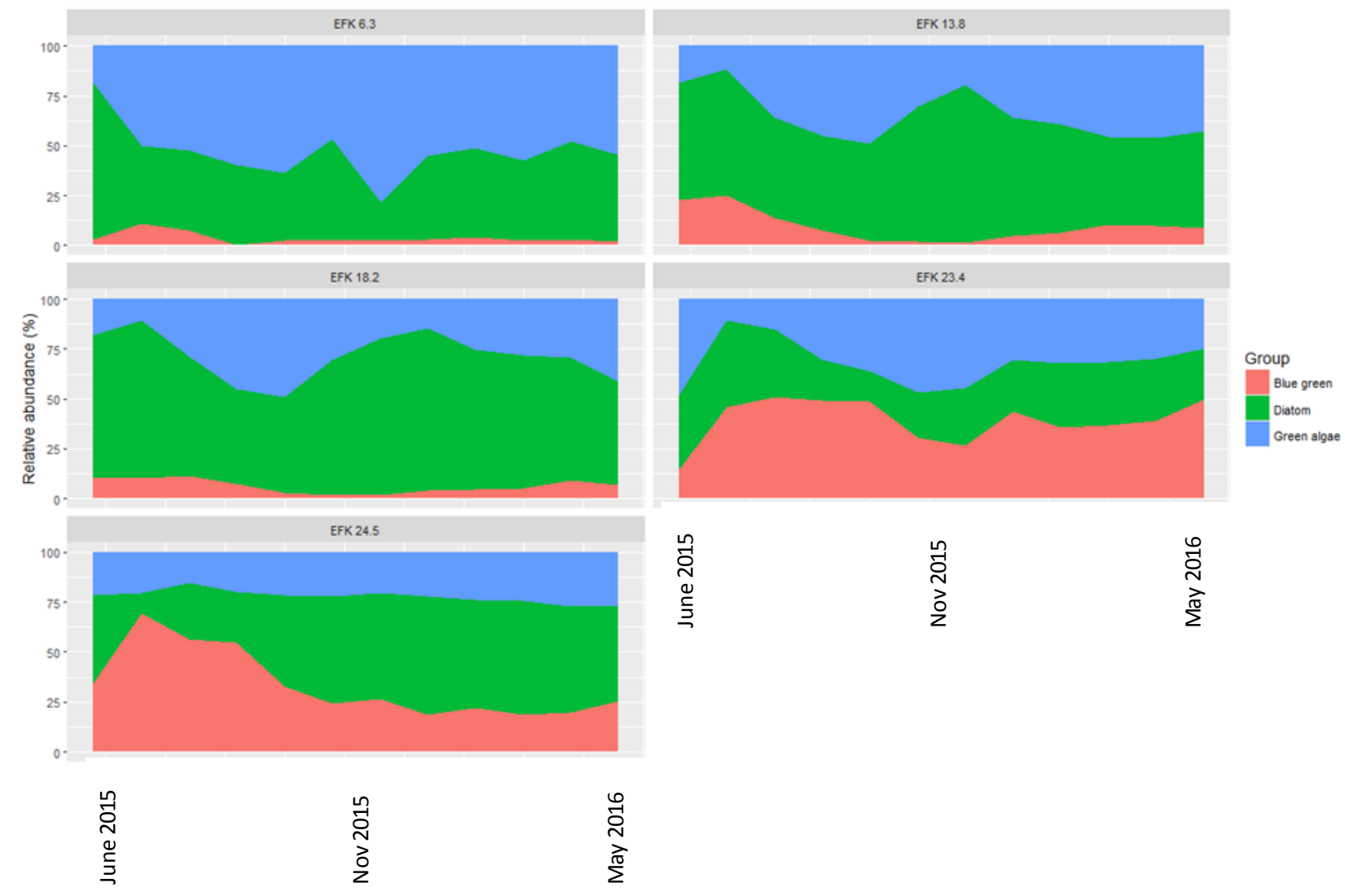

Fig. 4-2. Relative abundance of different algal groups collected monthly at five EFPC sampling sites, June 2015-May 2016.

\subsubsection{Historical community analysis}

To explain why fish tissue mercury concentrations have not decreased in response to decreases in aqueous mercury concentrations in EFPC (Fig. 4-3), researchers analyzed historic benthic macroinvertebrate community data, courtesy of the BMAP program. Both the invertebrate and fish community structure are relevant to understanding fish tissue mercury concentrations of mercury because mercury is primarily accumulated from dietary exposure. Analysis of the food web structure began with the invertebrates because of the diversity of organisms with different feeding habits, their high biomass and secondary production, their importance as a food source to fish, and the general lack of information on mercury bioaccumulation in invertebrates in EFPC.

Long-term changes in invertebrate community structure were examined at two sites in EFPC, EFKs 23.4 and 13.8, because these two sites have the most complete record of community analysis. Studies focused on three periods representative of different conditions with respect to $\mathrm{Hg}$ exposure in EFPC to investigate invertebrate community structure in more detail. Periods before, during, and after major remediation actions that correspond to high, intermediate, and (relatively) low aqueous $\mathrm{Hg}$ concentrations within the creek were selected. Because of inherent interannual variability, invertebrate counts were averaged over 3 consecutive years for each of the three periods as follows: (1) 1988-1990, (2) 1999-2001, and (3) 2012-2014. Because of the importance of food chain exposure to $\mathrm{Hg}$, analysis of the invertebrate community focused on functional feeding groups. 


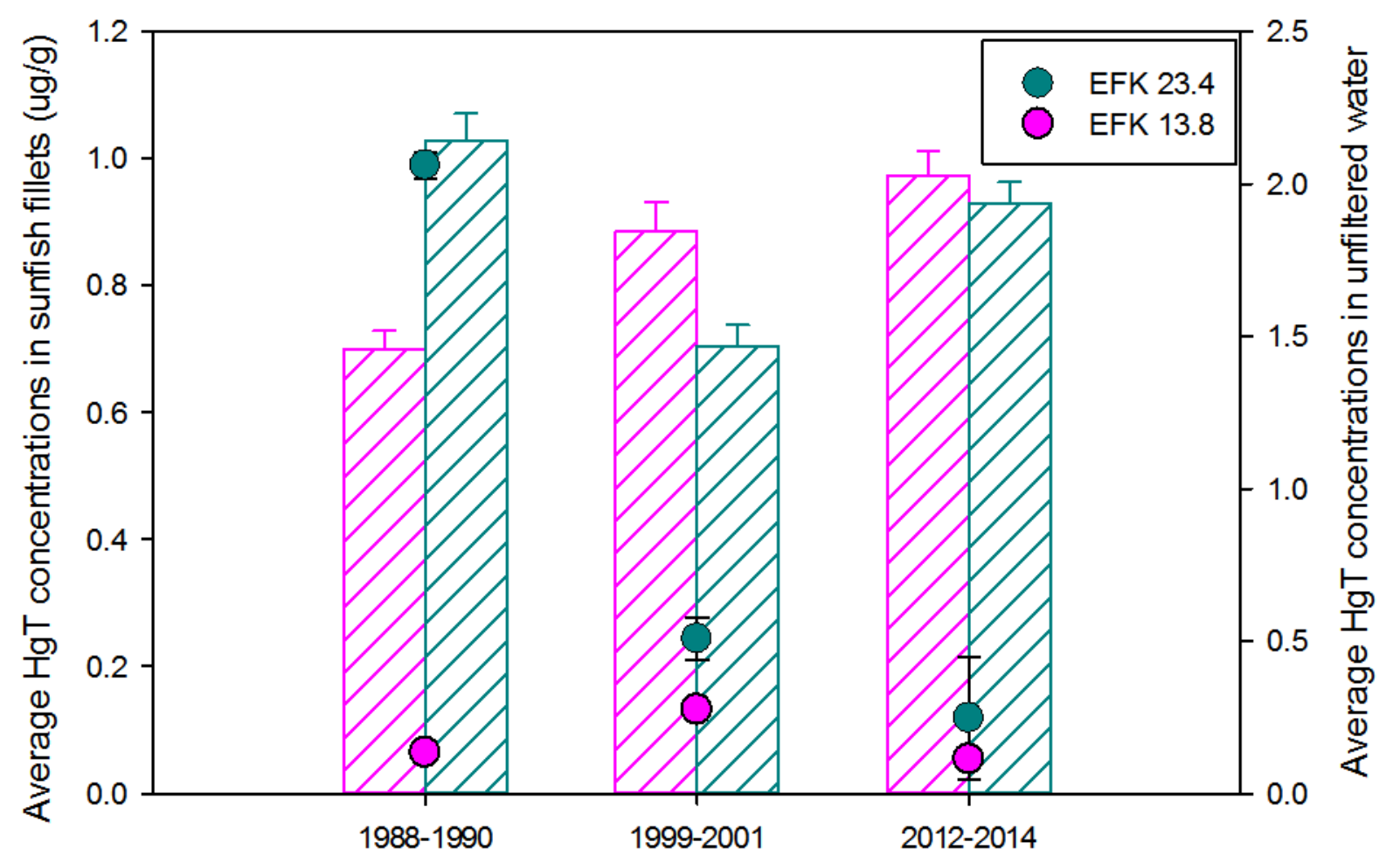

Fig. 4-3. Mean (+/- 1 sd) total mercury concentrations in fish (bars) and water (circles) at two sites in East Fork Poplar Creek over time. Concentrations were averaged over three 3-year periods that correspond to various remediation actions, as described in this report.

Benthic macroinvertebrate species richness, or the total number of species or taxa present at a given site, is a common metric used to evaluate water quality (i.e., higher species richness indicates higher water quality) but can also be an indication of the complexity of the food web at a given site. Across all periods considered in this study, species richness was higher at EFK 13.8 than it was at EFK 23.4 (Fig. 4-4A). Although the two sampling sites were chosen to be comparable in terms of riffle characteristics, the differences in species richness are likely due to differences in both water quality and habitat. The site further upstream, EFK 23.4, is located at the boundary of DOE's Y-12 facility and is closer than EFK 13.8 to the source of $\mathrm{Hg}$ contamination. The habitat at the EFK 23.4 site is typical of an industrial or urban setting: straightened concrete channels, riprap stream banks, minimal riparian zone. Approximately 10 miles further downstream at EFK 13.8, the habitat is more typical of a stream in an undeveloped secondary forest, with natural riparian zones and stream channels and larger, deeper pools. Total genera richness was relatively high (in the mid to upper 20s) at EFK 13.8 and did not change significantly over the periods in this study (Fig. 4-4A; $p>0.05$ ). In contrast, the number of genera present at EFK 23.4 has significantly increased from 11 to 24 genera from the 1980s to the 2010s $(p<0.05)$, such that at the most recent period, the genera richness at EFK 23.4 was not significantly different from that at EFK 13.8 (Fig. 4-4A; two-way analysis of variance test [ANOVA] $p>0.05$ ). The same overall trends were observed for Ephemeroptera, Plecoptera, and Trichoptera (EPT) taxa richness, with significant increases at EFK 23.4 (from 1.3 genera in 1988-1990 to 7.0 genera in 2012-2014, $p<0.05$ ), but relatively high numbers at EFK 13.8 which are typical of unimpacted reference streams in this region of East Tennessee (Fig. 4-4B). 
A.

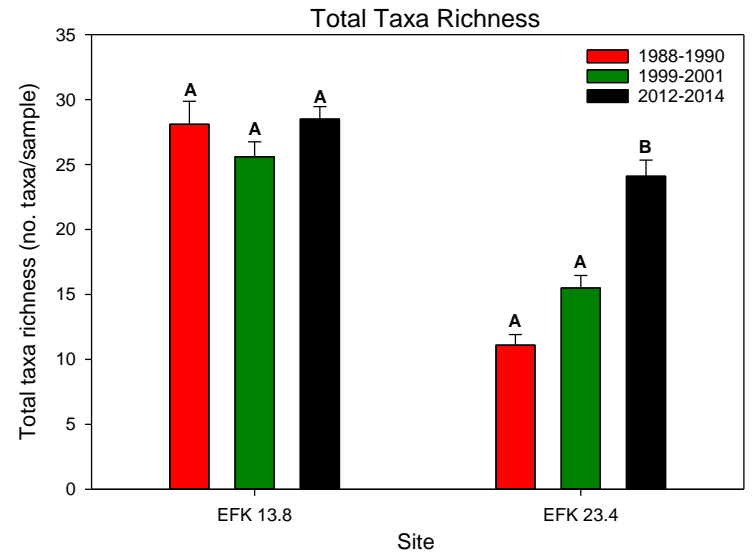

B.

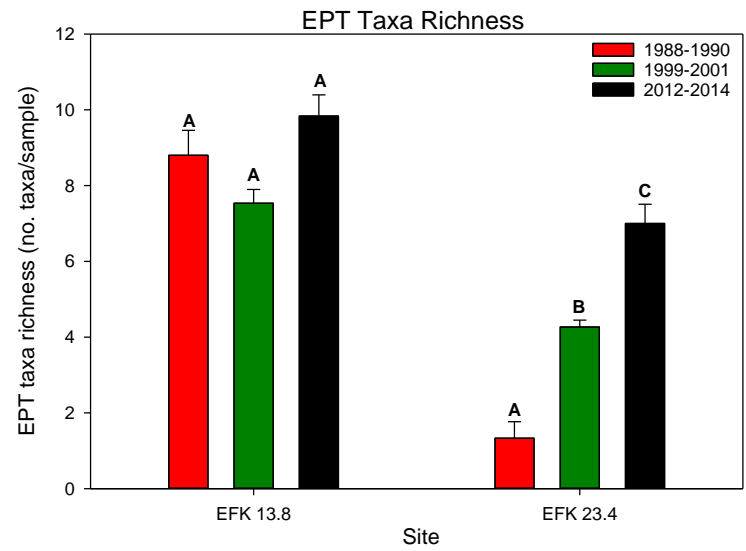

C.

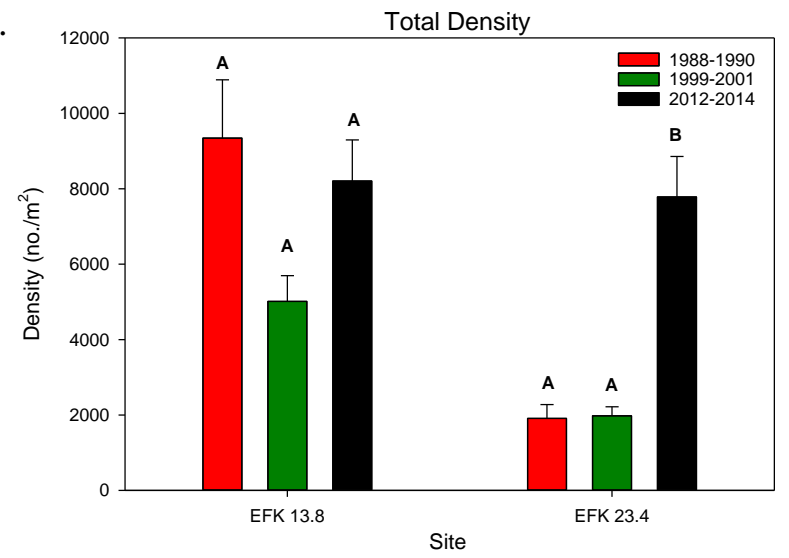

D.

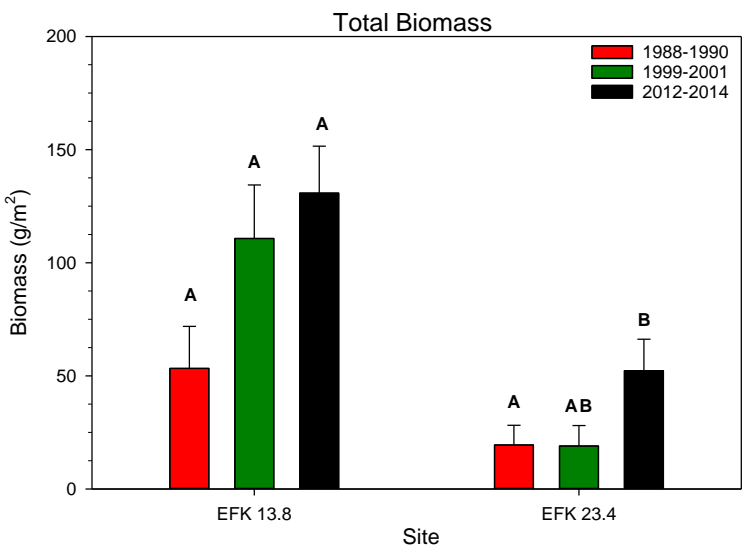

Fig. 4-4. (A). Total taxa richness (number of taxa/sample), (B) EPT taxa richness (number of taxa/sample), (C) density $\left(\right.$ number $\left./ \mathrm{m}^{2}\right)$, and (D) biomass $\left(\mathrm{grams} / \mathrm{m}^{2}\right)$ for benthic macroinvertebrate samples collected at EFKs 13.8 and 23.4 for three different periods considered. Values are means \pm 1 SE. Results of Tukey-Kramer test are for period differences within site and are shown by letters above bars; bars with different letters indicate a significant difference between those periods ( $p<0.05$; two-way ANOVA).

The increases in overall and sensitive species diversity at EFK 23.4 are consistent with improvements in water quality at that site over the period under question. For example, significant decreases in conductivity, sodium, calcium, and nitrate concentrations were observed in EFPC from 1988 to 2014 because of various remediation actions within the Y-12 facility (e.g., elimination of untreated discharges, flow management, dechlorination of cooling water discharges, etc.), and these changes were more significant at the upstream location EFK 23.4, closer to where remediation actions occurred. Concurrent with these other water quality improvements, aqueous total mercury concentrations also decreased from 1988 to 2014, and similar to spatial patterns for other water quality improvements, the decreases in aqueous $\mathrm{Hg}$ were also more marked at the upstream EFK 23.4 location (Fig. 4-3). However, despite significant differences in aqueous total $\mathrm{Hg}$ concentrations between the two sites and drastic decreases in aqueous total $\mathrm{Hg}$ concentrations throughout the creek over time, fish tissue concentrations have not decreased commensurately (Fig. 4-3) and remain above EPA guidelines, confounding remediation strategies in this creek.

To investigate the role dietary inputs may have played in explaining the observed $\mathrm{Hg}$ bioaccumulation patterns seen in fish, researchers examined the invertebrate community structure for changes in population density (Fig. 4-4 C), biomass (Fig. 4-4 D), most abundant species (Table 4-1), and abundance of species by feeding guild (Fig. 4-5) at the two sites during the same three periods. Similar to patterns 
seen for taxa richness, the total density of invertebrates (number of individual animals collected $/ \mathrm{m}^{2}$ ) and the biomass of invertebrates collected $\left(\right.$ grams $/ \mathrm{m}^{2}$ ) were generally higher at EFK 13.8 than at EFK 23.4.

Whereas mean invertebrate densities were variable at EFK 13.8 over the three periods considered, ranging between 5,015 and 9,344 individuals $/ \mathrm{m}^{2}$, the differences between periods were not statistically significant (Fig. 4-4C; $p>0.05$ ). The densities of invertebrates collected at EFK 23.4, however, increased significantly in the most recent period (mean 7,783 individuals $/ \mathrm{m}^{2}$ ) such that densities at this time were not significantly different from those seen at EFK 13.8. Total biomass has been variable but has generally been increasing over time at both sites; whereas the increase in biomass was not statistically significant at EFK 13.8, the density in the 2012-2014 period was significantly higher than the density in the 1988-1990 period $(p<0.05)$.

A.
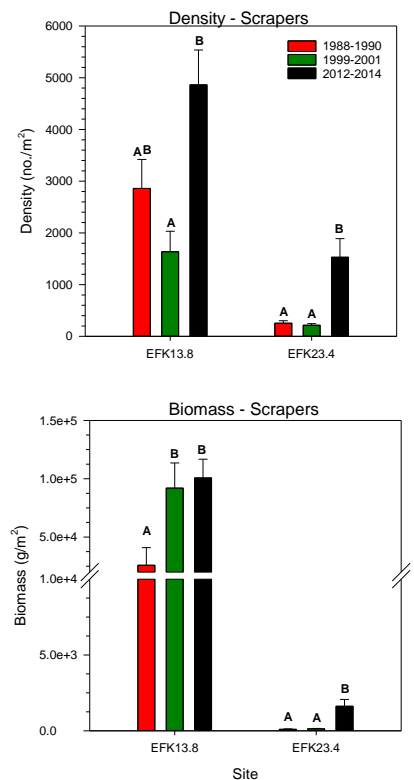

B.
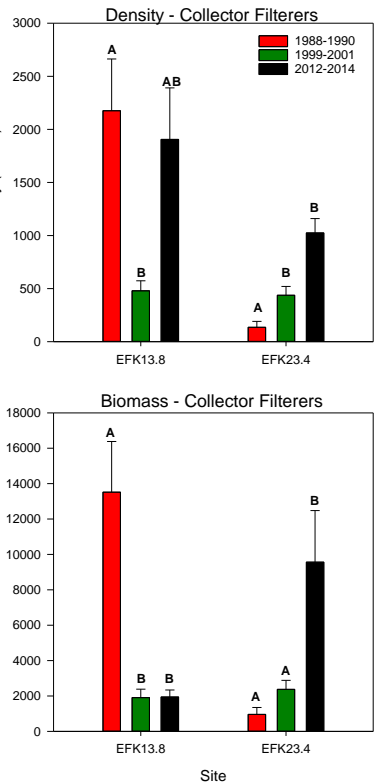

C.
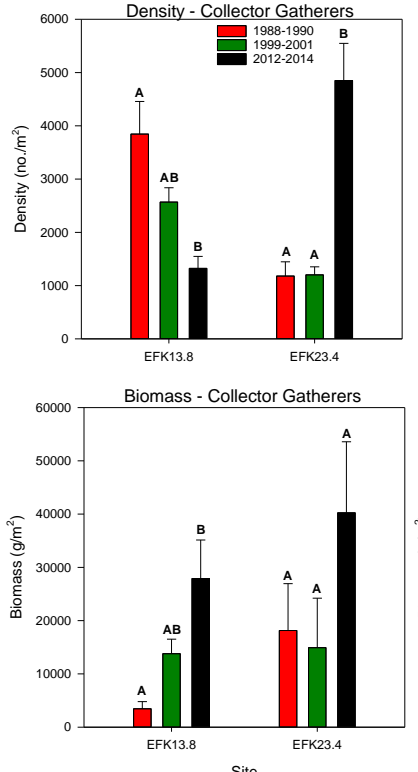

D.
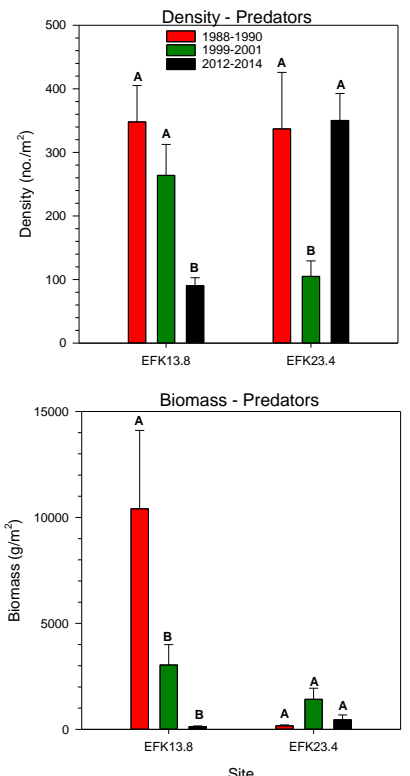

Fig. 4-5. Density and biomass for benthic macroinvertebrate samples collected at EFKs 13.8 and 23.4 for three different periods considered in this study for different functional feeding groups: (A) scrapers, (B)

collector-filterers, (C) collector-gatherers, and (D) predators. Values are means + 1 SE. Results of Tukey-Kramer test are for period differences within site and are shown by letters above bars; bars with different letters indicate a significant difference between those periods ( $p<0.05$; two-way ANOVA). 
Table 4-1. Top four functional feeding groups represented at sites along East Fork Poplar Creek during three periods of 3 years each

Species within each feeding guild are listed in order of abundance at each site. Common and scientific names are given.

\begin{tabular}{|c|c|c|c|c|c|c|}
\hline \multirow{2}{*}{ Feeding guild } & \multicolumn{3}{|c|}{ EFK 13.8 } & \multicolumn{3}{|c|}{ EFK 23.4} \\
\hline & 1988-1990 & 1999-2001 & 2012-2014 & $1988-1990^{a}$ & 1999-2001 & 2012-2014 \\
\hline $\begin{array}{l}\text { Scrapers } \\
\text { Graze on } \\
\text { periphyton/biofilm } \\
\text { found on hard } \\
\text { substrate (rocks) }\end{array}$ & $\begin{array}{l}\text { 1. Mayflies } \\
\text { (Heptageniidae) } \\
\text { 2. Beetles (Elmidae) } \\
\text { 3. Snails } \\
\text { (Ancylidae, } \\
\text { Pleuroceridae) }\end{array}$ & $\begin{array}{l}\text { 1. Mayflies } \\
\text { (Heptageniidae) } \\
\text { 2. Snails } \\
\text { (Ancylidae, } \\
\text { Pleuroceridae) } \\
\text { 3. Beetles (Elmidae) }\end{array}$ & $\begin{array}{l}\text { 1. Mayflies } \\
\text { (Heptageniidae) } \\
\text { 2. Beetles (Elmidae, } \\
\text { Psephenidae) } \\
\text { 3. Snails } \\
\text { (Ancylidae, } \\
\text { Pleuroceridae) }\end{array}$ & $\begin{array}{l}\text { 1. Snails } \\
\text { (Ancylidae) } \\
\text { 2. Beetles (Elmidae) }\end{array}$ & $\begin{array}{l}\text { 1. Beetles (Elmidae) } \\
\text { 2. Caddisflies } \\
\text { (Hydroptilidae) } \\
\text { 3. Snails } \\
\text { (Ancylidae) }\end{array}$ & $\begin{array}{l}\text { 1. Beetles } \\
\text { (Psephenidae, } \\
\text { Elmidae) } \\
\text { 2. Caddisflies } \\
\text { (Hydroptilidae) } \\
\text { 3. Mayflies } \\
\text { (Heptageniidae) } \\
\end{array}$ \\
\hline $\begin{array}{l}\text { Collector-filterers } \\
\text { Filter fine } \\
\text { particulate organic } \\
\text { matter from the } \\
\text { water column }\end{array}$ & $\begin{array}{l}\text { 1. Caddisflies } \\
\text { (Hydropsychidae) } \\
\text { 2. True flies } \\
\text { (Tanytarsini, } \\
\text { Simuliidae) } \\
\text { 3. Clams (Asiatic) }\end{array}$ & $\begin{array}{l}\text { 1. Caddisflies } \\
\text { (Hydropsychidae) } \\
\text { 2. True flies } \\
\text { (Tanytarsini, } \\
\text { Simuliidae) } \\
\text { 3. Clams (Asiatic) }\end{array}$ & $\begin{array}{l}\text { 1. Caddisflies } \\
\text { (Hydropsychidae) } \\
\text { 2. Mayflies } \\
\text { (Isonychia) } \\
\text { 3. True flies } \\
\text { (Tanytarsini, } \\
\text { Simuliidae) }\end{array}$ & $\begin{array}{l}\text { 1. Clams (Asiatic } \\
\text { and fingernail) } \\
\text { 2. Caddisflies } \\
\text { (Hydropsychidae) } \\
\text { 3. True flies } \\
\text { (Simuliidae) }\end{array}$ & $\begin{array}{l}\text { 1. Caddisflies } \\
\text { (Hydropsychidae) } \\
\text { 2. True flies } \\
\text { (Tanytarsini) } \\
\text { 3. Clams (Asiatic) }\end{array}$ & $\begin{array}{l}\text { 1. Caddisflies } \\
\text { (Hydropsychidae) } \\
\text { 2. True flies } \\
\text { (Tanytarsini, } \\
\text { Simuliidae) } \\
\text { 3. Clams (Asiatic) }\end{array}$ \\
\hline $\begin{array}{l}\text { Collector- } \\
\text { gatherers } \\
\text { Gather fine } \\
\text { particulate organic } \\
\text { matter from } \\
\text { sediment }\end{array}$ & $\begin{array}{l}\text { 1. Mayflies } \\
\text { (Baetidae) } \\
\text { 2. True flies } \\
\text { (Orthocladiinae) } \\
\text { 3. Nematodes } \\
\text { (Nematoda) }\end{array}$ & $\begin{array}{l}\text { 1. Mayflies } \\
\text { (Baetidae) } \\
\text { 2. True flies } \\
\text { (Orthocladiinae) } \\
\text { 3. Worms } \\
\text { (Oligochaeta) }\end{array}$ & $\begin{array}{l}\text { 1. Worms } \\
\text { (Oligochaeta) } \\
\text { 2. Mayflies } \\
\text { (Baetidae, } \\
\text { Ephemerellidae) } \\
\text { 3. Caddisflies } \\
\text { (Psychomyia) }\end{array}$ & $\begin{array}{l}\text { 1. True flies } \\
\text { (Orthocladiinae) } \\
\text { 2. Worms } \\
\text { (Oligochaeta) } \\
\text { 3. Flat worms } \\
\text { (Nematoda) }\end{array}$ & $\begin{array}{l}\text { 1. True flies } \\
\text { (Orthocladiinae) } \\
\text { 2. Flat worms } \\
\text { (Nematoda) } \\
\text { 3. Worms } \\
\text { (Oligochaeta) }\end{array}$ & $\begin{array}{l}\text { 1. True flies } \\
\text { (Orthocladiinae) } \\
\text { 2. Flat worms } \\
\text { (Nematoda) } \\
\text { 3. Mayflies } \\
\text { (Baetidae) }\end{array}$ \\
\hline $\begin{array}{l}\text { Predators } \\
\text { Consume other } \\
\text { animals }\end{array}$ & $\begin{array}{l}\text { 1. Ribbon worms } \\
\text { (Nemertea) } \\
\text { 2. True flies } \\
\text { (Tanypodinae, } \\
\text { Empididae) }\end{array}$ & $\begin{array}{l}\text { 1. Water mites } \\
\text { (Hydrachnidia) } \\
\text { 2. True flies } \\
\text { (Tanypodinae, } \\
\text { Empididae) } \\
\text { 3. Ribbon worms } \\
\text { (Nemertea) }\end{array}$ & $\begin{array}{l}\text { 1. Ribbon worms } \\
\text { (Nemertea) } \\
\text { 2. True flies } \\
\text { (Tanypodinae, } \\
\text { Empididae) } \\
\text { 3. Dragonflies, } \\
\text { damselflies } \\
\text { (Odonata) }\end{array}$ & $\begin{array}{l}\text { 1. True flies } \\
\text { (Tanypodinae, } \\
\text { Empididae) } \\
\text { 2. Ribbon worms } \\
\text { (Nemertea) }\end{array}$ & $\begin{array}{l}\text { 1. True flies } \\
\text { (Empididae) } \\
\text { 2. Ribbon worms } \\
\text { (Nemertea) } \\
\text { 3. Water mites } \\
\text { (Hydrachnidia) }\end{array}$ & $\begin{array}{l}\text { 1. Ribbon worms } \\
\text { (Nemertea) } \\
\text { 2. True flies } \\
\text { (Tanypodinae, } \\
\text { Empididae) } \\
\text { 3. Water mites } \\
\text { (Hydrachnidia) }\end{array}$ \\
\hline
\end{tabular}

${ }^{a}$ Collector-filterers did not exceed $1.0 \%$ of the total density at EFK 23.4 until 1990. 
The relative importance of species within different functional feeding groups differed between the two study sites and has significantly changed over time (Fig. 4-5). The major functional feeding groups encountered among invertebrates in EFPC included: collector-filterers, collector-gatherers, scrapers, and predators (Table 4-1). Scrapers, which graze on periphyton and biofilm found on hard substrates, were significantly more abundant at EFK 13.8 than at EFK 23.4, in terms of both density and biomass $(p<0.05 ;$ Fig 4-5A,B). Numbers and biomass of scrapers increased significantly at both sites over time $(p<0.05)$ such that scrapers were the most abundant invertebrates at EFK 13.8. At EFK 23.4, these changes can be seen in the most abundant species present: whereas snails and beetles were the most abundant scraper in the 1988-1990 period, the more sensitive hydroptilid caddisflies (Order Trichoptera) and heptageniid mayflies (Order Ephemeroptera) appeared among the most abundant scrapers at this site in the more recent periods, likely because of improved water quality at this site over time (Table 4-1). The most abundant scrapers at EFK 13.8 (heptageniid mayflies, elmid beetles, and ancylid and pleurocerid snails) did not change over time (Table 4-1). The higher biomass of scrapers at EFK 13.8 is due to the large size of pleurocerid snails.

Collector-filterers, which filter fine particulate matter from the water column, have changed over time at both sites in terms of density, biomass, and most abundant taxa present (Fig. 4-5B). At EFK 23.4, both the density and biomass of collector-filterers significantly increased between the 1988-1990 period and the two more recent periods. This change is reflected in the most abundant taxa in this feeding group at EFK 23.4; in the 1988-1990 period, Asiatic and fingernail clams were the most abundant taxa, followed by hydropsychid caddisflies and simuliid fly larvae. The two more recent periods were not significantly different from each other in terms of invertebrate biomass or density and were identical in terms of most abundant taxa present, with hydropsychid caddisflies being the most abundant, followed by tanytarsini larvae and Asiatic clams. The increase in biomass of collector-filterers over time at EFK 23.4 is notable, given the significant difference in mass between individual clams and caddisfly larvae. In contrast, the biomass of collector-filterers at EFK 13.8 has significantly decreased over time, though the density across periods has been variable. The significant decrease in biomass, despite no significant differences in the density over time, is likely due to the species present at the different periods. Whereas Asiatic clams were among the most abundant collector-filterer taxa at EFK 13.8 in the two earlier periods, they were replaced by the lower mass baetid and ephemerellid mayflies in the 2012-2014 period.

The abundance and biomass of collector-gatherers, which gather fine particulate organic matter from the sediment, showed opposite patterns over time at EFK 13.8. Whereas the density of this functional feeding group significantly decreased over time, the biomass increased significantly over time at this site. The most abundant collector-gatherer taxa at this site could help explain these patterns (Table 4-1). In response to improvements in water quality at this site over time, the most abundant taxa included species that are more sensitive to water quality such as oligochaetes, ephemerellid mayflies, and psychomyid caddisflies; these organisms are also more massive than the baetid mayflies, nematodes, and chironomids seen at this site in the 1980s (Table 4-1). At EFK 23.4, the abundance of collector-gatherers was significantly higher during the 2012-2014 period than in previous periods, though the biomass did not significantly change over time at this site. The most abundant taxa in this functional feeding group also changed in the 2012-2014 period to include baetid mayflies, which are more sensitive to water quality than the taxa seen in previous periods at this site.

Predators, which consume other animals, were among the least abundant invertebrates across all periods at both sites. The abundance and density of predators decreased significantly over time at EFK 13.8, whereas the density of predators was variable at EFK 23.4, and the biomass of predators did not change significantly over time at this site (Fig. 4-5D). The most abundant taxa present in the 1988-1990 period were identical between the two sites and changed over time to include odonates at EFK 13.8 in the 20122014 period. The most abundant taxa in the most recent period at EFK 23.4 are comparable to those seen at EFK 13.8 in 1999-2001. 


\subsubsection{Mercury inventories in biota}

During FY 2016 field surveys, 21 species of fish and 29 invertebrate families were collected from five sites (Table 4-2). Because of the extensive processing time for samples and turnaround time for sample analyses, current available data are presented here, but several data sets are still pending.

Table 4-2. Breakdown of invertebrate and fish samples collected during FY 2016 sampling efforts on East Fork Poplar Creek

\begin{tabular}{lcccc}
\hline \multicolumn{1}{c}{ Group } & Diversity & $\begin{array}{c}\text { Number of } \\
\text { individuals }\end{array}$ & $\begin{array}{c}\text { Number of } \\
\text { samples }\end{array}$ & Analyses \\
\hline Fish & 21 species & 1,150 & 509 & Stable isotope, $\mathrm{HgT}, \mathrm{MeHg}$ \\
Invertebrates & 29 families & 6,936 & 421 & Stable isotope, $\mathrm{HgT}, \mathrm{MeHg}$ \\
\hline \multicolumn{2}{l}{ Notes: $\mathrm{HgT}=$ total mercury; $\mathrm{MeHg}=$ methylmercury. }
\end{tabular}

Figures 4-6 to 4-10 present mean total and methylmercury concentrations in invertebrates from different functional feeding groups. The spatial patterns in bioaccumulation in invertebrates generally follow the patterns that have been observed in fish: the highest total mercury concentrations were found upstream, and concentrations decrease with distance downstream. Mercury and methylmercury concentrations within the different invertebrate groups collected also varied across taxonomic groups. Of all invertebrate groups, crayfish had the highest concentrations of methylmercury across sites (Fig. 4-11); concentrations of methylmercury in crayfish muscle tissue were significantly correlated with the size of the animal but were generally comparable to concentrations seen in upper trophic level fish fillets. Concentrations in predatory insects (Fig. 4-10) had the next highest levels of MeHg, followed by clams and other aquatic insects (caddisflies and mayflies). Clams, by far, had the highest levels of total mercury across sites, likely due to their filtering feeding strategy. EFK 13.8 had the highest MeHg concentrations of all sites across invertebrate species groups. In general, the trend for $\mathrm{MeHg}$ concentrations followed EFK $13.8>$ EFK $6.3>$ EFK $18.2>$ EFK $23.4>$ EFK 24.5. Trends in total mercury concentrations across sites were less obvious.

These are among the first quantitative estimates for the inventory of mercury and methylmercury in diverse invertebrate communities. Because of the importance of food chain transfer of mercury, these concentrations, along with biomass estimates (Fig. 4-5) are being used to quantify the trophic transfer of mercury and methylmercury to redbreast and rock bass (upper trophic level fish in this stream). This information is crucial to the understanding of baseline conditions in the biota of EFPC and to identifying crucial linkages in the food chain that lead to high mercury concentrations in fish. Any ecological manipulation that occurs will be tested against this baseline condition. 

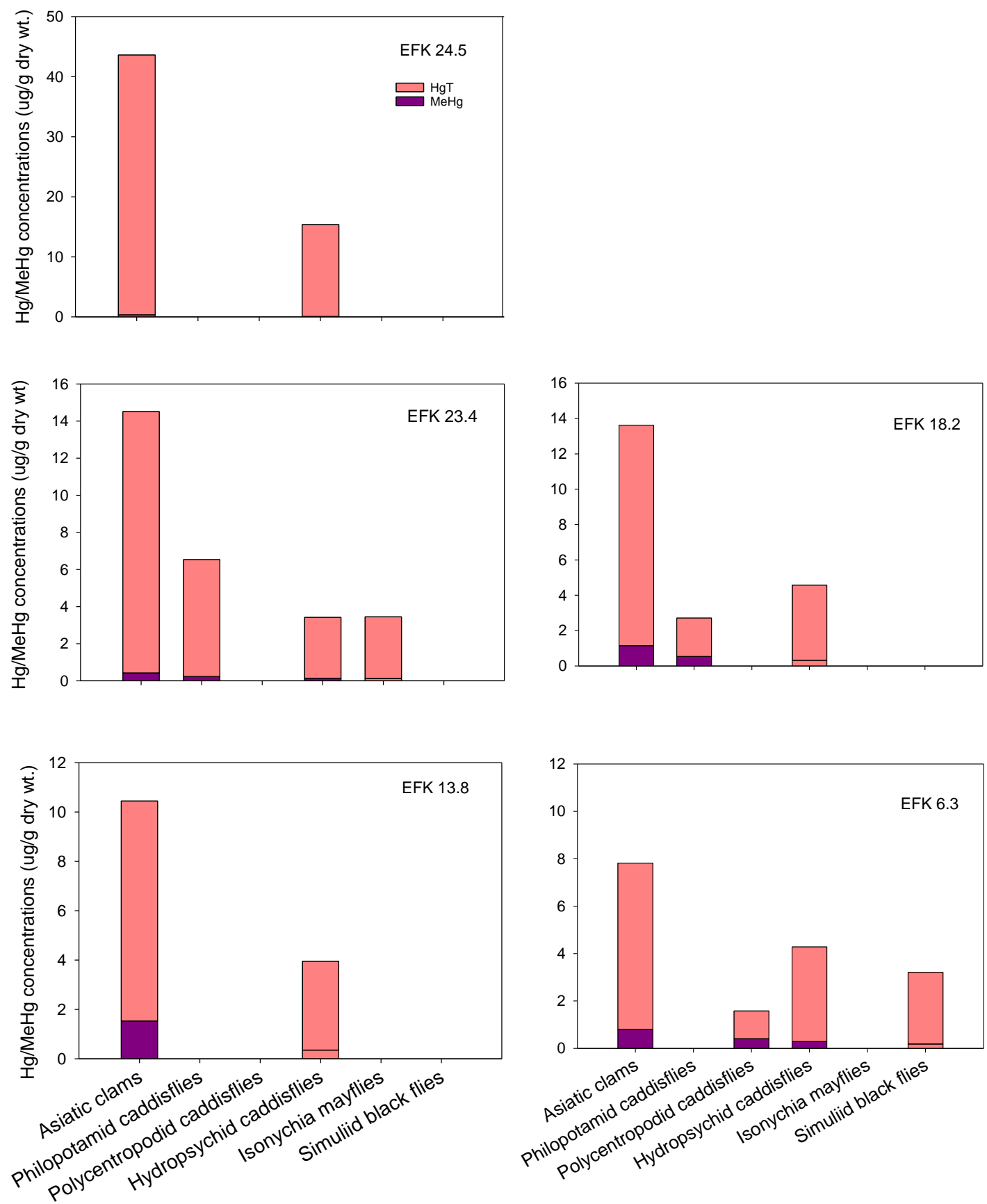

Fig. 4-6. Total and methylmercury concentrations in invertebrates from the collector-filterer feeding group at five collection sites in EFPC. The total height of the bar represents the mean total mercury concentration while the dark bar represents the fraction of mercury found as methylmercury ( $\mu \mathrm{g} / \mathrm{g}$ dry wt.). 

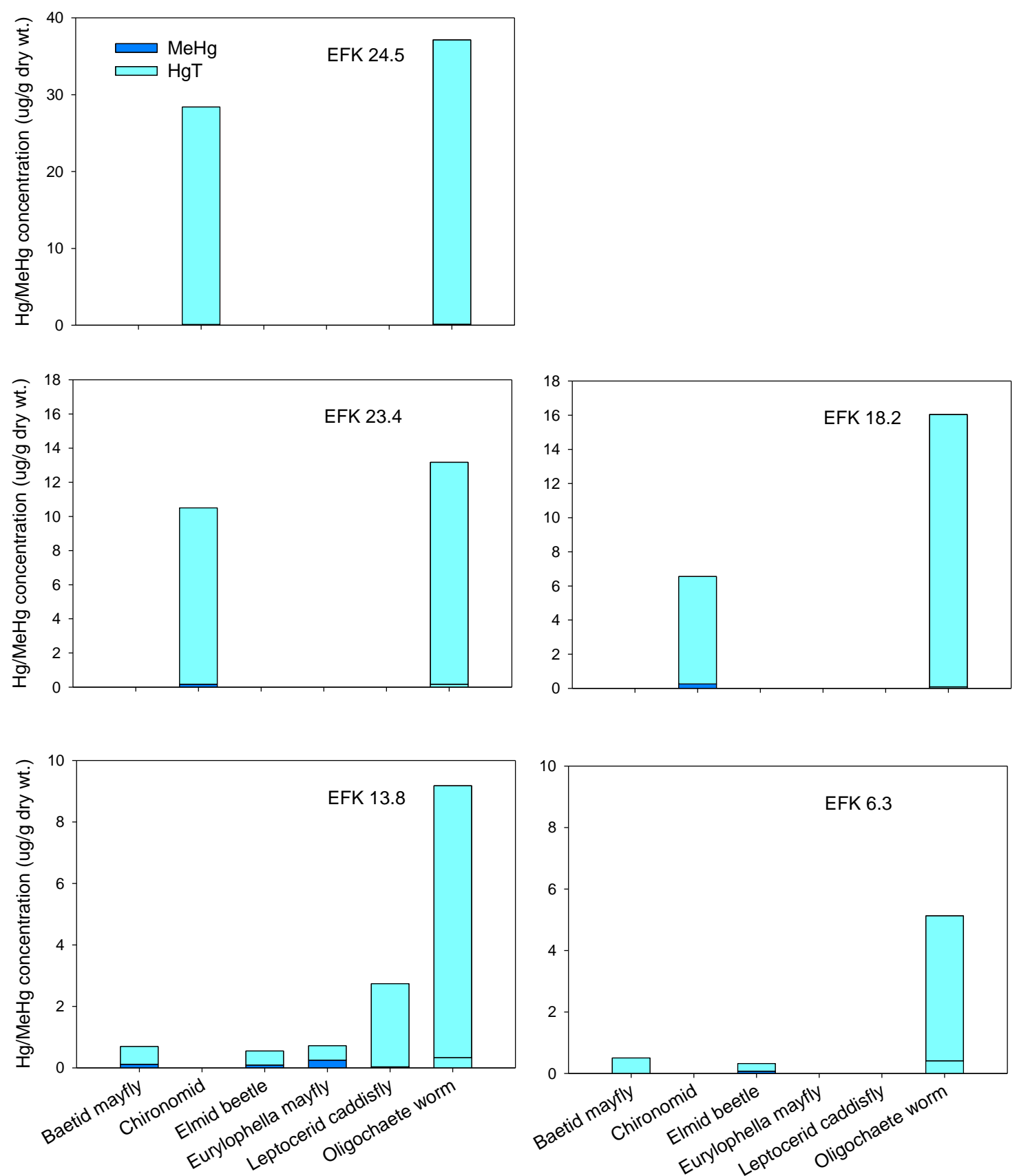

Fig. 4-7. Total and methylmercury concentrations in invertebrates from the collector-gatherer feeding group at five collection sites in EFPC. The total height of the bar represents the mean total mercury concentration whereas the dark bar represents the fraction of mercury found as methylmercury ( $\mu \mathrm{g} / \mathrm{g}$ dry wt.). 

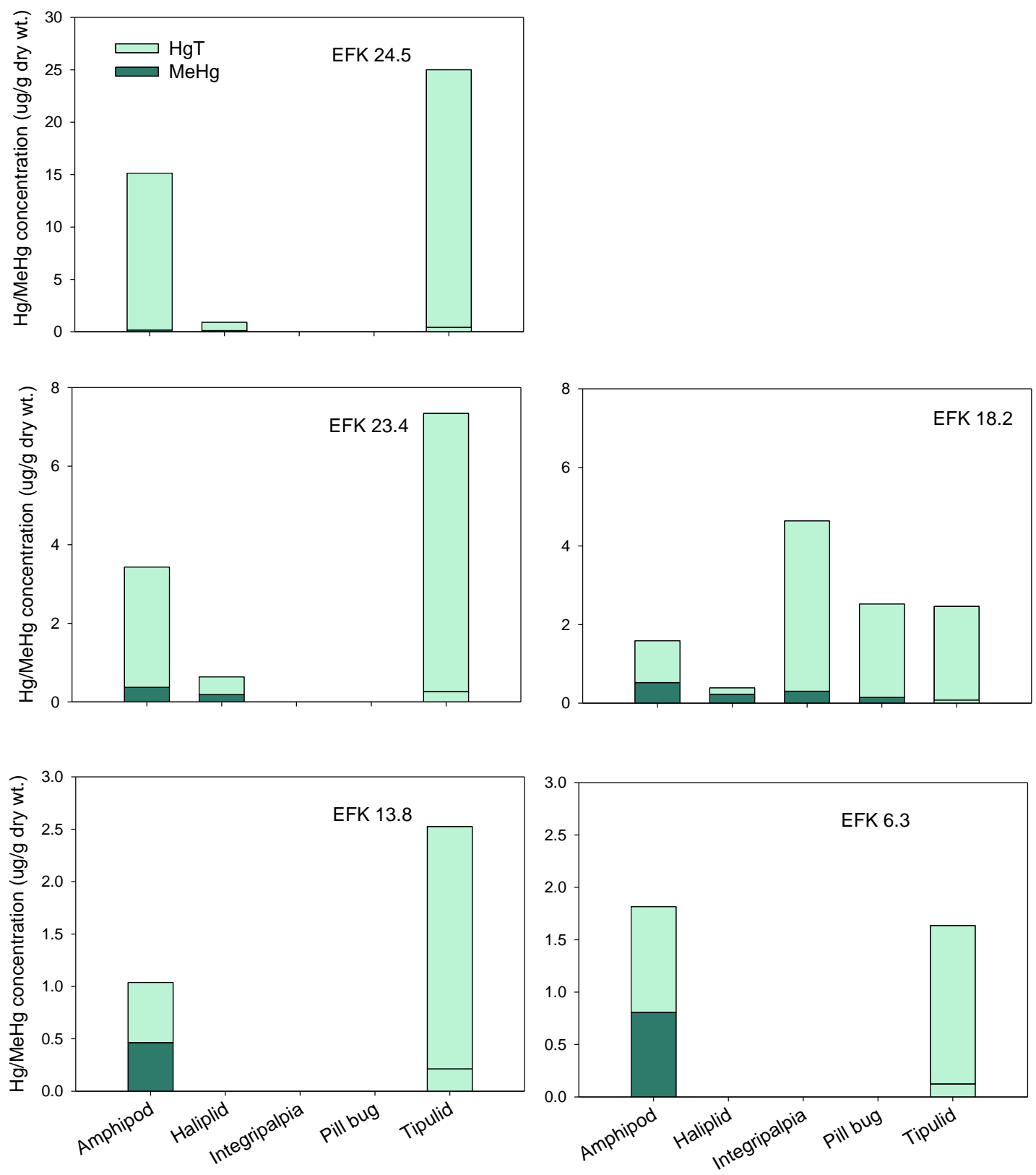

Fig. 4-8. Total and methylmercury concentrations in invertebrates from the shredder feeding group at five collection sites in EFPC. The total height of the bar represents the mean total mercury concentration, whereas the dark bar represents the fraction of mercury found as methylmercury $(\mu \mathrm{g} / \mathrm{g}$ dry wt.). 

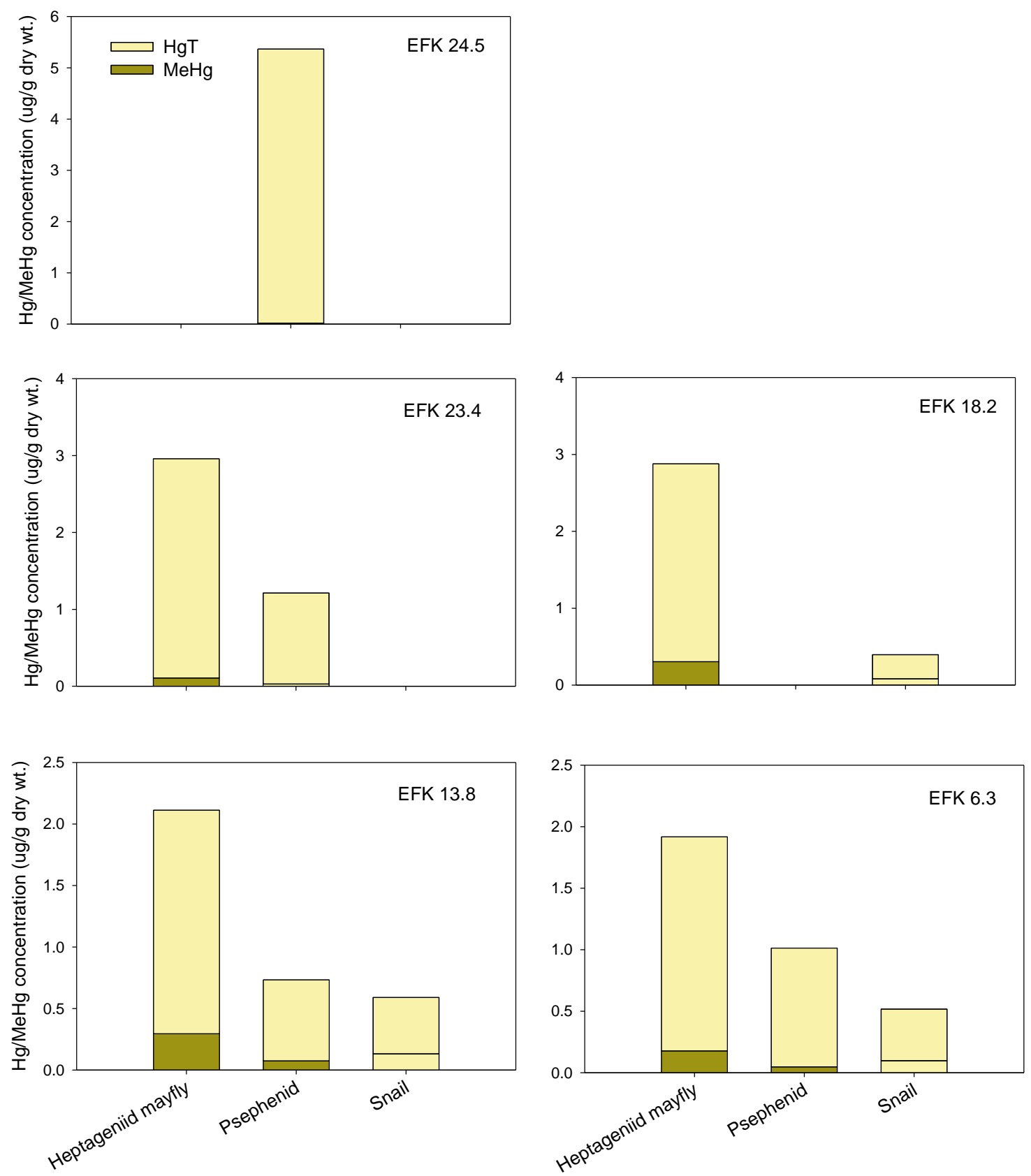

Fig. 4-9. Total and methylmercury concentrations in invertebrates from the scraper feeding group at five collection sites in EFPC. The total height of the bar represents the mean total mercury concentration, whereas the dark bar represents the fraction of mercury found as methylmercury ( $\mu \mathrm{g} / \mathrm{g}$ dry wt.) 

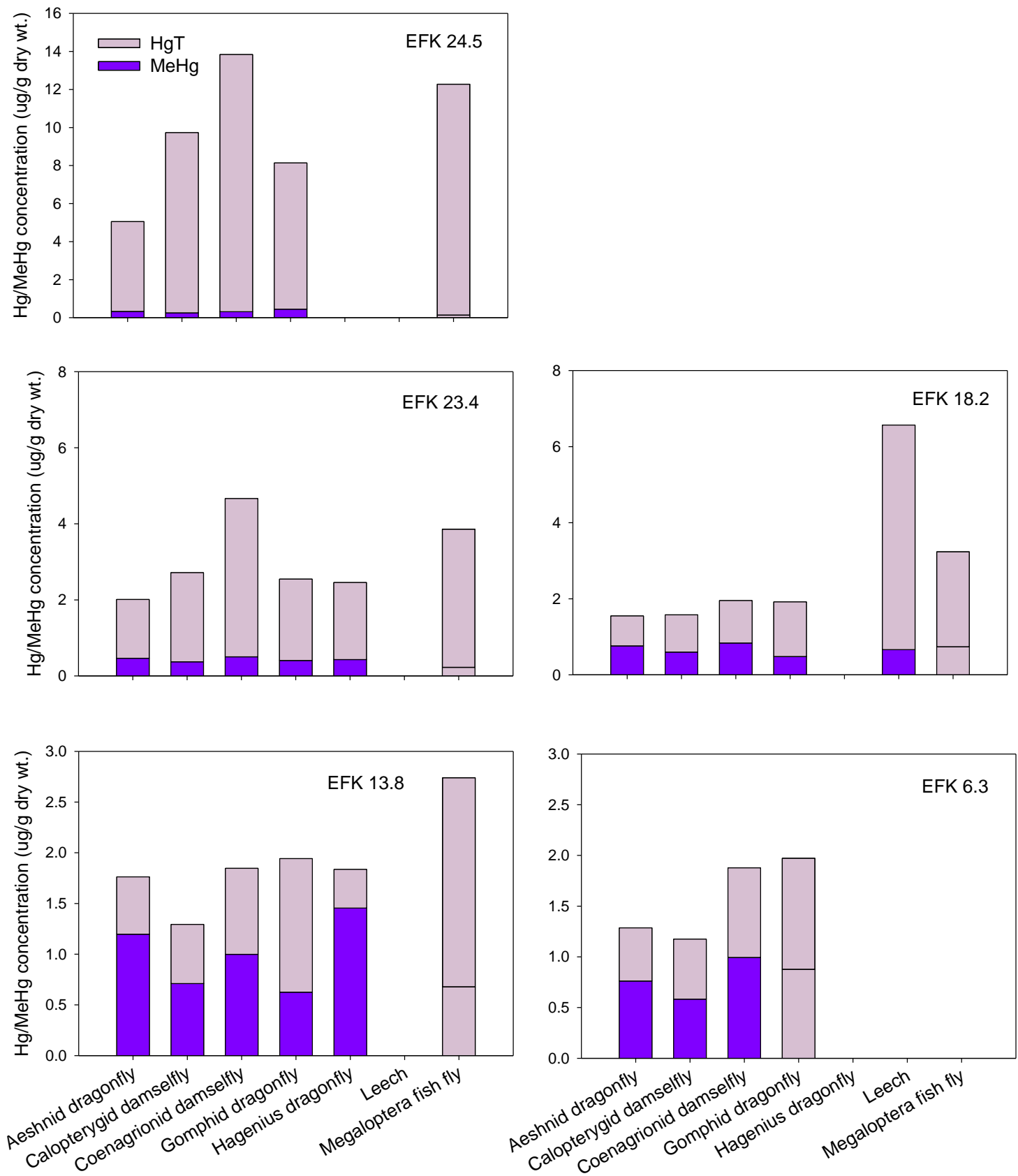

Fig. 4-10. Total and methylmercury concentrations in invertebrates from the predator feeding group at five collection sites in EFPC. The total height of the bar represents the mean total mercury concentration, whereas the dark bar represents the fraction of mercury found as methylmercury

( $\mu \mathrm{g} / \mathrm{g}$ dry wt.). 


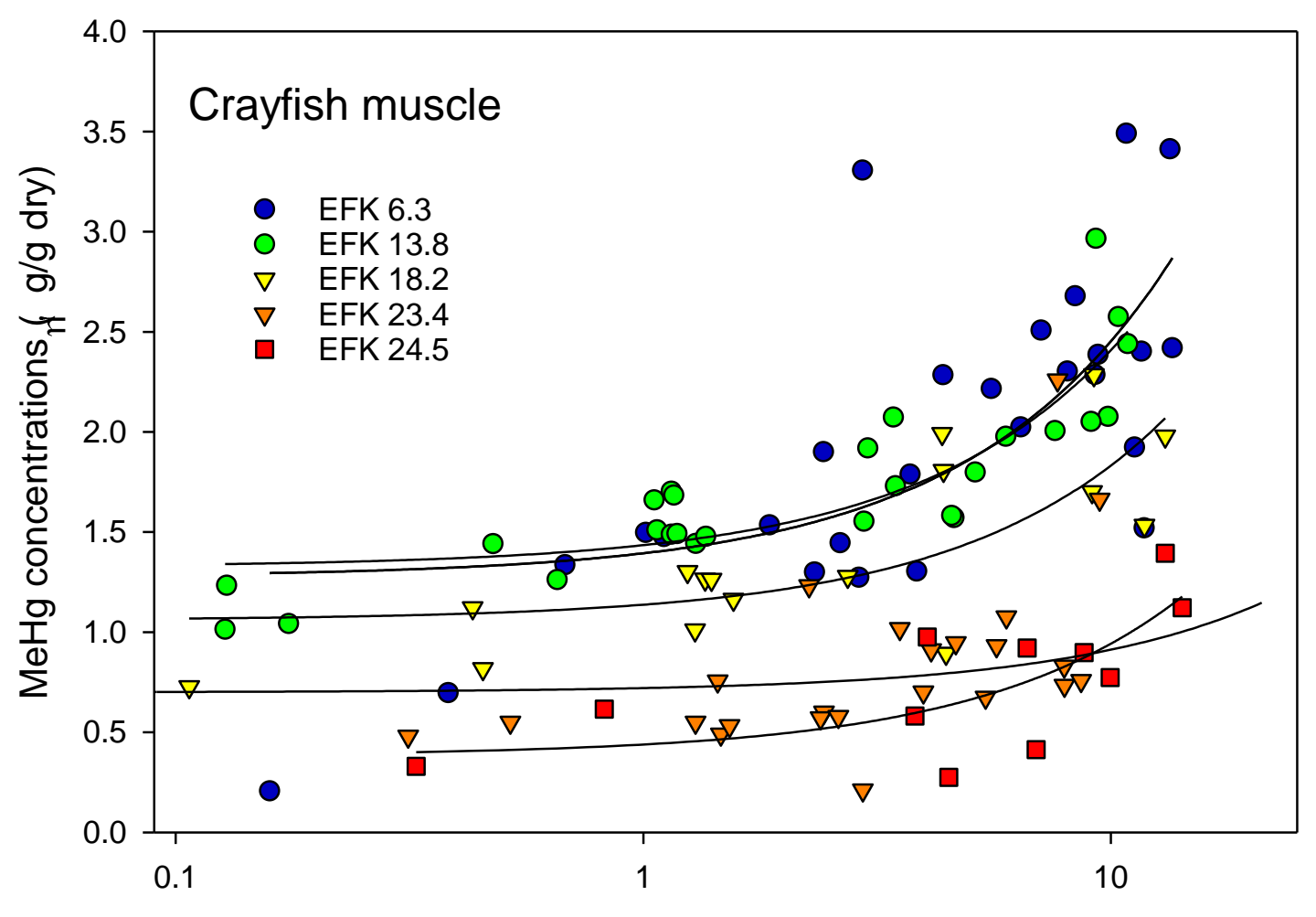

Log body wt.

Fig. 4-11. The relationship between methylmercury concentrations ( $\mu \mathrm{g} / \mathrm{g}$ dry wt.) in crayfish muscle tissue and body size, as shown by the log of total body weight $(\mathrm{g})$.

Although total mercury tissue concentrations for fish collected in this stream have been reported for decades, methylmercury bioaccumulation in fish within the creek is much less understood. Because fish removal and/or overstocking of certain species has been suggested as a possible ecological manipulation for mitigating the risk of methylmercury exposure, it is important to have a baseline for methylmercury concentrations in different fish species. Fig. 4-12 presents the proportion of mercury found as methylmercury in whole body fish collected throughout the creek. This proportion increases with increasing distance downstream, across all species considered. Fillet methylmercury concentrations are of particular interest because regulatory guidelines for mercury are based on fillet methylmercury concentrations (on a wet weight basis). Fig. 4-13 presents wet weight methylmercury concentrations in the upper trophic level fish encountered during routine community surveys in EFPC. Whereas this is only a small subset of fish (small sample numbers for each species at each site), all fish had fillet methylmercury concentrations above the fish tissue guidelines. Bluegill generally had lower methylmercury concentrations than any other fish species; however, at EFK 18.2, the methylmercury concentration in redbreast sunfish was lower than that in bluegill. Although rock bass are the most abundant upper trophic level fish in the creek, hybrid sunfish and warmouth that were encountered had higher methylmercury concentrations. 


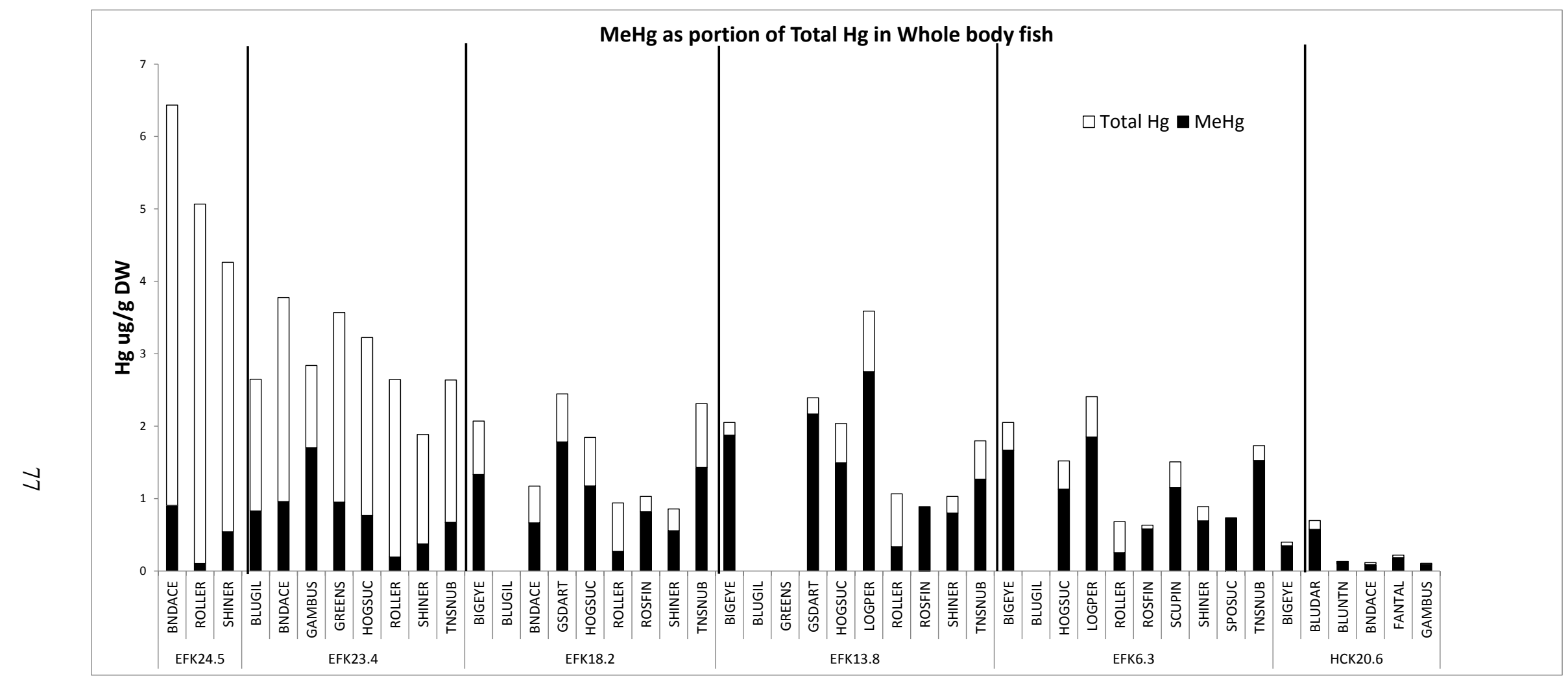

Fig. 4-12. Total and methylmercury concentrations in whole body fish at five collection sites in EFPC and the Hinds Creek reference site. The total height of the bar represents the mean total mercury concentration, whereas the dark bar represents the fraction of mercury found as methylmercury ( $\mu \mathrm{g} / \mathrm{g}$ dry wt.). 
Because methylmercury is correlated with size and sex of fish, more data are necessary to make spatial or interspecies comparisons. Fillet samples collected in spring 2016 are still pending methylmercury data.

Stable isotope ratios of nitrogen $\left(\delta^{15} \mathrm{~N}\right)$ were measured to reconstruct the food web at each site within EFPC, because increases in $\delta^{15} \mathrm{~N}$ signify movement up the food chain. Trophic level was calculated by comparing $\delta^{15} \mathrm{~N}$ of all samples to $\delta^{15} \mathrm{~N}$ at the base of the food chain at each site (periphyton). Figure 4-14 shows the relationship between trophic level and methylmercury concentrations at two selected sites within EFPC, EFK 23.4 and EFK 13.8 (to correspond with the analysis of invertebrate community data shown in Figs. 4-3 and 4-4). Figure 4-14 shows that methylmercury concentrations are lower throughout the food chain at EFK 23.4 than at EFK 13.8, which is not surprising given the inventories seen for different taxa considered separately. However, by representing trophic level using stable isotope ratios, researchers can quantitatively determine that the length of the food chain leading to rock bass at the lower site, EFK 13.8, is longer than at the upper site. Rock bass at EFK 23.4 are feeding at trophic level 3.38, whereas those at EFK 13.8 are feeding at trophic level 3.70. This quantitative information corroborates community survey data presented in Figs. 4-4 and 4-5, which suggest that the community is more diverse at the lower site.

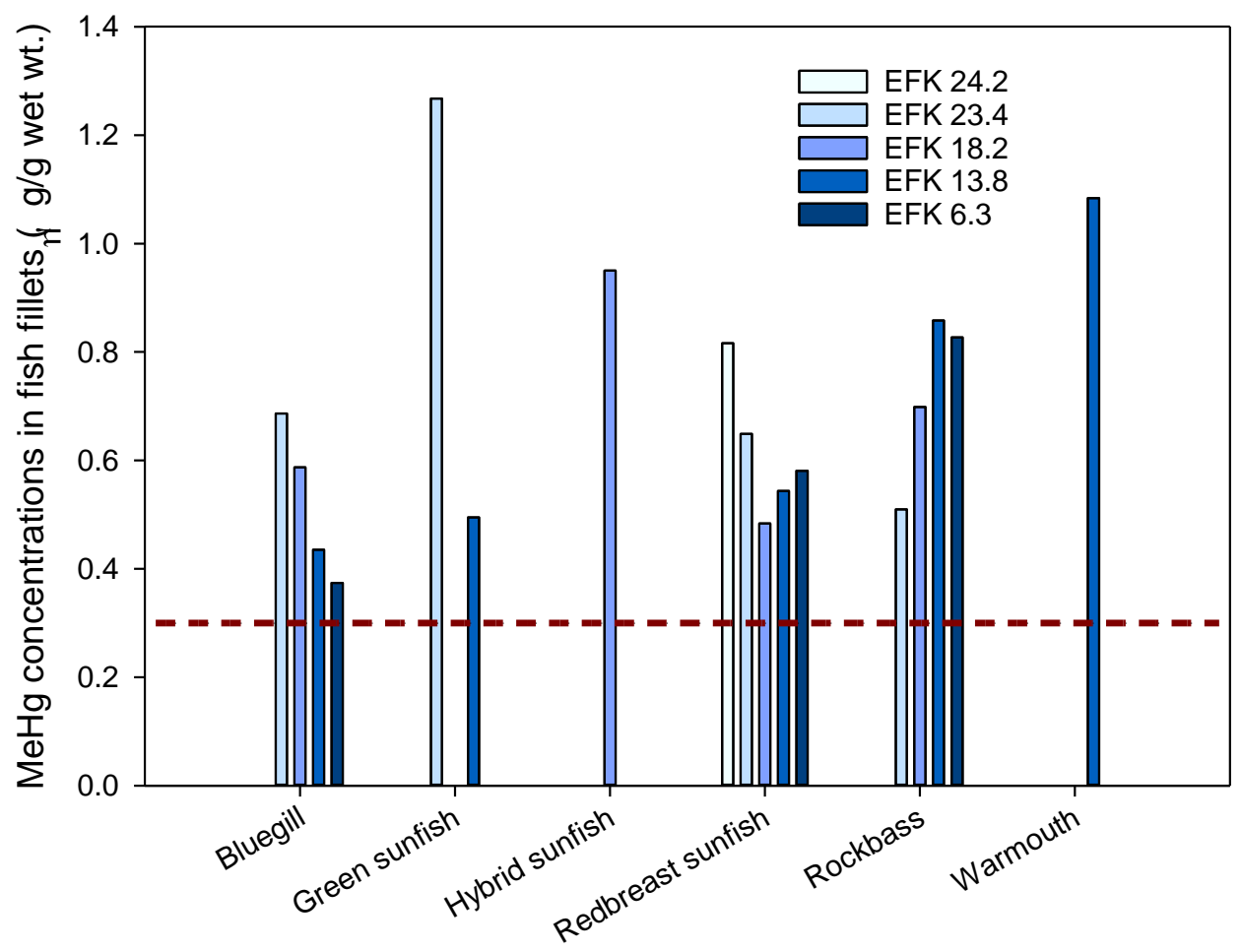

Fig. 4-13. Methylmercury concentrations in fish fillets collected throughout EFPC.

Dashed red line indicates tissue guidelines for methylmercury in fish $(0.3 \mu \mathrm{g} / \mathrm{g}$, wet weight). Note that whereas all other graphs report concentrations on a dry weight basis, here researchers have converted to wet weight concentrations using the moisture content of the fillets to directly compare to guideline concentrations. 


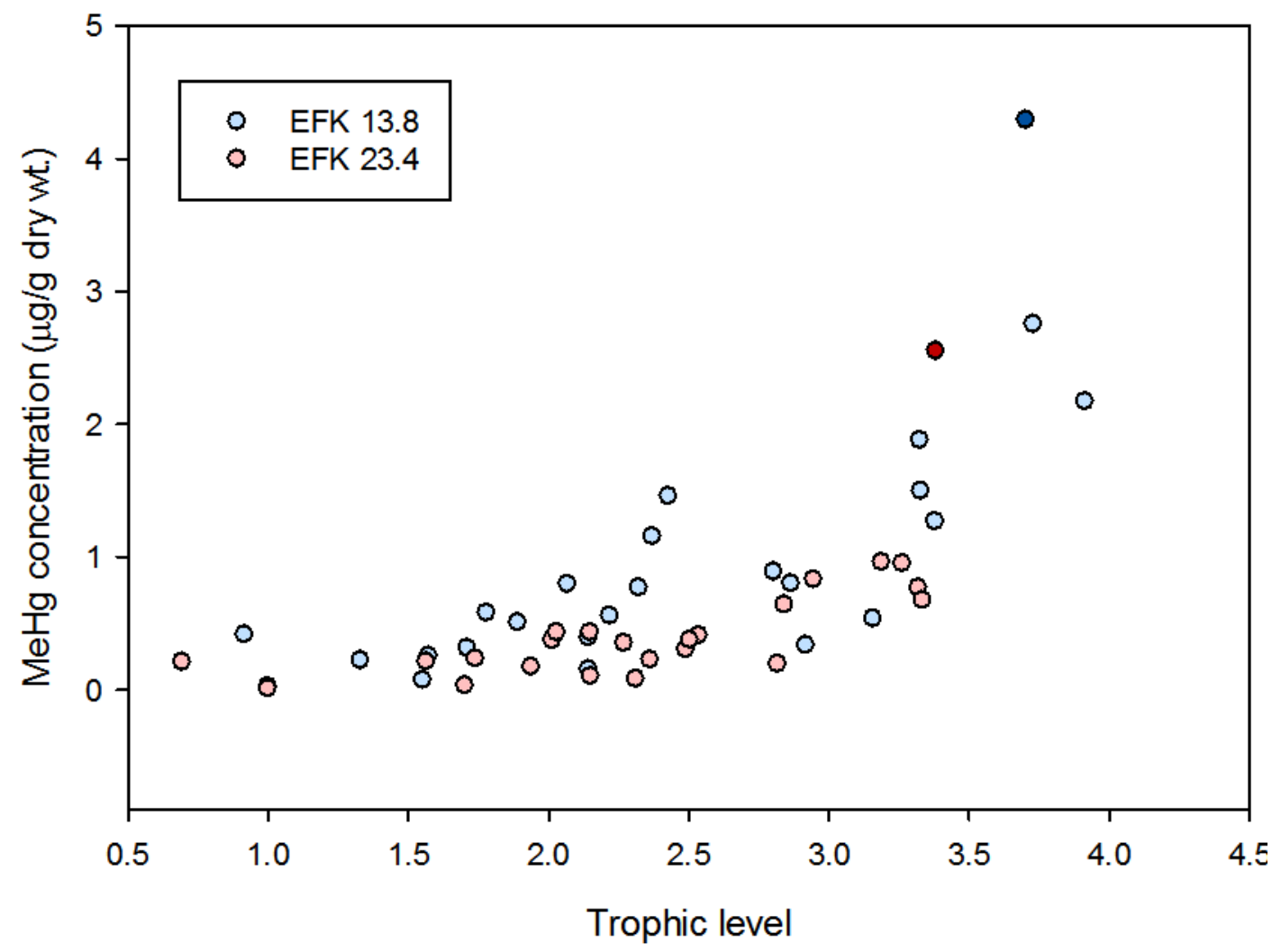

Fig. 4-14. The relationship between methylmercury concentrations and trophic level in the food webs of two selected sites in EFPC. Trophic level was calculated using $\delta^{15} \mathrm{~N}$ values as described in the text. The base of the food chain for trophic level calculations was periphyton. Symbols represent mean values for invertebrates and fish taxa at the two sites. The dark red and dark blue symbols represent rock bass at each sampling location.

More steps within a food web allow for greater mercury biomagnification from primary producers to the top predatory species (Fig. 4-15). This, along with the spatial trends in aqueous MeHg concentrations in EFPC, could explain the trends in fish mercury concentrations throughout the creek. Whereas controlling $\mathrm{MeHg}$ production may not be a realistic goal with the current understanding of mercury methylation dynamics, manipulating the food web structure to encourage the colonization of lower trophic level fish may be more achievable on timescales relevant to remediation decisions. This would provide an opportunity for decreased mercury bioaccumulation and potentially decreased ecological and human health exposure and risk. 


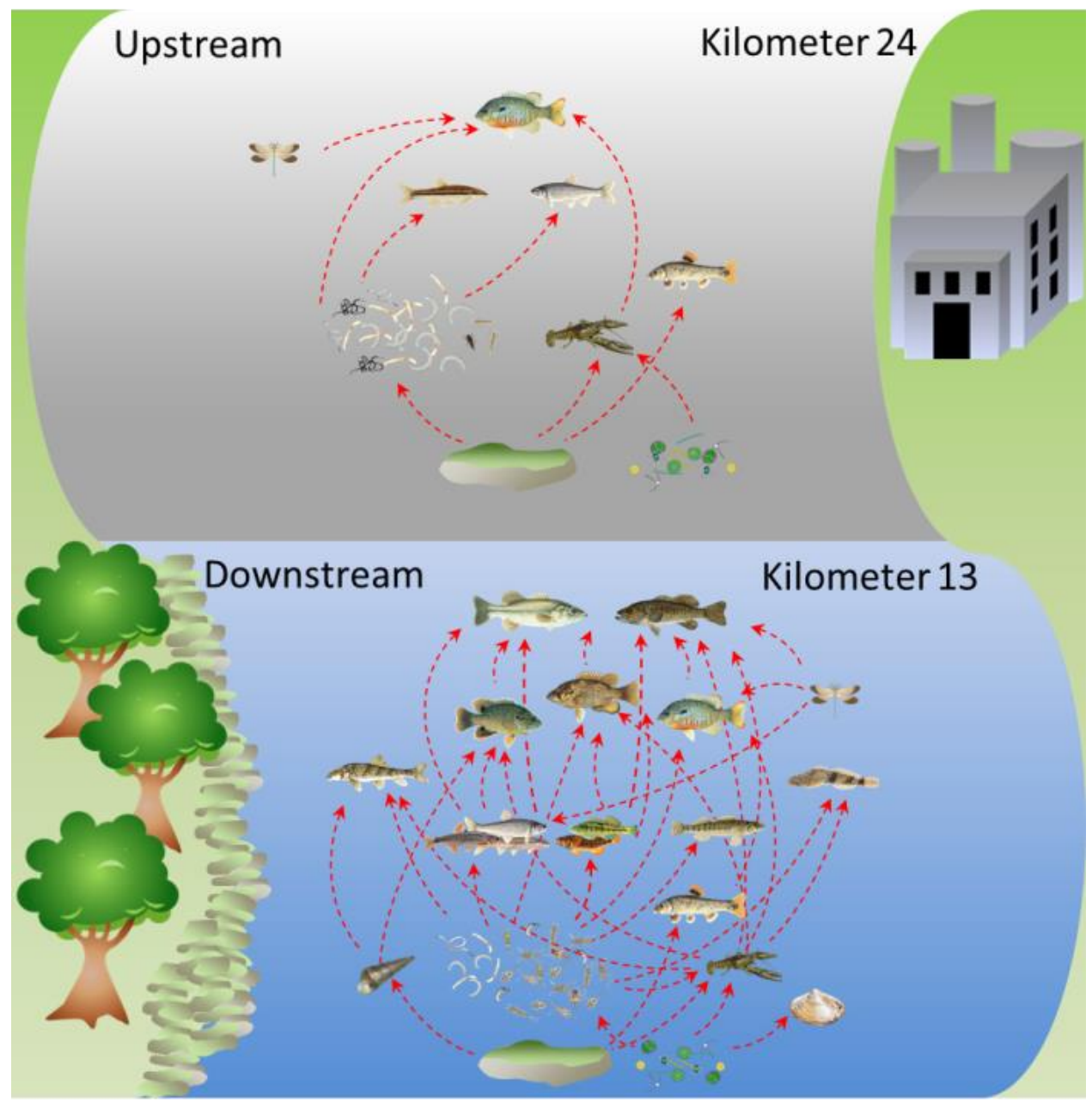

Fig. 4-15. Schematic representation of food webs at upstream (East Fork Poplar Creek [EFPC] kilometer [EFK] 24) and downstream (EFK 13) sites of EFPC. More complex food webs mean more opportunity for mercury biomagnification within the food web. (Source: Peterson, M. J., S. C. Brooks, T. J. Mathews, M. Mayes, A. Johs, D. B. Watson, M. D. Poteat, and E. Pierce. 2015. Mercury Remediation Technology Development for Lower East Fork Poplar Creek. ORNL/SPR-2014/645, Oak Ridge National Laboratory, Oak Ridge, TN.) 


\subsubsection{Back-casting macroinvertebrate bioconcentration}

The density and biomass information from historical community analyses are being used in conjunction with the current efforts to quantify mercury inventories within the biota of EFPC (Sections 4.1.2.2 and 4.1.2.3) to create a food web model to predict the most important factors leading to elevated mercury concentrations in fish. This information is crucial to understand in terms of designing strategies for ecological manipulation.

Historical and current unfiltered grab samples of $\mathrm{MeHg}$ in the water column were compiled for EFKs 23.4 and 13.8 from at least 14 different sources, including numerous past reports (Fig. 4-16). These values were used to create average trends of $\mathrm{MeHg}$ conditions in EFPC surface water. $\mathrm{MeHg}$ concentrations dramatically declined from 1989 to 1998 at EFK 23.4 with little variation because of the season in which the sample was collected (Fig. 4-16). In contrast, $\mathrm{MeHg}$ concentrations were relatively stable across the entire period for EFK 13.8; however, samples collected in the summer were consistently higher (Fig. 4-16).

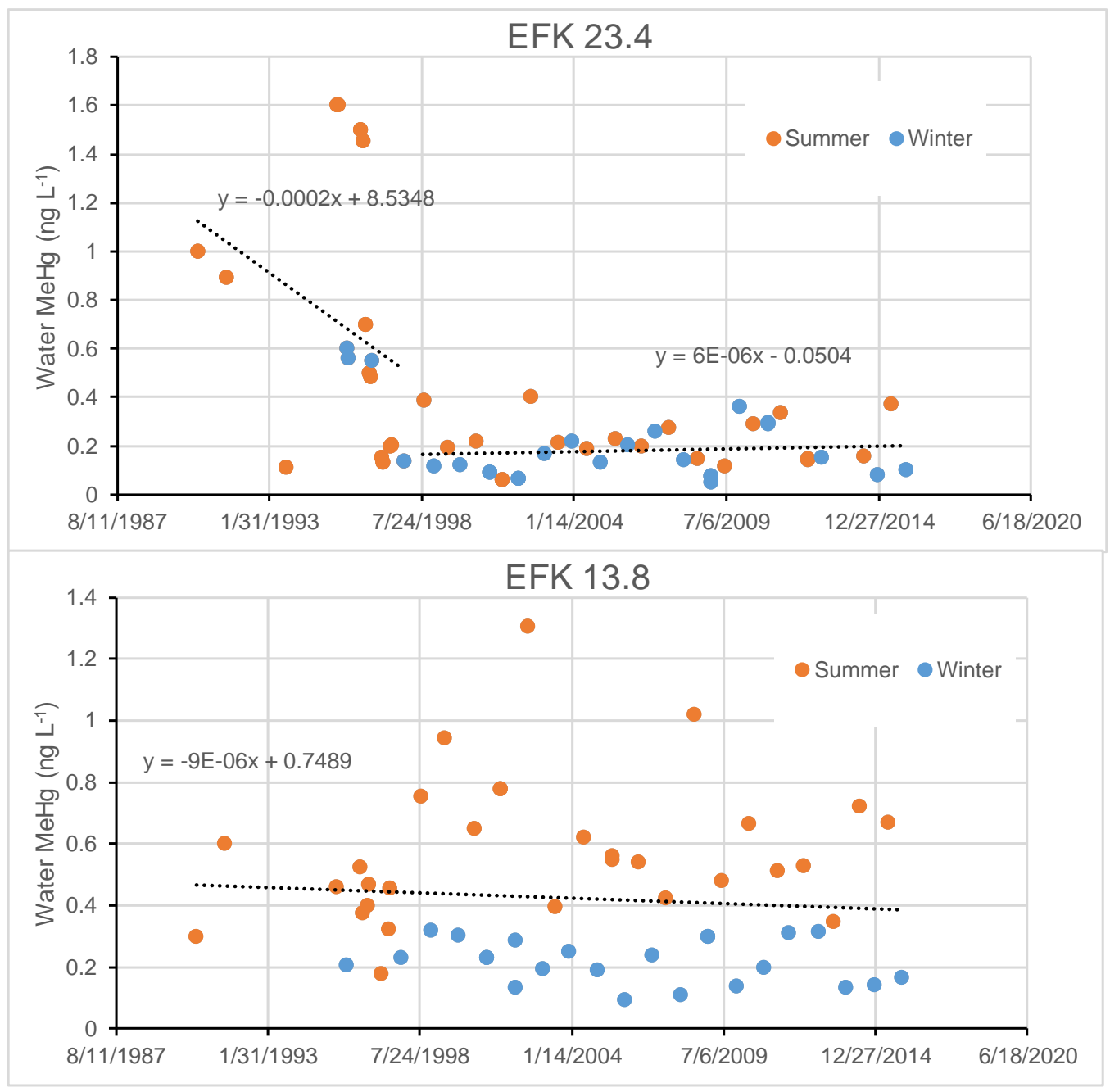

Fig. 4-16. Unfiltered grab samples of methylmercury (MeHg) in surface water collected in summer and winter at EFKs 23.4 and 13.8. 
Macroinvertebrate community samples from 1989 to present at EFKs 23.4 and 13.8 were summarized as biomass density per year at each site. Bioconcentration factors (BCFs) were calculated for macroinvertebrate families' functional feeding groups using $\mathrm{MeHg}$ concentrations in macroinvertebrates relative to $\mathrm{MeHg}$ water concentrations (unfiltered) for the 2013-2016 period. BCFs were then applied to historical $\mathrm{MeHg}$ water concentrations to back-cast $\mathrm{MeHg}$ concentrations in the macroinvertebrate community. Based on relative biomass densities of macroinvertebrates, a weighted concentration was calculated for each sample using two scenarios: (S1) all macroinvertebrates were included; and (S2) all macroinvertebrates except crayfish, snails, and clams were included (as more indicative of redbreast diets). Additionally, low and high estimates of $\mathrm{MeHg}$ water concentrations (based on seasonal variation) were applied to the S1 and S2 scenarios. Second, the total mass of $\mathrm{MeHg}$ represented in the macroinvertebrate community was also calculated based on biomass densities under the same scenarios.

Weighted concentrations of the macroinvertebrate community were highly divergent between EFKs 23.4 and 13.8 and among the scenarios (Fig. 4-17). At EFK 23.4, weighted concentrations across the macroinvertebrate community were high pre-1998, beyond which values were low and stable. At EFK 13.8, concentrations were highly variable across time, showing no clear trend except that extreme values seemed to be higher over time. Temporal trends in $\mathrm{MeHg}$ biomass were different from weighted concentrations. For example, at EFK 23.4, MeHg biomass displayed declines over time similar to weighted concentrations; however, values remained moderately high post-1998. In contrast to weighted concentrations, MeHg biomass at EFK 13.8 declined over time. This suggests that changes in the macroinvertebrate community, such as increases in trophic diversity, may be driving the availability of mercury to higher trophic groups (i.e., predatory fish), despite substantial reductions in $\mathrm{Hg}$ loading to EFPC.

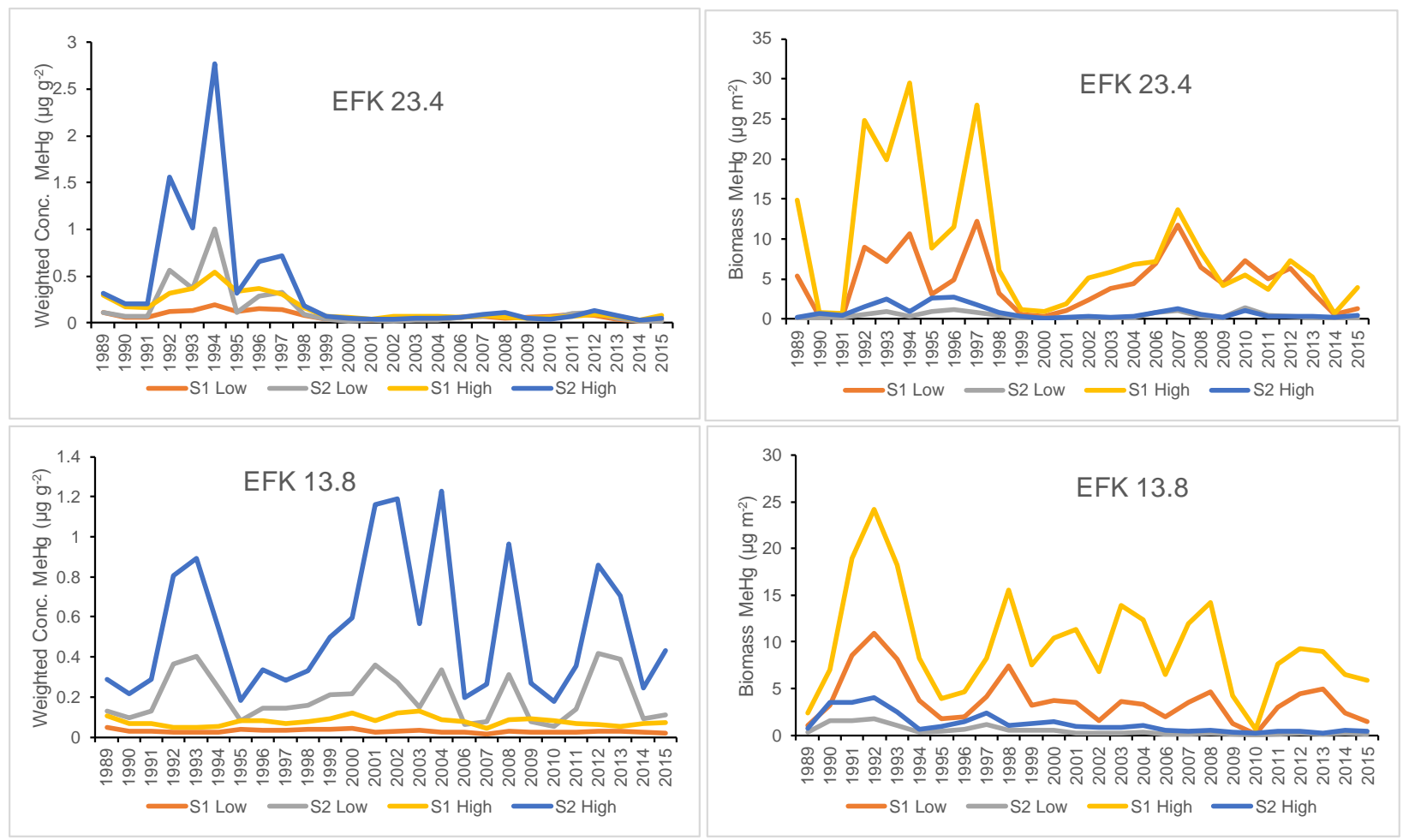

Fig. 4-17. Weighted methylmercury (MeHg) concentrations (left) and biomass of MeHg (right) in macroinvertebrate samples from EFKs 23.4 and 13.8. 


\subsubsection{Fish growth and somatic growth dilution effects on $\mathrm{MeHg}$ bioaccumulation}

Understanding the dynamics of $\mathrm{MeHg}$ bioaccumulation in higher trophic levels requires understanding shifts in the food base as well as changes in bioenergetics. Specifically, assessing among site and withinsite variation in fish growth may be important in accurately modeling MeHg body concentrations. Fish community sampling for the past 30 years provides a wealth of information to calculate age-growth relationships. Length and weight data for redbreast and stoneroller were acquired for all EFPC sites from 1985 to present. Because length data was more complete, a univariate clustering procedure was used to cluster fish into age groups based on length. A hierarchical Bayesian mixed model clustering algorithm was applied to length data (Laslett, Paige Eveson, and Polacheck 2004) using the mclust package in the R programming environment. An example of clustering results is provided for redbreast sunfish at EFK 23.4 (Fig. 4-18). The best model selected for clustering was an equal spherical shape, variable volume algorithm, which allows overlap in age groups. Because Bayesian methods were employed, uncertainty in age group determination can be explicitly reported (Fig. 4-18). The models allow for age groups to be assigned to fish based on size and estimate growth-at-age.

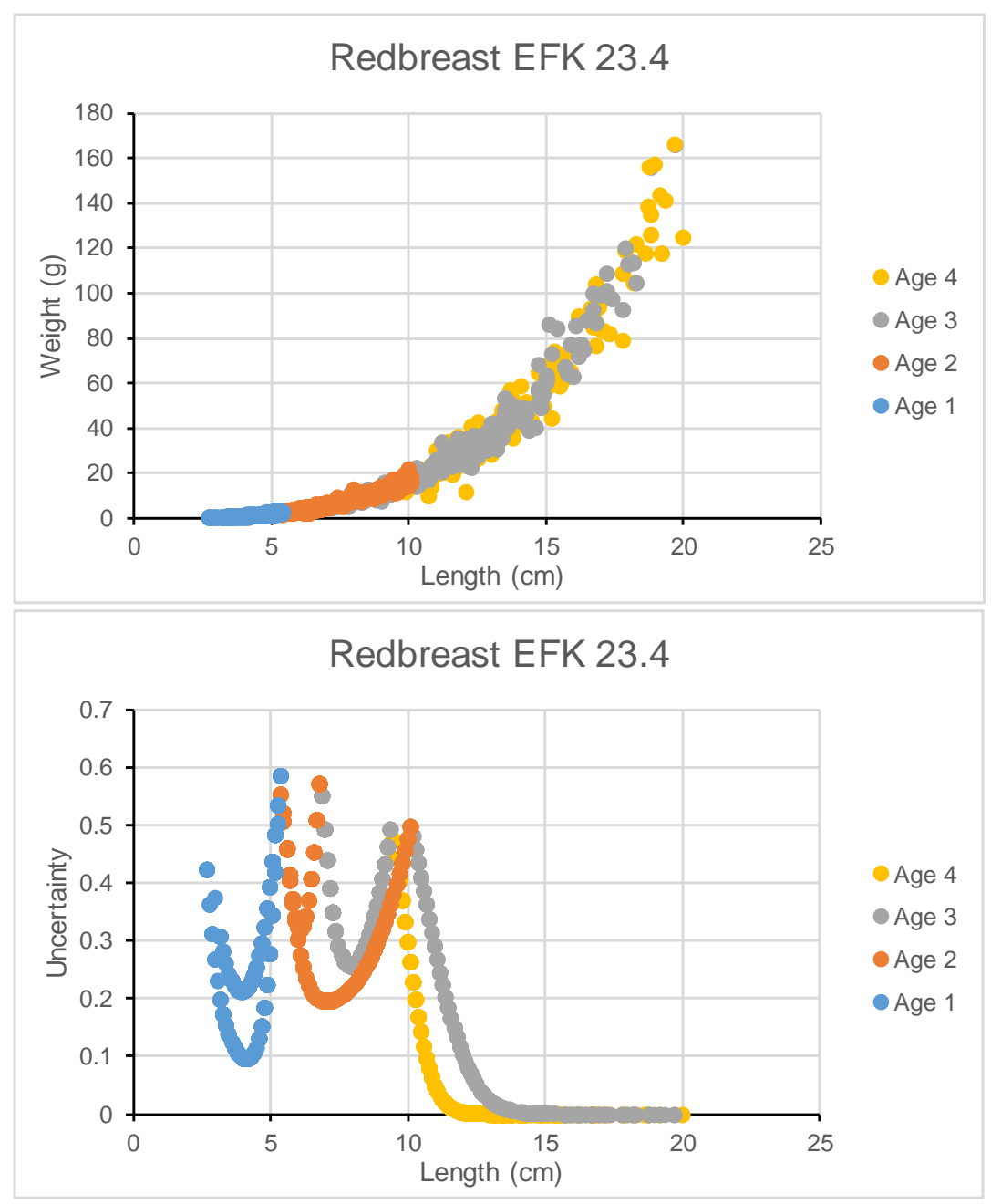

Fig. 4-18. Age groupings for redbreast sunfish based on hierarchical Bayesian clustering of length information. 
Average weight-at-age relationships provided the needed information to develop growth curves specific to each EFPC site. Deviations in weight values for each age class were used to develop different scenarios of growth. An example of different growth models is provided for redbreast sunfish at EFKs 23.4 and 13.8 (Fig. 4-19). Rapid growth occurs at younger ages at EFK 23.4 compared with EFK 13.8. For example, at 50 months of age, redbreast sunfish weights are 100 grams at EFK 23.4 compared with $\sim 60$ grams at EFK 13.8 (high growth scenario) (Fig. 4-19). Current redbreast body MeHg concentrations are higher for individuals at EFK 13.8 than those at EFK 23.4, which suggests an effect of somatic growth dilution (lower body burden of $\mathrm{MeHg}$ ).
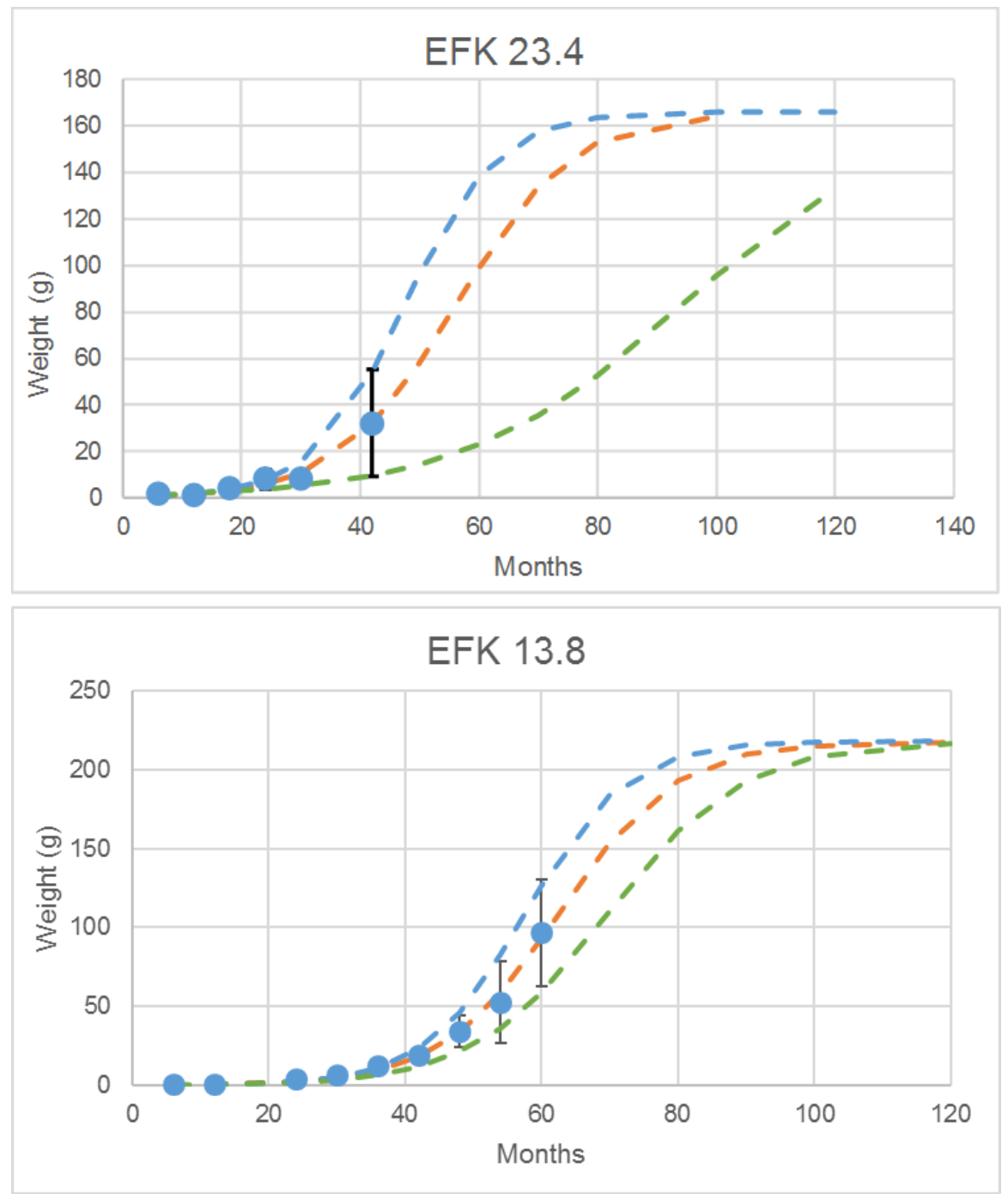

Fig. 1-19. Weight-at-age relationships developed from averages of age classes.Blue dots are observed weight-at-age values with standard deviation (error bars). Data were used to create baseline growth (orange line). Note: + or - 1 SD were used to develop high (blue line) and low (green line) growth conditions.

If growth influences $\mathrm{MeHg}$ body concentrations (via somatic growth dilution), one question that arises is what factors may influence fish growth. In an applied sense, it may be very important to understand whether fish populations can be managed to minimize $\mathrm{MeHg}$ body concentrations (i.e., maximize growth). However, finding ways to increase fish growth without considering population dynamics may be misleading. Whereas the somatic growth dilution concept suggests that higher growth rates will dilute 
$\mathrm{MeHg}$ body concentrations, higher growth rates are indicative of overall population-level growth and density-dependence. Populations showing signs of density-dependence should display declines in per capita growth with increasing population size (Myrvold and Kennedy 2015).

Age-class clusters were developed for stonerollers at EFPC sites using the Bayesian mixture model methodology described above. Based on age groupings, year-to-year growth was calculated for each ageclass and converted to per capita growth per day. Examples of stoneroller-at-age growth for EFKs 23.4 and 24.4 are provided in Figs. 4-20 and 4-21, respectively. For EFK 23.4, age 1 stonerollers displayed negative per capita growth with increasing population densities, whereas age 2 stonerollers displayed increased growth with higher densities (Fig. 4-20). Ages 3 and 4 fish showed no apparent relationship. This suggests that effects of density-dependence, if any, constrain growth in younger fish generations. Evidence of density dependence was stronger at EFK 24.4 where stoneroller populations are considerably higher (Fig. 4-21). All age groups displayed negative per capita growth versus population density at EFK 24.4, which has very high densities of stonerollers. However, despite showing stronger signs of density dependence, per capita growth is, on average, far higher at EFK 24.4 than at EFK 23.4. This suggests that whereas higher growth rates may dilute body $\mathrm{MeHg}$ concentrations, growth rates among EFPC sites are not indicative of population size. In other words, the total amount of $\mathrm{MeHg}$ within the food web may not mirror patterns of somatic growth dilution.

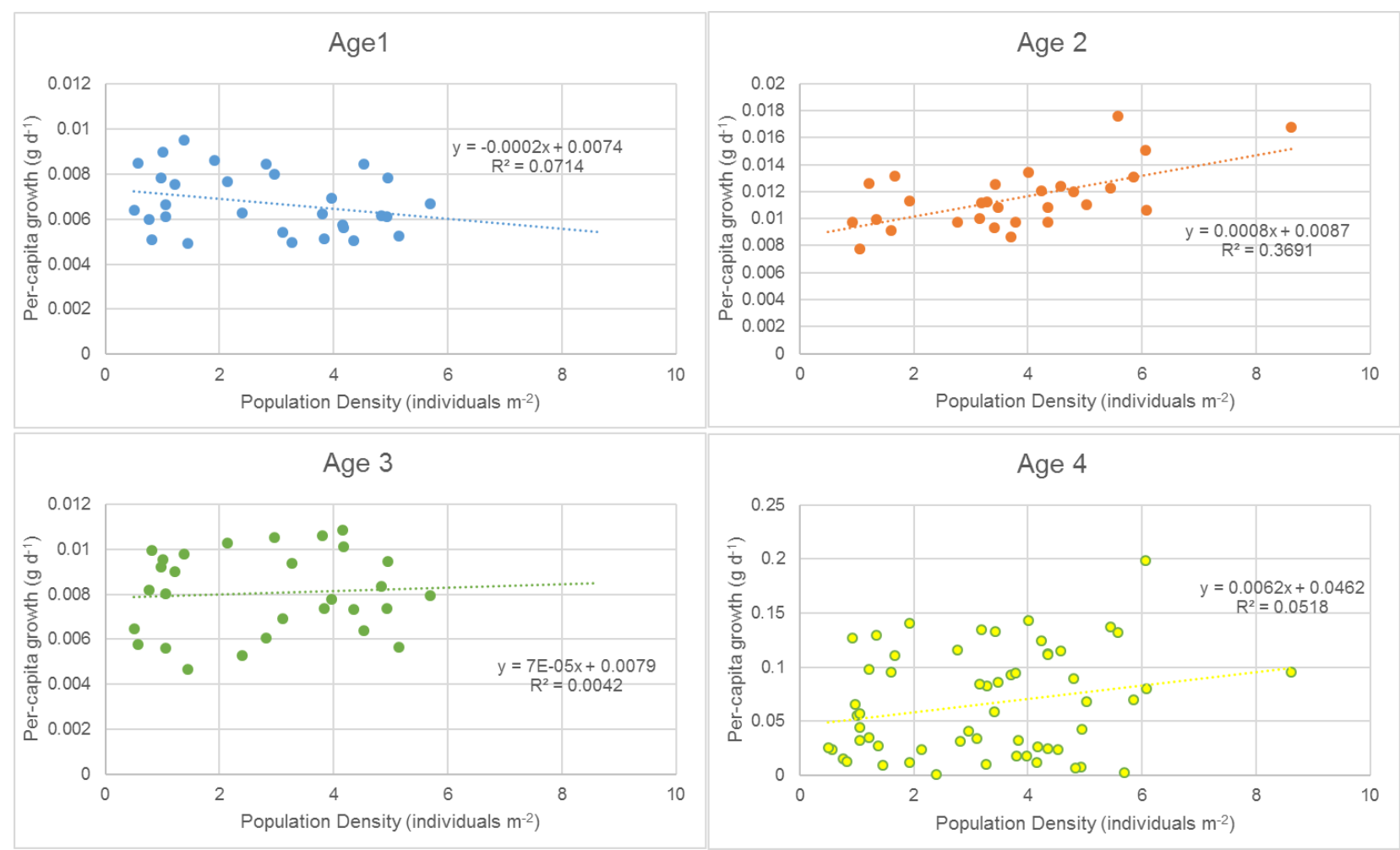

Fig. 4-20. Stoneroller per capita growth at age versus population density at EFK 23.4 


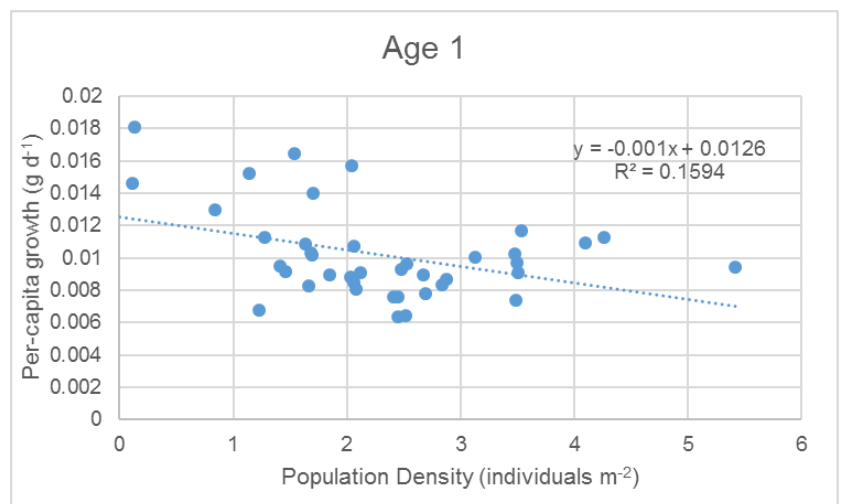

Age 3

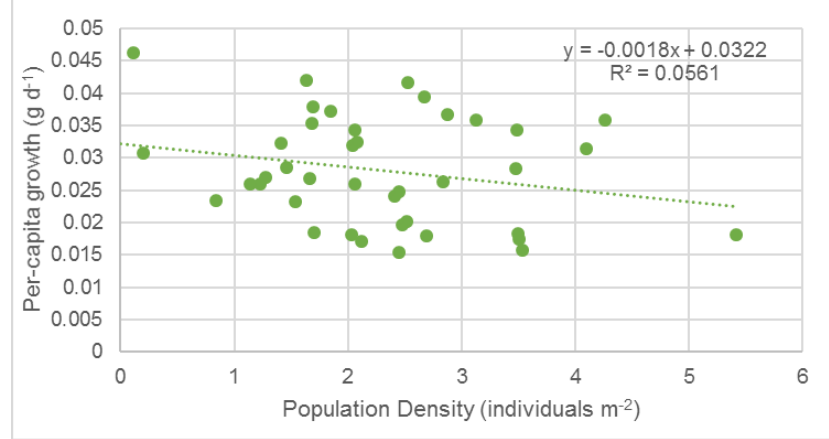

Age 2

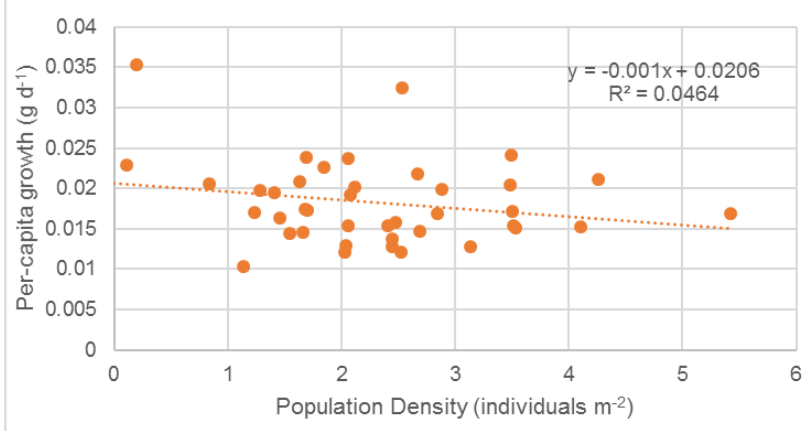

Age 4

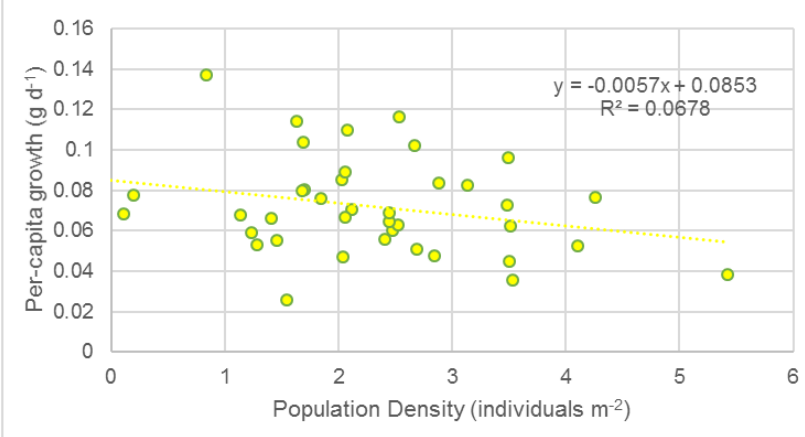

Fig. 4-21. Stoneroller per capita growth at age versus population density at EFK 23.4

\subsubsection{Applying biodynamics to understand fish MeHg concentrations}

Using back-casted estimates of the $\mathrm{MeHg}$ concentration of the macroinvertebrate community and information on fish bioenergetics, the biodynamics model was applied to redbreast at EFKs 23.4 and 13.8. Specifically, the ability to estimate current and historical samples of $\mathrm{MeHg}$ concentrations in body tissues was explored. The biodynamics equation (Luoma and Rainbow 2005) for estimating MeHg body concentration at steady state (MeHgss) is:

$$
M e H g_{s s}=\frac{\left[\left(k_{u} * C_{w}\right)+\left(A E * I R * C_{F}\right)\right]}{\left(k_{e}+g\right)}
$$

where $k_{u}$ is an uptake constant applied to the concentration of the water $\left(C_{w}\right), A E$ is assimilation efficiency, $I R$ is ingestion rate, $C F$ is the concentration of the food, $\mathrm{k}_{\mathrm{e}}$ is depuration rate, and $g$ is growth rate in $d^{-1}$. To appropriately calibrate the biodynamics model, excel solver was used to adjust model parameters within appropriate constraints (Pickhardt, Stepanova, and Fisher 2006). High and low estimates of growth rates (based on analysis above), diet (macroinvertebrate analysis), and ingestion rate (van Poorten and Walters 2015) were used to develop different biodynamic scenarios. An example of one scenario for redbreast in EFK 23.4 is provided (Fig. 4-22). Estimated MeHg body concentrations from the biodynamics model fell within the range of observed values; however, there was a general mismatch in temporal trends (Fig. 4-22). Temporal variations in MeHg body concentration from the biodynamics model were highly dependent on estimated changes in the dietary concentration based on shifts in the macroinvertebrate community. The data suggest that changes in body concentrations of redbreast at EFK 23.4 were somewhat independent of the dramatic changes in the macroinvertebrate community over time. 


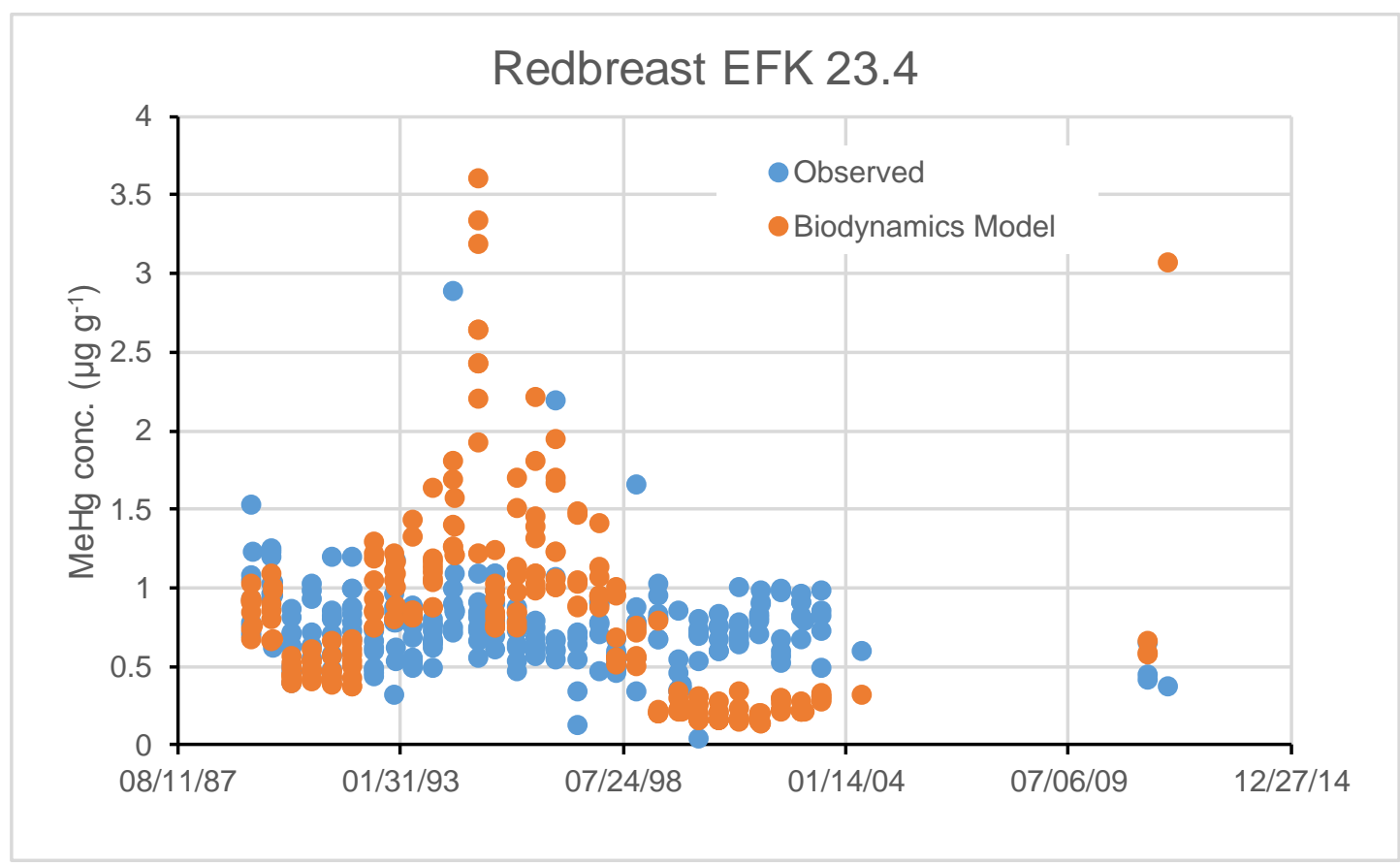

Fig. 4-22. Observed and estimated MeHg body concentrations for redbreast sunfish at EFK 23.4.

The biodynamics model (Luoma and Rainbow 2005) was used to estimate body concentrations.

\subsection{TASK 3 FUTURE DIRECTIONS}

Important research and technology development needs are to quantify the trophic transfer efficiency of mercury through the EFPC food chain and to identify the critical linkages for mercury transfer to fish. By understanding these critical linkages, design strategies can be developed to sustainably alter, or manipulate, the aquatic food chain to mitigate mercury transfer to fish.

Information regarding critical food chain linkages will be coupled with small-scale field and laboratory experiments to better understand mercury methylation and subsequent transfer through the food web in EFPC, and target key ecological manipulations that may have the most benefit to mitigating mercury bioaccumulation. Experiments planned for the next year will inform future mesocosm-scale experiments slated to take place in the FRS, and potentially inform small scale field manipulations. Based on current findings, are most promising lines of inquiry include:

- Experiments to examine the effects that riparian shading may have on $\mathrm{MeHg}$ production and bioaccumulation

- Determination of effects that the addition of native mussel species may have on dissolved and particle-associated mercury and methylmercury within the creek

- Experiments to examine the effect of fish population density and/or species abundance on mercury and methylmercury bioaccumulation

- Experiments to examine the effects of stocking mussels and lower trophic level fish on mercury bioaccumulation throughout the food chain 


\section{REFERENCES}

Cabana, G., and J. B. Rasmussen. 1994. "Modeling Food Chain Structure and Contaminant Bioaccumulation Using Stable Nitrogen Isotopes." Nature 372 (6503):255-257.

Carter, T. G., and et al. 2008. "New functional materials for heavy metal sorption: 'Supramolecular' attachment of thiols to mesoporous silica substrates." Chem Commun (Camb) 43:5583-5. doi: 10.1039/b810576f.

Crockett, M. P., et al. 2016. "Sulfur-Limonene Polysulfide: A Material Synthesized Entirely from Industrial By-Products and Its Use in Removing Toxic Metals from Water and Soil." Angewandte Chemie-International Edition 55 (5):1714-1718. doi: 10.1002/anie.201508708.

Dickson, J. O., et al. In review. Soil Investigation of Lower East Fork Poplar Creek. ORNL-TM/2015374, Oak Ridge National Laboratory, Oak Ridge TN.

Gilmour, C. C., et al. 2013a. "Mercury Methylation by Novel Microorganisms from New Environments." Environ. Sci. Technol. 47 (20):11810-11820. doi: 10.1021/es403075t.

Gilmour, C. C., et al. 2013b. "Activated Carbon Mitigates Mercury and Methylmercury Bioavailability in Contaminated Sediments.” Environmental Science \& Technology 47 (22):13001-13010. doi: Doi 10.1021/Es4021074.

Gomez-Eyles, J. L., et al. 2013. "Evaluation of Biochars and Activated Carbons for In Situ Remediation Of Sediments Impacted With Organics, Mercury, And Methylmercury." Environmental Science \& Technology 47 (23):13721-13729. doi: Doi 10.1021/Es403712q.

Haitzer, M., G. R. Aiken, and J. N. Ryan. 2002. "Binding of Mercury(II) to Dissolved Organic Matter: The Role of the Mercury-to-DOM Concentration Ratio.” Environmental Science \& Technology 36:3564-3570.

Hu, H., et al. 2013. "Oxidation and Methylation of Dissolved Elemental Mercury by Anaerobic Bacteria." Nature Geosci. 6:751-754. doi: 10.1038/NGSO1894.

Kolka, R. K., et al. 2011. "Mercury Cycling in Peatland Watersheds, Chapter 11." In Peatland biogeochemistry and watershed hydrology at the Marcell Experimental Forest, edited by R. K. Kolka, et al. Boca Raton, FL: CRC Press:349-370.

Laslett, G., J. Paige Eveson, and T. Polacheck. 2004. "Fitting Growth Models to Length Frequency Data." ICES J Marine Science 61:218-230.

Lexa, D., and et al. 1990. "Outer-Sphere and Inner-Sphere Processes in Reductive Elimination - Direct and Indirect Electrochemical Reduction of Vicinal Dibromoalkanes." Journal of the American Chemical Society 112 (17):6162-6177.

Looney, B., et al. 2008. Recommendations to Address Technical Uncertainties in the Mitigation and Remediation of Mercury Contamination at the Y-12 Plant, Oak Ridge, Tennessee. WSRC-STI2008-00212, US Department of Energy, Office of Environmental Management.

Luoma, S. N., and P. S. Rainbow. 2005. "Why is Metal Bioaccumulation So Variable? Biodynamics as a Unifying Concept.” Environ Sci Technol 39:1921-1931.

Mathews, T., et al. 2013. "Decreasing Aqueous Mercury Concentrations to Achieve Safe Levels in Fish: Examining the Water-Fish Relationship in Two Point-Source Contaminated Streams." Sci. Tot. Environ 443:836-843.

Miller, C. L., et al. 2009. "Kinetic Controls on the Complexation between Mercury and Dissolved Organic Matter in a Contaminated Environment.” Environmental Science \& Technology 43 (22):8548-8553. doi: 10.1021/es901891t.

Miller, C. L., et al. 2013. "Characterization of Soils from an Industrial Complex Contaminated with Elemental Mercury." Environmental Research 125:20-29.

Mousavi, A. 2011. "Predicting Mercury(II) Binding by Organic Ligands: A Chemical Model of Therapeutic and Environmental Interests." Environmental Forensics 12 (4):327-332. doi: $10.1080 / 15275922.2011 .632735$. 
Myrvold, K. M., and B. P. Kennedy. 2015. "Density Dependence and Its Impact on Individual Growth Rates in an Age-Structured Stream Salmonid Population." Ecosphere 6:1-15.

Parks, J. M., et al. 2013. "The Genetic Basis for Bacterial Mercury Methylation.” Science 339 (6125):1332-1335. doi: 10.1126/science.1230667.

Peterson, M. J., et al. 2015a. Mercury Remediation Technology Development for Lower East Fork Poplar Creek. ORNL/SPR-2014/645, Oak Ridge National Laboratory, Oak Ridge, TN.

Peterson, M. J., et al. 2016. Mercury Remediation Technology Development for Lower East Fork Poplar Creek-FY 2015 Progress Report. ORNL/TM-2016/48, Oak Ridge National Laboratory, Oak Ridge, TN.

Peterson, M. J., et al. 2015b. East Tennessee Technology Park Biological Monitoring and Abatement Program 2014 Calendar Year Report. ORNL/SPR-2015/43, Oak Ridge National Laboratory, Oak Ridge, TN.

Peterson, M. J., et al. 2011. Conceptual Model of Primary Mercury Source, Transport Pathways, and Flux at the Y-12 Complex and Upper East Fork Poplar Creek, Oak Ridge, Tennessee. ORNL/TM-2011/75, Oak Ridge National Laboratory, Oak Ridge, TN.

Pickhardt, P. C., M. Stepanova, and N. S. Fisher. 2006. "Contrasting Uptake Routes and Tissue Distributions of Inorganic and Methylmercury in Mosquitofish (Gambusia affinis) and Redear Sunfish (Lepomis microlophus)." Environ Tox Chem 25:2132-2142.

Ravichandran, M. 2004. "Interactions Between Mercury and Dissolved Organic Matter-A Review." Chemosphere 55 (3):319-331. doi: 10.1016/j.chemosphere.2003.11.011.

Riscassi, A. L., S. Brooks, and C. Miller. 2014. "Impact of Collection Container Material and Holding Times on Sample Integrity for Mercury and Methylmercury in Water." Limnology and Oceanography: Methods 12:407-420. doi: 10.4319/lom.2014.12.407.

Shacklette, H. T., and J. G. Boerngen. 1984. Element Concentrations in Soils and Other Surficial Materials of the Conterminous United States. US Geological Survey, Washington DC.

Southworth, G., et al. 2013. "Sources of Mercury in a Contaminated Stream-Implications for the Timescale of Recovery." Environmental Toxicology and Chemistry 32 (4):764-772. doi: 10.1002/etc. 2115 .

Southworth, G. R., et al. 2010. Sources of Mercury to East Fork Poplar Creek Downstream from the Y-12 National Security Complex: Inventories and Export Rates. ORNL/TM-2009/231, Oak Ridge National Laboratory, Oak Ridge, TN.

Sposito, G. 1980. "Derivation of the Freundlich Equation for Ion-Exchange Reactions in Soils." Soil Science Society of America Journal 44 (3):652-654.

Stoor, R. W., et al. 2006. "Subsurface sources of methyl mercury to Lake Superior from a wetlandforested watershed." Science of the Total Environment (368):99-110.

Tennessee Valley Authority. 1985a. Instream Contaminant Study, Task 2: Sediment Characterization, Report to US Department of Energy, Oak Ridge Operations Office. Tennessee Valley Authority, Office of Natural Resources and Economic Development, Knoxville, TN.

Tennessee Valley Authority. 1985b. Instream Contaminant Study, Task 3: Sediment Transport, Report to US Department of Energy. Tennessee Valley Authority, Office of Natural Resources and Economic Development, Knoxville, TN.

US Department of Energy. 2014. Mercury Technology Development Plan for Remediation of the Y-12 Plant and East Fork Poplar Creek. DOE/ORO-2489.

van Poorten, B. T., and C. J. Walters. 2015. "Dependence of Feeding Rates on Body Mass When Food Density is Limiting to Growth." Can J Fish Aquat Sci 72:1916-1922.

Wallschlager, D., et al. 1998. "Mercury speciation in floodplain soils and sediments along a contaminated river transect." Journal of Environmental Quality 27 (5):1034-1044. 